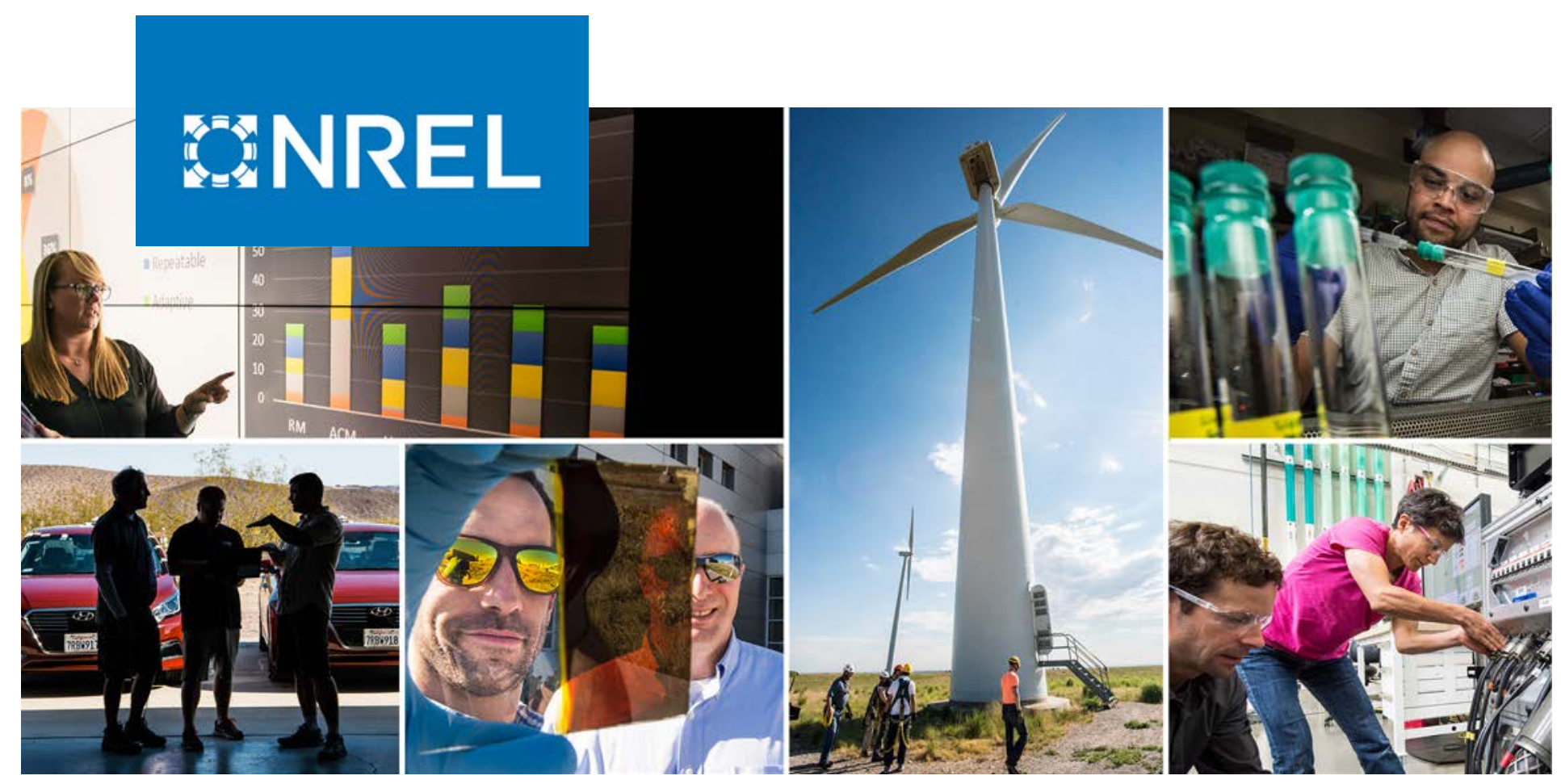

\title{
Regional Energy Deployment System (ReEDS) Model Documentation: Version 2020
}

Jonathan Ho, Jonathon Becker, Maxwell Brown, Patrick Brown, Ilya Chernyakhovskiy, Stuart Cohen, Wesley Cole, Sean Corcoran, Kelly Eurek, Will Frazier, Pieter Gagnon, Nathaniel Gates, Daniel Greer, Paige Jadun, Saroj Khanal, Scott Machen, Madeline Macmillan, Trieu Mai, Matthew Mowers, Caitlin Murphy, Amy Rose, Anna Schleifer, Brian Sergi, Daniel Steinberg, Yinong Sun, and Ella Zhou

National Renewable Energy Laboratory

NREL is a national laboratory of the U.S. Department of Energy Office of Energy Efficiency \& Renewable Energy

Operated by the Alliance for Sustainable Energy, LLC

This report is available at no cost from the National Renewable Energy Laboratory (NREL) at www.nrel.gov/publications.
Technical Report

NREL/TP- 6A20-78195 June 2021 


\section{GANREL}

\section{Regional Energy Deployment System (ReEDS) Model Documentation: Version 2020}

Jonathan Ho, Jonathon Becker, Maxwell Brown, Patrick Brown, Ilya Chernyakhovskiy, Stuart Cohen, Wesley Cole, Sean Corcoran, Kelly Eurek, Will Frazier, Pieter Gagnon, Nathaniel Gates, Daniel Greer, Paige Jadun, Saroj Khanal, Scott Machen, Madeline Macmillan, Trieu Mai, Matthew Mowers, Caitlin Murphy, Amy Rose, Anna Schleifer, Brian Sergi, Daniel Steinberg, Yinong Sun, and Ella Zhou

National Renewable Energy Laboratory

\section{Suggested Citation}

Ho, Jonathan, Jonathon Becker, Maxwell Brown, Patrick Brown, llya Chernyakhovskiy, Stuart Cohen, Wesley Cole, et al. 2021. Regional Energy Deployment System (ReEDS) Model Documentation: Version 2020. Golden, CO: National Renewable Energy Laboratory. NREL/TP-6A20-78195. https://www.nrel.gov/docs/fy21osti/78195.pdf.

NREL is a national laboratory of the U.S. Department of Energy Office of Energy Efficiency \& Renewable Energy Operated by the Alliance for Sustainable Energy, LLC

This report is available at no cost from the National Renewable Energy Laboratory (NREL) at www.nrel.gov/publications.
Technical Report NREL/TP- 6A20-78195 June 2021

National Renewable Energy Laboratory 15013 Denver West Parkway Golden, CO 80401

303-275-3000 • www.nrel.gov 


\section{NOTICE}

This work was authored by the National Renewable Energy Laboratory, operated by Alliance for Sustainable Energy, LLC, for the U.S. Department of Energy (DOE) under Contract No. DE-AC36-08GO28308. Funding provided by the U.S. Department of Energy Office of Energy Efficiency and Renewable Energy Solar Energy Technologies Office and Office of Strategic Programs. The views expressed herein do not necessarily represent the views of the DOE or the U.S. Government.

This report is available at no cost from the National Renewable Energy Laboratory (NREL) at www.nrel.gov/publications.

U.S. Department of Energy (DOE) reports produced after 1991 and a growing number of pre-1991 documents are available free via www.OSTI.gov.

Cover Photos by Dennis Schroeder: (clockwise, left to right) NREL 51934, NREL 45897, NREL 42160, NREL 45891, NREL 48097, NREL 46526.

NREL prints on paper that contains recycled content. 


\section{Acknowledgments}

We gratefully acknowledge the many people whose efforts contributed to this report. The ReEDS modeling and analysis team at the National Renewable Energy Laboratory (NREL) was active in developing and testing the ReEDS model version 2020. We also acknowledge the vast number of current and past NREL employees on and beyond the ReEDS team who have participated in data and model development, testing, and analysis. We are especially grateful to Walter Short who first envisioned and developed the Wind Deployment System (WinDS) and ReEDS models. We thank Walter Short, Owen Zinaman, Laura Vimmerstedt, Jeffrey Logan, Cara Marcy, Gokul Iyer, and Mike Meshek for their comments and improvements on successive versions of this report. Finally, we are grateful to all those who helped sponsor ReEDS model development and analysis, particularly supporters from the U.S. Department of Energy (DOE) but also others who have funded our work over the years. This report was funded by the DOE Office of Energy Efficiency and Renewable Energy under contract number DE-AC3608GO28308. Any errors or omissions are the sole responsibility of the authors.

\section{ReEDS Team Members for version 2020}

Jonathon Becker

Maxwell Brown

Patrick Brown

Ilya Chernyakhovskiy

Stuart Cohen

Wesley Cole

Sean Corcoran

Kelly Eurek

Will Frazier
Pieter Gagnon

Nathaniel Gates

Daniel Greer

Jonathan Ho

Paige Jadun

Saroj Khanal

Scott Machen

Madeline Macmillan

Trieu Mai
Matthew Mowers

Caitlin Murphy

Amy Rose

Anna Schleifer

Brian Sergi

Daniel Steinberg

Yinong Sun

Ella Zhou 


\section{List of Abbreviations and Acronyms}

$\mathrm{AC}$

AEO

ATB

BA

CAES

CAIR

$\mathrm{CC}$

CCS

CES

$\mathrm{CF}$

CFL

$\mathrm{CO}_{2}$

CMIP

CPP

CPUC

CSAPR

CSP

$\mathrm{CT}$

$\mathrm{CV}$

$\mathrm{DC}$

DG

DNI

DOE

DSIRE

DUPV

EAC

EGR

EGS

EIA

ELCC

EMM

EOR

EPA

ERC

ERCOT

FERC

GCM

GHG

GIS

GW

HMI

HSIP

HVDC

IGCC

IOU alternating current

Annual Energy Outlook

Annual Technology Baseline

balancing area

compressed-air energy storage

Clean Air Interstate Rule

combined cycle

carbon capture and sequestration

clean energy standard

capacity factor

compact fluorescent lamp

carbon dioxide

Coupled Model Intercomparison Project

Clean Power Plan

California Public Utilities Commission

Cross-State Air Pollution Rule

concentrating solar power

combustion turbine

capacity value

direct current

distributed generation

direct normal insolation

U.S. Department of Energy

Database of State Incentives for Renewables \& Efficiency

distribution-side utility-scale photovoltaic

early action credit

enhanced gas recovery

enhanced geothermal system

U.S. Energy Information Administration

effective load carrying capability

Electricity Market Module

enhanced oil recovery

U.S. Environmental Protection Agency

emission rate credit

Electric Reliability Council of Texas

Federal Energy Regulatory Commission

general circulation model

greenhouse gas

geographic information systems

gigawatt

U.S. Bureau of Reclamation Hydropower Modernization Initiative

Homeland Security Infrastructure Project

high-voltage direct current

integrated gasification combined cycle

investor-owned utility 


\begin{tabular}{|c|c|}
\hline IPM & U.S. Environmental Protection Agency Integrated Planning Model \\
\hline IPP & independent power producer \\
\hline ISO & independent system operator \\
\hline IRS & Internal Revenue Service \\
\hline ITC & investment tax credit \\
\hline JEDI & Jobs and Economic Development Impact model \\
\hline $\mathrm{km}^{2}$ & square kilometer \\
\hline $\mathrm{kV}$ & kilovolt \\
\hline $\mathrm{kW}$ & kilowatt \\
\hline $\mathrm{kWh}$ & kilowatt hour \\
\hline LCOE & levelized cost of energy \\
\hline LDC & load-duration curve \\
\hline LED & light-emitting diode \\
\hline LOLP & loss of load probability \\
\hline MACRS & Modified Accelerated Cost Recovery System \\
\hline MATS & Mercury and Air Toxic Standards \\
\hline MMBtu & million British thermal units \\
\hline MPI & materials price index \\
\hline MW & megawatt \\
\hline MWh & megawatt hour \\
\hline $\mathrm{NaS}$ & sodium-sulfur \\
\hline NEB & Canadian National Energy Board \\
\hline NEMS & National Energy Modeling System \\
\hline NERC & North American Electric Reliability Corporation \\
\hline NG & natural gas \\
\hline NHAAP & National Hydropower Asset Assessment Program \\
\hline NLDC & net load-duration curve \\
\hline $\mathrm{NO}_{\mathrm{x}}$ & nitrogen oxide \\
\hline NPD & non-powered dam \\
\hline NRC & Nuclear Regulatory Commission \\
\hline NREL & National Renewable Energy Lab \\
\hline NSD & new stream-reach development \\
\hline NSRDB & National Solar Radiation Database \\
\hline O\&M & operation and maintenance \\
\hline OGS & oil-gas steam \\
\hline $\mathrm{PCM}$ & production-cost model \\
\hline PRODESEN & Mexican Programa de Desarrollo del Sistema Eléctrico Nacional \\
\hline PSH & pumped storage hydropower \\
\hline PTC & production tax credit \\
\hline PV & photovoltaic \\
\hline $\mathrm{RCP}$ & representative concentration pathway \\
\hline $\mathrm{REC}$ & renewable energy certificate \\
\hline ReEDS & Regional Energy Deployment System \\
\hline $\mathrm{reV}$ & Renewable Energy Potential tool \\
\hline RGGI & Regional Greenhouse Gas Initiative \\
\hline RLDC & residual load-duration curve \\
\hline
\end{tabular}




$\begin{array}{ll}\text { RPS } & \text { renewable portfolio standard } \\ \text { RROE } & \text { rate of return on equity } \\ \text { RTO } & \text { regional transmission organization } \\ \text { SAM } & \text { System Advisor Model } \\ \text { SENER } & \text { Secretaría de Energía for Mexico } \\ \text { SM } & \text { solar multiple } \\ \mathrm{SO}_{2} & \text { sulfur dioxide } \\ \text { T\&D } & \text { transmission and distribution } \\ \text { TDY } & \text { typical direct normal insolation year } \\ \text { TEPPC } & \text { Transmission Expansion Planning Policy Committee } \\ \text { tCO } & \text { metric ton of carbon dioxide } \\ \text { TW } & \text { terawatt } \\ \text { TWh } & \text { terawatt hour } \\ \text { UPV } & \text { utility-scale photovoltaic } \\ \text { VRE } & \text { variable renewable energy } \\ \text { WACC } & \text { weighted average cost of capital } \\ \text { WECC } & \text { Western Electricity Coordination Council } \\ \text { WIND } & \text { Wind Integration National Dataset } \\ \text { WinDS } & \text { Wind Deployment System }\end{array}$




\section{Table of Contents}

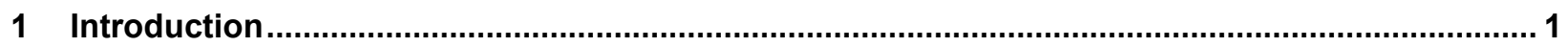

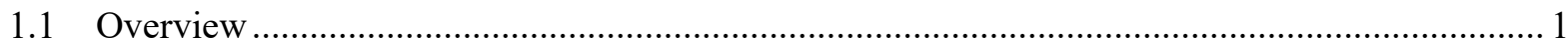

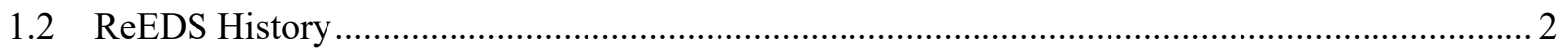

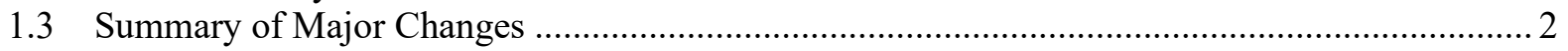

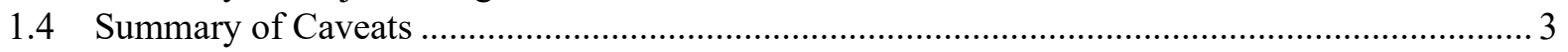

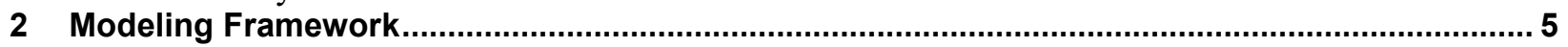

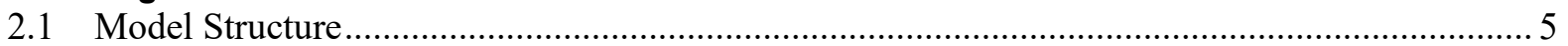

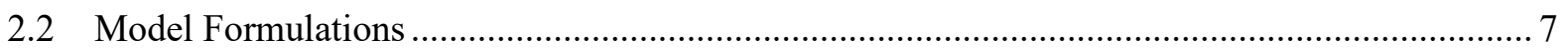

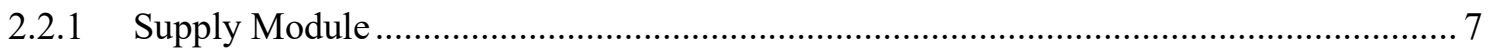

2.2.2 Demand Module ............................................................................ 9

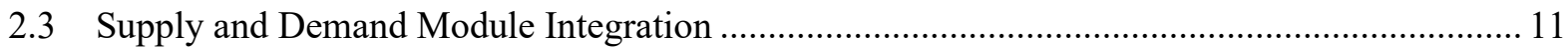

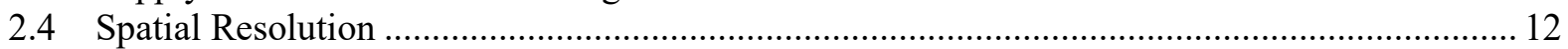

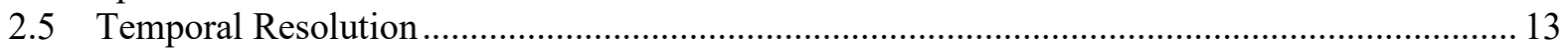

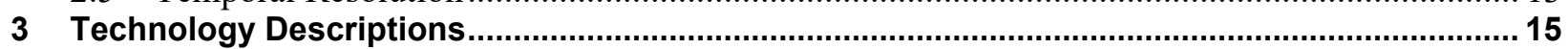

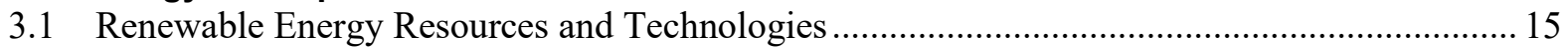

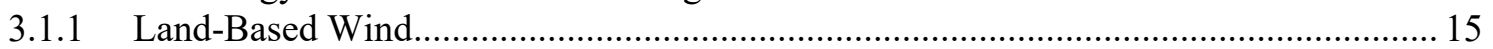

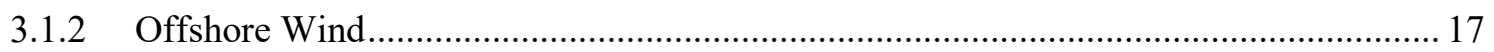

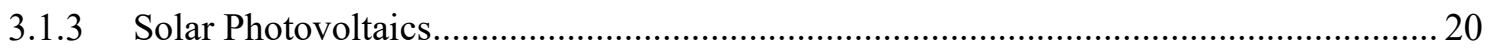

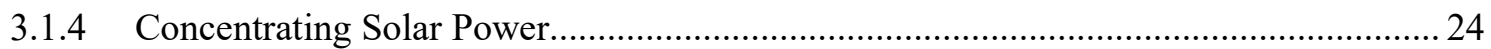

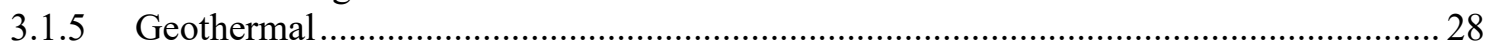

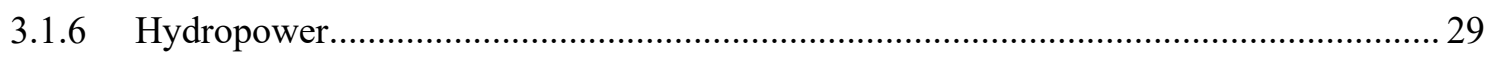

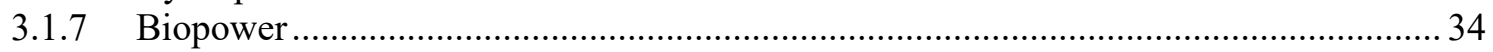

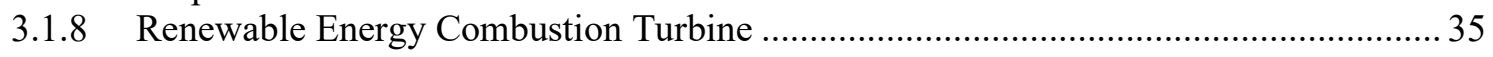

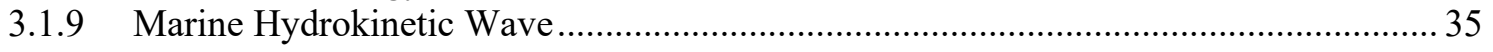

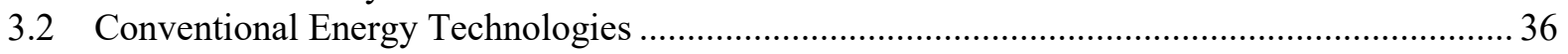

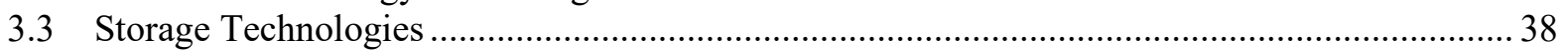

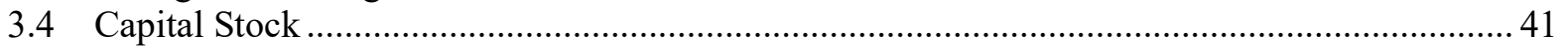

3.4.1 Initial Capital Stock, Prescribed Builds, and Restrictions........................................... 41

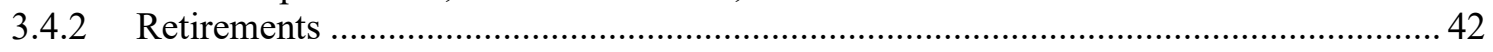

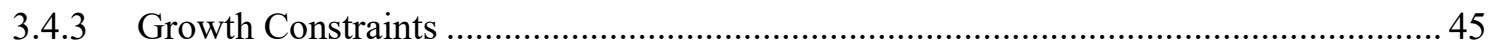

3.5 Regional Parameter Variations and Adjustments.......................................................... 45

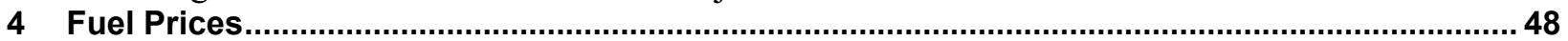

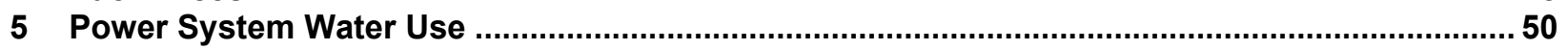

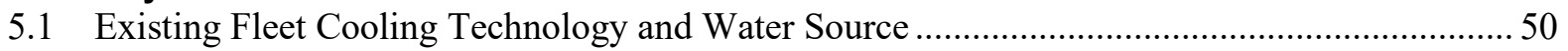

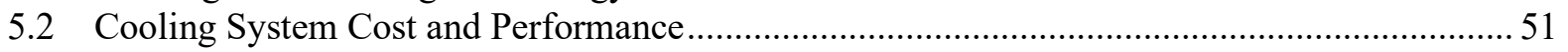

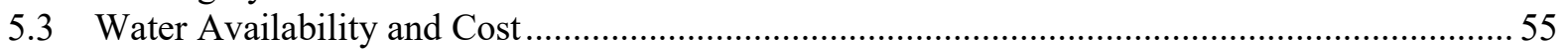

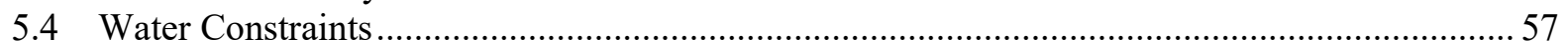

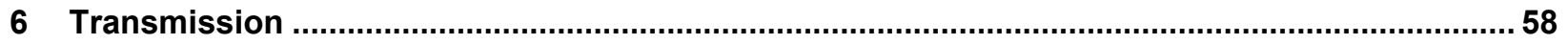

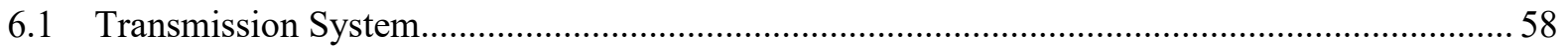

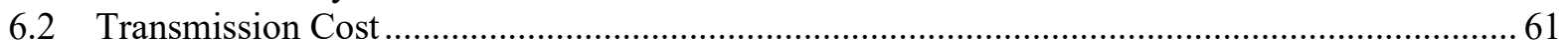

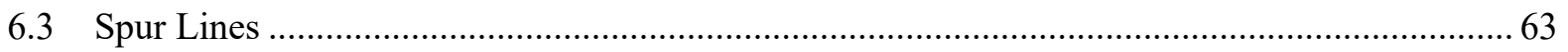

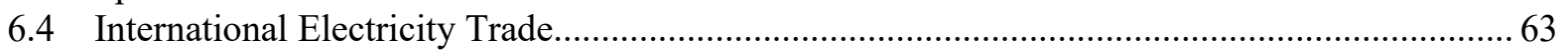

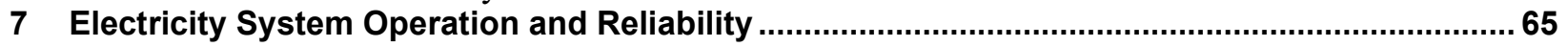

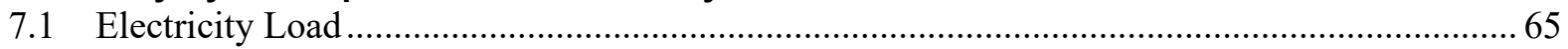

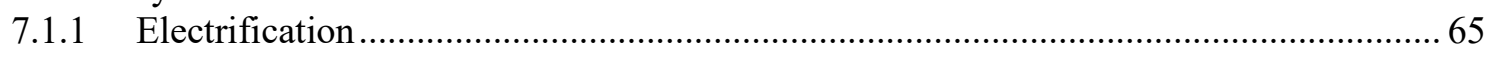

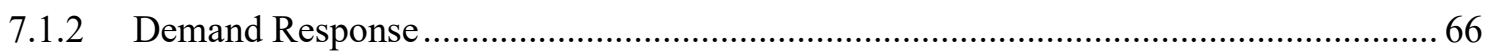

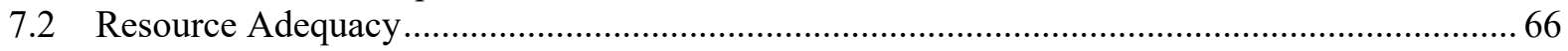

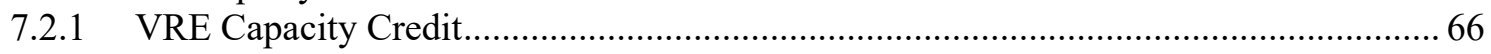

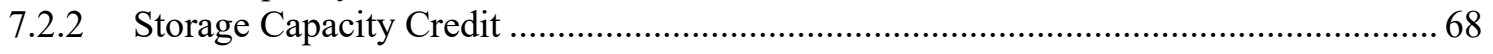


7.2.3 Planning Reserve Margins ................................................................................. 75

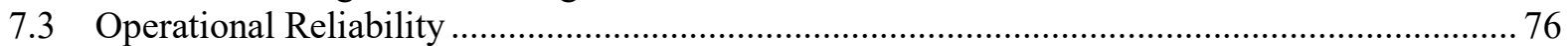

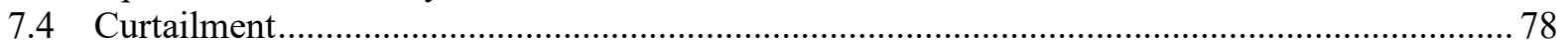

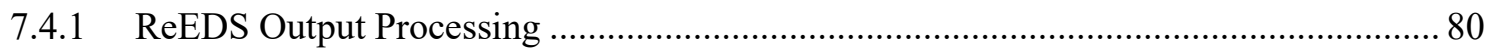

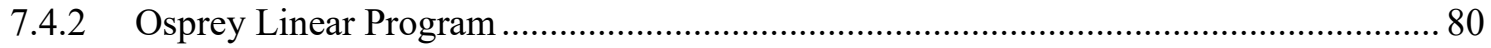

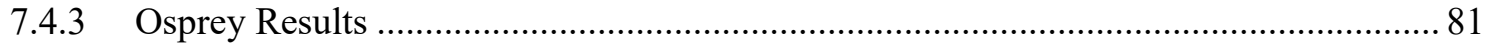

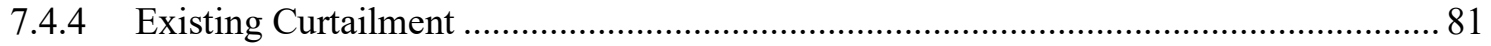

7.4.5 Marginal Curtailment ……………………………………………………….... 83

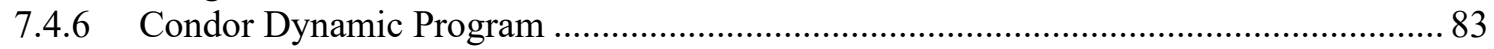

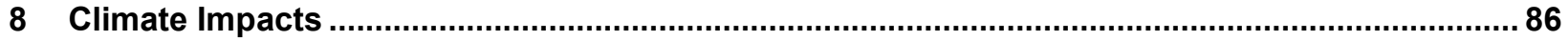

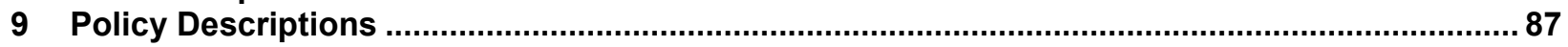

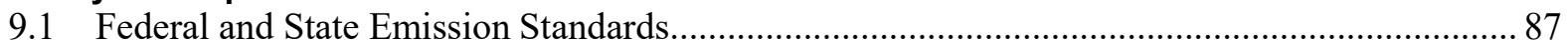

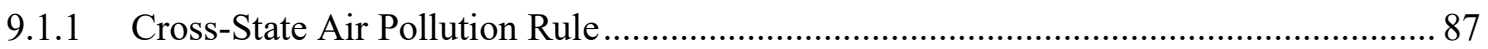

9.1.2 Mercury and Air Toxic Standards ....................................................................... 87

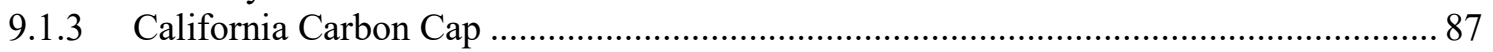

9.1.4 Regional Greenhouse Gas Initiative....................................................................... 87

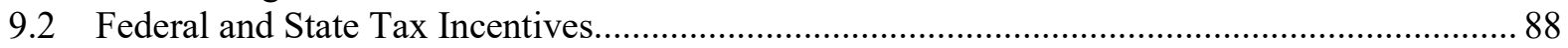

9.2.1 Renewable Production and Investment Tax Credits ................................................ 88

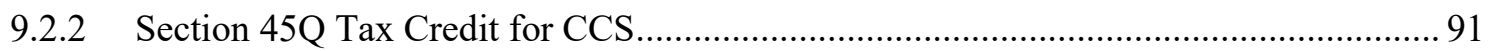

9.2.3 Penalty for Monetizing Tax Credit Incentives ……………………………………….. 91

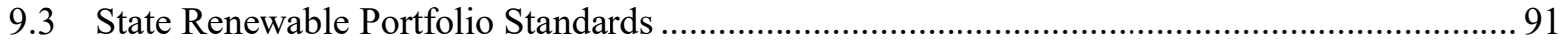

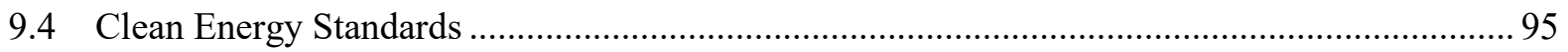

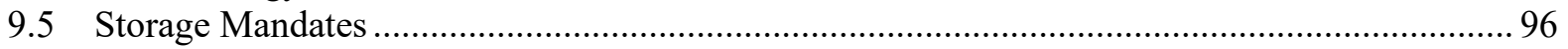

9.6 Nuclear Power Plant Assistance Programs ……………………………………………......... 96

9.7 Other Policy Capabilities ................................................................................................ 96

10 Capital Financing, System Costs, and Economic Metrics …………….....................................98

10.1 Financing of Capital Stock ............................................................................................. 98

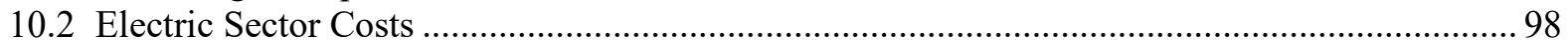

10.2.1 Present Value of Direct Electric Sector Cost ............................................................. 98

10.2.2 Electricity Price .................................................................................................. 98

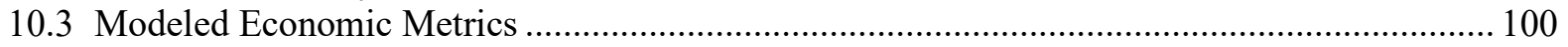

10.3.1 Levelized Cost of Energy …………………………………………………….... 100

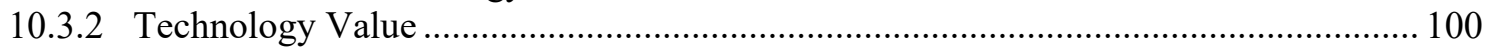

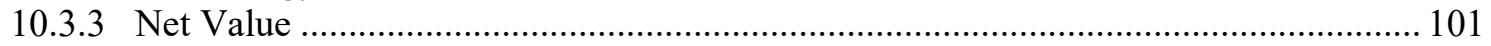

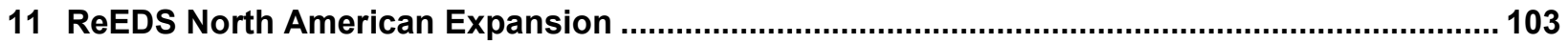

11.1 Fuel Price and Availability ................................................................................................. 104

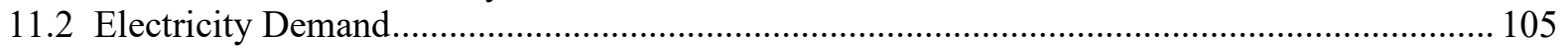

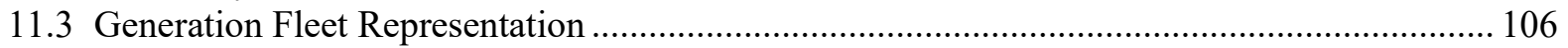

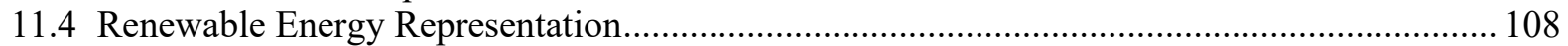

11.4.1 Hydropower Generation Capacity .......................................................................... 108

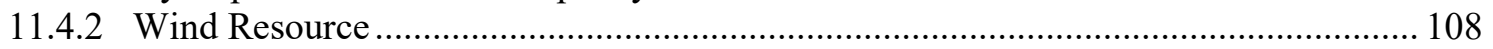

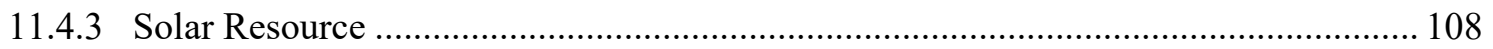

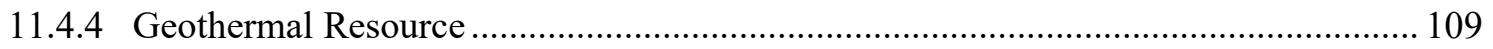

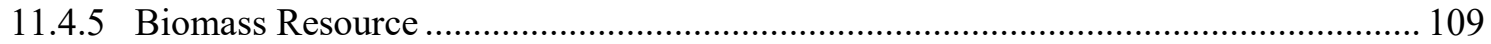

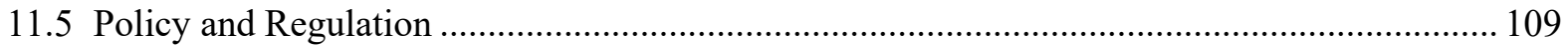

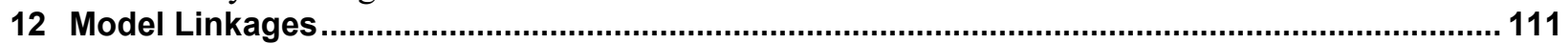

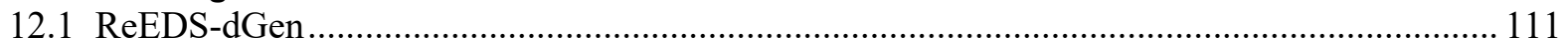

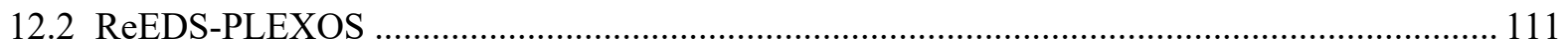

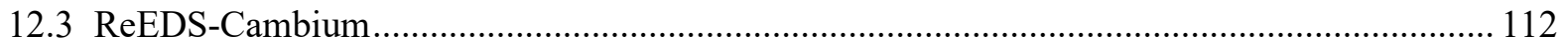

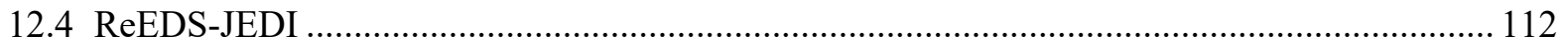

12.5 ReEDS-reV 


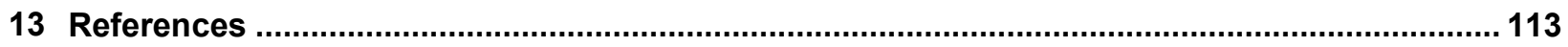

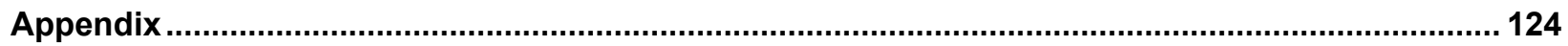

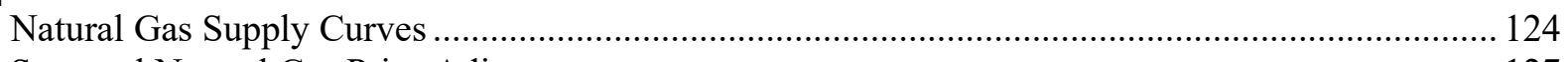

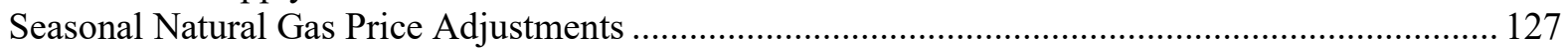

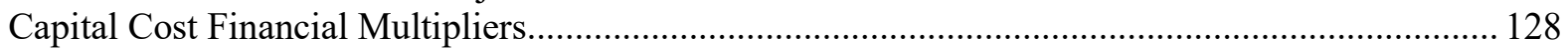

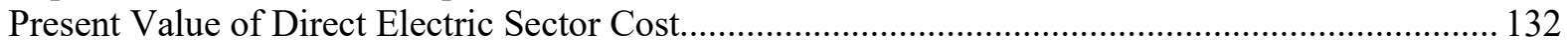

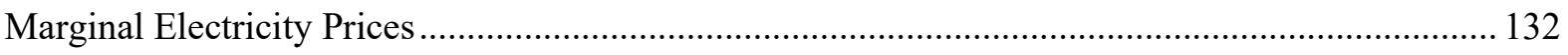

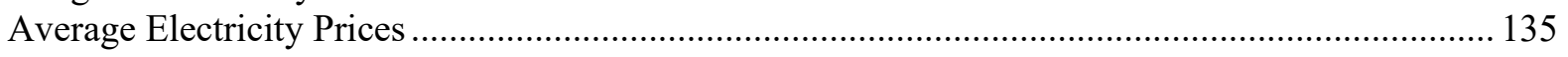

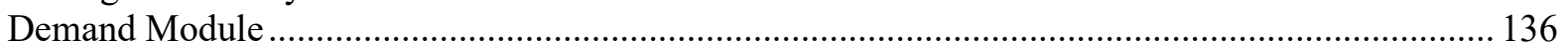

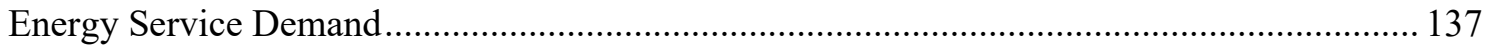

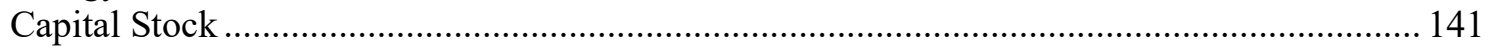

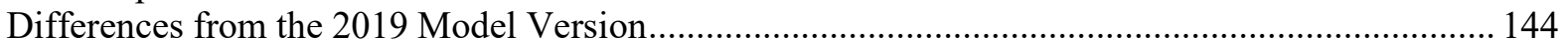

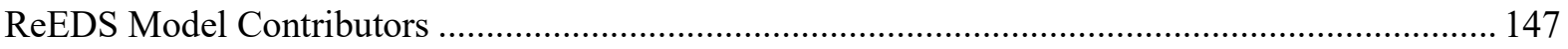




\section{List of Figures}

Figure 1. Schematic illustrating the ReEDS structure with a sequential solve................................... 6

Figure 2. Schematic illustrating the ReEDS structure with sliding window or perfect foresight........... 7

Figure 3. Energy service consumption equilibrium for two different device efficiency levels............ 11

Figure 4. Map showing the ReEDS regional structure ................................................................... 13

Figure 5. Land-based wind resource map for the contiguous United States ..................................... 17

Figure 6. Offshore wind resource map for the contiguous United States....................................... 20

Figure 7. UPV and DUPV resource areas available for development considering land use exclusions

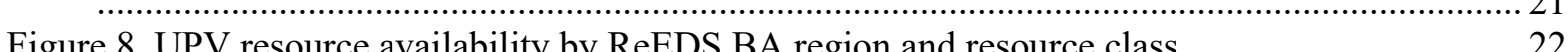

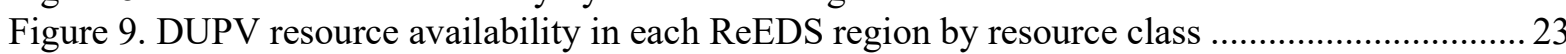

Figure 10. CSP resource availability in each ReEDS resource region by 12 resource class................ 27

Figure 11. National capital cost supply curves for geothermal capacity used in the base

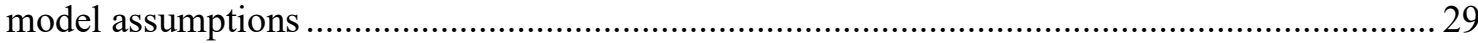

Figure 12. Modeled hydropower upgrade resource potential (DOE 2016b) ..................................... 31

Figure 13. Modeled non-powered dam resource potential (DOE 2016b) ......................................... 32

Figure 14. Modeled new stream-reach development resource potential (DOE 2016b) ...................... 33

Figure 15. National hydropower supply curve of capital cost versus cumulative capacity potential... 33

Figure 16. National supply curve for biomass feedstock .................................................................. 35

Figure 17. Modeled new PSH resource potential (DOE 2016b) ......................................................... 40

Figure 18. National PSH supply curve of capital cost versus cumulative capacity potential............... 40

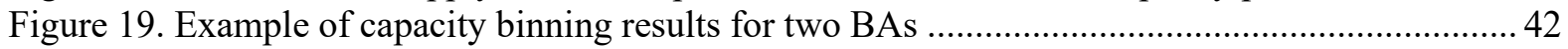

Figure 20. Maps of regional capital cost multipliers for the various technology types....................... 47

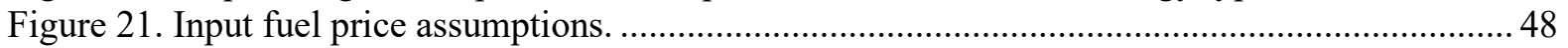

Figure 22. Water availability and cost for each water type in each ReEDS balancing area................ 57

Figure 23. Existing long-distance transmission infrastructure as represented in ReEDS .................. 58

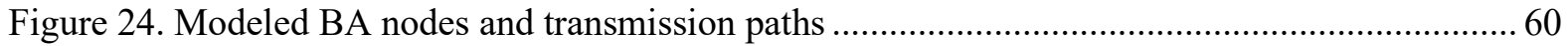

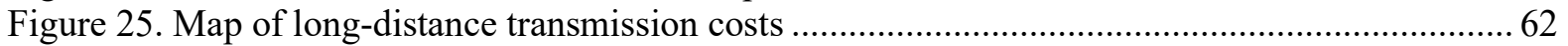

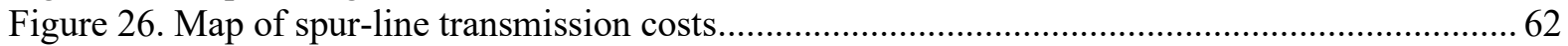

Figure 27. Imports from Canada to the United States and exports from the United States to Canada. 64

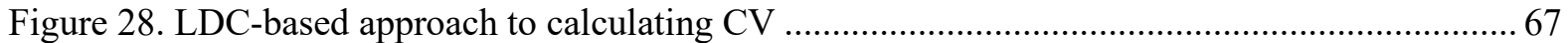

Figure 29. Map of ReEDS 134 BA regions and 18 resource assessment regions ...............................6 68

Figure 30: Model results for determining energy capacity requirements for storage in NYISO in 2020

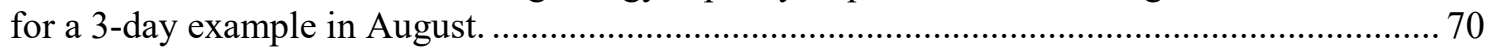

Figure 31: Determining storage peaking capacity potential in ReEDS........................................... 71

Figure 32: Installed battery capacity and resource adequacy contribution (capacity derated by capacity

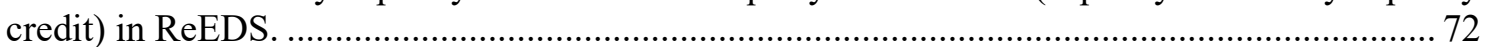

Figure 33. An example of storage capacity credit allocation in ReEDS. ...................................... 74

Figure 34. The same example from Figure 33 but this time with $300 \mathrm{MW}$ of 12-hour pumped hydro storage. Since there is only $100 \mathrm{MW}$ of 12 -hour peaking potential, remaining pumped-hydro

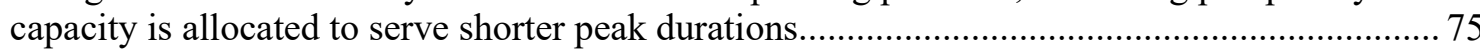

Figure 35. Map of ReEDS 134 BA regions and 18 NERC reliability subregions as applied to the

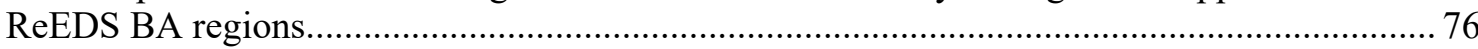

Figure 36: Summary workflow of the ReEDS Augur module. BA is balancing area, CF is capacity factor, GDX is GAMS (General Algebraic Modeling Language) Data eXchange, and SOC is state of charge. The names of the different elements of the flow chart correspond to the names of the scripts that are part of the ReEDS model.

Figure 37: Summary of hourly minimum generation (min-gen) level adjustment used to compute existing curtailment. Example shown for a generator with a 50\% min-gen fraction. ................. 82

Figure 38: Condor dynamic program dispatch results for a 4-hr battery in a region during the winter. 
Figure 39. Regions defined in the North America version of the ReEDS model.............................. 104

Figure 40. Map of EIA Census Division boundaries extended to Canadian provinces...................... 105

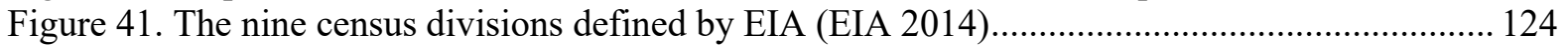

Figure 42. $\beta$ values for the nine census divisions ................................................................... 125

Figure 43. Natural gas futures prices from the New York Mercantile Exchange for July 10, 2014 .. 127

Figure 44. Natural gas futures prices from Figure 43 separated by season ..................................... 128

Figure 45. Examples of survival rates for different scale and shape parameterizations..................... 142

\section{List of Tables}

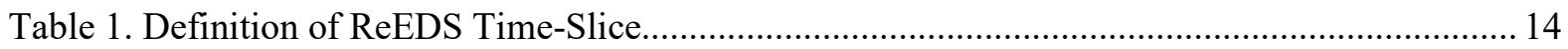

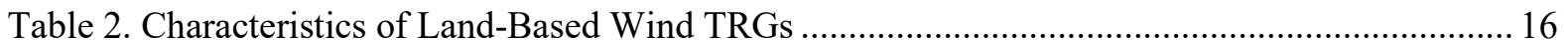

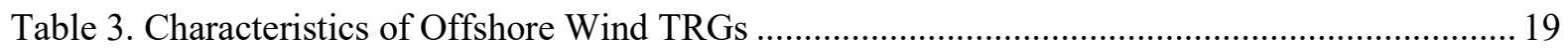

Table 4. Characteristics of UPV and DUPV Resource Classes...................................................... 21

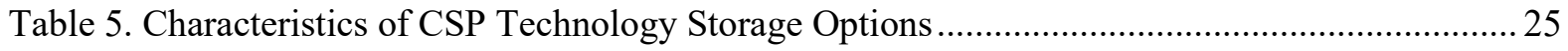

Table 6. Resource Classes for CSP Plants Using a Solar Multiple (SM) of 2.4 ................................ 25

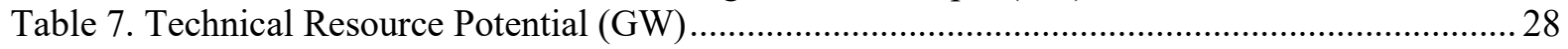

Table 8. Multipliers Applied to Full-Load Heat Rates to Approximate Heat Rates for Part-

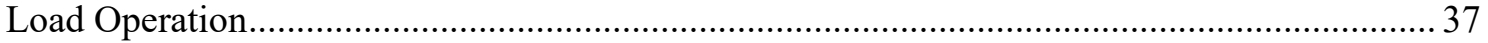

Table 9. Emissions Rate by Generator Type in Pounds per MMBtu (EPA 2008) ${ }^{\mathrm{a}}$.............................. 38

Table 10. Lifetimes of Renewable Energy Generators and Batteries................................................ 43

Table 11. Lifetimes of Conventional Energy Generators (ABB 2018) ............................................ 43

Table 12. Amount of Nuclear Power Plant Capacity (in GW) in Each Bin ......................................... 44

Table 13. Nuclear Power Plant Lifetime for Each Scenario by Bin (years) ....................................... 45

Table 14. List of Notable DC Transmission Connections Modeled in ReEDS...................................59

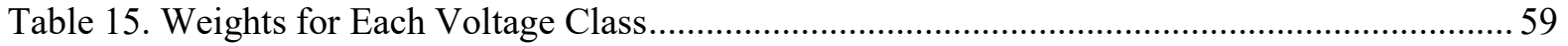

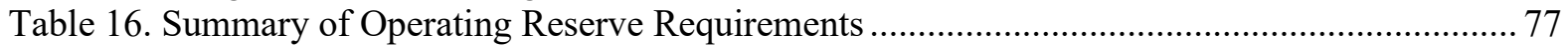

Table 17. Flexibility Parameters of the ReEDS Generation Technologies ........................................ 78

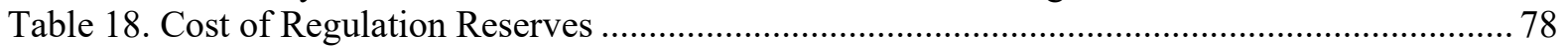

Table 19. Actual and Modeled Schedule of Wind and Solar Tax Credits from the Consolidated

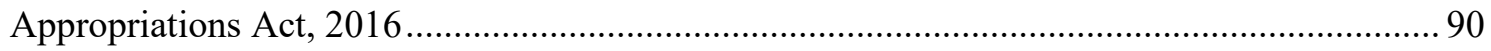

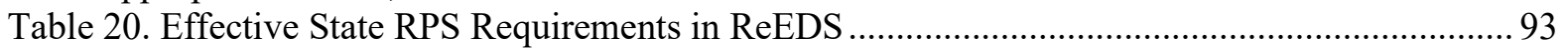

Table 21. Cumulative Offshore Wind Capacity (MW) Mandated in ReEDS ................................... 95

Table 22. Clean Energy Requirement as a Percentage of In-State Sales............................................ 96

Table 23. Relationships of Constraints to Grid Services Used to Calculate the Competitive Electricity

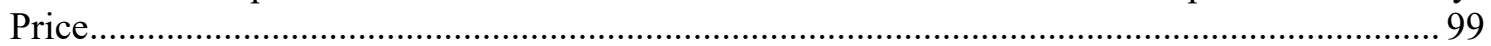

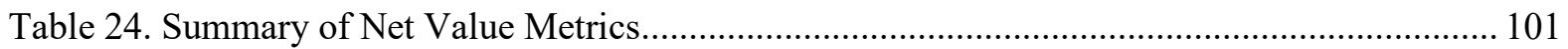

Table 25. Pending Cross-Border Transmission Lines as of January 2016 (DOE 2016a) .................. 107

Table 26. International REC Trading Rules Implemented in ReEDS ......................................... 109

Table A-1. End Uses and Devices Modeled in ReEDS ................................................................... 136

Though the economics literature is replete with estimates of the price elasticity of electricity demand,

few studies have attempted to estimate the price elasticity of service demand for specific end

uses. This is perhaps due to the substantial data requirements needed to perform such an

analysis, specifically household-level information on appliances, electricity consumption for specific end uses, and utility rate schedules. Therefore, we take a conservative approach to parameterizing our energy service demand curves, tending toward lower elasticity values, with the expectation that future work will lend better insight into appropriate elasticity values. Our

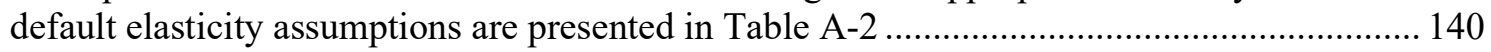

Table A-2. Default Electricity and Energy Service Demand Elasticity Values ................................ 141

Table A-3. Default Assumptions for Discount Rates by Income Class ........................................... 144

Table A-4. Key Differences in Model Inputs and Treatments for ReEDS Model Versions ............... 144 
Table A-5. Key Differences in dGen Model Versions......

This report is available at no cost from the National Renewable Energy Laboratory (NREL) at www.nrel.gov/publications. 


\section{Introduction}

This document describes the structure and key data elements of the Regional Energy Deployment System model architecture 2.0 (ReEDS 2.0, or simply ReEDS) version 2020, which is maintained and operated by the National Renewable Energy Laboratory (NREL). ${ }^{1}$ ReEDS 2.0 builds upon the original ReEDS model architecture (hereafter, Heritage ReEDS), adding more flexibility and additional capabilities while maintaining the features that have contributed to the model's attractiveness as a decision-support tool. In the past, Heritage ReEDS has been used in support of both public and private sector clients to analyze the evolution of the U.S. (and in some cases, North American) power sector in response to policies and technological change. In this introduction, we provide a high-level overview of ReEDS 2.0 objectives, capabilities, and applications. We also briefly describe the history of the Heritage ReEDS model and discuss major changes introduced by the transition to ReEDS 2.0. Finally, we provide a short discussion of important caveats that apply to any ReEDS analysis.

To access the ReEDS model code and inputs, see https://www.nrel.gov/analysis/reeds/requestaccess.html.

\subsection{Overview}

ReEDS is a mathematical programming model of the electric power sector. Given a set of input assumptions, ReEDS models the evolution and operation of generation, transmission, and enduse demand technologies. ${ }^{2}$ The results can be used to explore the impacts of a variety of future technological and policy scenarios on, for example, economic and environmental outcomes for the entire power sector or for specific stakeholders. ReEDS employs a modular structure to maximize user flexibility. Currently, the model consists of three separate but interrelated modules: a supply module, which solves a linear program for the cost-minimizing levels of power sector investment and operation; a demand module, which solves a separate linear program for the utility-maximizing levels of end-use device investment and operation; and a variable renewable energy and storage (VRE) module, ${ }^{3}$ which calculates key parameters for assessing the value of VRE generators and storage. The modules are executed iteratively until a supply-demand equilibrium for electricity is achieved.

Power markets are represented in the model by separating the continent into model regions, each of which has sources of supply and demand. Regions are connected by a representation of the transmission network, which includes existing transmission capacity and endogenous new capacity. On the supply side, the model represents all existing generating units, planned future builds, and endogenous new capacity within each region. On the demand side, the model represents the existing stock of end-use devices as well as an endogenous composition of new device purchases for residential consumers. The model is intended to solve on the decadal scale, though the time horizon for a particular model run (and the intervening model solve years) can

\footnotetext{
1 "Regional Energy Deployment System Model," NREL, https://www.nrel.gov/analysis/reeds/

${ }^{2}$ Currently, ReEDS only explicitly models end-use device and service demands for the residential buildings sector. Additional work is required to extend this capability to the commercial buildings, industrial, and transportation sectors.

${ }^{3}$ VRE is also sometimes referred to as Variable Renewable Resource
} 
be selected by the user. Within each year, a collection of operation time blocks is used to characterize seasonal and diurnal patterns in supply and demand.

\subsection{ReEDS History}

The ReEDS model heritage traces back to National Renewable Energy Laboratory's (NREL's) seminal electric sector capacity expansion model, called the Wind Deployment System (WinDS) model. The WinDS model was developed beginning in 2001 to examine long-term market penetration of wind in the electric power sector (Walter Short et al. 2003). From 2003 to 2008, WinDS was used in a variety of wind-related analyses, including the production of hydrogen from wind power, the impacts of state-level policies on wind deployment, the role plug-in hybrid electric vehicles in wind markets, the impacts of high wind penetration on U.S wind manufacturing, the potential for offshore wind, the benefits of storage to wind power, and the feasibility of producing 20\% of U.S. electricity from wind power by 2030 (DOE 2008). In 2006, a variation of WinDS was developed to analyze concentrating solar power (CSP) potential and its response to state and federal incentives. In 2009, WinDS was recast as ReEDS - a generalized tool for examining the long-term deployment interactions of multiple technologies in the power sector (Walter Short et al. 2009).

Since 2009, ReEDS has been the primary analytical tool in several studies, including the Hydropower Vision (DOE 2016b), Wind Vision (DOE 2015), SunShot Vision (DOE 2012), Geothermal Vision (DOE 2019), and Renewable Electricity Futures (NREL 2012). NREL currently uses ReEDS to publish an annual Standard Scenarios report, which provides a U.S. electric sector outlook under a wide range of possible futures (W. Cole et al. 2019). ReEDS has also been used to examine impacts of a range of existing and proposed energy policies (Lantz et al. 2014; Mai et al. 2015; 2015; Gagnon et al. 2017). Other recent studies have used ReEDS to examine the role of natural gas, high renewable scenarios, and other important issues for the U.S. electricity sector (Mignone et al. 2012; Logan et al. 2013; Clemmer et al. 2013; Mai et al. 2014; Sullivan et al. 2015; W. Cole et al. 2015; 2016; Richards and Cole 2017; W. Cole, Frew, et al. 2018). The ReEDS website ${ }^{4}$ includes an up-to-date list of publications that use ReEDS.

\subsection{Summary of Major Changes}

Since the inception of WinDS and ReEDS, NREL has conducted a diverse suite of analyses. Within each analysis, new capabilities were developed, thereby improving the sophistication of the model. The incremental development was often completed by different analysts with unique intentions and coding preferences. Over time, the model became increasingly difficult to maintain. Additionally, as the model evolved, so did the research questions. Therefore, in the fall of 2016, NREL began to rebuild Heritage ReEDS from the ground up. After three years, the resulting product was a cleaner, more flexible, and more advanced tool called ReEDS 2.0. Though ReEDS' fundamental structure and functionality have remained constant, ReEDS 2.0 introduces several changes to the heritage version of the model. The most notable changes include the following:

\footnotetext{
4 “Regional Energy Deployment System Model Publications," NREL, https://www.nrel.gov/analysis/reeds/publications.html
} 
- Demand-Side Representation: ReEDS 2.0 includes a representation of consumer demand for energy services. Energy services are provided by end-use devices, which are associated with different efficiency levels. The combination of demand for energy services and efficiency maps to consumer demand for electricity. In ReEDS 2.0, consumer demand for electricity is elastic, responding to changes in prices through both changes in demand for energy services and changes in the composition of end-use devices. In contrast, Heritage ReEDS did not explicitly model the demand for energy services. Moreover, electricity demand was assumed to be inelastic within a given solve year, with a demand elasticity applied for consumption in future years.

- Model Foresight and Solve Year Flexibility: ReEDS 2.0 can solve using one of three different types of foresight into future years. As in Heritage ReEDS, the model can be solved sequentially, with decision-making in each model year based on the assumption of static operating conditions for the next 20 years. However, ReEDS 2.0 can also be run as a fully intertemporal model with perfect foresight, or, as a middle ground, with sliding window foresight. Each ReEDS 2.0 model run can also be performed over a fully customizable set of model years. In contrast, Heritage ReEDS could only be solved in two-year time steps.

- Modular Structure and Iteration: To address non-linearities introduced by the demandside representation and the intertemporal optimization option, ReEDS now consists of three stand-alone modules (supply, demand, and VRE). When a model run is launched using both the supply and demand modules, the solution is obtained through an iterative procedure. When a model run includes both the supply and VRE modules and perfect or sliding window foresight, the solution is again obtained through an iterative procedure. However, when a model run includes the supply and VRE modules with a sequential solve, the model does not need to iterate, just as was the case with Heritage ReEDS.

While there are major architectural changes with ReEDS 2.0, many of the incumbent data and methods supporting ReEDS were updated incrementally. This documentation describes the data and methods for the 2020 version of ReEDS. The "Differences from the 2019 Model Version" section of the appendix summarizes more of the specific changes to made to ReEDS since the 2019 version.

\subsection{Summary of Caveats}

Though ReEDS represents many aspects of the U.S. electricity system, it necessitates simplifications, as all models do. We offer a list of some important limitations and caveats that result from these simplifications.

System-wide optimization: ReEDS takes a system-wide, least-cost perspective that does not necessarily reflect the perspectives of individual decision makers, including specific investors, regional market participants, or corporate or individual consumer choice; nor does it model contractual obligations or noneconomic decisions. In addition, like other optimization models, ReEDS finds the absolute (deterministic) least-cost solution that does not fully reflect real distributions or uncertainties in the parameters; however, the heterogeneity resulting from the high spatial resolution of ReEDS mitigates this effect to some degree. 
- Resolution: Though ReEDS has high spatial, temporal, and process resolution for models of its class and scope, it cannot generally represent individual units and transmission lines, and it does not have the temporal resolution to characterize detailed operating behaviors, such as ramp rates and minimum plant runtime. It also does not represent all intra-annual time scales, such as weekly or monthly trends, as ReEDS intraannual time slices are designed to characterize one day in each season. Many of the time slice shortcomings are addressed by using hourly data in VRE modules, not non-VRE generators do not get that higher resolution.

- Foresight and behavior: Except when running with intertemporal optimization, the model has limited foresight and therefore model decision-making does not account for anticipated changes to markets and policies. For example, non-intertemporal runs in ReEDS do not endogenously model banking and borrowing of credits for carbon, renewable, or clean energy policy between solve periods.

- Project pipeline: The model incorporates data of planned or under-construction projects, but these data likely do not include all projects in progress.

- Manufacturing, supply chain, and siting: The model does not explicitly simulate manufacturing, supply chain, or siting and permitting processes. Potential bottlenecks or delays in project development stages for new generation or transmission are not fully reflected in the results. All technologies are assumed to be available at their defined capital cost in any quantity up to their technical resource potential. Penalties for rapid growth are applied in ReEDS; however, these do not fully consider all potential manufacturing or deployment limits. Dates associated with cost inputs in the model reflect project costs for the commercial operation date but not necessarily when equipment is ordered.

- Financing: Though the model can use annually varying financing parameters to capture near-term market conditions and technology-specific financing to account for differences in typical investment strategies across technologies, ReEDS cannot fully represent differences in project financing terms across markets or ownership types and thus does not allow multiple financing options for a given technology.

- Technology learning: Future technology improvements are considered exogenously and thus are not a function of deployment in each scenario.

- Power sector: ReEDS models only the power sector within its defined regional scope (contiguous United States or United States with Canada and/or Mexico), and it does not represent the broader U.S. or global energy economy. For example, competing uses of resources (e.g., natural gas) across sectors are not dynamically represented in ReEDS, and end-use electricity demand is exogenously input into ReEDS.

Notwithstanding these limitations - many of which exist in other similar tools - the modeling approach considers complex interactions among numerous policies and technologies while ensuring electric system reliability requirements are maintained within the resolution and scope of the model. In doing so, ReEDS can comprehensively estimate the system cost and value of a wide range of technology options given a set of assumptions, and we can use the model to generate self-consistent future deployment portfolios. 
A comparison against historical data using ReEDS was completed by Cole and Vincent (2019) and is useful for providing context for how ReEDS can perform relative to what actually occurred in historical years.

\section{Modeling Framework}

In this section, we describe the modeling framework underlying ReEDS, including the modular structure of the model (and how outputs are passed between modules and convergence is achieved), spatial resolution, temporal resolution, technology represented, and the model formulations.

\subsection{Model Structure}

ReEDS combines two optimization modules with a simulation module. One of the two optimization modules represents electricity supply, and the other represents end-use energy service demand. The simulation model uses a dispatch algorithm and multiple years of chronological hourly wind, solar, and load data to estimate the contribution of storage and VRE units to capacity (see Section 7.2) and the level of curtailment for VRE units (see Section 7.4). Though both optimization modules are described here, only the supply module is used for most ReEDS analysis (i.e., the demand module is typically turned off for most runs).

The model can be run sequentially, intertemporally, or using a sliding window. Figure 1 illustrates how the modules interact when the model is run in sequential solve mode. Within an iteration, the supply and VRE modules are run in sequence for each model solve year. For a given model year $t$, the supply module, which has been provided with a set of inputs dependent on the results from previous model years, is solved and a subset of the outputs are passed along to the VRE and storage module. Using these inputs, the module then calculates the capacity value of VRE and storage, and curtailment rates for VRE units, which are then applied to the next model year solve $(\mathrm{t}+1) .{ }^{5}$ After this recursive procedure is executed for all model years, the resulting electricity prices for all model years are passed to the demand module. Based on those prices, the demand module solves and exports new values for load, which the supply module then uses the in the next iteration. This process repeats until convergence (i.e., until the results of successive iterations are sufficiently close)

\footnotetext{
${ }^{5}$ Here, the $\mathrm{t}+1$ notation is used heuristically, as the model year subsequent to $t$ can be $t+1, t+2, t+3$, etc.
} 


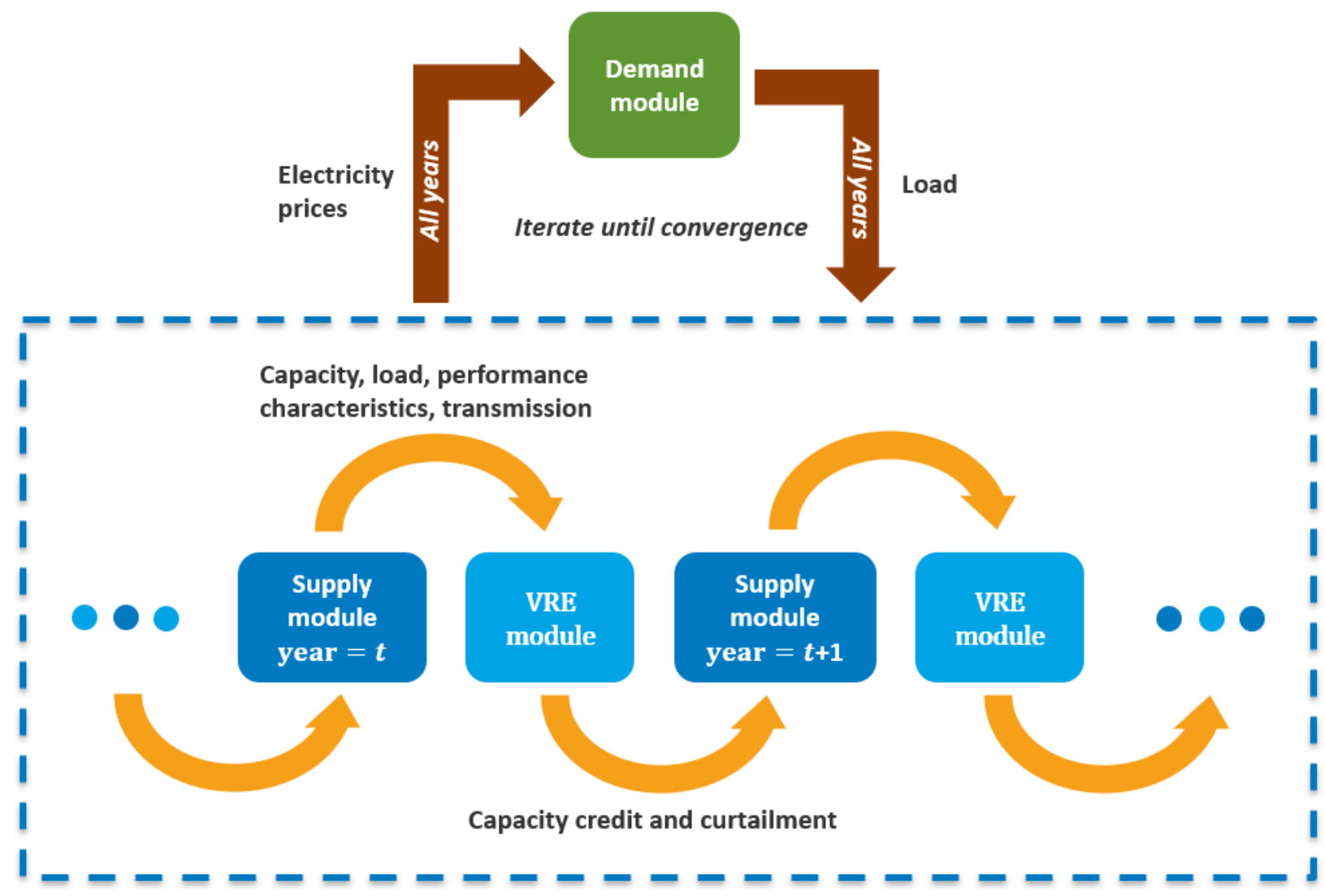

Figure 1. Schematic illustrating the ReEDS structure with a sequential solve

Figure 2 illustrates how the core modules interact when the model is run with sliding window or perfect foresight. Each iteration begins with an execution of the supply module for all model years. The outer cycle (red arrows) illustrates the order in which the modules are executed: after the supply module, the VRE module is executed, followed by the demand module. After the demand module is executed, the next iteration begins with the supply module. This process is repeated until convergence. The inner cycles (orange arrows) illustrate how information is shared by the modules. The types of information shared by the three modules is the same as for the sequential solve mode. The major difference is that the supply module passes information for all model years to the VRE and storage module (and vice versa), and that an iterative process occurs between the two modules. Note also that the VRE and demand modules are still only indirectly linked by way of the supply module.

Regardless of which foresight mode is chosen, the modular structure allows each part of the model to be executed independently. However, the supply and VRE and storage modules are unlikely to be executed without each other, except for testing purposes. This is because one of the key strengths of ReEDS resides in its detailed representation of VRE integration and valuation. 


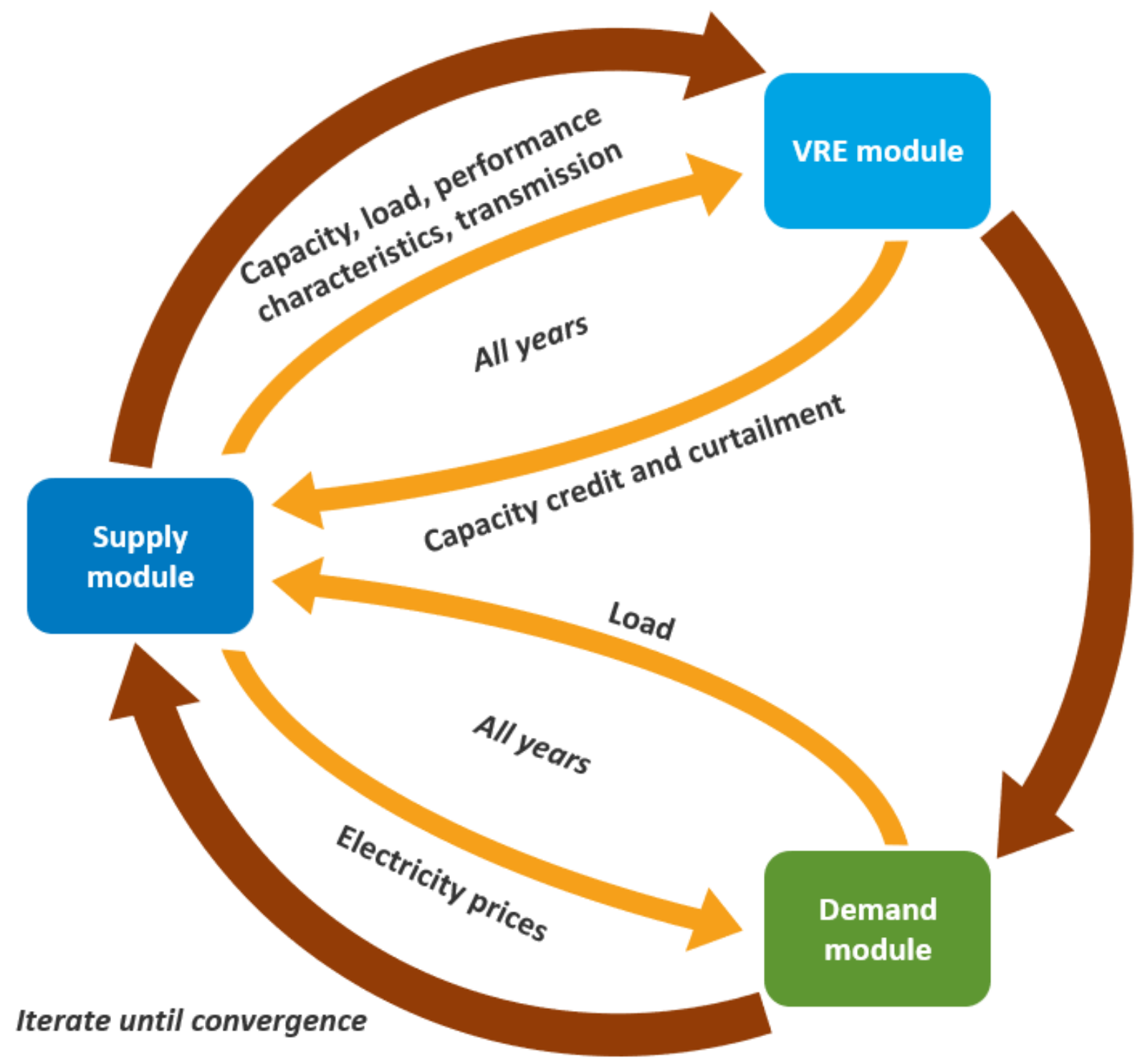

Figure 2. Schematic illustrating the ReEDS structure with sliding window or perfect foresight

\subsection{Model Formulations}

The supply and demand modules are both cast as linear programs, and each can be described by its objective function, decision variables, and constraints. This section describes each of these elements for both modules.

\subsubsection{Supply Module}

The supply module is a linear program that governs the evolution and operation of the generation and transmission system. This module seeks to minimize power sector costs as it makes various operational and investment decisions, subject to a set of constraints on those decisions.

The objective function is a minimization of both capital and operating costs for the U.S. electric sector, including: 
- The net present value of the cost of adding new generation, storage, and transmission capacity (including project financing)

- The present value of operating expenses over the evaluation period ${ }^{6}$ (e.g., expenditures for fuel and operation and maintenance $[\mathrm{O \& M}]$ ) for all installed capacity

- The cost of several categories of ancillary services and storage

- The cost or incentive applied by any policies that directly charge or credit generation or capacity

- Penalties for rapid capacity growth as a proxy for manufacturing, supply chain, and siting/permitting limitations.

By minimizing these costs and meeting the system constraints (discussed below), the linear program determines the types of new capacity to construct in each region during each model year to minimize systemwide cost. Simultaneously, the linear program determines how generation and storage capacity should be dispatched to provide the necessary grid services in each of the 17 time-slices. The capacity factor for each dispatchable technology therefore is an output of the model and not an input assumption.

The constraints that govern how ReEDS builds and operates capacity fall into several main categories:

- Load Balance Constraints: Sufficient power must be generated within or imported by the transmission system to meet the projected load in each of the 134 balancing areas (BAs) in each of the 17 time-slices. The annual demand and the time-slice-specific electricity demand in future years are scaled based on load growth inputs.

- Planning Reserve Constraints: Each region must have sufficient available capacity to meet the forecasted peak demand as well as an additional planning reserve margin (NERC 2018). Dispatchable technologies contribute their full capacity toward planning reserves. For variable renewable energy (VRE) technologies, ReEDS uses a load-duration curve (LDC) approximation to estimate the effective load-carrying capacity of both existing capacity and potential capacity additions to determine their contribution to meeting the reserve margin. For storage, a chronological simulation using hourly data is used to assess its contribution. Planning reserve capacity can also be traded between regions if transmission capacity is available. ${ }^{7}$

- Operating Reserve Constraints: These constraints ensure enough capacity is available to meet unexpected changes in generation and load in each reserve-sharing group (Section 7.3) and time-slice. ReEDS accounts for the following operating reserve requirements: regulation reserves, spinning reserves, and flexibility reserves.

- Generator Operating Constraints: Technology-specific constraints bound the minimum and maximum power production and capacity commitment based on physical limitations and assumed average outage rates.

\footnotetext{
${ }^{6}$ The current default is 20 years but it can be adjusted by the user.

${ }^{7}$ Hydropower's contribution to planning reserves depends on its categorization as dispatchable or non-dispatchable, which is discussed in Section 3.1.6.
} 
- Transmission Constraints: Power transfers among regions are constrained by the nominal carrying capacity of transmission corridors that connect the regions. Transfers of planning reserves are also subject to transmission limits. A detailed description of the transmission constraints can be found in Section 6.

- Resource Constraints: Many renewable technologies, including wind, solar, geothermal, biopower, and hydropower, are spatially heterogeneous and constrained by the quantity available at each location. Several of the technologies include cost- and resource-quality considerations in resource supply curves to account for depletion, transmission, and competition effects. The resource assessments that seed the supply curves come from various sources; these are discussed in Section 3, where characteristics of each technology are also provided.

- Emissions Constraints: ReEDS can limit or cap the emissions from fossil-fueled generators for sulfur dioxide $\left(\mathrm{SO}_{2}\right)$, nitrogen oxide $\left(\mathrm{NO}_{\mathrm{x}}\right)$, and carbon dioxide $\left(\mathrm{CO}_{2}\right)$. The emission limit and the emission per megawatt-hour by fuel and plant type are inputs to the model. Emissions can be either capped or taxed, with flexibility for applying either. Alternatively, emissions intensities can also be limited to certain bounds in ReEDS.

- Renewable Portfolio Standards or Clean Electricity Standards: ReEDS can represent renewable portfolio standards (RPSs) and clean electricity standards constraints at the national and state levels. All renewable generation is considered eligible under a national RPS requirement. The renewable generation sources include hydropower, wind, CSP, geothermal, PV, and biopower (including the biomass fraction of cofiring plants). The eligibility of technologies for state RPSs depends on the state's specific requirements and thus varies by state. RPS targets over time are based on an externally defined profile. Penalties for noncompliance can be imposed for each megawatt-hour shortfall occurring in the country or a given state. In the same way, a clean energy standard constraint can be implemented to include non-renewable clean energy resources, such as nuclear, fossil fuels with carbon capture and sequestration (CCS), or natural gas.

\subsubsection{Demand Module}

The demand module represents demand for energy services (e.g., lumens for lighting) for different customer classes. In the residential buildings sector, customer classes are defined on the basis of income. Services are provided by end-use devices, which are associated with different efficiency levels. The desirability of different device efficiency levels depends in part on the subjective discount rates for each customer class, with higher income customers being associated with lower discount rates. Over time, the stock of devices evolves according to the costs and benefits associated with new technologies.

The objective function for the demand module represents the net present value of total consumer welfare over the model horizon. The function has three components: one corresponding to the capital investment and two for the use of devices. For the latter two, the components are illustrated in Figure 3 (page 11) for a low-efficiency device (equilibrium point $E_{\text {low }}$ ) and a highefficiency device $\left(E_{\text {high }}\right)$. The letters in the figure (A, B, C, D, and E) denote the area of the associated region. 
- Consumer benefit corresponds to the area under the energy service demand curve. It captures the difference between customer willingness to pay (reflected in points along the demand curve) and the equilibrium price paid for the consumption of service below the equilibrium level. In Figure 3, these benefits are equal to $\mathrm{A}+\mathrm{B}+\mathrm{C}$ for a low-efficiency device and $\mathrm{A}+\mathrm{B}+\mathrm{C}+\mathrm{D}+\mathrm{E}$ for a high-efficiency device. For a given device purchase in the model, consumer benefits are summed over the entire lifetime of the device.

- Operational costs represent the price paid for the electricity required to achieve a given level of service. In Figure 3, these costs are equal to B+C for a low-efficiency device and $\mathrm{C}+\mathrm{E}$ for a high-efficiency device. Like consumer benefits, for a given device purchase, operational costs are summed over the entire lifetime of the device. ${ }^{8}$

- Capital costs represent the purchase price of a new device. We assume this is a one-time payment for customers that does not depend on the level of service consumed. Because they do not depend on service levels, capital costs are not explicitly captured in Figure 3. However, they relate to the figure in the following way: if the figure represents operations for a device with a one-year lifetime, the consumer will choose the lowefficiency device if the net operational benefit (consumer benefit less operational cost, or A) less the capital cost of the device is greater than the net operational benefit $(\mathrm{A}+\mathrm{B}+\mathrm{D})$ less the capital cost of the high-efficiency device. Thus, the choice of device will depend on the magnitude of the increased operational benefit of the high-efficiency device (B+D) versus its (presumably) higher capital cost.

Details about the demand module are in the Demand Module section of the appendix. The demand module is typically not used in ReEDS runs, and therefore it is given less emphasis in this documentation.

\footnotetext{
${ }^{8}$ For devices that remain in the capital stock in the terminal model year, both consumer benefits and operational costs are weighted by an end-of-horizon factor based on the expected remaining lifespan of the device
} 


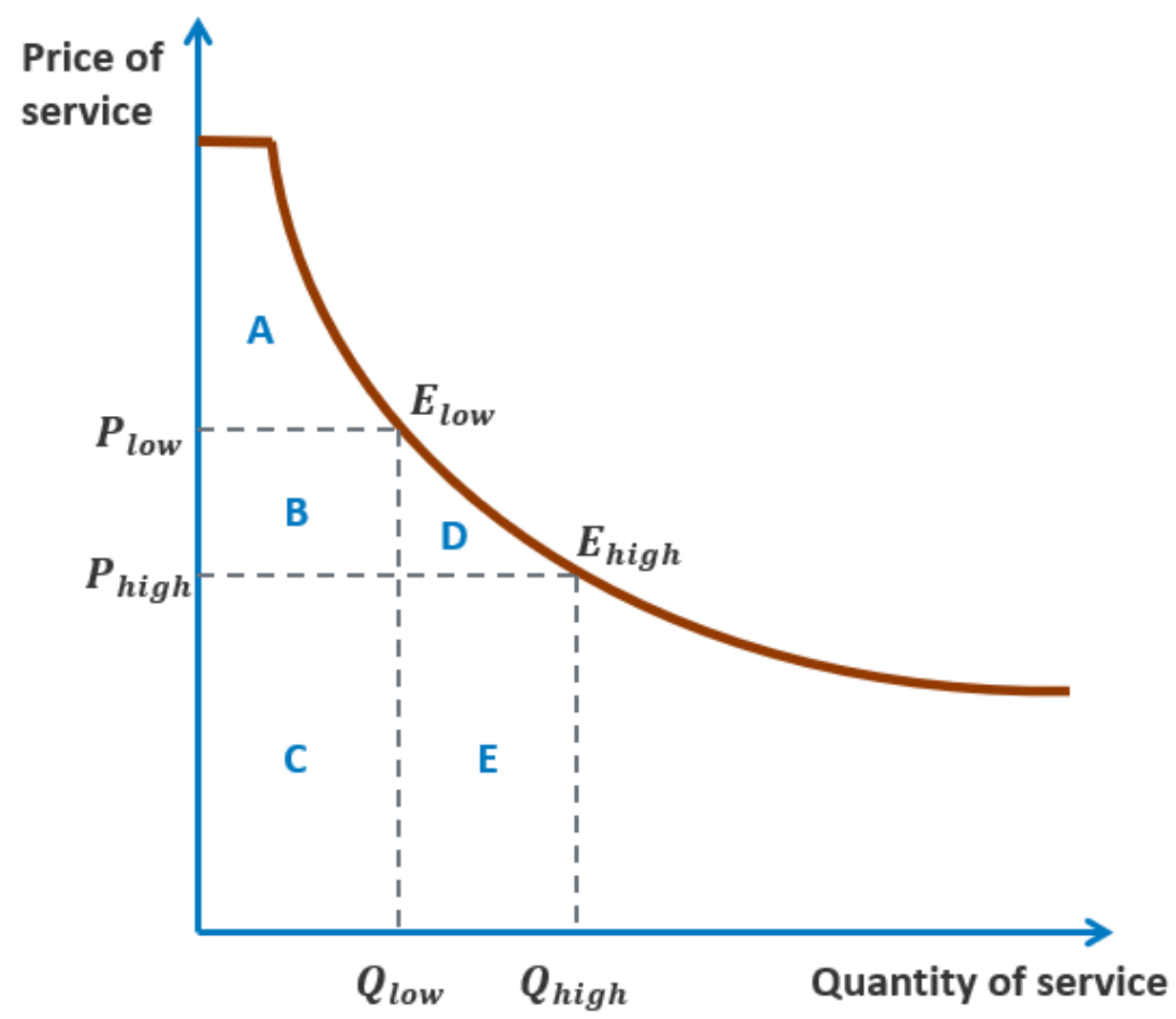

Figure 3. Energy service consumption equilibrium for two different device efficiency levels

\subsection{Supply and Demand Module Integration}

After each supply module solve, the model passes retail electricity prices to the demand module to inform consumers' purchase and use decisions about devices. The calculation of retail electricity prices for this supply-to-demand module interaction is different from the supply-side reported electricity prices that are discussed in Section 10.2.2. To obtain retail electricity prices that can be fed into the demand module, regional and sector-specific transmission and distribution $(T \& D)$ adders are applied to the wholesale electricity prices. The adders are constructed by combining state-wide historical retail electricity sales data from EIA( EIA 2016a) with T\&D price component data from the Annual Energy Outlook (AEO) (EIA 2017a), using 2016 data for each. The process that we use is as follows:

1. Sum the National Energy Modeling System (NEMS) T\&D price components: Because we treat both the T\&D components of electricity prices as exogenous, we create an aggregated T\&D factor to represent both. The end result is a single factor for each NEMS Electricity Market Module (EMM) region.

2. Map ReEDS BAs to states and EMM regions: To calculate adders at the ReEDS BA, we define the mapping between each BA and its state and EMM region. As is the case for states, there is a one-to-many relationship between EMM regions and ReEDS BAs.

3. Remove the wholesale electricity price component from retail prices: To calculate sectorspecific adders, we make two assumptions: first, each sector-specific retail price from the 
EIA historical data has two components, a generation component that is common to all sectors and a T\&D component that is sector-specific; and second, the aggregated T\&D factor from AEO is a sales-weighted average of the sector-specific adders. Combining these assumptions, we can calculate expressions for sector specific adders by calculating and removing the wholesale price component from the sector-specific retail prices.

Our assumptions can be formalized by the following set of equations:

$$
\begin{gathered}
r_{i}=p+a_{i} \\
\bar{a}=\sum_{i} a_{i} q_{i} / \sum_{i} q_{i}
\end{gathered}
$$

where $i$ indexes sectors, $r$ denotes retail a price, $p$ denotes a wholesale electricity price, $a$ denotes a T\&D adder, $\bar{a}$ denotes a sales-weighted average adder across sectors, and $q$ denotes electricity sales. The only unknown quantities in these equations are the wholesale electricity price and the sector-specific adders. Solving this set of linear equations for the adders yields:

$$
a_{i}=r_{i}-\sum_{i} r_{i} q_{i} /\left(\bar{a} \sum_{i} q_{i}\right)
$$

This adder is used to adjust supply-side wholesale prices into retail prices that can be used by the demand module.

\subsection{Spatial Resolution}

ReEDS can model the contiguous United States, Canada, and Mexico, though the model is typically used to study the contiguous United States. ${ }^{9}$ In Section 11, we discuss the model and data requirements for continental optimization. Within the contiguous United States, ReEDS models capacity expansion and grid service requirements in 134 model BAs, shown in Figure 4. The model BAs are not designed to represent or align perfectly with real balancing authority areas; they are county aggregates intended to represent model nodes where electricity supply and demand is balanced. The model's synthetic transmission network connects the BAs and is composed of roughly 300 representative corridors across the three asynchronous interconnections: the Western Interconnection, the Eastern Interconnection, and Electric Reliability Council of Texas (ERCOT). The BAs also respect state boundaries, allowing the model to represent individual state regulations and incentives. The BAs are further subdivided into 356 resource supply regions that describe wind and CSP resource supply (both quality and quantity) to have more spatial granularity for these resources. Resource supply regions also consist of one or more counties. All other renewable resources are represented the BA level of spatial resolution. Additional geographical layers used for defining model characteristics include 3 electricity interconnects, 18 model regional transmission operators designed after existing

\footnotetext{
${ }^{9}$ A ReEDS-India model version has also been developed. Details of the implementation are not discussed here.
} 
regional transmission operators, 19 North American Electric Reliability Corporation (NERC) reliability subregions, 9 census divisions as defined by the U.S. Census Bureau, and 48 states. $^{10}$

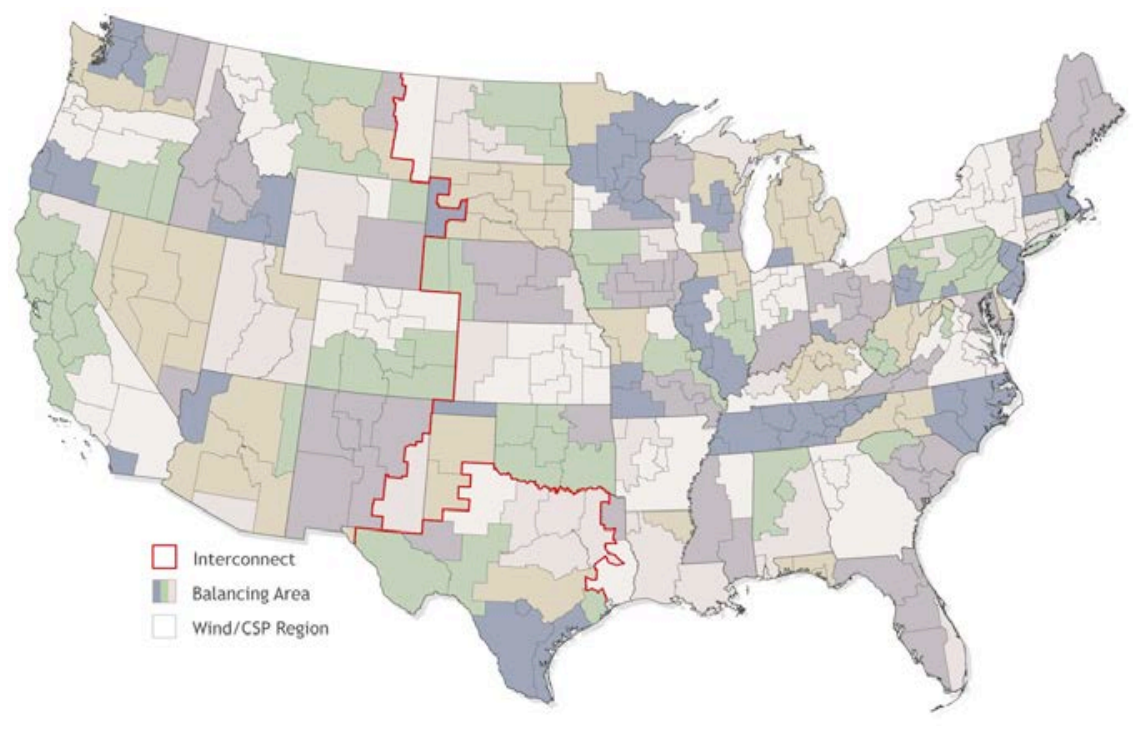

Figure 4. Map showing the ReEDS regional structure

ReEDS includes 3 interconnections, 134 model BAs, and 356 wind and CSP resource regions.

\subsection{Temporal Resolution}

ReEDS has three levels of temporal resolution: 17 time-slices, one year of hourly chronological data, and seven years of hourly chronological data. ReEDS serves load and maintains operational reliability using a reduced-order dispatch in 17 time-slices within each model year, as defined in Table 1. Each of the four seasons is modeled with four time blocks of non-chronological aggregate hours, organized by when they occur: overnight, morning, afternoon, and evening. ${ }^{11}$ The $17^{\text {th }}$ time-slice is a summer "superpeak" representing the top 40 hours of summer load. Though this schedule does allow the model to capture seasonal and diurnal variations in demand, wind, and solar profiles, it is insufficient to address some of the shorter time-scale challenges associated with unit commitment and economic dispatch, especially under scenarios with high penetration of variable generation (e.g., wind and solar). To more accurately represent how renewable grid integration might affect investment and dispatch decisions, the ReEDS model includes parameters designed to address intra-time-slice variability and uncertainty of wind, solar, and other variable renewable resources. These parameters are derived from chronological hourly data and updated between each solve year. The parameters for curtailment estimates and storage arbitrage value are computed using one year of chronological hourly data, and the parameters for capacity credit are computed using seven years of chronological hourly data. These hourly calculations are discussed in detail in Section 7.

\footnotetext{
${ }^{10}$ These additional geographical layers defined in ReEDS do not necessarily align perfectly with the actual regions, except for state boundaries, which are accurately represented.

${ }^{11}$ The modeled load for each time-slice is an average of all hours represented by that time-slice. Therefore, the representative days are non-chronological across seasons. However, for the purposes of storage charging and discharging, we assume that time-slices within a season are chronological.
} 
Table 1. Definition of ReEDS Time-Slice. Winter is November-February, Spring is March-May, Summer is June-August, and Fall is September-October.

\begin{tabular}{|c|c|l|l|l|}
\hline Time-Slice & Hours/Year & Season & Time of Day & Period \\
\hline H1 & 736 & Summer & Overnight & 10 p.m. to 6 a.m. \\
\hline H2 & 644 & Summer & Morning & 6 a.m. to 1 p.m. \\
\hline H3 & 328 & Summer & Afternoon & 1 p.m. to 5 p.m. \\
\hline H4 & 460 & Summer & Evening & 5 p.m. to 10 p.m. \\
\hline H5 & 488 & Fall & Overnight & 10 p.m. to 6 a.m. \\
\hline H6 & 427 & Fall & Morning & 6 a.m. to 1 p.m. \\
\hline H7 & 244 & Fall & Afternoon & 1 p.m. to 5 p.m. \\
\hline H8 & 305 & Fall & Evening & 5 p.m. to 10 p.m. \\
\hline H9 & 960 & Winter & Overnight & 10 p.m. to 6 a.m. \\
\hline H10 & 840 & Winter & Morning & 6 a.m. to 1 p.m. \\
\hline H11 & 480 & Winter & Afternoon & 1 p.m. to 5 p.m. \\
\hline H12 & 600 & Winter & Evening & 5 p.m. to 10 p.m. \\
\hline H13 & 736 & Spring & Overnight & 10 p.m. to 6 a.m. \\
\hline H14 & 644 & Spring & Morning & 6 a.m. to 1 p.m. \\
\hline H15 & 368 & Spring & Afternoon & 1 p.m. to 5 p.m. \\
\hline H16 & 460 & Spring & Evening & 5 p.m. to 10 p.m. \\
\hline H17 & 40 & Summer & Peak & 40 highest demand hours of H3 \\
\hline
\end{tabular}




\section{Technology Descriptions}

This section describes the electricity generating technologies included in ReEDS. Cost and performance assumptions for these technologies are not included in this report but are taken directly from the 2020 Annual Technology Baseline (ATB) (NREL 2020).

\subsection{Renewable Energy Resources and Technologies}

Because renewable energy technologies are a primary focus area of the ReEDS model, they are characterized in detail. Their characterization encompasses resource assessments, ${ }^{12}$ projected technology improvements, grid interconnection costs, and operational implications of integration. Renewable energy technologies modeled include land-based and offshore wind power, solar PV (both distributed and utility-scale), CSP with and without thermal storage, ${ }^{13}$ hydrothermal geothermal, near-field enhanced geothermal systems (EGS), deep EGS, run-of-theriver and traditional hydropower (including upgrades and non-powered dams), dedicated biomass, cofired biomass, land-fill gas, renewable energy combustion turbines, and marine hydrokinetic wave technologies. The input assumptions, data sources, and treatments of these technologies are discussed in the following sections. Transmission considerations for renewable energy technologies are discussed in Section 6.3. ${ }^{14}$

\subsubsection{Land-Based Wind}

Wind technologies are modeled using representative turbine technologies by region depending on wind resource quality. Details of the wind resource data and technology representation can be found in Appendix H of the Wind Vision study (DOE 2015). In the current version of ReEDS, we have relied on the same data sources and approach; however, we extend the wind resource data to lower-quality wind sites.

The resource assessment for land-based wind uses a resource map of hourly wind speeds for the United States and offshore areas (for offshore wind, see Section 3.1.2) and considers land use exclusions (Lopez et al. 2021). The Reference Access resource totals more than 7,700 gigawatts (GW), although a Limited Access and Open Access supply curves are also available.

Individual wind sites are grouped into ten resource classes for ReEDS, based on average wind speed (

\footnotetext{
${ }^{12}$ All renewable resource assessments are independent and mutually exclusive of each other due to their unique nature and to allow ReEDS to dynamically evaluate cost-optimal capacity expansion without any upstream ranking of which technologies would be preferred at a given site. This implementation ignores any possible land-use conflicts between multiple technologies at the same site, but spatial aggregation and resource heterogeneity is expected to alleviate this limitation.

${ }^{13}$ CSP refers to solar thermal power and not concentrating PV.

${ }^{14}$ Where given in the sections below, renewable energy resource potential values refer to the resource potential represented in ReEDS and not the total technical resource potential. The renewable potential capacity modeled in ReEDS includes exclusions in the pre-processing steps for the model, such as site exclusions, assumed transmission access limits, or a narrower set of technologies considered. Lopez et al. (2012) present renewable technical potential for the United States.
} 
Table 2). ${ }^{15}$ The modeling and assessment of individual wind sites was facilitated using NREL's Renewable Energy Potential (reV) tool (Maclaurin et al. 2019). The meteorological data for onshore wind are from the Wind Integration National Dataset (WIND) Toolkit, using long-term average data for the resource assessment. Figure 5 shows the land-based wind resource data modeled in ReEDS for all 10 classes, where the highest average wind speeds belong to class 1 and the lowest to class 10 (Mai et al. 2021). Each class is then further differentiated by a supply curve for grid interconnection costs in each region. See Section 6.3 for a discussion of interconnection supply curves for accessing the wind resource.

Distinct wind production profiles are also modeled for each class and wind resource region. In addition, to inform capacity credit and curtailment calculations, we use hourly production data for each region and class. Timeslice profiles are based on the 2012 weather year, and hourly profiles are from the 2007-2013 weather years.

Table 2. Land-Based Wind Class Definitions

\begin{tabular}{|l|r|r|}
\hline Wind Class & $\begin{array}{l}\text { Wind Speed } \\
\text { Range (m/s) }\end{array}$ & $\begin{array}{l}\text { Potential Wind Plant } \\
\text { Capacity (GW) }\end{array}$ \\
\hline 1 & $>9.01$ & 106 \\
\hline 2 & $8.77-9.01$ & 91 \\
\hline 3 & $8.57-8.77$ & 188 \\
\hline 4 & $8.35-8.57$ & 356 \\
\hline 5 & $8.07-8.35$ & 684 \\
\hline 6 & $7.62-8.07$ & 1,266 \\
\hline 7 & $7.10-7.62$ & 1,191 \\
\hline 8 & $6.53-7.10$ & 1,159 \\
\hline 9 & $5.90-6.53$ & 1,144 \\
\hline 10 & $<5.90$ & 1,587 \\
\hline
\end{tabular}

More information can be found in the NREL Annual Technology Baseline (NREL 2020).

\footnotetext{
15 The wind resource is not evenly binned into the 10 classes, as the better classes have higher resolution (smaller
} bins). 

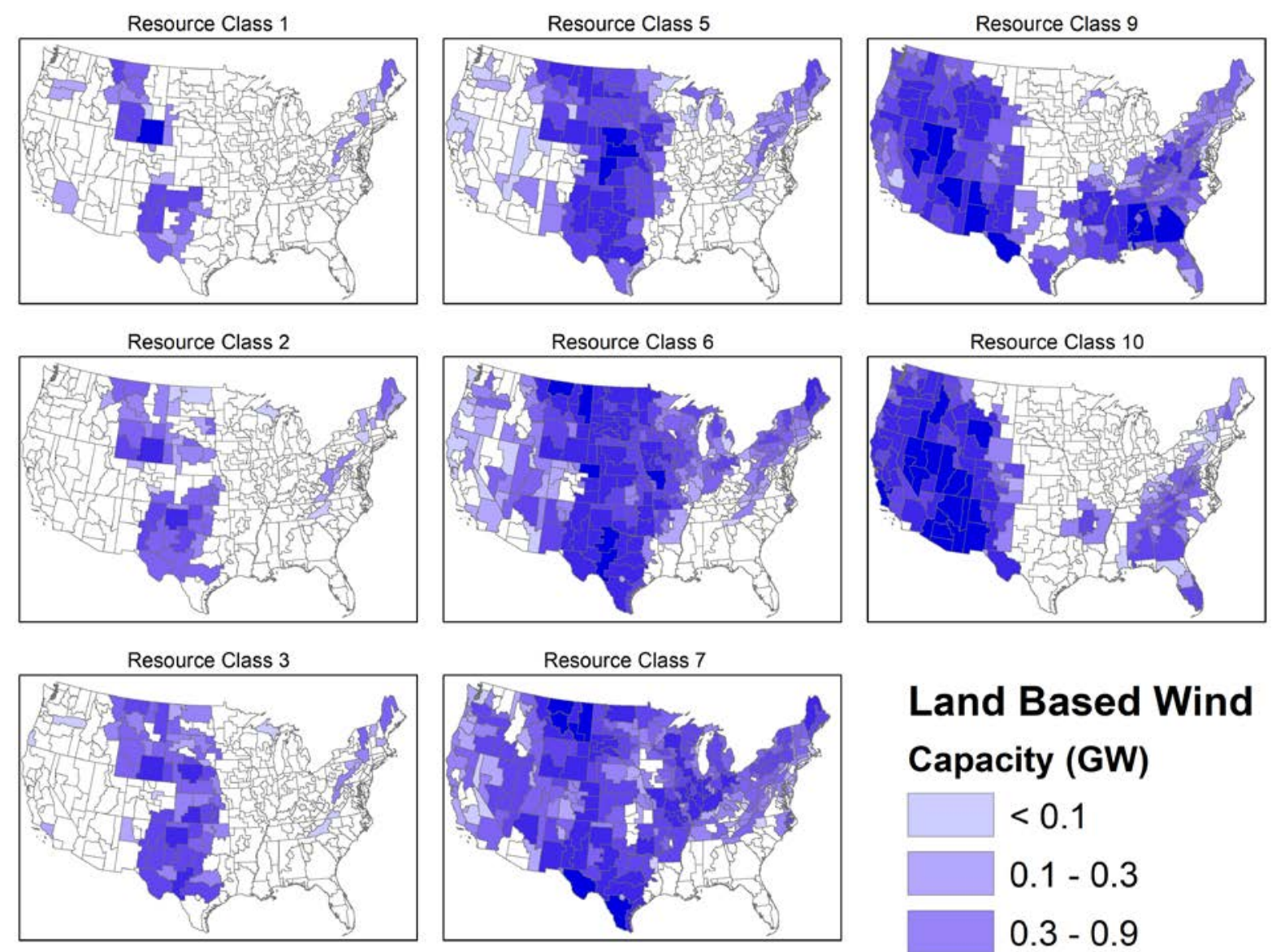

Land Based Wind Capacity (GW)
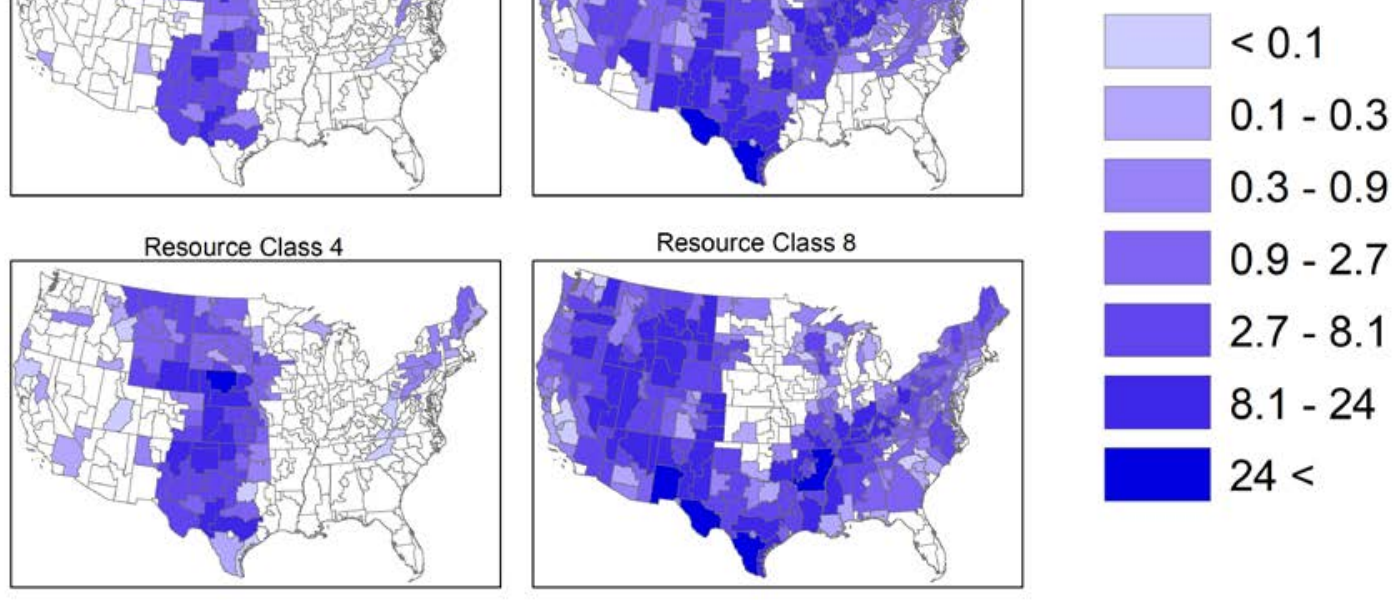

Figure 5. Land-based wind resource map for the contiguous United States

\subsubsection{Offshore Wind}

There is substantial diversity in offshore wind generators, in distance from shore, water depth, and resource quality. ReEDS subdivides offshore wind potential into fourteen resource classes: seven each for fixed-bottom and floating turbine designs. Fixed bottom offshore wind development is limited to resources $<60$ meters $[\mathrm{m}]$ in depth using either current-technology monopile foundations $(0-30 \mathrm{~m})$; or jacket (truss-style) foundations $(30-60 \mathrm{~m})$. Offshore wind using a floating anchorage could be developed for greater depths and are assumed the only feasible technology for development for resource deeper than $60 \mathrm{~m}$. Within each category, the classes are distinguished by resource quality, and then supply curves differentiate resource by cost of accessing transmission in a similar fashion as land-based wind. 
Eligible offshore area for wind development includes open water within the U.S.-exclusive economic zone having a water depth less than 1,000 m, including the Great Lakes. As with landbased resource, offshore zones are filtered to remove areas considered unsuitable for development, including national marine sanctuaries, marine protected areas, wildlife refuges, shipping and towing lanes, offshore platforms, and ocean pipelines. The offshore technology selection is made using the Offshore Wind Cost Model, which selects the most economically feasible technology for developing a wind resource (Beiter and Stehly 2016). More than 4,900 $\mathrm{GW}$ of technical offshore wind potential remain after applying the exclusions.

Current-day cost data are derived from the published data of the global offshore wind industry as well as estimates from recent development activity on the Atlantic Coast of the United States (Musial et al. 2019; NREL 2019). These data are coupled with engineering assessments and distance-based cost functions (specific to the offshore export cable and incremental construction cost associated with moving farther from shore) to determine expected site-specific costs for technology across a broad range of water depths and distances from shore (Beiter et al. 2017). Cost and performance for offshore wind plants are based on assuming a representative plant size of $600 \mathrm{MW}$.

Other aspects of our model representations for offshore wind follow the same methods as those for land-based wind (Lopez et al. 2021). Figure 6 shows the offshore wind resource potential modeled in ReEDS for each of the 14 classes. Classes 1-7 represent fixed-bottom offshore wind resources with class 1 representing the highest wind speeds. Classes 8-14 represent floating offshore wind resources with class 8 being the highest wind speeds. The higher speed classes have smaller bin sizes to capture the highest quality resources with greater resolution. 
Table 3. Offshore Wind Class Definitions

\begin{tabular}{|l|l|r|r|}
\hline \multicolumn{2}{|c|}{ Wind Class } & \multicolumn{1}{|c|}{$\begin{array}{l}\text { Wind Speed } \\
\text { Range (m/s) }\end{array}$} & $\begin{array}{l}\text { Potential } \\
\text { Wind Plant } \\
\text { Capacity } \\
\text { (GW) }\end{array}$ \\
\hline \multirow{5}{*}{ Fixed-Bottom } & 1 & $>9.98$ & 24 \\
\cline { 2 - 4 } & 2 & $9.31-9.98$ & 23 \\
\cline { 2 - 4 } & 3 & $9.13-9.31$ & 53 \\
\cline { 2 - 4 } & 4 & $8.85-9.13$ & 97 \\
\cline { 2 - 4 } & 5 & $7.93-8.85$ & 197 \\
\cline { 2 - 4 } & 6 & $7.07-7.93$ & 396 \\
\cline { 2 - 4 } & 7 & $<7.07$ & 445 \\
\hline \multirow{5}{*}{ Floating } & 8 & $>10.30$ & 73 \\
\cline { 2 - 5 } & 9 & $10.18-10.30$ & 71 \\
\cline { 2 - 4 } & 10 & $10.01-10.18$ & 152 \\
\cline { 2 - 4 } & 11 & $9.60-10.01$ & 293 \\
\cline { 2 - 4 } & 12 & $8.84-9.60$ & 590 \\
\cline { 2 - 4 } & 13 & $7.43-8.84$ & 1189 \\
\cline { 2 - 4 } & 14 & $<7.43$ & 1320 \\
\hline
\end{tabular}

More information can be found in the NREL Annual Technology Baseline (NREL 2020).
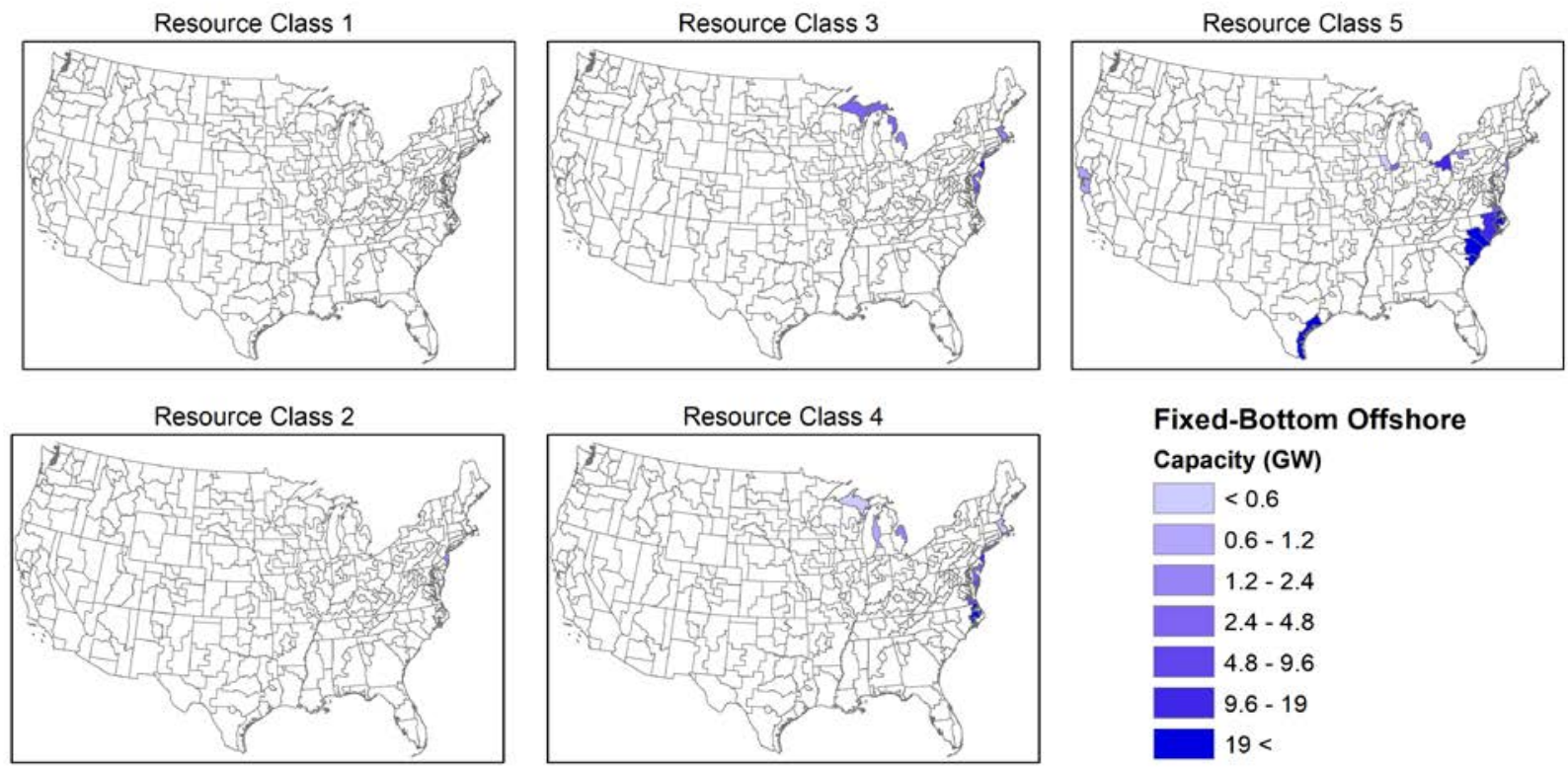

Fixed-Bottom Offshore

Capacity (GW)

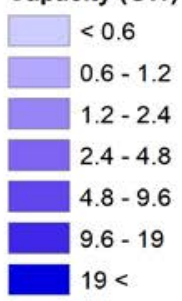

Figure 6 Fixed-Bottom offshore wind resource map for the contiguous United States 

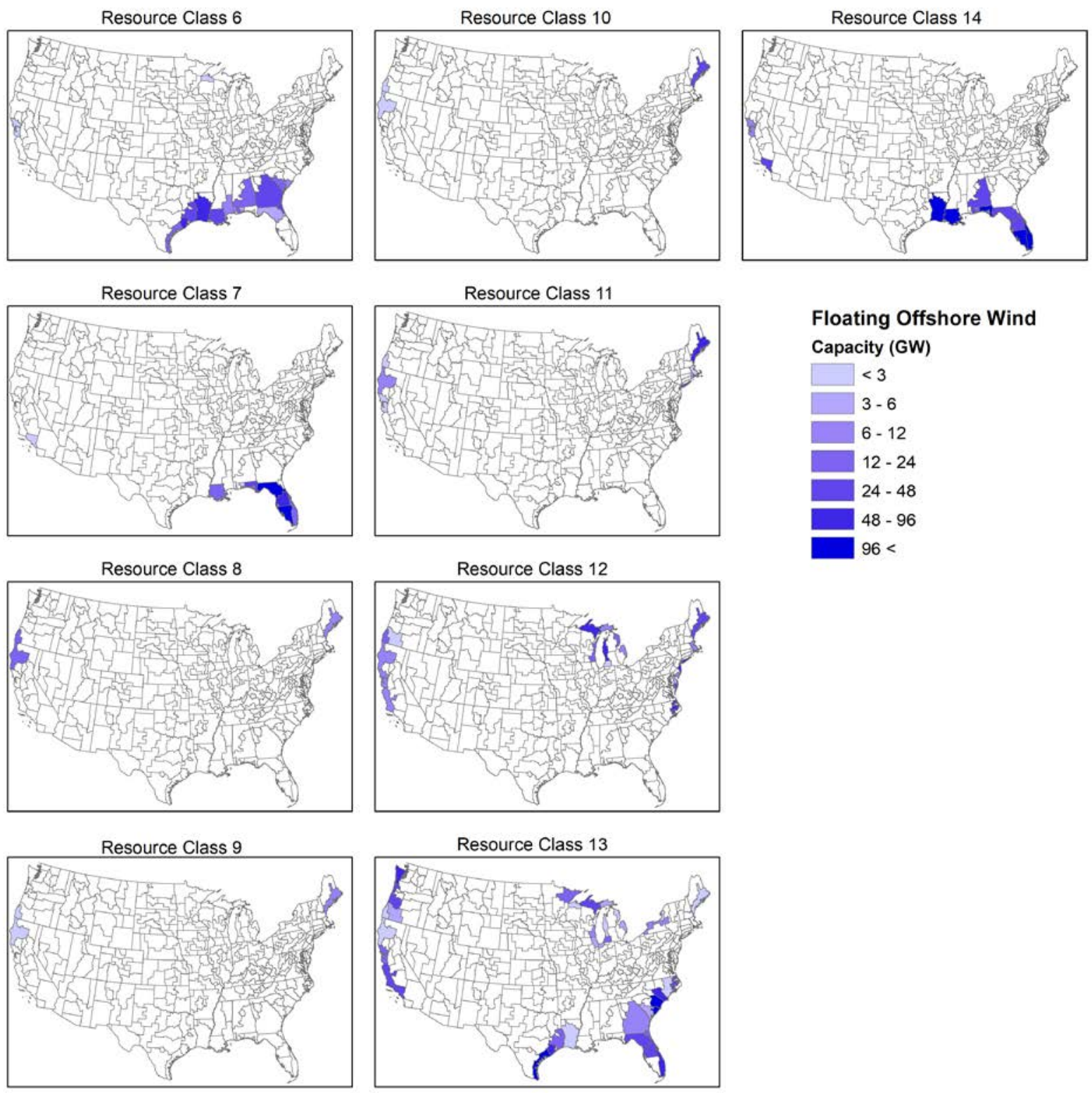

Figure 7. Floating offshore wind resource map for the contiguous United States

\subsubsection{Solar Photovoltaics}

ReEDS differentiates between three solar photovoltaic technologies: large-scale utility PV (UPV), distribution-side utility-scale PV (DUPV), and rooftop PV. Investments in UPV and DUPV are evaluated directly in ReEDS, while rooftop PV deployment and performance are exogenously input into ReEDS from the dGen model.

UPV in ReEDS represents utility-scale single-axis-tracking PV systems with a representative size of 100 megawatts (MW) and an array density of $39 \mathrm{MW}$ per square kilometer $\left(\mathrm{km}^{2}\right)$ with an inverter loading ratio of 1.3. Resource potential is assumed to be located on large parcels outside urban boundaries, excluding federally protected lands, inventoried "roadless" areas, U.S. Bureau of Land Management areas of critical environmental concern, and areas with slope greater than 
$5 \%$. Each eligible UPV site is characterized by a raw hourly $(8,760)$ irradiance profile that is representative of the solar resource within a $10 \mathrm{~km}^{2}$ contiguous area. Each of these UPV sites are compiled into supply curves for each of the 134 ReEDS BAs with 9 PV resource classes, which are further differentiated by cost to connect to the transmission network (process described in Section 6.3). The resource classes reflect different resource qualities based on the annual average global horizontal irradiance (GHI) reported by the latest National Solar Radiation Database (NSRDB), assuming a tilt angle equal to the latitude (Table 4). The UPV supply curves input into ReEDS for the conterminous U.S. include 156 terawatts (TW) of potential, which is shown by resource class in Figure 8.

Table 4. UPV and DUPV Resource Classes

\begin{tabular}{|c|c|c|c|}
\hline Class & $\begin{array}{l}\text { GHI } \\
\text { (kWh/m²/day) }\end{array}$ & $\begin{array}{l}\text { Potential UPV } \\
\text { Capacity (GW) }\end{array}$ & $\begin{array}{l}\text { Potential } \\
\text { DUPV } \\
\text { Capacity (GW) }\end{array}$ \\
\hline 1 & $3.0-3.5$ & 167 & 14 \\
\hline 2 & $3.5-4.0$ & 16,870 & 184 \\
\hline 3 & $4.0-4.5$ & 30,238 & 434 \\
\hline 4 & $4.5-5.0$ & 37,438 & 511 \\
\hline 5 & $5.0-5.5$ & 20,372 & 222 \\
\hline 6 & $5.5-6.0$ & 11,868 & 116 \\
\hline 7 & $6.0-6.5$ & 332 & 4 \\
\hline
\end{tabular}

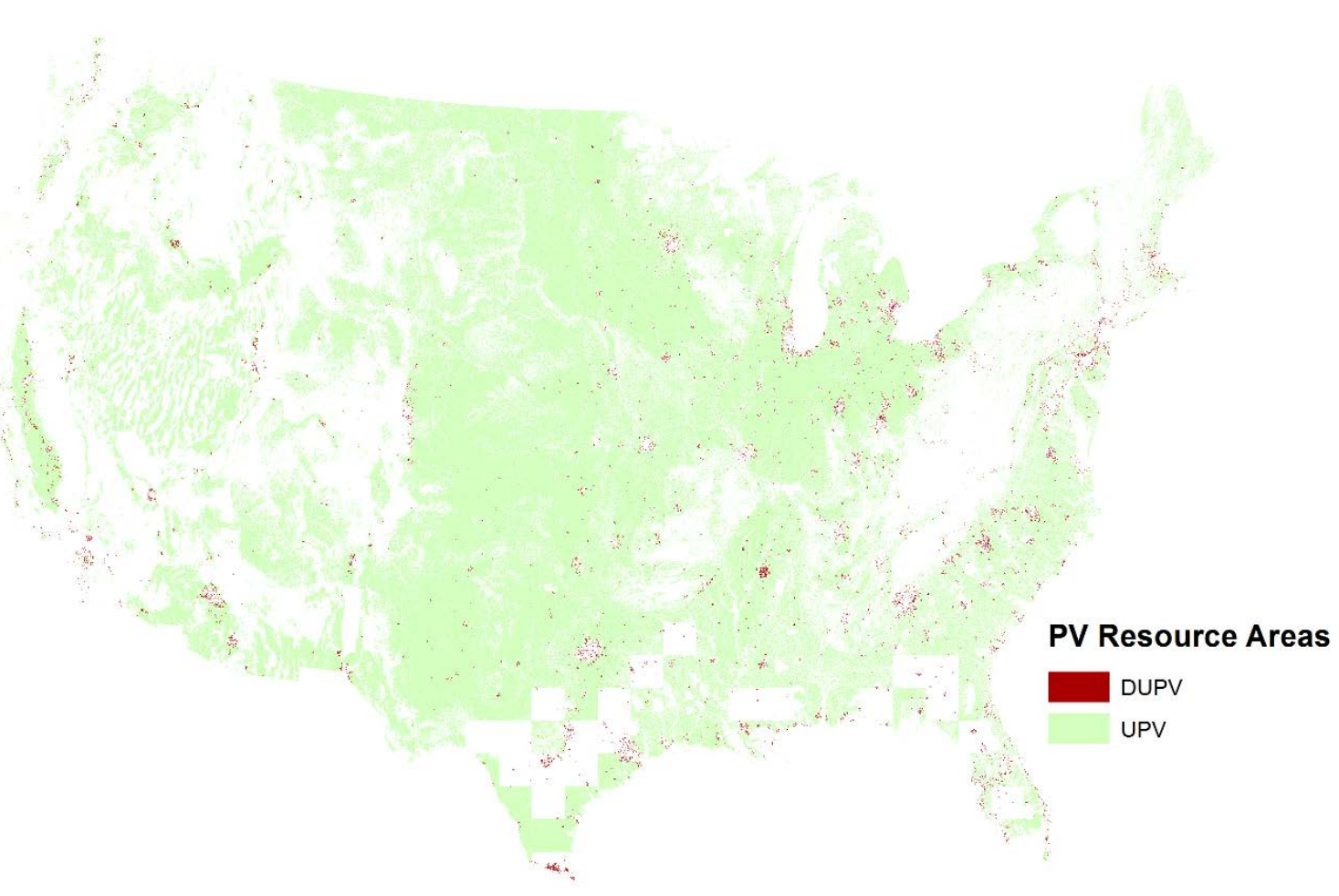

Figure 8. UPV and DUPV resource areas available for development considering land use exclusions 
Class 1

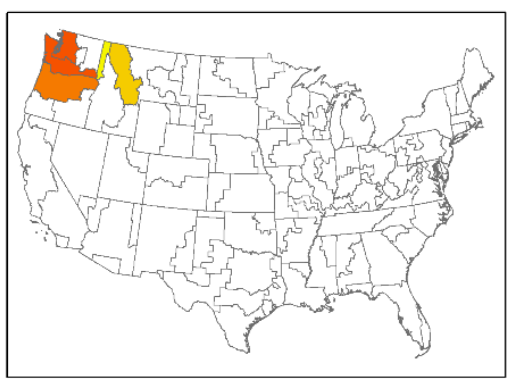

Class 2

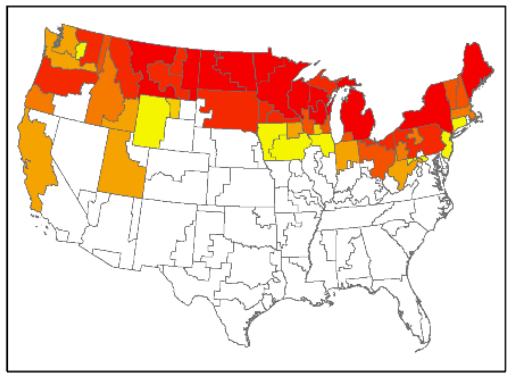

Class 3

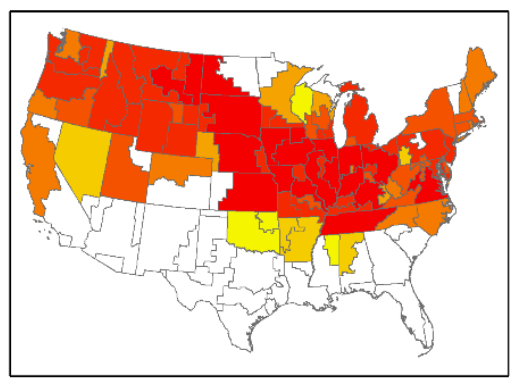

Class 4

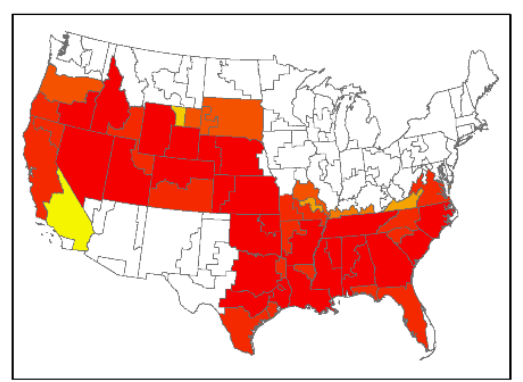

Class 5

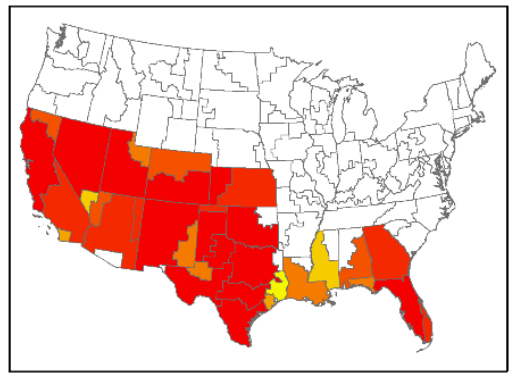

Class 6

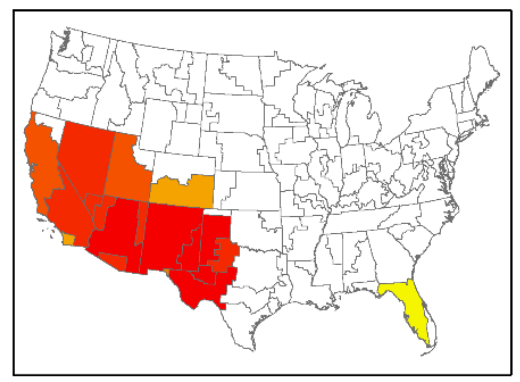

Class 7

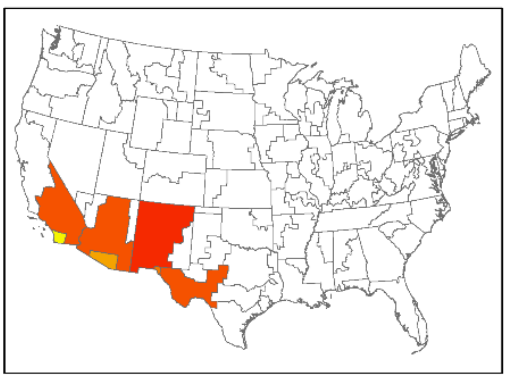

UPV Resource

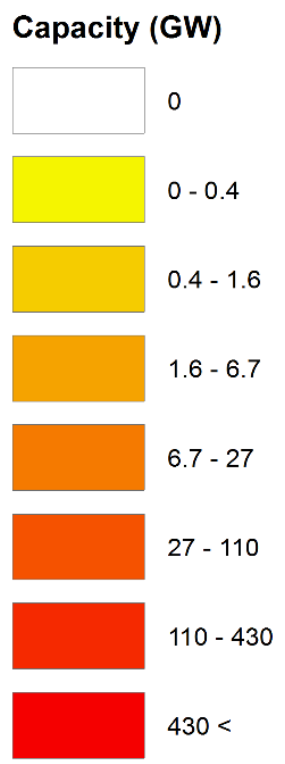

Figure 9. UPV resource availability by ReEDS BA region and resource class

DUPV in ReEDS assumes utility-scale single-axis-tracking systems with a representative size of $1 \mathrm{MW}$ and an array density of $39 \mathrm{MW} / \mathrm{km}^{2}$ with an inverter loading ratio of 1.3 . These systems are located within or are directly connected to distribution networks in urban areas. Resource potential estimates for DUPV are made by defining the eligible area as open space within urban areas and near existing distribution substations. Parking lots, roads, and urbanized areas are excluded by identifying areas with imperviousness greater than or equal to 1\% (Fry et al. 2011). Additional exclusions for landmarks, parks, and water further exclude areas deemed unlikely for development. Each DUPV site within the resulting eligible rural land areas is characterized by a raw hourly $(8,760)$ irradiance profile that is representative of the solar resource within a $10 \mathrm{~km}^{2}$ contiguous area. This process returns an urban DUPV potential of nearly $1.15 \mathrm{TW}$ across the contiguous United States (see Figure 9), with resource potential generally correlated with region size and population, and with higher-quality potential in the Southwest. The two order-ofmagnitude difference in resource capacity relative to UPV is a result of the significantly smaller land area with access to the distribution networks. Similar to UPV, these values are input into ReEDS as supply curves by BA region and the nine PV resource classes from Table 4. 


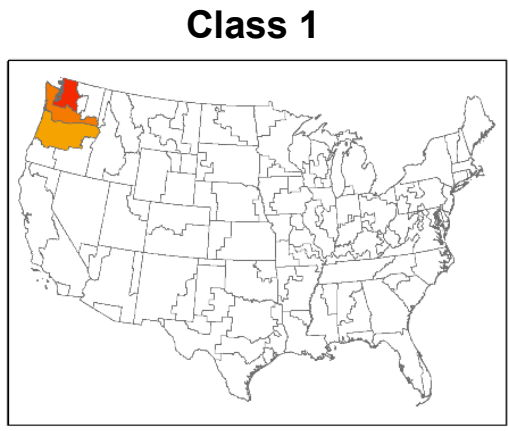

Class 2

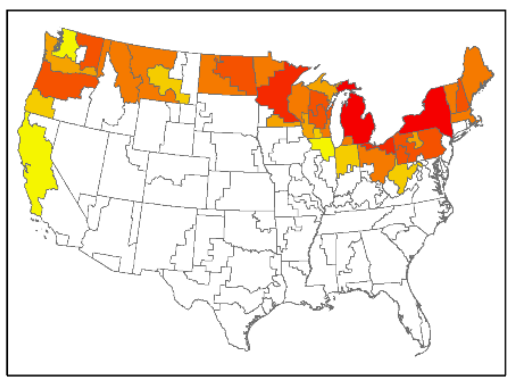

Class 3

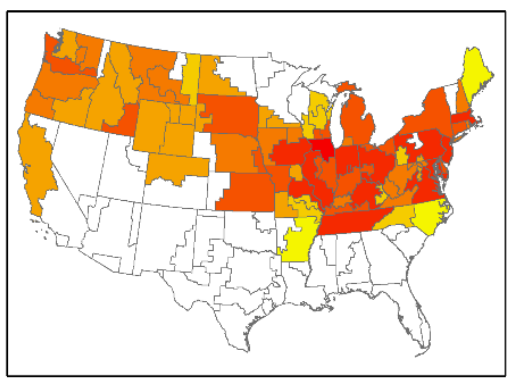

Class 4

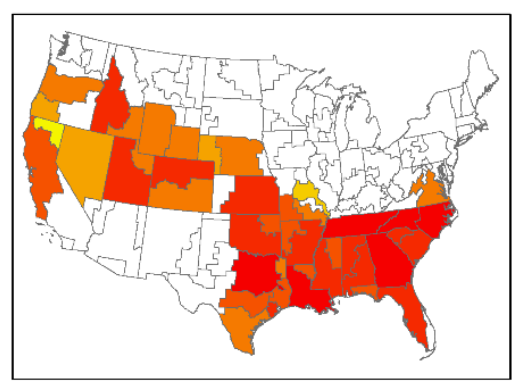

Class 5

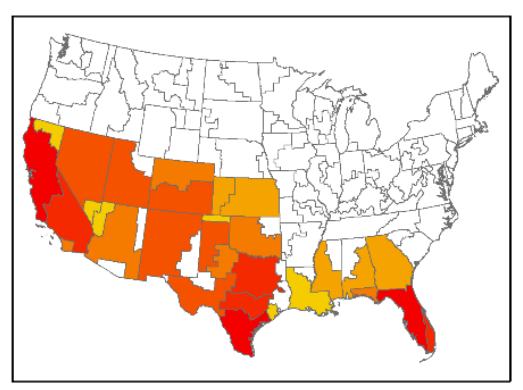

Class 6

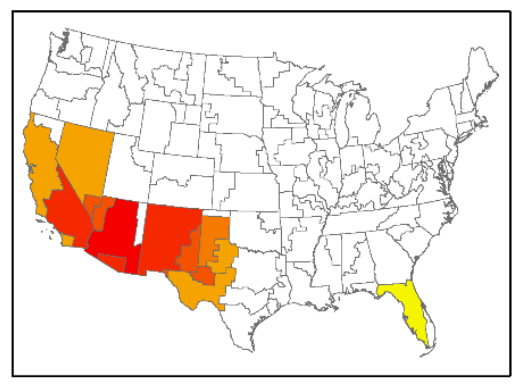

Class 7

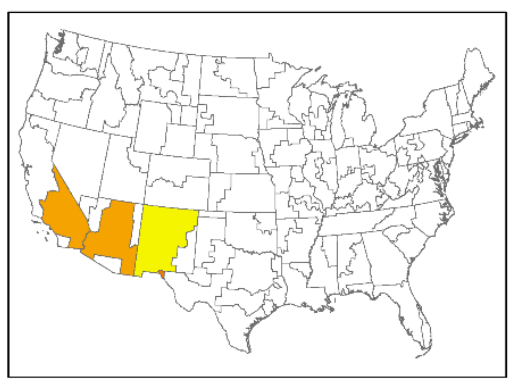

DUPV Resource

Capacity (GW)

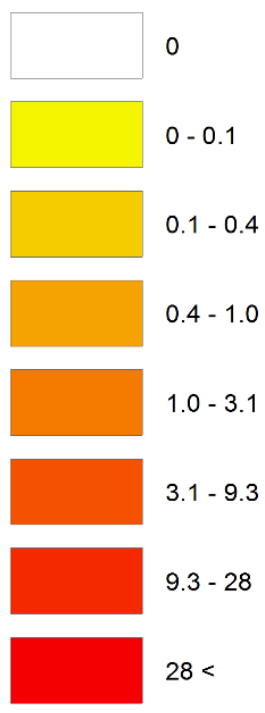

Figure 10. DUPV resource availability in each ReEDS region by resource class

DUPV systems have lower infrastructure requirements than large-scale rural UPV systems; we assume they connect to existing nearby distribution substations at about 13 kilovolts $(\mathrm{kV})$, whereas the representative UPV system connects to a high-voltage bus at $230 \mathrm{kV}$ and may require a spur line several miles long to reach that connection point. The cost of the spur line is handled separately in the accessibility supply curve (Section 6.3), but the additional transformers and power electronics associated with the larger systems and higher-voltage interconnections add cost and losses to the UPV systems. On the other hand, the larger UPV systems benefit from economies of scale. On balance, we assume a per-kW capital cost penalty of $29 \%{ }^{16}$ and $5 \%$ higher delivered energy (i.e., reduced losses) for DUPV relative to UPV.

Performance characteristics for UPV and DUPV were developed using NREL's reV Tool, using multiyear hourly weather files from the National Solar Radiation Database ${ }^{17}$ at $4-\mathrm{km}$ by $4-\mathrm{km}$ parcels throughout the contiguous United States from 1998 to 2016. No changes or

\footnotetext{
${ }^{16}$ Represents the difference in overnight capital cost from the $5 \mathrm{MW}$ system (the smallest reported) and the $100 \mathrm{MW}$ system from Figure 28 of Fu, Feldman, and Margolis (2018).

${ }^{17}$ https://nsrdb.nrel.gov/
} 
improvements in capacity factor over time are assumed for PV technologies. For each ReEDS BA region, resource quality classifications were made by averaging across the 1998-2016 period for all available parcels. Hourly generation profiles were taken from 2007-2013. The generation profiles from 2012 from all the regions in a BA for each resource class were averaged to provide ReEDS with average capacity factors by time-slice and resource class.

To mitigate excessive wheeling of distributed PV generation, ReEDS assumes all power generated by both DUPV and rooftop PV systems is permitted to be exported to neighboring BAs only when total generation in the source region exceeds the load for a given time-slice. UPV-generated electricity, in contrast, can be exported in all time-slices and regions.

Degradation of the efficiency of solar PV capacity over time is also modeled at $0.7 \%$ /year (NREL 2020). This degradation is modeled by reducing the generating capacity of PV by $0.7 \% /$ year.

Rooftop PV includes commercial, industrial, and residential systems. These systems are assumed to have an inverter loading ratio of 1.1. The Distributed Generation Market Demand model (dGen), a consumer adoption model for the contiguous U.S. rooftop PV market, is used to develop future scenarios for rooftop PV capacity, including the capacity deployed by BA and the pre-curtailment energy production by that capacity (Sigrin et al. 2016). The default dGen trajectories used in this version of ReEDS are based on the residential and commercial PV cost projections as described in the 2020 ATB (NREL 2020). There are 11 unique rooftop PV trajectories available in ReEDS that are from the 2020 Standard Scenarios report (W. Cole, Corcoran, et al. 2020). These trajectories were created by running a ReEDS scenario and feeding the electricity price outputs from ReEDS back into dGen. The trajectories incorporate existing net metering policy as of spring 2020, and they include the investment tax credit (ITC) as discussed in Section 9.2.

Assumptions for each dGen scenario are made consistent with the ReEDS scenario assumptions as much as is possible. For example, the Tax Credit Extension scenario also includes an extension of the ITC in dGen, and the Low PV Cost scenario uses low trajectory from ATB for commercial and rooftop PV costs.

\subsubsection{Concentrating Solar Power}

Concentrating solar power (CSP) technology options in ReEDS encompass a subset of possible thermal system configurations, with and without thermal storage, as shown in Table 5. The various system types access the same resource potential, which is divided into 12 resource classes based on direct normal insolation (DNI) (Table 6). The CSP resource and technical potential are based on the latest version of NSRDB. Details of the CSP resource data and technology representation can be found in Appendix B of Murphy et al. (2019). By default, recirculating and dry cooling systems are allowed for future CSP plants getting built in ReEDS. CSP cost and performance estimates are a based on an assumed plant size of $100 \mathrm{MW}$. 
Table 5. Characteristics of CSP Technology Options

\begin{tabular}{|c|c|c|c|c|}
\hline $\begin{array}{l}\text { Storage Duration } \\
\text { (hours) }\end{array}$ & $\begin{array}{l}\text { Solar } \\
\text { Multiple }^{18}\end{array}$ & Dispatchability & Capacity Credit & Curtailment \\
\hline None & 1.4 & insolation-dependent & $\begin{array}{l}\text { Calculated based on } \\
\text { hourly insolation }\end{array}$ & Allowed \\
\hline 6 & 1.0 & dispatchable & $\begin{array}{l}\text { Calculated based on } \\
\text { storage duration and } \\
\text { hourly insolation }\end{array}$ & Not allowed \\
\hline 8 & 1.3 & dispatchable & $\begin{array}{l}\text { Calculated based on } \\
\text { storage duration and } \\
\text { hourly insolation }\end{array}$ & Not allowed \\
\hline 10 & 2.4 & dispatchable & $\begin{array}{l}\text { Calculated based on } \\
\text { storage duration and } \\
\text { hourly insolation }\end{array}$ & Not allowed \\
\hline 14 & 2.7 & dispatchable & $\begin{array}{l}\text { Calculated based on } \\
\text { storage duration and } \\
\text { hourly insolation }\end{array}$ & Not allowed \\
\hline
\end{tabular}

The CSP resource classes are defined by power density of DNI, developable land area having been filtered based on land cover type, slope, and protected status. CSP resource in each resource region is therefore represented as a supply curve of megawatts of solar collector potential, assuming a power density of $14.9 \mathrm{MW} / \mathrm{km} .{ }^{2}$ Performance for each CSP resource class is developed using 2012 hourly resource data (Sengupta et al. 2018) from representative sites of each resource region. The 2012 weather files are processed through the CSP modules of the System Advisor Model (SAM) to develop performance characteristics for each CSP resource class and representative CSP system considered in ReEDS. CSP capacity credit calculations are based on hourly profiles from 2007-2013. As with wind and PV technologies, CSP resources are further distinguished by grid accessibility in each resource region (Section 6.3).

Table 6. Resource Classes for CSP Plants Using a Solar Multiple (SM) of 2.4

Resources are then scaled in ReEDS by the ratio of the model-determined SM and 2.4.

\begin{tabular}{|c|c|c|c|}
\hline $\begin{array}{l}\text { Resource } \\
\text { Class }\end{array}$ & $\begin{array}{l}\text { DNI } \\
\text { (kWh/m²/day) }\end{array}$ & $\begin{array}{l}\text { Weighted Average Field } \\
\text { CF for } \mathrm{SM}=1 \text { system }(\%)^{\mathrm{a}}\end{array}$ & $\begin{array}{l}\text { Available Resource } \\
\text { (GW) }\end{array}$ \\
\hline Class 1 & $5-5.25$ & 17 & 2,641 \\
\hline Class 2 & $5.25-5.5$ & 18 & 1,925 \\
\hline Class 3 & $5.5-5.75$ & 19 & 1,495 \\
\hline Class 4 & $5.75-6$ & 20 & 1,725 \\
\hline Class 5 & $6-6.25$ & 21 & 1,850 \\
\hline Class 6 & $6.25-6.5$ & 22 & 1,282 \\
\hline Class 7 & $6.5-6.75$ & 23 & 1,252 \\
\hline
\end{tabular}

${ }^{18}$ The solar multiple (SM) is defined as the ratio of the design solar field aperture area to the aperture area required to produce the power cycle design thermal input (and power output) under reference environmental conditions. 


\begin{tabular}{|l|c|c|c|}
\hline $\begin{array}{l}\text { Resource } \\
\text { Class }\end{array}$ & $\begin{array}{l}\text { DNI } \\
\text { (kWh/m²/day) }\end{array}$ & $\begin{array}{l}\text { Weighted Average Field } \\
\text { CF for SM=1 system (\%) }\end{array}$ & $\begin{array}{l}\text { Available Resource } \\
\text { (GW) }\end{array}$ \\
\hline Class 8 & $6.75-7$ & 24 & 1,098 \\
\hline Class 9 & $7-7.25$ & 26 & 1,381 \\
\hline Class 10 & $7.25-7.5$ & 27 & 1,251 \\
\hline Class 11 & $7.5-7.75$ & 28 & 677 \\
\hline Class 12 & $>7.75$ & 29 & 114 \\
\hline
\end{tabular}

a The field capacity factors (CF) shown here are from SAM (version 2017.09.05, SDK version 181) simulation assuming an $\mathrm{SM}=1$ system. This field capacity factor is meant to represent the upper limit of corresponding turbine capacity factor for all systems with $S M>1$.

The representative CSP system without storage used to define system performance in ReEDS is a 100-MW trough system with a SM of 1.4. As CSP systems without storage are non-dispatchable, output capacity factors are defined directly from SAM results. The average annual capacity factors for the solar fields of these systems range from 20\% (Class 1 resource) to $29 \%$ (Class 12 resource). 

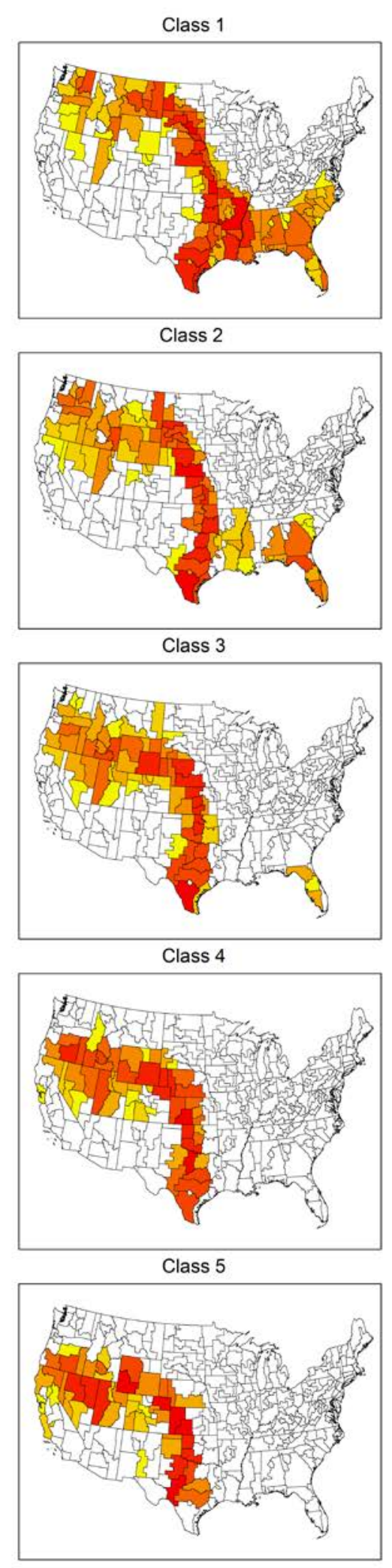

Class 6

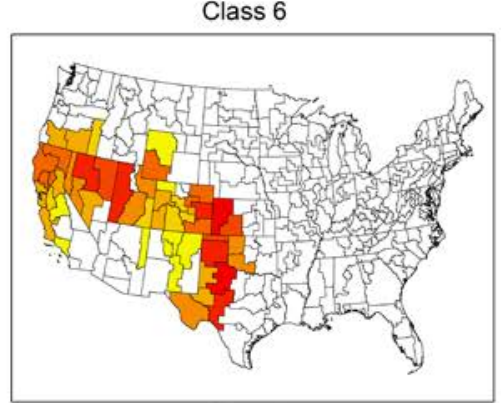

Class 7

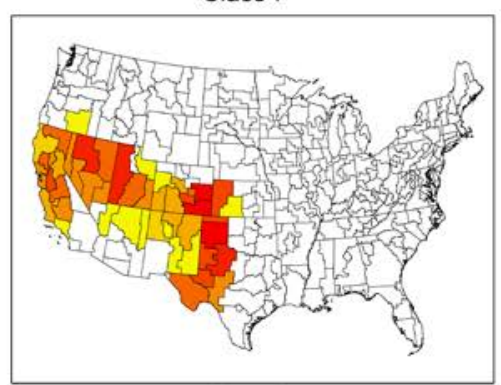

Class 8

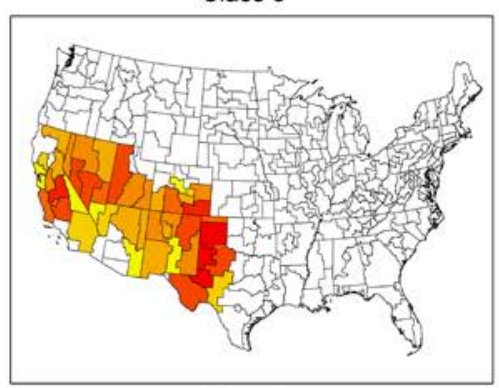

Class 9

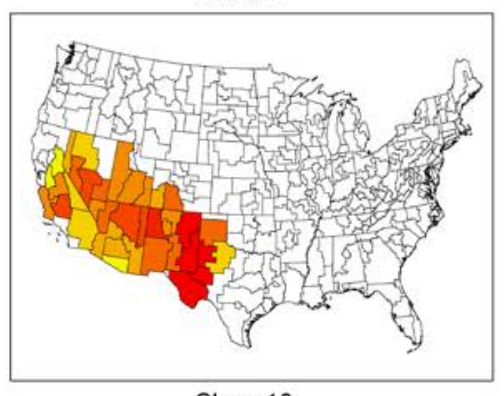

Class 10

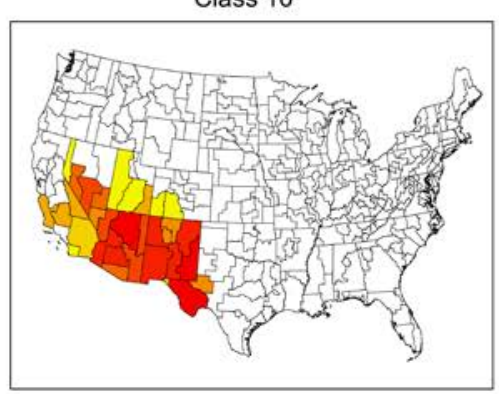

Class 11

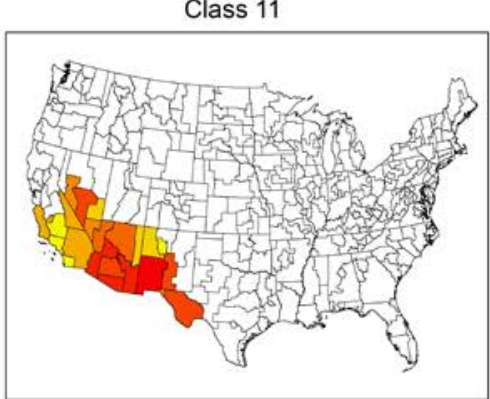

Class 12

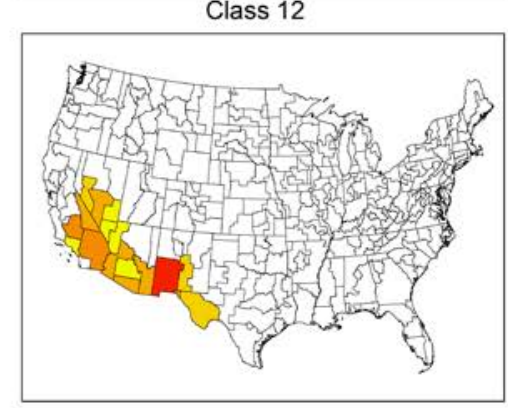

CSP Resource

Capacity (GW)

$0-0.3$

$0.3-1.4$

$1.4-5.0$

$5.0-13$

$13-29$

$29-58$

$58-128$

$128<$

Figure 11. CSP resource availability in each ReEDS resource region by 12 resource class 
The representative system for any new CSP with thermal energy storage is a tower-based configuration with a molten-salt heat-transfer fluid and a thermal storage tank between the heliostat array and the steam turbine. ${ }^{19}$ Two CSP with storage configurations are available as shown in Table 5.

For CSP with storage, plant turbine capacity factors by time-slice are an output of the model, not an input, as ReEDS can dispatch collected CSP energy independent of irradiation. Instead, the profile of power input from the collectors (solar field) of the CSP plants are model inputs, based on SAM simulations from 2012 weather files.

The capacity credit of CSP with storage is calculated using the same method as the calculation of the capacity credit of other storage technologies, except that rather than using net load to show opportunities to charge, DNI resource is used to show opportunities to charge the storage. See Section 7.2.2 for details.

\subsubsection{Geothermal}

The geothermal resource has several subcategories in ReEDS:

- The hydrothermal resource represents potential sites with appropriate geological characteristics for the extraction of heat energy. The hydrothermal potential included in the base supply curve consists of only identified sites, with a separate supply curve representing the undiscovered hydrothermal resource.

- EGS sites are geothermal resources that have sufficient temperature but lack the natural permeability, in-situ fluids, or both to be hydrothermal systems. Developing these sites with water injection wells could create engineered geothermal reservoirs appropriate for harvesting heat.

- Near-field EGS is a subset of EGS that implies proximity to existing or known hydrothermal sites.

Table 7 lists the technical resource potential for the different geothermal categories.

Table 7. Technical Resource Potential (GW)

\begin{tabular}{|l|c|r|c|c|}
\hline & Hydrothermal & $\begin{array}{l}\text { Undiscovered } \\
\text { Hydrothermal }\end{array}$ & Near-Field EGS & Deep EGS \\
\hline Binary & 1.7 & 6.8 & 0.6 & $2,263.4$ \\
\hline Flash & 3.4 & 12.0 & 0.8 & $1,111.9$ \\
\hline Total & 5.1 & 18.8 & 1.4 & $3,375.3$ \\
\hline
\end{tabular}

The default geothermal resource assumptions allow for new construction at identified hydrothermal sites and undiscovered geothermal sites. The development of undiscovered geothermal resources is limited by a discovery rate defined as part of the GeoVision Study (DOE 2019). Though near-field EGS and additional deep EGS resources are not allowed under default assumptions because of uncertain feasibility, these geothermal resource categories can be

\footnotetext{
${ }^{19}$ Historical and announced trough-based systems are characterized with technology-appropriate characteristics.
} 
included as additional resource in ReEDS. The geothermal supply curves are based on the analysis described by Augustine et al. (2019) and are shown in Figure 11. The hydrothermal and near-field EGS resource potential is derived from the U.S. Geological Survey's 2008 geothermal resource assessment (Williams, Reed, and Mariner 2008), while the deep EGS resource potential is based on an update of the EGS potential from the Massachusetts Institute of Technology (Tester et al. 2006). As with other technologies, geothermal cost and performance projections are from the ATB (NREL 2020).

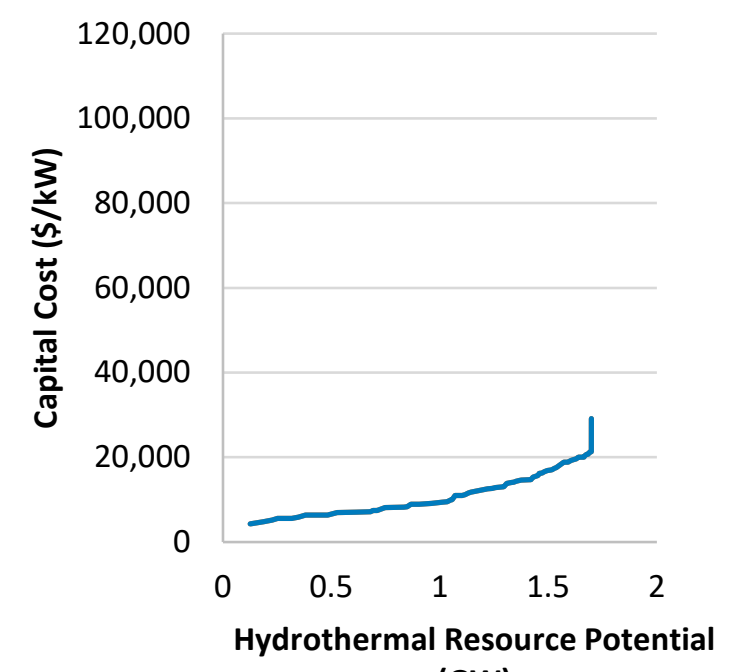

(GW)

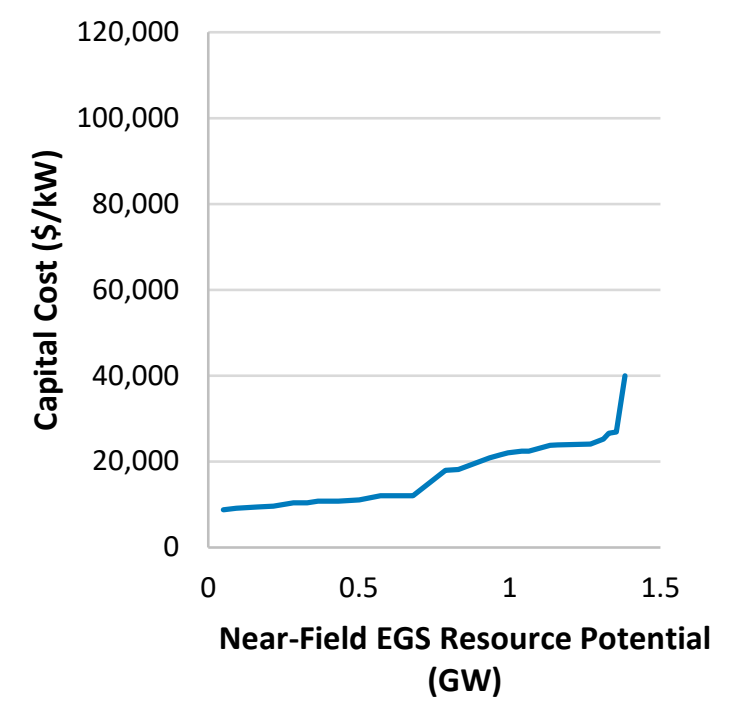

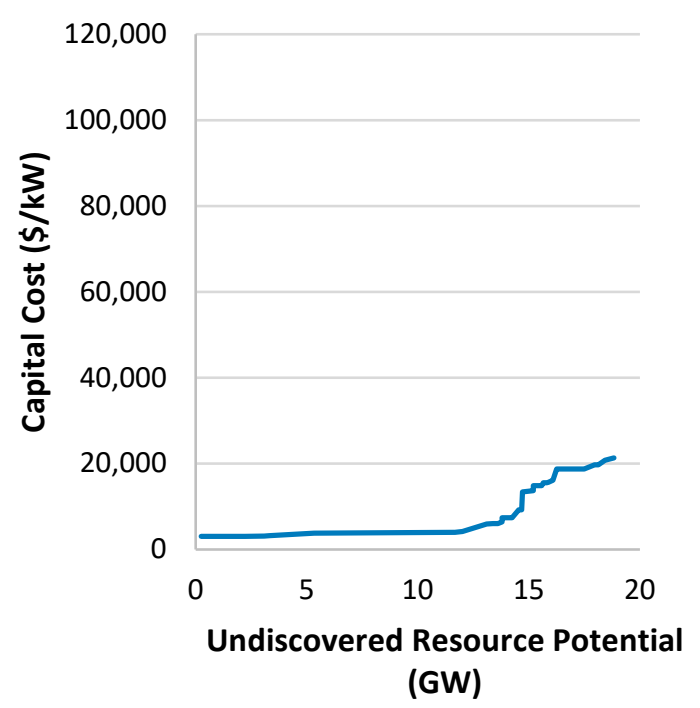

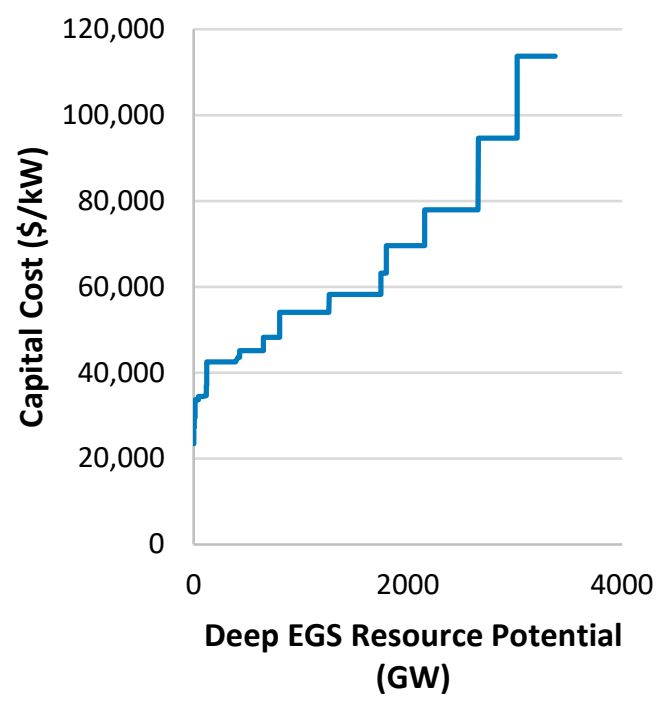

Figure 12. National capital cost supply curves for geothermal capacity used in the base model assumptions

\subsubsection{Hydropower}

The existing hydropower fleet representation is informed by historical performance data. From the nominal hydropower capacity in each BA, seasonal capacity adjustments are used for Western Electricity Coordinating Council (WECC) regions based on data from the Transmission 
Expansion Planning Policy Committee (TEPPC) 2024 Common Case (WECC 2013; 2015). Seasonal capacity adjustments allow more realistic seasonal variations in maximum capacity due to changes in water availability and operating constraints. These data are not available for nonWECC regions. Energy availability for the existing fleet for 2016 and beyond is defined seasonally using region-specific seasonal hydropower capacity factors averaged for 2006-2015 as reported by the National Hydropower Asset Assessment Program (NHAAP), ${ }^{20}$ totaling 270 terawatt hours per year (TWh/yr). Capacity factors for 2010-2014 model years are calibrated so that modeled generation matches historical generation. PSH, both existing and new, is discussed in Section 3.3 on storage technologies.

Three categories of new hydropower resource potential are represented in the model:

1. Upgrade and expansion potential for existing hydropower

2. Potential for powering non-powered dams (NPD)

3. New stream-reach development potential (NSD).

The supply curves for each are discussed in detail in the Hydropower Vision report (DOE 2016b), particularly Chapter 3 and Appendix B.

ReEDS does not currently distinguish between different types of hydropower upgrades, so upgrade potential is represented generically as a potential for capacity growth that is assumed to have the same energy production potential per capacity (i.e., capacity factor) as the corresponding existing hydropower capacity in the region. The quantity of available upgrades is derived from a combination of limited resource assessments and case studies by the U.S. Bureau of Reclamation Hydropower Modernization Initiative (HMI), U.S. Army Corps of Engineers (Corps), and NHAAP Hydropower Advancement Project (Montgomery, Watson, and Harza 2009; Bureau of Reclamation 2011). Upgrade availability at federal facilities not included in the HMI is assumed to be the HMI average of $8 \%$ of the rated capacity, and upgrade availability at non-federal facilities is assumed to be the NHAAP average of $10 \%$ of the rated capacity. Rather than making all upgrade potential available immediately, upgrade potential is made available over time at the earlier of either (1) the Federal Energy Regulatory Commission (FERC) license expiration (if applicable) or (2) the turbine age reaching 50 years. This feature better reflects institutional barriers and industry practices surrounding hydropower facility upgrades. The total upgrade potential from this methodology is $6.9 \mathrm{GW}(27 \mathrm{TWh} / \mathrm{yr})$.

${ }^{20}$ http://nhaap.ornl.gov/content/nhaap-data-sources 


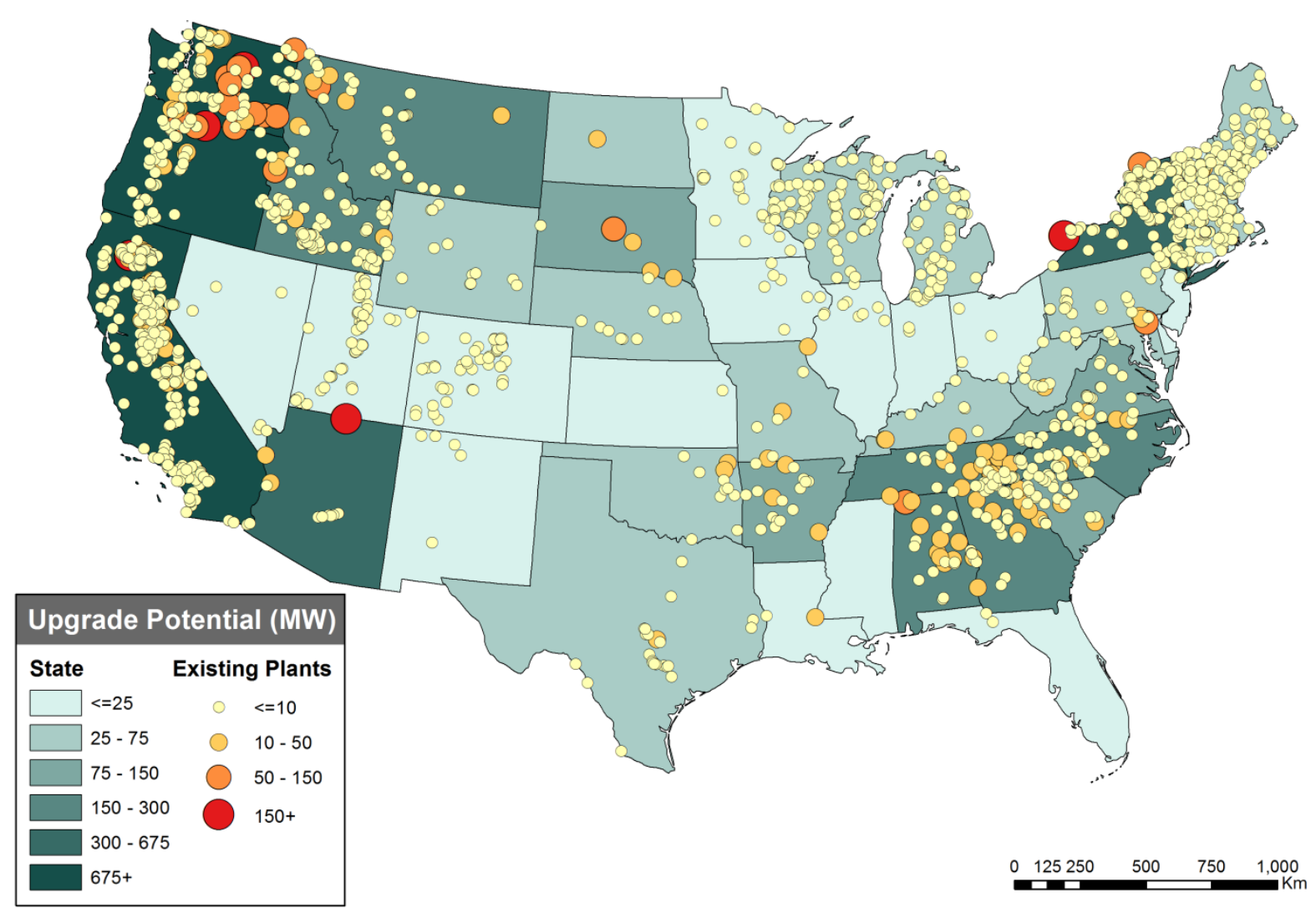

Figure 13. Modeled hydropower upgrade resource potential (DOE 2016b)

NPD resource is derived from the 2012 NHAAP NPD resource assessment (Hadjerioua, Wei, and Kao 2012; Hadjerioua et al. 2013), where the modeled resource of $5.0 \mathrm{GW}$ (27 TWh/yr) reflects an updated site sizing methodology, data corrections, and an exclusion of sites under 500 $\mathrm{kW}$ to allow better model resolution for more economic sites. 


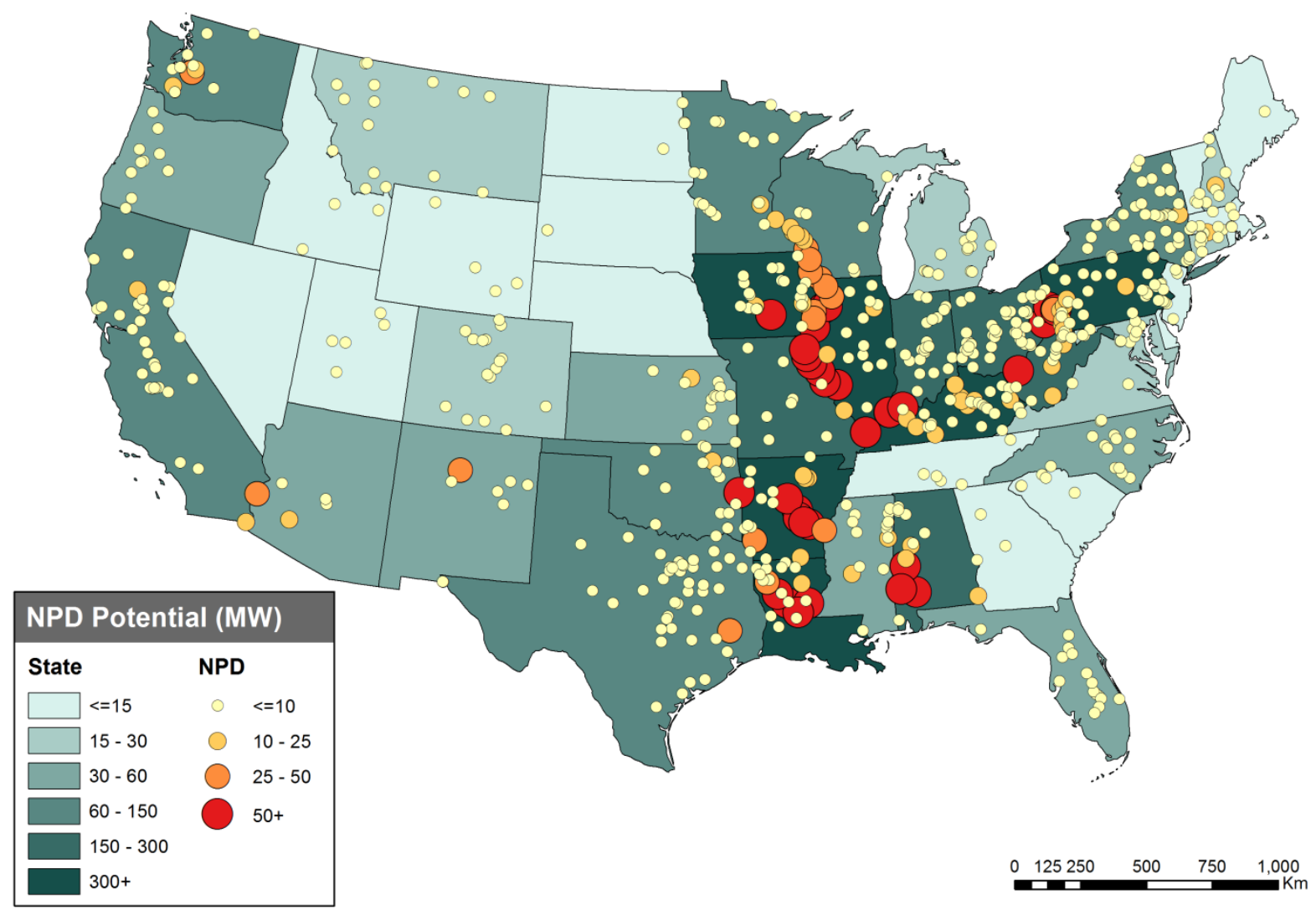

Figure 14. Modeled non-powered dam resource potential (DOE 2016b)

NSD resource is based on the 2014 NHAAP NSD resource assessment (Kao et al. 2014), where the modeled resource of $30.7 \mathrm{GW}(176 \mathrm{TWh} / \mathrm{yr})$ reflects the same sizing methodology as NPD and a sub-1 MW site exclusion, again to improve model resolution for lower-cost resource. The NSD resource assumes "low head" sites inundating no more than the 100-year flood plain and excludes sites within areas statutorily barred from development—national parks, wild and scenic rivers, and wilderness areas. 


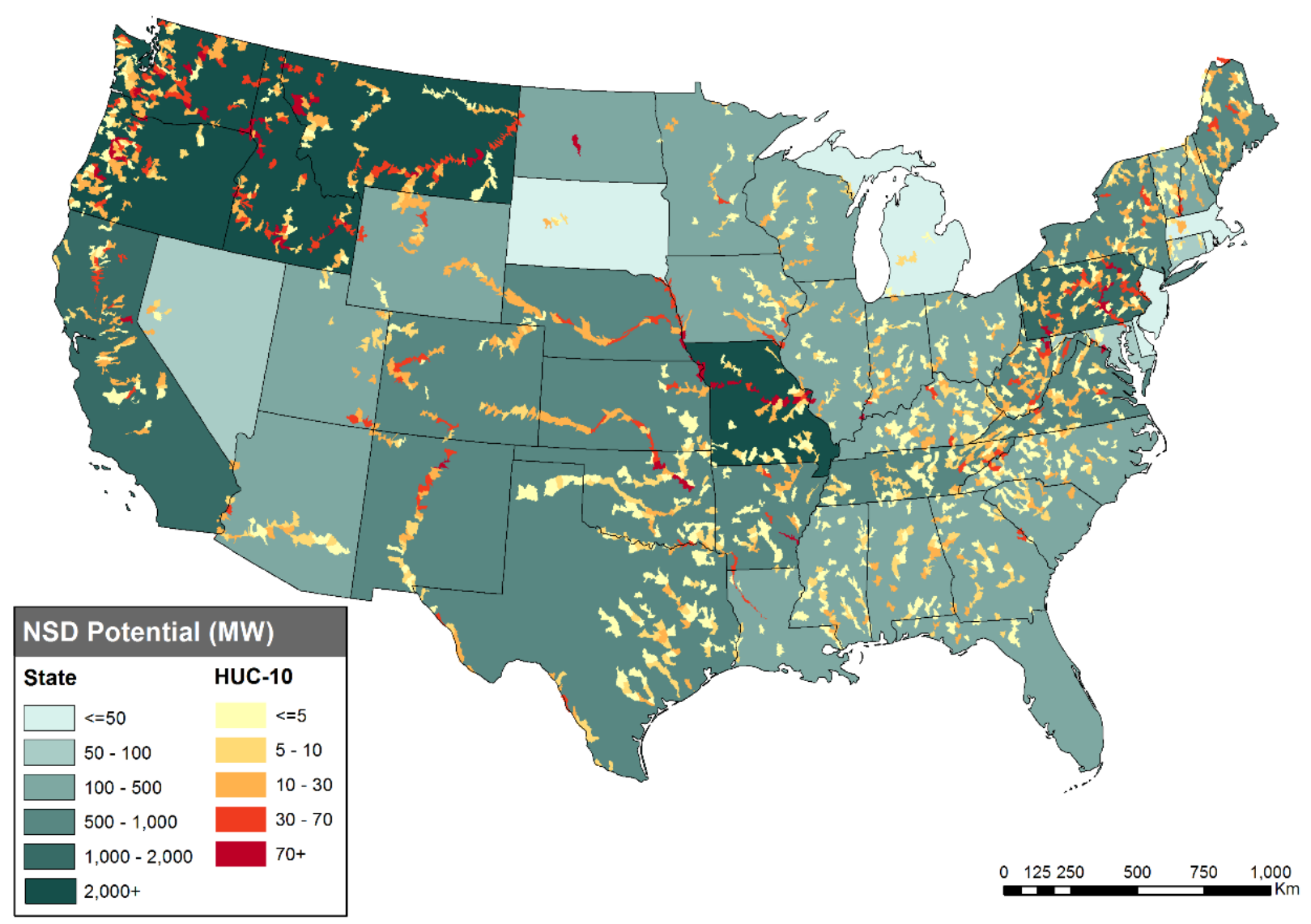

Figure 15. Modeled new stream-reach development resource potential (DOE 2016b)

The combined hydropower capacity coupled with the costs from the ATB (NREL 2020) results in the supply curve shown in Figure 15.

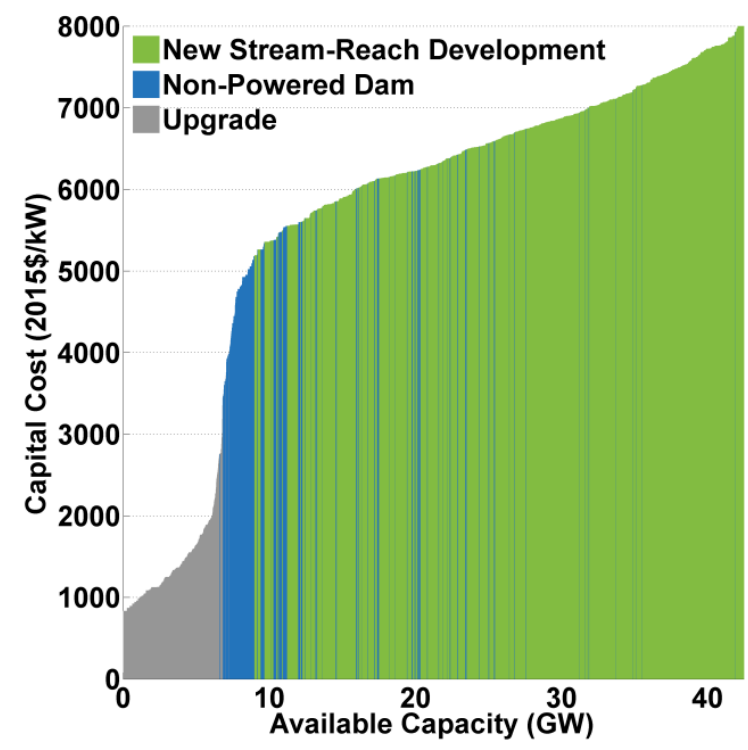

Figure 16. National hydropower supply curve of capital cost versus cumulative capacity potential 
The hydropower operating parameters and constraints included in ReEDS do not fully reflect the complex set of operating constraints on hydropower in the real world. Detailed site-specific considerations involving a full set of water management challenges are not easily represented in a model with the scale and scope of ReEDS, but several available parameters allow a stylized representation of actual hydropower operating constraints (Stoll et al. 2017).

Each hydropower category can be differentiated into "dispatchable" or "non-dispatchable" capacity, with "dispatchable" defined in ReEDS as the ability to provide the following services:

1. Diurnal load following within the capacity and average daily energy limits for each season

2. Planning (adequacy) reserves with full rated capacity

3. Operating reserves up to a specified fraction of rated capacity if the capacity is not currently being utilized for energy production.

"Non-dispatchable" capacity, on the other hand, provides:

1. Constant energy output in each season such that all available energy is utilized

2. Planning reserves equal to the output power for each season

3. No operating reserves.

Dispatchable capacity is also parameterized by a fractional minimum load, with the maximum fractional capacity available for operating reserves as one minus the fractional minimum load. The existing fleet and its corresponding upgrade potential are differentiated by dispatchability using data from the TEPPC 2024 Common Case for WECC and the NHAAP Hydropower Market Report for other regions (WECC 2013; 2015; Uria-Martinez, O'Connor, and Johnson 2015). All WECC facilities that do not follow load are assumed non-dispatchable, and all nonWECC facilities in the following NHAAP categories are non-dispatchable: run-of-river, run-ofriver/peaking (downstream), and regulating. This methodology chooses only the most obvious facilities as non-dispatchable while leaving all other existing and upgrade capacity as dispatchable. In total, $43 \%$ of existing capacity and $49 \%$ of upgrade potential is assumed nondispatchable.

The same TEPPC database is used to define region-specific fractional minimum capacity for dispatchable existing and upgrade hydropower in WECC. Lacking minimum capacity data for non-WECC regions, 0.5 is chosen as a reasonable fractional minimum capacity.

Both the NPD and NSD resource assessments implicitly assume inflexible, run-of-river hydropower, so all NPD and NSD resource potential is assumed non-dispatchable. Additional site-specific analysis could allow re-categorizing portions of these resources as dispatchable, but $100 \%$ non-dispatchable remains the default assumption.

\subsubsection{Biopower}

ReEDS can generate electricity from biomass either in dedicated biomass integrated gasification combined cycle (IGCC) plants or cofired with coal in facilities that have been retrofitted with an auxiliary fuel feed. These cofire-ready coal plants can use biomass in place of coal to supply the 
fuel for up to $15 \%$ of the plant's electricity generation. A cofire retrofit costs $305 \$ 2017 / \mathrm{kW}$ based on EIA's Electricity Market Module assumptions (EIA 2017b, 101).

Dedicated and cofired plants source feedstock from the same biomass supply curves, which are derived from the U.S. Billion-Ton Update report (DOE 2011). The biomass types from this study included in ReEDS supply curves are crop and forest residues (including forest residues from federal lands) and energy crops. Figure 16 shows the national supply curve for biomass feedstock through the 2012 solve year, after which both supply and prices are adjusted each year through 2030 to follow projections in the U.S. Billion-Ton Update report (DOE 2011).

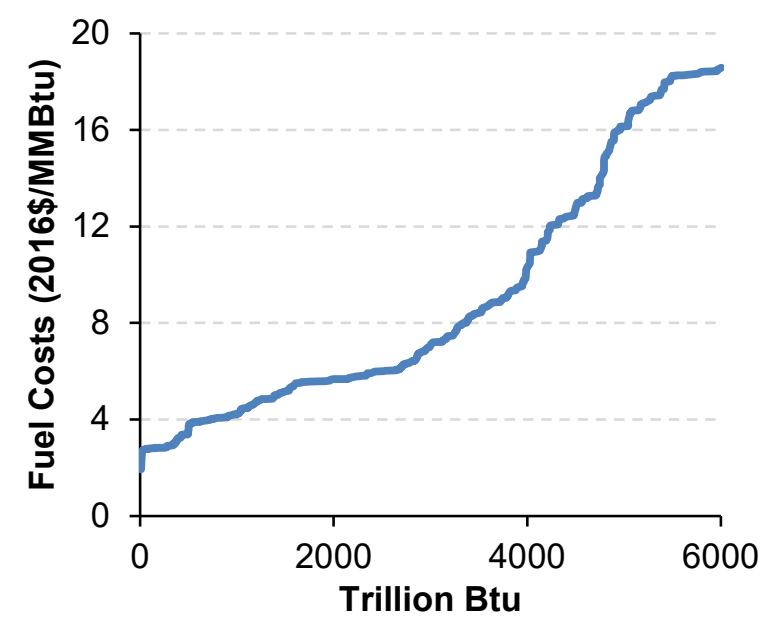

Figure 17. National supply curve for biomass feedstock

\subsubsection{Renewable Energy Combustion Turbine}

The Renewable Energy Combustion Turbine (RE-CT) technology is a RE-fueled combustion turbine. It is based on commercial gas turbines that are fired with renewable fuels (Mitsubishi 2020; Ruth et al. 2020), and it is assumed to have the same heat rate and operation and maintenance (O\&M) cost as regular gas-fired combustion turbines (see Section 3.2), but with a $20 \%$ higher overnight capital cost (slightly higher than the $10 \%$ value reported by Ruth et al. (2020) in order to allow the RE-CT to be clutched and act as a synchronous generator). Fuel costs are assumed to be $\$ 20 / \mathrm{MMBtu}$, which is consistent with costs for hydrogen produced using an electrolyzer powered by dedicated wind or PV (Mahone et al. (2020) report a range of \$7$35 / \mathrm{MMBtu}$ ), and falls within the range of current ethanol (\$12/MMBtu) and biodiesel (\$30/MMBtu) prices (DOE 2020). It is also consistent with Hargreaves and Jones (2020) which reports \$20/MMBtu for carbon-neutral biogas. This fuel cost includes the cost of production, delivery, and storage. Use of curtailed RE for RE-CT fuel production is not explicitly considered. Existing gas generators can be upgraded to this RE-CT technology by paying the $20 \%$ difference in capital cost between the two generators.

\subsubsection{Marine Hydrokinetic Wave}

ReEDS does have a representation of marine hydrokinetic wave technologies, but this capability is not utilized in any of the recent or current ReEDS modeling work. 


\subsection{Conventional Energy Technologies}

ReEDS includes all major categories of conventional generation technologies within its operating fleet or its investment choices. In the context of ReEDS, "conventional" is defined as thermal generating technologies driven by coal, gas, oil, or nuclear fuel. Coal technologies are subdivided into pulverized and gasified (IGCC) categories, with the pulverized plants further distinguished by 1) whether $\mathrm{SO}_{2}$ scrubbers are installed and 2) their vintage ${ }^{21}$ as pre- or post1995. Pulverized coal plants have the option of adding a second fuel feed for biomass. New coal plants can be added with or without CCS technology. Existing coal units built after 1995 with $\mathrm{SO}_{2}$ scrubbers installed also have the option of retrofitting CCS capability.

Natural gas generators are categorized as combustion turbine (CT), combined cycle (CC), or gas$\mathrm{CC}$ with CCS. ${ }^{22}$ There are also nuclear (steam) generators, landfill gas generators, ${ }^{23}$ and oil/gas steam generators, though the latter two are not offered as options for new construction besides those that are already under construction. The model distinguishes each conventional-generating technology by costs, efficiency, and operational constraints.

Where renewable energy technologies have many unique characteristics, ReEDS conventional technologies are characterized more generally by the following parameters:

- Capital cost (\$/MW)

- Fixed and variable operating costs (dollars per megawatt-hour [\$/MWh])

- Fuel costs (dollars per million British thermal units [\$/MMBtu])

- Heat rate (MMBtu/MWh)

- Construction period (years) and expenses

- Equipment lifetime (years)

- Financing costs (such as interest rate, loan period, debt fraction, and debt-servicecoverage ratio)

- Tax credits (investment or production)

- Minimum turndown ratio (\%)

- Ramp rate (fraction per minute)

- Planned and unplanned outage rates (\%).

\footnotetext{
${ }^{21}$ While differentiating pre- and post-1995 is somewhat arbitrary, it allows the model to better represent performance differences between relatively old and new coal technologies.

${ }^{22}$ Retrofits from Gas-CC to Gas-CC-CCS are also allowed. Additionally, Gas-CT plants are allowed to be retrofitted to burn a renewable energy fuel, such as hydrogen, green methane, or biodiesel. These retrofits can occur with existing Gas-CT plants or with new builds. Within ReEDS these plants are called RE-CT plants, and have the same O\&M and heat rate as Gas-CT plants.

${ }^{23}$ Landfill gas generators are classified as conventional generators but can count toward renewable portfolio standard requirements.
} 
Cost and performance assumptions for all new conventional technologies are taken from the ATB (NREL 2020), which are based on the projections from the AEO2020 Reference scenario. ${ }^{24}$ The NEMS Electricity Market Module, which is used for AEO analyses, represents technological learning endogenously, with costs falling as more capacity of that type is built. Because ReEDS does not include endogenous learning, the technology cost projections used in ReEDS reflect technology growth in the AEO Reference scenario. The AEO assumptions include a projected materials price index (MPI) that also influences capital costs over time; we remove the MPI from our projections for better consistency of ReEDS technology representations across both renewable and conventional energy sources. Regional variations and adjustments are included and described in Section 3.4. Fixed operation and maintenance costs for coal and nuclear plants increase over time with the plants age. These escalation factors are taken from the AEO2020.

In addition to the performance parameters listed above, technologies are differentiated by their ability to provide operating reserves. In general, natural gas plants, especially combustion turbines, are better suited for ramping and reserve provision, while coal and nuclear plants are typically designed for steady operation. See Section 7.3 for more details.

The existing fleet of generators in ReEDS is taken from the NEMS unit database from AEO2020 (EIA 2020). In particular, ReEDS uses the net summer capacity, location, heat rate, variable O\&M, and fixed O\&M to characterize the existing fleet. ReEDS uses a modified "average" heat rate for existing stock: a small, technology-specific increase on the full-load heat rate is applied to accommodate for units not always operating at their design point. The modifiers, shown in Table 8, are based on the relationship between full-load and average heat rates for generators in the ABB Velocity Suite database (ABB 2018). Coal adjustment factors also take into account the historical observed fleet-wide heat-rates, which are calculated using EIA form 923.

Table 8. Multipliers Applied to Full-Load Heat Rates to Approximate Heat Rates for PartLoad Operation

\begin{tabular}{|l|c|}
\hline Technology & Adjustment Factor \\
\hline Coal (all) & 1.0674 \\
\hline Gas-CC & 1.0545 \\
\hline Gas-CT & 1.1502 \\
\hline OGS & 1.1704 \\
\hline
\end{tabular}

Emissions rates from conventional plants are a function of the fuel emission rate and the plant heat rate. Burner-tip emissions rates are shown in Table 9. Because ReEDS does not differentiate coal fuel types, the coal $\mathrm{CO}_{2}$ emissions rate in the model is the average of the bituminous and subbituminous emissions rate. ${ }^{25}$

\footnotetext{
${ }^{24}$ Where AEO includes two separate projections (advanced and conventional) for any single ReEDS technology, ReEDS uses an average of those figures to represent a medium level of technological advancement.

${ }^{25}$ See https://www.eia.gov/tools/faqs/faq.cfm?id=74\&t=11, accessed November 11, 2016.
} 
Table 9. Emissions Rate by Generator Type in Pounds per MMBtu (EPA 2008) ${ }^{a}$

\begin{tabular}{|c|c|c|c|}
\hline Generator & $\begin{array}{l}\mathrm{SO}_{2} \text { Emissions } \\
\text { Rate }\end{array}$ & $\begin{array}{l}\mathrm{NO}_{\mathrm{x}} \text { Emissions } \\
\text { Rate }\end{array}$ & $\begin{array}{l}\mathrm{CO}_{2} \text { Emissions } \\
\text { Rate }\end{array}$ \\
\hline Hydropower & 0.0 & 0.0 & 0.0 \\
\hline Gas-CT & 0.0098 & 0.15 & 117.00 \\
\hline Gas-CC & 0.0033 & 0.02 & 117.00 \\
\hline Gas-CC-CCS & 0.0033 & 0.02 & 11.70 \\
\hline Pulverized Coal with Scrubbers (pre-1995) & 0.2 & 0.19 & 210.55 \\
\hline Pulverized Coal with Scrubbers (post-1995) & 0.1 & 0.08 & 210.55 \\
\hline Pulverized Coal without Scrubbers & 1.11 & 0.19 & 210.55 \\
\hline IGCC Coal & 0.0555 & 0.085 & 210.55 \\
\hline Coal-CCS & 0.0555 & 0.085 & 21.06 \\
\hline Oil/Gas Steam & 0.299 & 0.1723 & 137.00 \\
\hline Nuclear & 0.0 & 0.0 & 0.0 \\
\hline Geothermal & 0.0 & 0.0 & 0.0 \\
\hline Biopower & 0.08 & 0.0 & 0.0 \\
\hline
\end{tabular}

a The assumed $\mathrm{CO}_{2}$ pollutant rate for land-fill gas is zero, so ReEDS does not see the emissions benefits of land-fill gas. However, ReEDS can track land-fill gas emissions and the associated benefits as a post-processing calculation. Land-fill gas is assumed to have negative effective carbon emissions because the methane gas would be flared otherwise, thereby it produces the less potent greenhouse gas.

Not all parameter data are given in this document. For those values not included here, see the NREL ATB (NREL 2020), or see the values in the ReEDS repository. ${ }^{26}$. Financing parameters and calculations are discussed in Section 10.1.

\subsection{Storage Technologies}

ReEDS includes three utility-scale energy storage options: PSH, batteries, and CAES. All three storage options are capable of load shifting (arbitrage), providing planning and operating reserves, and reducing curtailment of VRE. Load shifting can be done only within a season's representative day, and it is accomplished by charging the reservoir during inexpensive lowdemand time-slices and discharging at peak times. The nameplate capacity of storage can contribute toward planning reserves (though at a potentially reduced rate, see Section 6.2.2), and capacity not being used for charge or discharging can be utilized to provide any of the operating reserves products represented in ReEDS (see Section 7 on how reserves are differentiated in ReEDS). Batteries are represented with durations of 2, 4, 6, 8, and 10 hours, while PSH and CAES are both assumed to have durations of 12 hours.

The ReEDS framework also allows for standalone thermal energy storage, though this technology is inactive by default because its site-specific nature makes it difficult to include in a nationwide optimization framework. This technology is representative of chilled water and ice

\footnotetext{
${ }^{26} \mathrm{See}$ https://www.nrel.gov/analysis/reeds/request-access.html to get access to the repository.
} 
storage units in buildings where, during the summer, cold water or ice is produced during cooler hours when loads are lower and used to replace or supplement the air conditioning during the warmer hours. Only units for commercial buildings are considered. A supply curve for thermal energy storage units was developed at the NERC subregions level. The model restricts the use of thermal energy storage devices by the regional cooling load profile, with power delivered from thermal energy storage available only during times of high cooling load (e.g., summer afternoons). Thermal energy storage technologies can contribute to operating and planning reserves and reduce curtailment.

Although storage is neither directly linked nor assumed co-located with renewable energy technologies in ReEDS, it can play an important role in reducing curtailed electricity from variable generation resources by charging during time-slices with excess renewable generation. The ability of storage to reduce curtailment is calculated endogenously as described in Section 7.4 .

Existing PSH totals $22 \mathrm{GW}$, and ReEDS includes the existing CAES facility in Alabama. New PSH and CAES are location-restricted due to hydrology and topography (for PSH) and geology (for CAES). In contrast, utility-scale batteries are not restricted to any subset of regions. New PSH potential is derived from FERC license applications since $1980^{27}$ with an additional 750 MW of high-cost "artificial" resource placed in each region to prevent over-constraining PSH expansion in regions without FERC applications while remaining consistent across all regions. In total, there is $108.7 \mathrm{GW}$ FERC-based PSH resource and 100.5 GW artificial PSH resource in ReEDS. FERC-based PSH capital costs are based on O'Connor et al. (2015), and artificial capacity is assumed to be $\$ 3,500 / \mathrm{kW},{ }^{28}$ which is near the upper bound of greenfield PSH resource sized at $750 \mathrm{MW}$ (Figure 18). PSH fixed O\&M costs are also based on O'Connor et al. 2015 , and round-trip efficiency is assumed to be $80 \%$ for all existing and new capacity. CAES site development costs are estimated based on the underground geology, where domal salt is the least costly resource at $\$ 1170 / \mathrm{kW}(22.6 \mathrm{GW}$ available), bedded salt is the next most costly resource at $\$ 1,420 / \mathrm{kW}(37.0 \mathrm{GW})$, and aquifers (porous rock) are the most costly resource at $\$ 1,680 / \mathrm{kW}(61.6 \mathrm{GW})$ (Black \& Veatch 2012; Lazard 2016). ${ }^{29}$ CAES requires a natural gas fuel input when supplying power output, and its heat rate is assumed to be $4.91 \mathrm{MMBtu} / \mathrm{MWh}$. This additional fuel input (to the electrical power input during compression) results in a roundtrip efficiency of $125 \%$.

\footnotetext{
${ }^{27}$ See "Preliminary Permits," FERC, updated October 11, 2016, http://www.ferc.gov/industries/hydropower/geninfo/licensing/pre-permits.asp.

${ }^{28}$ In $2015 \$$

${ }^{29}$ Values in $2016 \$$
} 


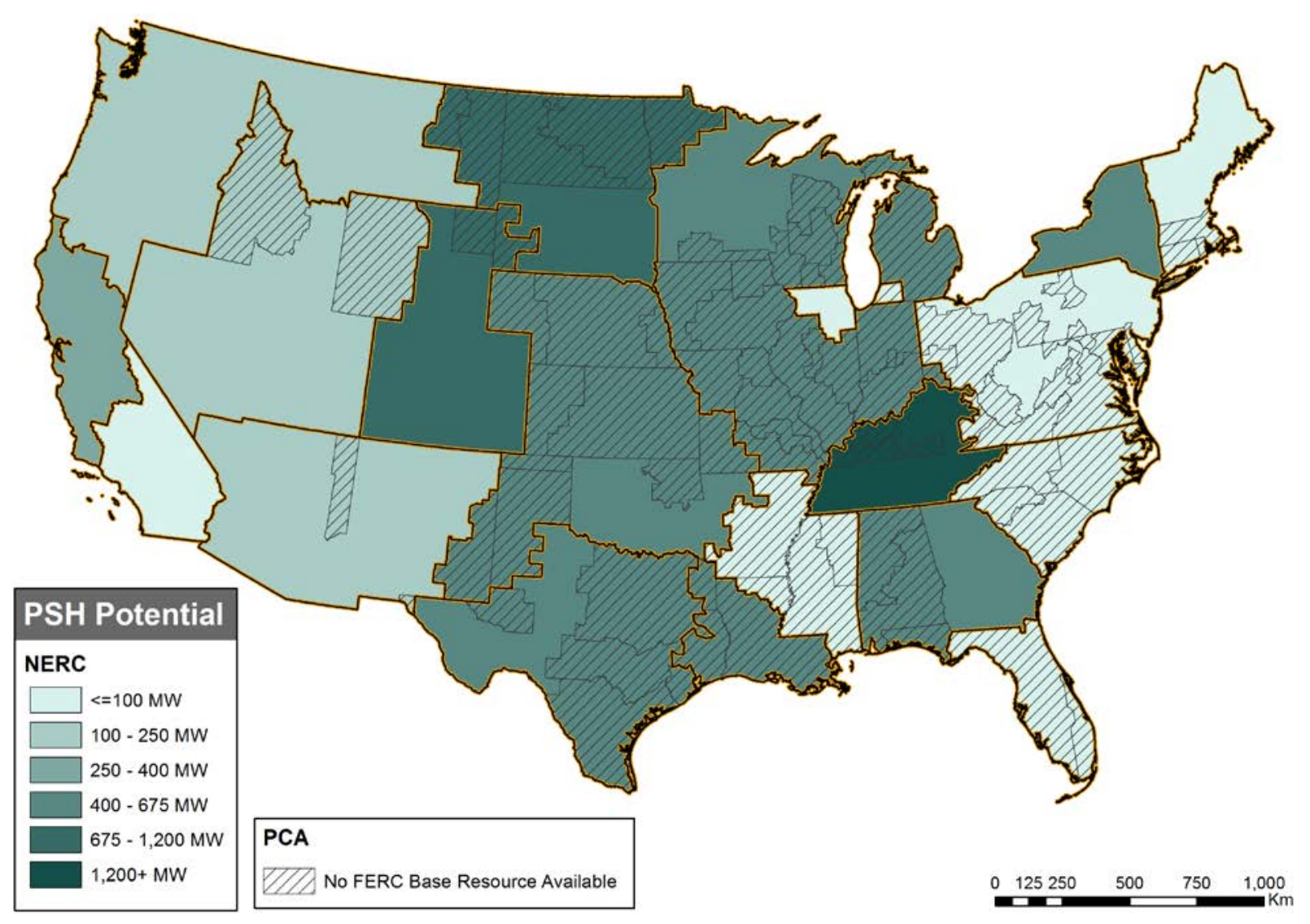

Figure 18. Modeled new PSH resource potential (DOE 2016b)

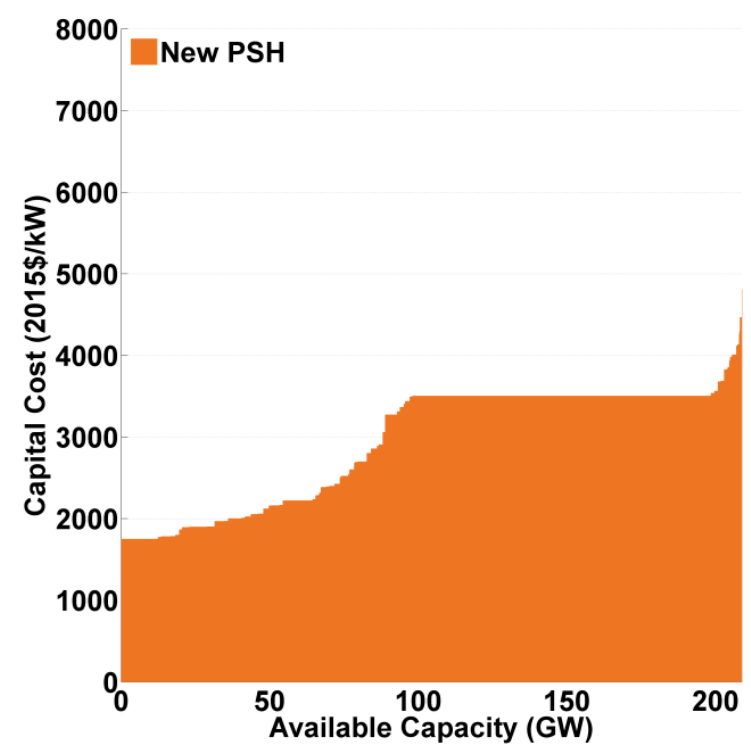

Figure 19. National PSH supply curve of capital cost versus cumulative capacity potential

Battery cost and performance assumptions are based on lithium-ion battery systems, with costs taken from Cole and Frazier (2020). Low, mid, and high cost projections are available and scale 
with the user-defined battery duration. In contrast to all other generator technologies in ReEDS which outlast the 20-year evaluation window of the model, the battery is assumed to last 15 years. As a result, its capital cost is uprated by 1.21 to account for the equipment lifetime shortfall. This uprate is the ratio of the 15-year CRF and the 20-year CRF. The batteries are assumed to have a round-trip efficiency of $85 \%$. The contribution of storage toward the reserve margin requirement is discussed in Section 7.2. Battery storage has a representative size of 60 MW.

\subsection{Capital Stock}

\subsubsection{Initial Capital Stock, Prescribed Builds, and Restrictions}

Existing electricity generation capacity is taken from the EIA NEMS unit database (EIA 2020). Units are mapped to ReEDS technologies based on a combination of fuel source and prime mover of the generation technology. Units of the same technology type within a region can be aggregated or represented individually. ${ }^{30}$ If they are aggregated, the aggregation is done by clustering the units based on heat rates.

The binning structure is designed flexibly such that users can choose the appropriate levels of model fidelity and computational speed for each application. Historical units are binned using a k-means clustering algorithm for each BA and technology category (e.g., coal with or without $\mathrm{SO}_{2}$ scrubbers, and natural gas combined cycle) combination. The user specifies a maximum number of bins and a minimum deviation across unit heat rates. Any two plants are eligible to form separate bins if the difference between their heat rates is greater than the minimum deviation parameter. The number of bins formed is then equal to the smaller of the maximum bin number parameter and the number of units after applying the minimum deviation criteria. For each bin, the assigned heat rate is equal to the capacity-weighted average of the heat rates for the units inside the bin. An illustrative example of the results is depicted for two BAs in Figure 19, assuming a maximum of seven bins and minimum deviation of $50 \mathrm{BTU}$ per $\mathrm{kWh}$. The horizontal axis corresponds to the heat rate for a given power plant unit from the NEMS database, while the vertical axis corresponds to the heat rate each bin is assigned in ReEDS. Points on the 45-degree line illustrate units for which the ReEDS heat rate is the same as the NEMS heat rate. The more tightly clustered the points are around this line, the less the model will suffer from aggregation bias. The figure illustrates that, in general, the fewer the number of units in a given technology category (in this example, nuclear and scrubbed coal), the closer the binned heat rates are to the actual heat rates.

\footnotetext{
${ }^{30}$ The level of plant aggregation is a scenario input option. Plants can be aggregated to one plant type per region or left at their native unit-level resolution.
} 


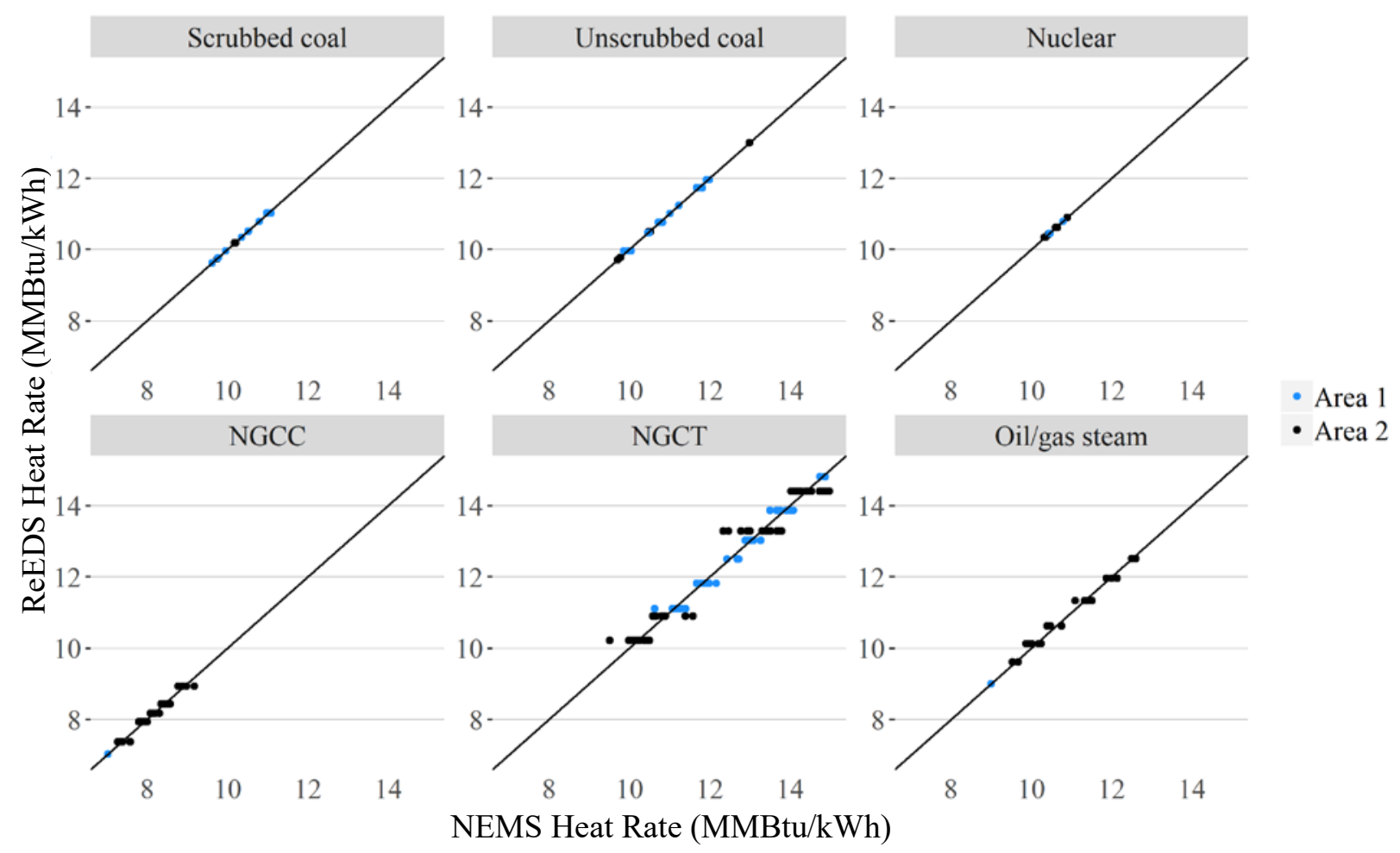

Figure 20. Example of capacity binning results for two BAs

Hydropower has additional subcategories to differentiate dispatchability as discussed in Section 3.1.6. In addition, any plants that are listed as under construction become prescribed builds. In other words, ReEDS builds any under-construction units, with the units coming online in the anticipated online year listed in the database.

For wind technologies, near-term regional growth restrictions reflect the difficulty of immediately scaling the wind industry. Specifically, wind plant construction through the 2020 solve year is limited to plants that are planned to be installed before the end of 2020. After 2020, no wind capacity limits are implemented.

\subsubsection{Retirements}

Renewable energy generator and battery retirements are (by default) ${ }^{31}$ based on assumed lifetimes. Once a generator has reached its lifetime, it is retired. Renewable energy and battery lifetime assumptions are shown in

Table 10. When renewable energy capacity is retired, the resource associated with that capacity is made available, and ReEDS can choose to rebuild a renewable energy generator using the newly available resource, without the need to rebuild the grid interconnection infrastructure. A consequence of this assumption is that retired renewable capacity can be replaced without incurring interconnection costs and, with all other considerations being equal, re-powered or re-

\footnotetext{
${ }^{31}$ When running with endogenous retirements, any technology type can be eligible to be retired endogenously by the model. However, some technologies are not represented properly to be appropriately considered for endogenous retirements.
} 
built renewable capacity has lower cost than new "green-field" capacity of the same type. ${ }^{32}$ One exception to this procedure is hydropower, which due to assumed non-power requirements is never retired unless there is an announced hydropower capacity retirement listed in the NEMS unit database.

Table 10. Lifetimes of Renewable Energy Generators and Batteries

\begin{tabular}{|l|c|l|}
\hline Technology & $\begin{array}{c}\text { Lifetime } \\
\text { (Years) }\end{array}$ & Source \\
\hline Land-based Wind & 30 & LBNL Survey (Wiser and Bolinger 2019) \\
\hline Offshore Wind & 30 & LBNL Survey (Wiser and Bolinger 2019) \\
\hline Solar Photovoltaic & 30 & SunShot Vision (DOE 2012) \\
\hline Concentrating Solar Power & 30 & SunShot Vision (DOE 2012) \\
\hline Geothermal & 30 & $\begin{array}{l}\text { Renewable Electricity Futures Study, Vol. 1 (Mai et } \\
\text { al. 2012) }\end{array}$ \\
\hline Hydropower & 100 & Hydropower Vision (DOE 2016b) \\
\hline Biopower & 50 & ABB (2010) \\
\hline Marine Hydrokinetic & 20 & Previsic et al. (2012) \\
\hline Battery & 15 & Cole and Frazier (2020) \\
\hline
\end{tabular}

Retirements of existing conventional energy generators in ReEDS are primarily a function of announced retirement dates and technology-specific estimated lifetimes, taken from the NEMS plant database. Estimated retirement dates depend on the size of the unit, and the most common lifetimes are shown in Table 11 for plants that are smaller or larger than $100 \mathrm{MW}$. Nuclear plants are assumed to have a mix of 60- and 80-year lifetimes as explained below. All conventional generators that are economically built in ReEDS are given the lifetime of plants greater than 100 $\mathrm{MW}$, and these lifetimes are used as necessary when the solution period extends beyond 2050 .

Table 11. Lifetimes of Conventional Energy Generators (ABB 2018)

\begin{tabular}{|l|c|c|}
\hline Technology & $\begin{array}{c}\text { Lifetime less than 100 MW } \\
\text { (Years) }\end{array}$ & $\begin{array}{c}\text { Lifetime greater or equal } \\
\text { to 100 MW (Years) }\end{array}$ \\
\hline Gas Combustion Turbine & 50 & 50 \\
\hline Gas Combined Cycle and CCS & 60 & 60 \\
\hline Coal, all techs, including cofired & 65 & 75 \\
\hline Oil-Gas-Steam & 50 & 75 \\
\hline Compressed-Air Energy Storage & 100 & 100 \\
\hline
\end{tabular}

In addition to age-based retirements, ReEDS includes the option to endogenously retire technologies (this option is turned on by default). When doing endogenous retirements, ReEDS is trading off the value provided to the system by the plant versus the costs incurred by keeping the plant online. If the value is not sufficient to recover the costs, ReEDS will choose to retire the

\footnotetext{
${ }^{32}$ ReEDS does not account for any decommissioning costs for renewable or any other capacity type.
} 
plant. ReEDS includes a "retirement friction" parameter that allows a plant to stay online as long as it is recovering at least a portion of its fixed operating costs. For example, if this retirement friction parameter is set to 0.5 , then a plant will only retire if it does not recover at least half of its fixed costs. Additionally, ReEDS includes a minimum retirement age for existing conventional plants of 20 years, meaning that a conventional plant is not allowed to be endogenously retired until it is at least 20 years old.

ReEDS includes four exogenous nuclear retirement scenario settings. The four settings are defined by first dividing the currently operating reactors into two bins. Any plants participating in a restructured market and all single-reactor plants are assigned to Bin 1. The remaining plants, which are all multi-reactor plants in a traditional regulated environment, are assigned to Bin 2. The only exception to these categorizations is that plants that have announced their intent to seek a second operating license renewal from the Nuclear Regulatory Commission (NRC) are included in Bin 2. Table 12 breaks down the bins and shows total capacity in each case. These bins are categorizations that reflect the current discussion pointing to more economic pressure on restructured and single-reactor units (Haratyk 2017; Steckler 2017).

Table 12. Amount of Nuclear Power Plant Capacity (in GW) in Each Bin

\begin{tabular}{|l|r|r|}
\hline Plant Category & \multicolumn{1}{|l|}{ Bin 1 } & \multicolumn{1}{|l|}{ Bin 2 } \\
\hline Restructured, Single Reactor & 8.7 & - \\
\hline Restructured, Multi Reactor & 27.5 & $2.0^{\mathrm{a}}$ \\
\hline Regulated, Single Reactor & 15.7 & - \\
\hline Regulated, Multi Reactor & - & 42.1 \\
\hline Total & $\mathbf{5 1 . 9}$ & $\mathbf{4 4 . 1}$ \\
\hline
\end{tabular}

a The Peach Bottom plant $(2.0 \mathrm{GW})$ has announced its intent to seek a second license renewal. Therefore, it is moved from Bin 1 to Bin 2 even though it is in a restructured market.

The four nuclear retirement scenarios are: (1) Early Retirement, (2) 60-Year Lifetime, (3) MidCase (mix of 60 and 80-year lifetimes), and (4) 80-Year Lifetime (see Table 13). The Early Retirement scenario retires nuclear capacity in Bin 1 when its lifetime reaches 50 years, and capacity in Bin 2 at 60 years. The 50-year lifetime emulates the retirements of recent plants that did have a renewed operating license but retired before they reached the end of their license. The 60 -Year Lifetime scenario retires all plants at 60 years, which would be at the end of their first operating license renewal. The 80 -Year Lifetime scenario retires all plants at 80 years, simulating a successful completion of a second operating license renewal from the NRC. The Mid-Case scenario serves as the default setting in ReEDS and retires capacity in Bin 1 at 60 years and capacity in Bin 2 at 80 years. 
Table 13. Nuclear Power Plant Lifetime for Each Scenario by Bin (years)

\begin{tabular}{|l|c|c|}
\hline Scenario Name & Bin 1 & Bin 2 \\
\hline Early Retirement & 50 & 60 \\
\hline $60-$ Year Lifetime & 60 & 60 \\
\hline Mid-Case & 60 & 80 \\
\hline 80-Year Lifetime & 80 & 80 \\
\hline
\end{tabular}

\subsubsection{Growth Constraints}

As of the 2019 version of ReEDS, there are no longer growth penalties as had existed in the previous versions of ReEDS. Instead, there are optional growth constraints that are disabled by default. The model can represent either absolute growth constraints (e.g., wind builds cannot exceed $100 \mathrm{GW}$ per year) or relative growth constraints (e.g., wind capacity cannot grow by more than $50 \%$ per year). The growth constraints are designed to target a broader technology group as opposed to the individual classes of wind, PV, and CSP; as an example, the growth constraint would restrict the builds of all wind technologies and classes and not just a specific class. The default values for the absolute growth constraints are the highest year-over-year changes of each technology type's capacity from 2010 to 2020 (computed by appending the necessary EIA AEOs). For CSP, the default absolute growth limit is assigned the same as PV, as it has not seen the capacity buildout as PV or wind have as of 2020. The relative growth limits are user-defined. For both the relative and absolute growth constraints, the user should exercise caution when defining the limits of technology buildouts.

\subsection{Regional Parameter Variations and Adjustments}

For most generation technologies, regional cost multipliers are applied to reflect variations in installation costs across the United States (see Figure 20). These regional multipliers are applied to the base overnight capital cost presented in earlier sections. The regional multipliers are technology-specific and are derived primarily from the EIA/Leidos Engineering report (EIA 2016b) that is the source of capital cost assumptions for the NEMS model. While the regional costs presented in the EIA/Leidos Engineering report are based on particular cities, the regional multipliers for ReEDS are calculated by interpolating between these cities and using the average value over the ReEDS regions for each technology. For technologies such as CSP that are not included in the newer report, we rely on the older EIA/Science Applications International Corporation report (EIA 2013). 

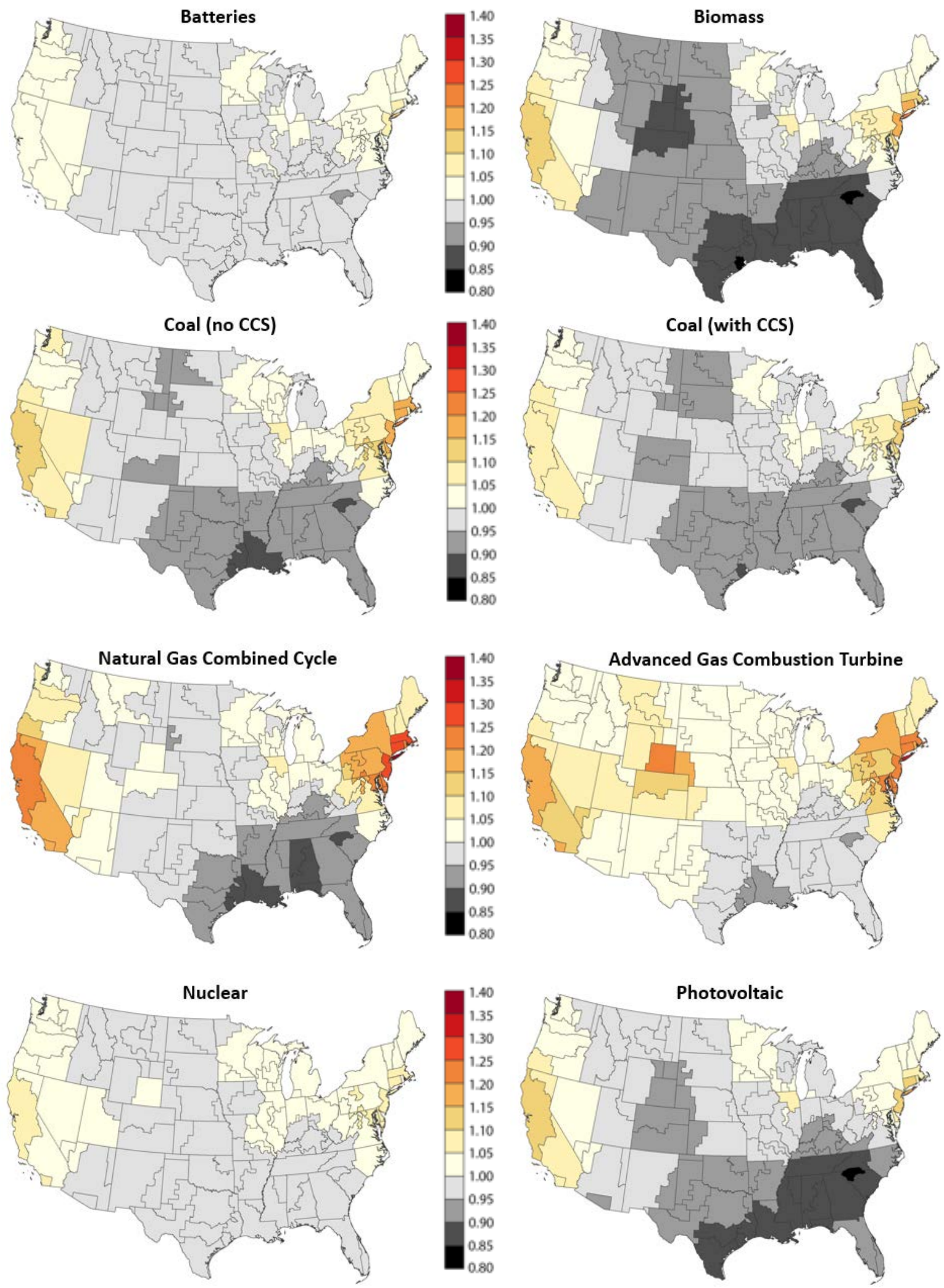

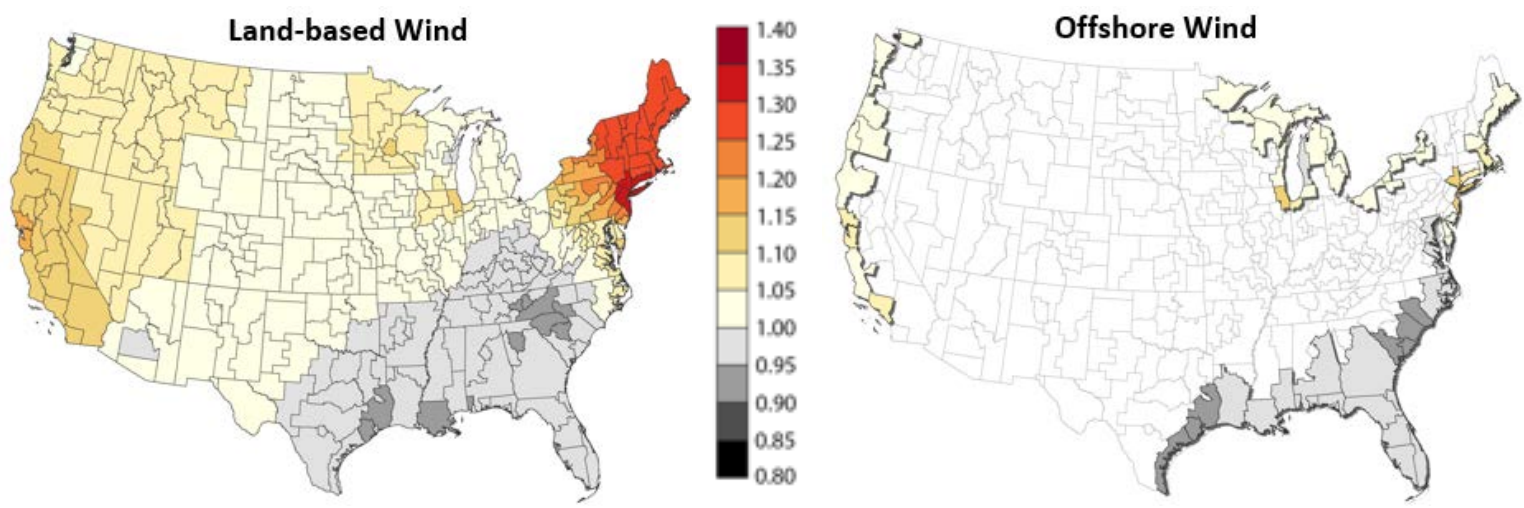

Figure 21. Maps of regional capital cost multipliers for the various technology types

Regions shown in white for offshore wind indicate that there is not offshore wind resource in that region. 


\section{Fuel Prices}

Natural gas, coal, and uranium prices in ReEDS are based on the most recent AEO. Coal prices are provided for each of the nine EIA census divisions. Low and high natural gas price alternatives are taken from the Low and High Oil and Gas Resource and Technology scenarios. ReEDS includes only a single national uranium price trajectory. Base fuel price trajectories are shown in Figure 21 for the AEO2020 (EIA 2020). Biomass fuel prices are represented using supply curves with five bins in each region. The costs and resource availability are based on the U.S. Billion-Ton Update study (DOE 2011). Biomass costs range from \$2.02/MMBtu to \$19.43/MMBtu (in 2018\$).
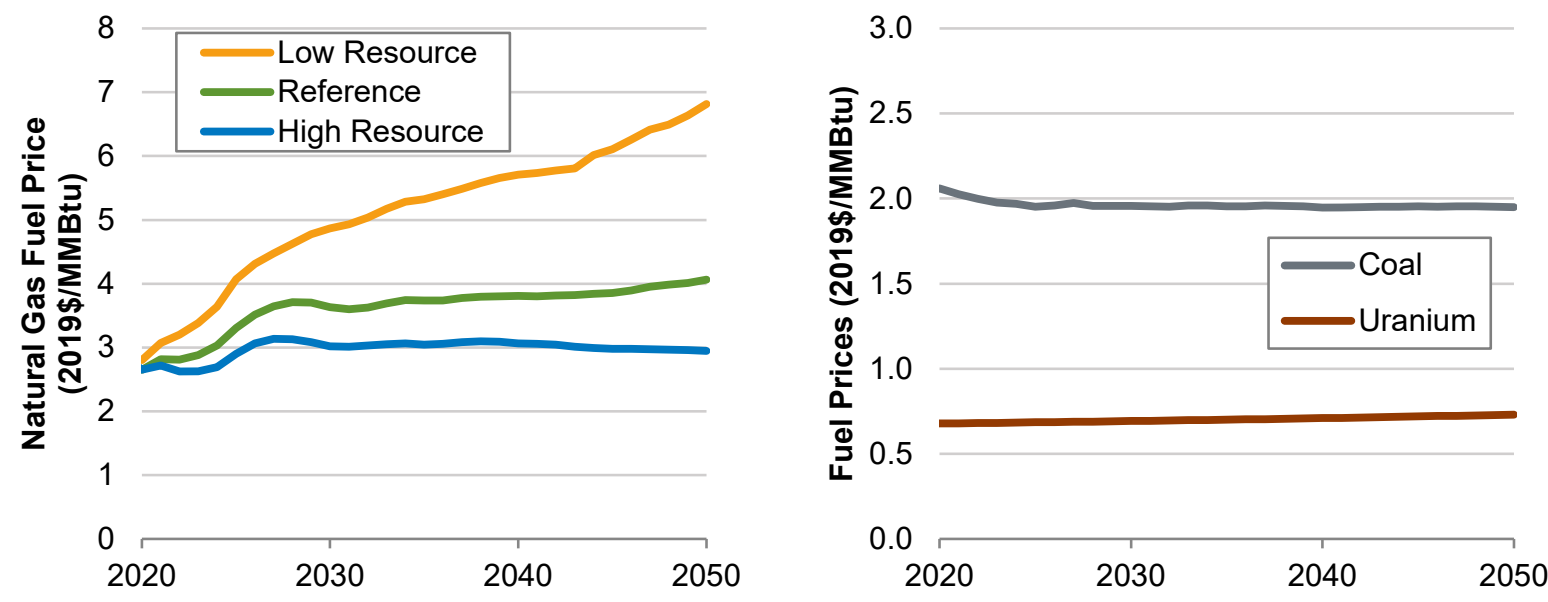

Figure 22. Input fuel price assumptions. Natural gas fuel prices are adjusted by the model as explained below.

Coal and uranium are assumed to be perfectly inelastic; the price is predetermined and insensitive to the ReEDS demand for the fuel. With natural gas, however, the price and demand are linked. Actual natural gas prices in ReEDS are based on the AEO scenario prices but are not exactly the same; instead, they are price-responsive to ReEDS natural gas demand. In each year, each census division is characterized by a price-demand "set point" taken from the AEO Reference scenario but also by two elasticity coefficients: regional $\left(\beta_{\mathrm{r}}\right)$ and national $\left(\beta_{\mathrm{n}}\right)$ elasticity coefficients for the rate of regional price change with respect to (1) the change in the regional gas demand from its set-point and (2) the overall change in the national gas demand from the national price-demand set point respectively. The set of regional and national elasticity coefficients are developed through a linear regression analysis across an ensemble of AEO scenarios ${ }^{33,34}$ to estimate changes in fuel prices driven solely by electric sector natural gas demand (as described in Logan et al. (2013) and Cole, Medlock III, and Jani (2016), though the coefficients have since been updated for the latest AEO data). Though there is no explicit representation of natural gas demand beyond the electricity sector, the regional supply curves reflect natural gas resource, infrastructure, and nonelectric sector demand assumptions embedded

\footnotetext{
${ }^{33}$ Supply curves are nonlinear in practice, but a linear regression approximation has been observed to be satisfactory under most conditions.

34 The elasticity coefficients are derived from all scenarios of AEO2018, but the price-demand set points are taken from any one single scenario of the AEO.
} 
within the AEO modeling. For details, see the Natural Gas Supply Curves section of the appendix.

ReEDS includes options for other types of fuel supply curve representations. Supply curves can be national-only, census-region-only, or static. With the national-only supply curve, there are census division multipliers to adjust prices across the census divisions. In the static case, fuel prices are not responsive to demand.

The natural gas fuel prices also include a seasonal price adjustor, making winter prices higher than the natural gas prices seen during the other seasons of the year. For details, see the Seasonal Natural Gas Price Adjustments section of the appendix. 


\section{Power System Water Use}

The 2020 ReEDS version includes an updated representation of power system water use that improves upon the formulation described in the ReEDS version 2019 documentation (Brown et al. 2020) as well as (Jordan Macknick et al. 2015). Though inactive by default to limit computational complexity, users can activate a power system water use formulation that characterizes the existing fleet and new generation investments by both their cooling technology and water source type, if applicable. Cooling technology affects power system cost and performance, and water use is constrained using technology withdrawal and consumption rates in conjunction with water availability and cost data from (Tidwell et al. 2018). The rest of this section describes each component of this formulation.

\subsection{Existing Fleet Cooling Technology and Water Source}

Thermal generating technologies in ReEDS are differentiated by the following cooling technology types: once-through, recirculating, pond, and dry(air)-cooled. Cooling technologies determine water withdrawal and consumption rates as well as capital cost, operating cost, and heat rate as described in Section 5.2. Generating technologies without cooling systems are designated as having no cooling; however, these technologies can still be assigned water use rates to account for processes such as evaporation from hydropower reservoirs or cleaning PV arrays. All power-cooling technology combinations (including water-using technologies without cooling) are also assigned one of the following six water source types included in the model: fresh surface water that is currently appropriated, unassigned/unappropriated fresh surface water, fresh groundwater, brackish or saline groundwater, saline surface water, and wastewater treatment facility effluent. These water source types align with the water supply curves described in Section 5.3. Representing both cooling technology and water source allows a high-fidelity representation of water source-sink relationships and constraints.

Cooling technology and water source of the baseline 2010 generation fleet and subsequent prescribed builds is assigned using several data sources mapped to the unit database that exogenously defines capital stock in ReEDS. The EIA NEMS unit database described in Section 3.4.1 is first merged with the 2018 version of the EIA thermoelectric cooling water dataset (USEIA 2018). Cooling technology assignment uses the "860 Cooling Type 1" field where possible, followed by the "860 Cooling Type 2" and finally "923 Cooling Type". Hybrid cooling systems are assigned as recirculating except for hybrid dry/induced draft systems, which are assigned as dry cooling. Any remaining gaps in cooling technology assignment are filled using the UCS EW3 Energy-Water Database (Union of Concerned Scientists 2012). This procedure enables annual updates through yearly reporting of EIA thermoelectric cooling water data. Thermal units with no available information on cooling technology are assigned recirculating cooling by default.

Water source in ReEDS is assigned where possible using the "Water Type" and "Water Source" fields in the EIA cooling water dataset and then supplemented using raw EIA Form 860 plantlevel data ("Form EIA-860 Detailed Data with Previous Form Data (EIA-860A/860B)" 2018). When the water source is unclear from the type and source, the "Water Source Name" is used to help discern additional water source types and determine which units use municipal water. Municipal water is treated as an intermediary of the ultimate water source, which is defined using U.S. Geological Survey (USGS) water use data for 2015 that includes water sources for 
municipal use (Dieter and Linsey 2017). Generating units that use municipal water are assigned the water source that supplies the majority of municipal water use in the USGS database. The UCS EW3 database is also used to assign water sources unavailable in EIA data (Union of Concerned Scientists 2012). Remaining unknown water source types are assigned from USGS data using the majority water source for the power sector, further differentiated by once-through or recirculating cooling. If there is no USGS data for power sector water use in the relevant county, the majority source of overall water use is applied.

Beyond this multi-database approach to assign cooling technology and water source, water source must be reassigned for some prescribed new builds if the water availability described in Section 5.3 is insufficient for that unit's water needs. For these instances, a final adjustment procedure that temporary relaxes water use constraints is used to identify these units and manually modify water source types to use the BA's least-cost water source with sufficient availability for the prescribed unit.

\subsection{Cooling System Cost and Performance}

Alternative cooling technologies are represented for the following power system types:

- Coal: all types, including coal with CCS and biomass-cofired coal

- Gas-CC: including Gas-CC with CCS

- Oil-Gas-Steam: also allows "no cooling" to represent capacity that does not use thermal cooling water (e.g., internal combustion engines)

- Nuclear

- Biopower: also allows "no cooling" to represent capacity that does not use thermal cooling water

- Landfill Gas: also allows "no cooling" to represent capacity that does not use thermal cooling water

- CSP: all thermal storage durations and resource classes

Water use is also characterized and constrained for hydropower, Gas-CT, geothermal, and distributed rooftop PV technologies, albeit without cooling technology disaggregation. This construct allows total power sector water use to be estimated and could be expanded upon in later model versions, particularly for geothermal technologies.

Some power-cooling technology pairs are also prohibited for new construction by default. New, non-prescribed capacity for all technologies cannot use once-through cooling due to U.S.

Environmental Protection Agency (EPA) regulations and industry trends (40 CFR Parts 122 and 125 2014). In addition, all new non-prescribed capacity cannot choose pond cooling because pond cooling designs are site-dependent, and ReEDS does not have sufficient detail to characterize location-specific cooling pond design. The model also prevents new nuclear and coal-CCS capacity from using dry cooling because existing designs have very high cooling requirements where dry cooling is considered impractical. 
Cooling technology affects capital cost, variable operating cost, heat rate, water withdrawal rate, and water consumption rate. Cost and heat rate are adjusted for cooling technology by multiplying baseline technology data by the factors in Table 14, 15, and 16, where recirculating cooling is the reference cooling technology (J. Macknick et al. 2012). Typically, once-through cooling systems are less expensive and allow higher overall thermal efficiency, while dry cooling is more expensive and results in lower net thermal efficiency. Pond cooling systems are typically intermediate to once-through and recirculating cooling, but the model uses once-through cooling characteristics as an approximation because actual cost and performance is site-specific. No data exists for some power-cooling technology combinations (Gas-CC-CCS + once-through and pond; Coal-CCS + pond, CSP + once-through and pond) because no existing or planned units of those types exist.

Table 14. Capital Cost Multipliers for Power-Cooling Technology Combinations

\begin{tabular}{lllll}
\hline Power Technology & $\begin{array}{l}\text { Once- } \\
\text { Through }\end{array}$ & Recirculating & Dry & $\begin{array}{l}\text { Cooling } \\
\text { Pond }\end{array}$ \\
\hline Gas-CC & 0.978 & 1.000 & 1.102 & 0.978 \\
Gas-CC-CCS & $\mathrm{n} / \mathrm{a}$ & 1.000 & 1.075 & $\mathrm{n} / \mathrm{a}$ \\
Pulverized coal with scrubbers (pre-1995) & 0.981 & 1.000 & 1.045 & 0.981 \\
Pulverized coal without scrubbers & 0.981 & 1.000 & 1.045 & 0.981 \\
Pulverized coal with scrubbers & 0.981 & 1.000 & 1.045 & 0.981 \\
(post-1995) & 0.988 & 1.000 & 1.033 & 0.988 \\
IGCC coal & 0.982 & 1.000 & $\mathrm{n} / \mathrm{a}$ & $\mathrm{n} / \mathrm{a}$ \\
Coal-CCS & 0.981 & 1.000 & 1.045 & 0.981 \\
Oil/gas steam & 0.981 & 1.000 & $\mathrm{n} / \mathrm{a}$ & 0.981 \\
Nuclear & 0.981 & 1.000 & 1.045 & 0.981 \\
Biopower & 0.981 & 1.000 & 1.045 & 0.981 \\
Cofired coal (pre-1995) & 0.981 & 1.000 & 1.045 & 0.981 \\
Cofired coal (post-1995) & $\mathrm{n} / \mathrm{a}$ & 1.000 & 1.050 & $\mathrm{n} / \mathrm{a}$ \\
\hline CSP & & &
\end{tabular}

Table 15. Variable Operations and Maintenance Cost Multipliers for Power-Cooling Technology Combinations

\begin{tabular}{lllll}
\hline Power Technology & $\begin{array}{l}\text { Once- } \\
\text { Through }\end{array}$ & Recirculating & Dry & $\begin{array}{l}\text { Cooling } \\
\text { Pond }\end{array}$ \\
\hline Gas-CC & 0.996 & 1.000 & 1.021 & 0.996 \\
Gas-CC-CCS & $\mathrm{n} / \mathrm{a}$ & 1.000 & 1.107 & $\mathrm{n} / \mathrm{a}$ \\
Pulverized coal with scrubbers (pre-1995) & 0.989 & 1.000 & 1.051 & 0.989 \\
Pulverized coal without scrubbers & 0.989 & 1.000 & 1.051 & 0.989 \\
Pulverized coal without scrubbers (post-1995) & 0.989 & 1.000 & 1.051 & 0.989 \\
IGCC coal & 0.996 & 1.000 & 1.021 & 0.996
\end{tabular}




\begin{tabular}{lllll}
\hline Power Technology & $\begin{array}{l}\text { Once- } \\
\text { Through }\end{array}$ & Recirculating & Dry & $\begin{array}{l}\text { Cooling } \\
\text { Pond }\end{array}$ \\
\hline Coal-CCS & 0.993 & 1.000 & $\mathrm{n} / \mathrm{a}$ & $\mathrm{n} / \mathrm{a}$ \\
Oil/gas steam & 0.989 & 1.000 & 1.051 & 0.989 \\
Nuclear & 0.989 & 1.000 & $\mathrm{n} / \mathrm{a}$ & 0.989 \\
Biopower & 0.989 & 1.000 & 1.051 & 0.989 \\
Cofired coal (pre-1995) & 0.989 & 1.000 & 1.051 & 0.989 \\
Cofired coal (post-1995) & 0.989 & 1.000 & 1.051 & 0.989 \\
CSP & $\mathrm{n} / \mathrm{a}$ & 1.000 & 1.050 & $\mathrm{n} / \mathrm{a}$ \\
\hline
\end{tabular}

Table 16. Heat Rate Multipliers for Power-Cooling Technology Combinations

\begin{tabular}{lllll}
\hline Power Technology & $\begin{array}{l}\text { Once- } \\
\text { Through }\end{array}$ & Recirculating & Dry & $\begin{array}{l}\text { Cooling } \\
\text { Pond }\end{array}$ \\
\hline Gas-CC & 0.980 & 1.000 & 1.050 & 0.980 \\
Gas-CC-CCS & $\mathrm{n} / \mathrm{a}$ & 1.000 & 1.075 & $\mathrm{n} / \mathrm{a}$ \\
Pulverized coal with scrubbers (pre-1995) & 0.985 & 1.000 & 1.050 & 0.985 \\
Pulverized coal without scrubbers & 0.985 & 1.000 & 1.050 & 0.985 \\
Pulverized coal with scrubbers (post-1995) & 0.985 & 1.000 & 1.050 & 0.985 \\
IGCC Coal & 0.980 & 1.000 & 1.050 & 0.98 \\
Coal-CCS & 0.800 & 1.000 & $\mathrm{n} / \mathrm{a}$ & $\mathrm{n} / \mathrm{a}$ \\
Oil/Gas Steam & 0.985 & 1.000 & 1.050 & 0.985 \\
Nuclear & 0.973 & 1.000 & $\mathrm{n} / \mathrm{a}$ & 0.973 \\
Biopower & 0.985 & 1.000 & 1.050 & 0.985 \\
Cofired Coal (pre-1995) & 0.985 & 1.000 & 1.050 & 0.985 \\
Cofired Coal (post-1995) & 0.985 & 1.000 & 1.050 & 0.985 \\
CSP & $\mathrm{n} / \mathrm{a}$ & 1.000 & $1.000^{\mathrm{a}}$ & $\mathrm{n} / \mathrm{a}$ \\
\hline
\end{tabular}

a There are currently no data to inform a heat rate multiplier for CSP.

More efficient-less expensive cooling technologies typically require greater volumes of water withdrawal and consumption, creating a tradeoff between cost and water use. Withdrawal and consumption rates for power-cooling technology combinations are shown in Table 17 and Table 18 (J. Macknick et al. 2012). Table 19 includes water use rates for power technologies that are not differentiated by cooling technology; aside from geothermal these values are negligible but could be modified by the user if desired. Further, the model can accommodate BA-specific withdrawal and consumption rates, so the values shown below could be made regionally heterogeneous with sufficient data. Water withdrawal and consumption rates coupled with assignment of water source type allow ReEDS to characterize power system water demand for each technology, BA, and water source combination. 
Table 17. Water Withdrawal Rates for Power-Cooling Technology Combinations (gal/MWh)

\begin{tabular}{lllll}
\hline Power Technology & $\begin{array}{l}\text { Once- } \\
\text { Through }\end{array}$ & Recirculating & Dry & $\begin{array}{l}\text { Cooling } \\
\text { Pond }\end{array}$ \\
\hline Gas-CC & 11,380 & 255 & 2 & 5950 \\
Gas-CC-CCS & $\mathrm{n} / \mathrm{a}$ & 506 & $\mathrm{n} / \mathrm{a}$ & $\mathrm{n} / \mathrm{a}$ \\
Pulverized coal with scrubbers (pre-1995) & 36,350 & 1,005 & 0 & 12,225 \\
Pulverized coal without scrubbers & 36,350 & 1,005 & 0 & 12,225 \\
Pulverized coal with scrubbers (post-1995) & 27,088 & 587 & 0 & 17,914 \\
IGCC Coal & 18,136 & 393 & 0 & 9,635 \\
Coal-CCS & 56,483 & 1,224 & $\mathrm{n} / \mathrm{a}$ & $\mathrm{n} / \mathrm{a}$ \\
Oil/gas steam & 35,000 & 1,203 & 0 & 5,950 \\
Nuclear & 44,350 & 1,101 & $\mathrm{n} / \mathrm{a}$ & 7,050 \\
Biopower & 35,000 & 878 & 0 & 450 \\
Cofired coal (pre-1995) & 35,000 & 878 & 0 & 450 \\
Cofired coal (post-1995) & 35,000 & 878 & 0 & 450 \\
CSP & $\mathrm{n} / \mathrm{a}$ & 786 & 26 & $\mathrm{n} / \mathrm{a}$ \\
\hline
\end{tabular}

Table 18. Water Consumption Rates for Power-Cooling Technology Combinations (gal/MWh)

\begin{tabular}{lllll}
\hline Power Technology & $\begin{array}{l}\text { Once- } \\
\text { Through }\end{array}$ & Recirculating & Dry & $\begin{array}{l}\text { Cooling } \\
\text { Pond }\end{array}$ \\
\hline Gas-CC & 100 & 205 & 2 & 240 \\
Gas-CC-CCS & $\mathrm{n} / \mathrm{a}$ & 378 & $\mathrm{n} / \mathrm{a}$ & $\mathrm{n} / \mathrm{a}$ \\
Pulverized coal with scrubbers (pre-1995) & 250 & 687 & 0 & 545 \\
Pulverized coal without scrubbers & 250 & 687 & 0 & 545 \\
Pulverized coal with scrubbers (post-1995) & 113 & 479 & 0 & 545 \\
IGCC coal & 90 & 380 & 0 & 32 \\
Coal-CCS & 217 & 921 & $\mathrm{n} / \mathrm{a}$ & $\mathrm{n} / \mathrm{a}$ \\
Oil/gas steam & 240 & 826 & 0 & 240 \\
Nuclear & 269 & 672 & $\mathrm{n} / \mathrm{a}$ & 610 \\
Biopower & 300 & 553 & 0 & 390 \\
Cofired coal (pre-1995) & 300 & 553 & 0 & 390 \\
Cofired coal (post-1995) & 300 & 553 & 0 & 390 \\
CSP & $\mathrm{n} / \mathrm{a}$ & 786 & 26 & n/a \\
\hline
\end{tabular}


Table 19. Water withdrawal and consumption rates for technologies that are undifferentiated by cooling technology (gal/MWh)

\begin{tabular}{lll}
\hline Power Technology & $\begin{array}{l}\text { Withdrawal } \\
\text { Rate }\end{array}$ & $\begin{array}{l}\text { Consumption } \\
\text { Rate }\end{array}$ \\
\hline Hydropower & 1 & 1 \\
Gas-CT & 1 & 1 \\
Geothermal & 40 & 40 \\
Landfill-Gas & 1 & 1 \\
Distributed rooftop PV & 1 & 1 \\
\hline
\end{tabular}

\subsection{Water Availability and Cost}

All generating capacity that exists in a given model year is required to have access to water if that technology uses water. The quantity of required water access is defined conservatively to ensure sufficient water is available to generate at maximum power output during the expected annual low water flow condition. To align with annualized water availability data, this requirement is formulated as the annual volume of water needed to operate continuously at maximum output for the entire year (100\% capacity factor), i.e., the product of generating capacity (MW), water use rate (gal/MWh), and 8760 hours per year. For capacity that uses surface water, requirements are based on the water consumption rate to account for the return of most withdrawn water directly to the water source at the site of withdrawal. For all other water sources, water access requirements are based on withdrawal rates because these water types (e.g., groundwater, wastewater effluent) are not generally returned to the site of withdrawal.

Generating capacity in the initial 2010 model year is assumed to have secured sufficient water access prior to 2010. However, any new prescribed or optimized investments must procure water access from a power sector water availability supply curve developed by Sandia National Laboratories (Tidwell et al. 2018). For use in ReEDS, water availability and cost are aggregated to the BA resolution for each of five water source types: fresh surface water that is currently appropriated, unassigned/unappropriated fresh surface water, fresh groundwater, brackish or saline groundwater, and wastewater treatment facility effluent (Figure 22). Saline surface water is available to existing capacity that currently uses it, but this water source is assumed unavailable to new capacity due to current regulatory constraints and industry expectations (40 CFR Parts 122 and 125 2014). Tidwell et al. use a unique resource assessment and costing methodology for each water source type, based on technical and legal considerations. Costs include both capital and annualized operating costs associated with each water source. Unassigned/unappropriated fresh surface water is assumed to have negligible access cost, and costs typically increase in the order of fresh groundwater, appropriated fresh surface water, wastewater, and brackish/saline groundwater. Appropriated water is only relevant to western U.S. water law, so there is no appropriated water in the east, and many western regions lack unappropriated water (i.e., 100\% of total water is appropriated).

When capacity retires, its water access is automatically available to any new capacity at the cost associated with the capacity's water source and region. For the initial 2010 fleet, all capacity that uses fresh surface water is designated as using the "appropriated fresh surface water" category so 
that retired water access is given the cost of other appropriated water in that region. For the eastern U.S. where water appropriation is inapplicable, retired fresh surface water access is assigned a small nominal cost to avoid over procurement of water in the model. This structure implies that any water access owned by the power sector remains in the power sector and that increased competition does not affect water supply or cost. Scenario analysis and future model development could explore this assumption in greater detail.

Similar to retirements, changes in water needs due to upgrades or refurbishments are also accounted for in the water access requirement.

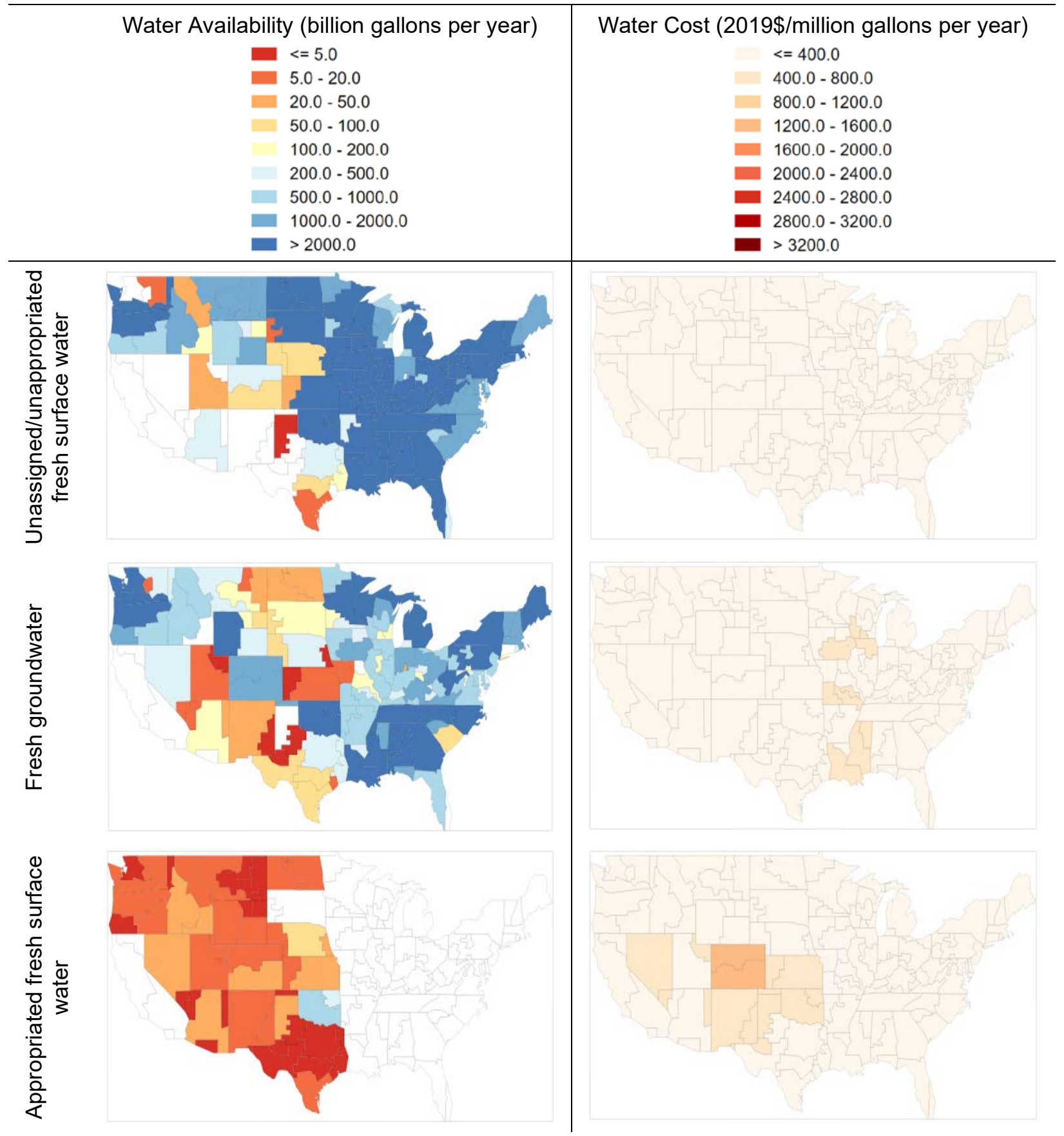



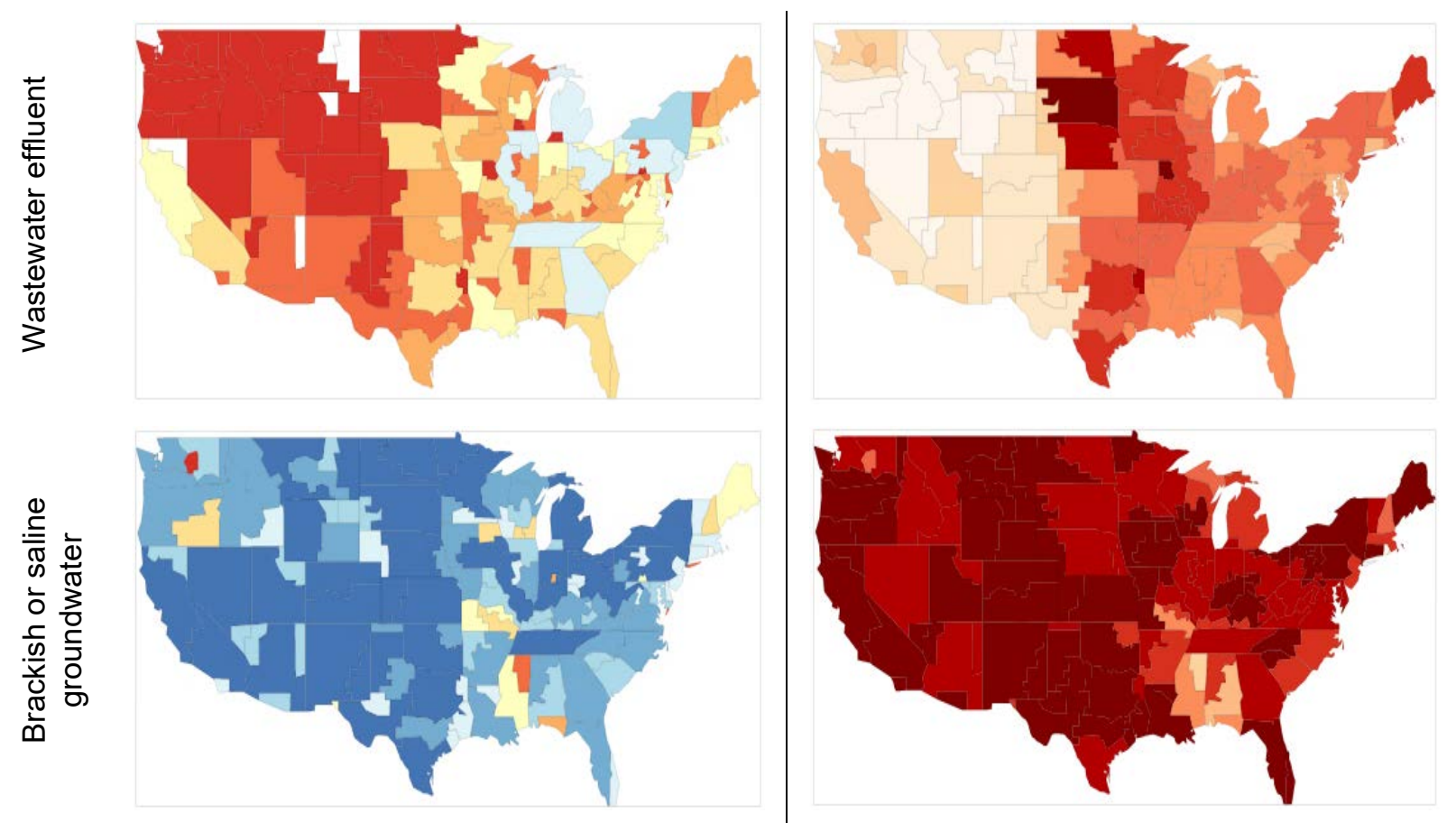

Figure 23. Water availability and cost for each water type in each ReEDS balancing area.

\subsection{Water Constraints}

Several model constraints govern the ReEDS power sector water use formulation. Water withdrawal and consumption quantities are tracked for each power technology, cooling technology, water source, power technology vintage, BA, timeslice, and year, providing high resolution with which to examine power sector water use. Separately, water access requirements are related explicitly to the capacity available for each power technology, cooling technology, water source, power technology vintage, BA, and year based on either the withdrawal or consumption rate as described in Section 5.3. This water access is then limited by the total access available for each water source and region as defined by the water allocation in 2010 and the supply available to post-2010 capacity.

Quantities of water used for each power technology, cooling technology, water source, power technology vintage, and BA are then constrained within each season based on the seasonal allocation of available water access. Water access must be purchased from the water availability supply curve before water can be used. Hydrology data is used to define the seasonal allocation of unassigned/unappropriated fresh surface water (Jordan Macknick et al. 2015), and all other water types are assumed available uniformly throughout the year. Additional detail on seasonal water allocation and the potential for changes over time requires additional data, but the framework generally allows the capability for incentivizing water sources that are more available when electricity demands are higher. 


\section{Transmission}

\subsection{Transmission System}

ReEDS uses a synthetic network with 134 nodes defined by roughly 300 corridors for the contiguous 48 states. Each corridor has a nominal carrying capacity limit (Figure 23) that is determined for the start-year (2010) based on power-flow analysis using ABB's GridView model and NERC-reported line limits (NERC 2010). The carrying capacity of DC transmission connections are taken from project websites. A few notable DC transmission connections that are modeled in ReEDS are listed in Table 20.

In later years, ReEDS can expand these carrying capacities, though the model cannot build new node-to-node pathways. Transmission expansion is limited before 2022 based on new construction that is already planned (ABB 2013). After 2022, that limitation is dropped. ReEDS constrains transmission flows in each of the 17 time-slices when dispatching generation and contracting operating reserves, and available transmission capacity can also be used for firm power contracts to meet system adequacy needs.

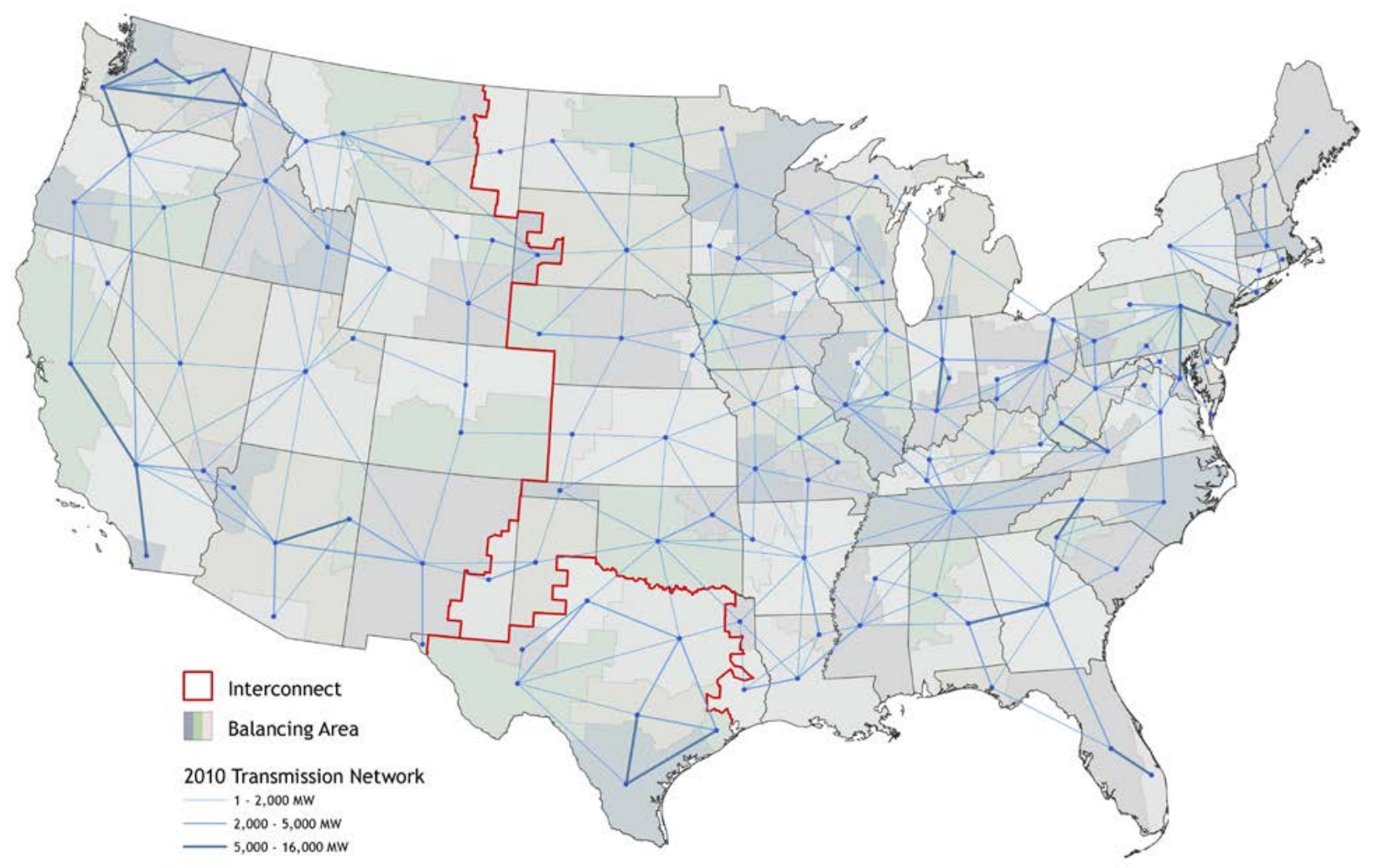

Figure 24. Existing long-distance transmission infrastructure as represented in ReEDS 
Table 20. List of Notable DC Transmission Connections Modeled in ReEDS

\begin{tabular}{|l|c|}
\hline Project & Capacity (MW) \\
\hline Pacific DC Intertie & 2,780 \\
\hline Intermountain Power Project & 1,920 \\
\hline Miles City Intertie (West-East) & 200 \\
\hline Virginia Smith Intertie (West-East) & 200 \\
\hline Segall Intertie (West-East) & 110 \\
\hline Artesia Intertie (West-ERCOT) & 200 \\
\hline Blackwater Intertie (West-East) & 200 \\
\hline Rapid City Intertie (West-East) & 200 \\
\hline Lamar Intertie (West-East) & 210 \\
\hline CU HVDC & 1,500 \\
\hline Square Butte & \\
\hline Oklaunion Intertie (ERCOT-East) & 220 \\
\hline Welsh Intertie (ERCOT-East) & 600 \\
\hline
\end{tabular}

In general, the modeled nodes are located at the largest population center of each BA, although some manual adjustments are made. ${ }^{35}$ Distances between BA nodes are estimated by tracing the "shortest path" distance along existing transmission lines, giving preference for the trace follow higher voltage lines. Voltages for each transmission line were defined using the Homeland Security Infrastructure Project (HSIP) transmission database and converted into 1-km grid. The maximum voltage in each grid cell was identified and assigned a weight based on the voltage classification per Table 21 to create a tension grid. Using this tension grip, a least "cost" (lowest weight) path was traced between every BA-to-BA corridor was determined using the tension grid. Finally, the great circle formula is used to calculate the distance of the traced paths. Figure 26 shows the resulting transmission paths between the modeled nodes. The lengths of DC corridors are taken from values reported on project websites.

Table 21. Weights for Each Voltage Class

\begin{tabular}{|l|r|}
\hline Voltage Class (kV) & Weight \\
\hline No line & 1,000 \\
\hline $100-161$ & 10 \\
\hline $230-300$ & 5 \\
\hline 345 & 3 \\
\hline 500 & 2 \\
\hline 735 and above & 1 \\
\hline
\end{tabular}

\footnotetext{
${ }^{35}$ For example, Vancouver and Portland are the largest populations centers in the southern Washington and northern Oregon regions respectively. However, these centers are only about 10 miles apart. Modeling such a short distance between these nodes would potentially create a bias for transmission investments between Washington and Oregon. So Yakima was used in lieu of Vancouver as the node location for southern Washington.
} 


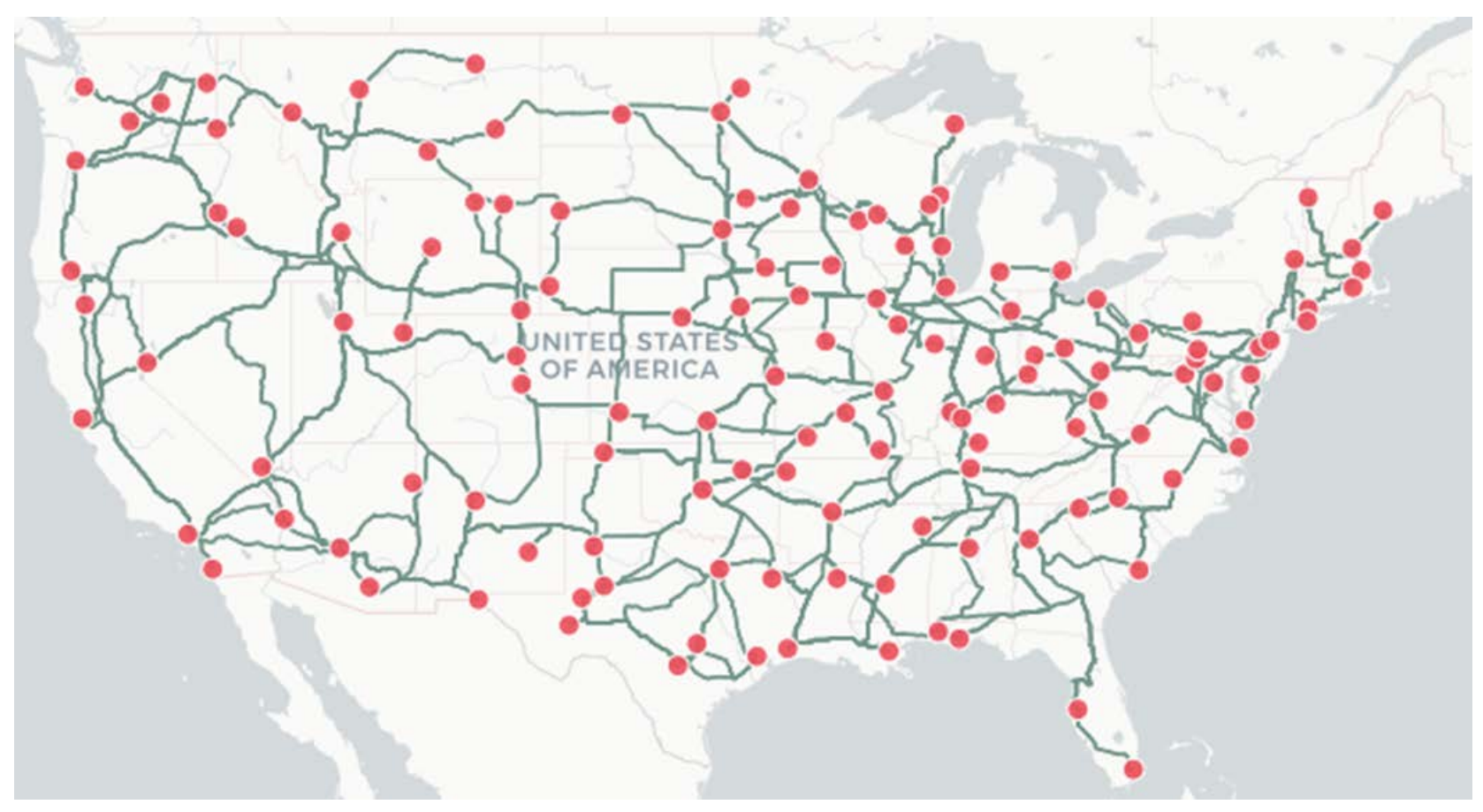

Figure 25. Modeled BA nodes and transmission paths

Transmission network flows in ReEDS are limited based on the nominal carrying capacity of the corridors (Figure 23). ReEDS can choose to build additional transmission capacity on the existing network to reduce congestion, but expansion of AC-DC-AC interconnection ties are not allowed under default assumptions. New long-distance HVDC lines are not allowed by default, but can be specified in the model inputs. ReEDS does not represent reactive power and does not address AC-power-flow issues of voltage, frequency, or limiting phase angle differences. IntraBA T\&D networks are similarly ignored, effectively ignoring the effects of transmission congestion within each region.

Transmission and distribution losses are considered in the model. There are bulk transmission losses of $1 \%$ per 100 miles for power that flows between BAs. In addition, distribution losses of $5 \%$ are assumed and thus added to the end-use demand (Section 7.1) to scale end-use demand to busbar load. Distribution losses do not apply to rooftop PV, as they are assumed to be downstream within distribution networks, but they do apply at a lower rate to DUPV systems, which are assumed to connect directly to low-voltage distribution substations (Section 7.1).

Wind, CSP, and PV technologies are highly sensitive to location and often require spur lines to connect remote locations to the bulk transmission system. The GIS supply curve algorithm described in Section 6.3 estimates spur line distances and costs for potential development sites for these technologies, which are then grouped into supply curve bins. These spur lines, which are distinct from the inter-BA bulk transmission system for ReEDS, are assumed to link remote sites to the larger transmission system and to load centers. All other technologies are assumed to be built close to existing transmission infrastructure, and they therefore need only a nominaldistance spur line. Because the plant envelope used to determine technology capital cost 
assumptions includes the onsite switchyard, a short spur line, and relevant upgrades at the substation (EIA 2013), those technologies incur no additional grid interconnection cost.

\subsection{Transmission Cost}

The long-distance and spur-line transmission costs in ReEDS are based on regional line voltage and cost premium assumptions. For long-distance interregional transmission lines, an assumed voltage $(345 \mathrm{kV}, 500 \mathrm{kV}$, or $765 \mathrm{kV})$ is applied for each region. The voltage assumption in each BA for long-distance transmission is taken from the highest voltage line currently operating in the BA from the Homeland Security Infrastructure Project (HSIP 2012). For BAs where the highest voltage of currently operating transmission lines is less than $500 \mathrm{kV}$, the voltage in the future is assumed to be $765 \mathrm{kV}$, and the associated costs for $765-\mathrm{kV}$ lines are used for all years. For BAs where the highest voltage of currently operating transmission lines is $500 \mathrm{kV}$, the costs for $500-\mathrm{kV}$ lines are used. The only exception to these rules for voltages in the Eastern Interconnection are for BAs in New England (Connecticut, Maine, Massachusetts, New Hampshire, Rhode Island, and Vermont), which are assumed to use $345-\mathrm{kV}$ transmission lines for all years.

Each voltage class is associated with a base capital cost sourced from the Phase II Eastern Interconnection Planning Collaborative (EIPC) report: \$2,333/MW-mile, \$1,347/MW-mile, and $\$ 1,400 / \mathrm{MW}$-mile for $345-\mathrm{kV}, 500-\mathrm{kV}$, and $765-\mathrm{kV}$ transmission lines respectively (EIPC 2012). ${ }^{36}$ All wind and solar spur line costs are based on $230-\mathrm{kV}$ line costs, assumed to be $\$ 3,667 / \mathrm{MW}$-mile (ibid). ${ }^{37}$ For DC transmission lines, an additional cost of $\$ 253,000 / \mathrm{MW}$ (in $2015 \$$ ) is applied to account for the cost of the converter stations.

In addition to the base transmission costs, regional multipliers are also applied and are largely based on assumptions from EIPC (2012). Regional transmission cost multipliers are the average of the EIPC report's high and low multipliers in each North American Electricity and Environmental Model region, and they are associated with the assumed voltage within the region. BAs in ERCOT and the Western Interconnection (excluding Canada and California) are assumed to have a regional transmission multiplier of one (1). Long-distance transmission costs in BAs in the California Independent System Operator are 2.25 times the cost of the other baseline costs for the rest of the Western Interconnection. For long-distance transmission between BAs with different transmission costs, the average cost is used. The same process is applied to wind and solar spur line costs.

Figure 25 and Figure 26 show the regional long-distance and spur-line transmission costs, respectively, that result from the previously described steps and assumptions.

\footnotetext{
36 The base transmission costs for ReEDS are converted to \$/MW-mile according to new transmission line cost and capacity assumptions for single circuit conductors for each voltage in EIPC (2012).

${ }^{37}$ Wind and solar spur line costs are applied within the development of the resource supply curves. These cost values are in $2015 \$$.
} 


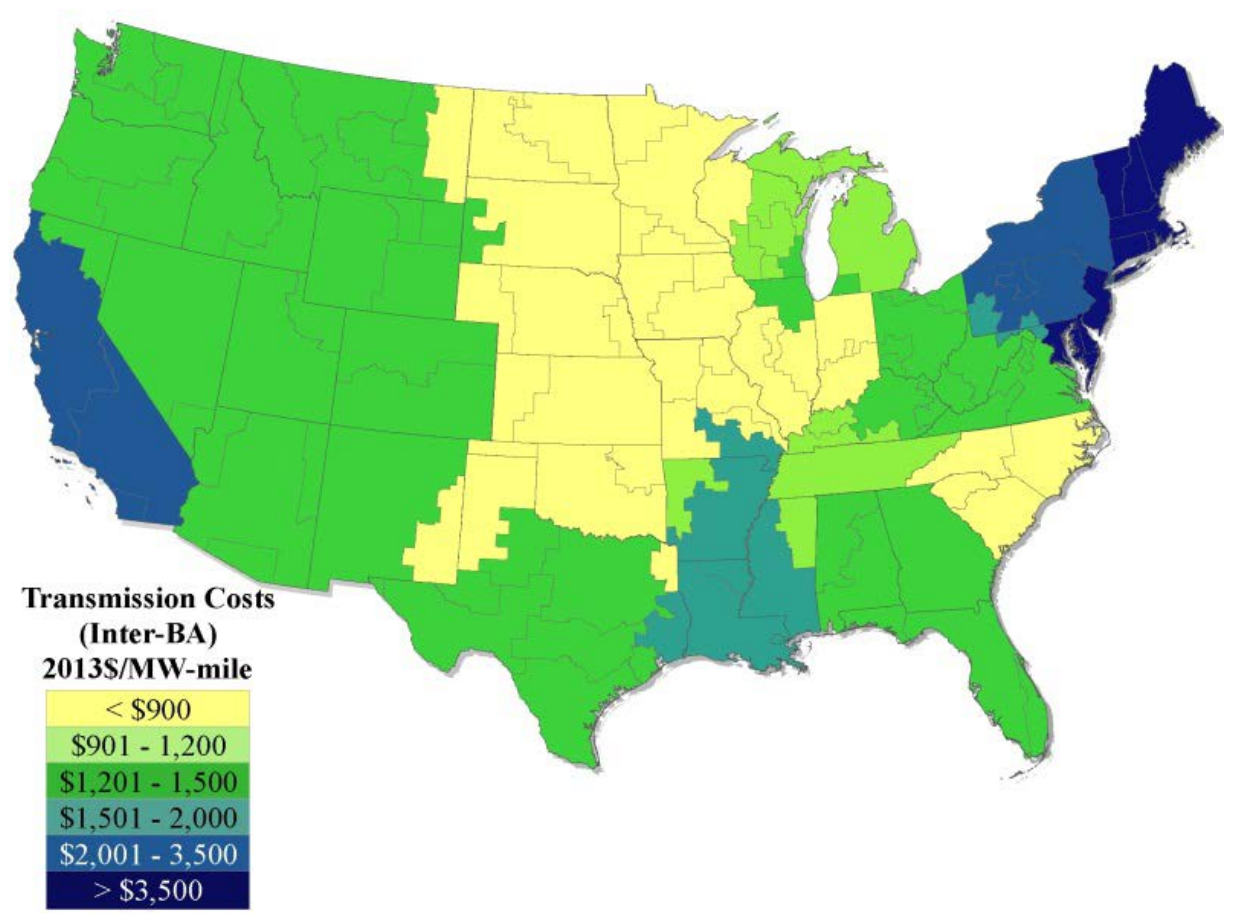

Figure 26. Map of long-distance transmission costs

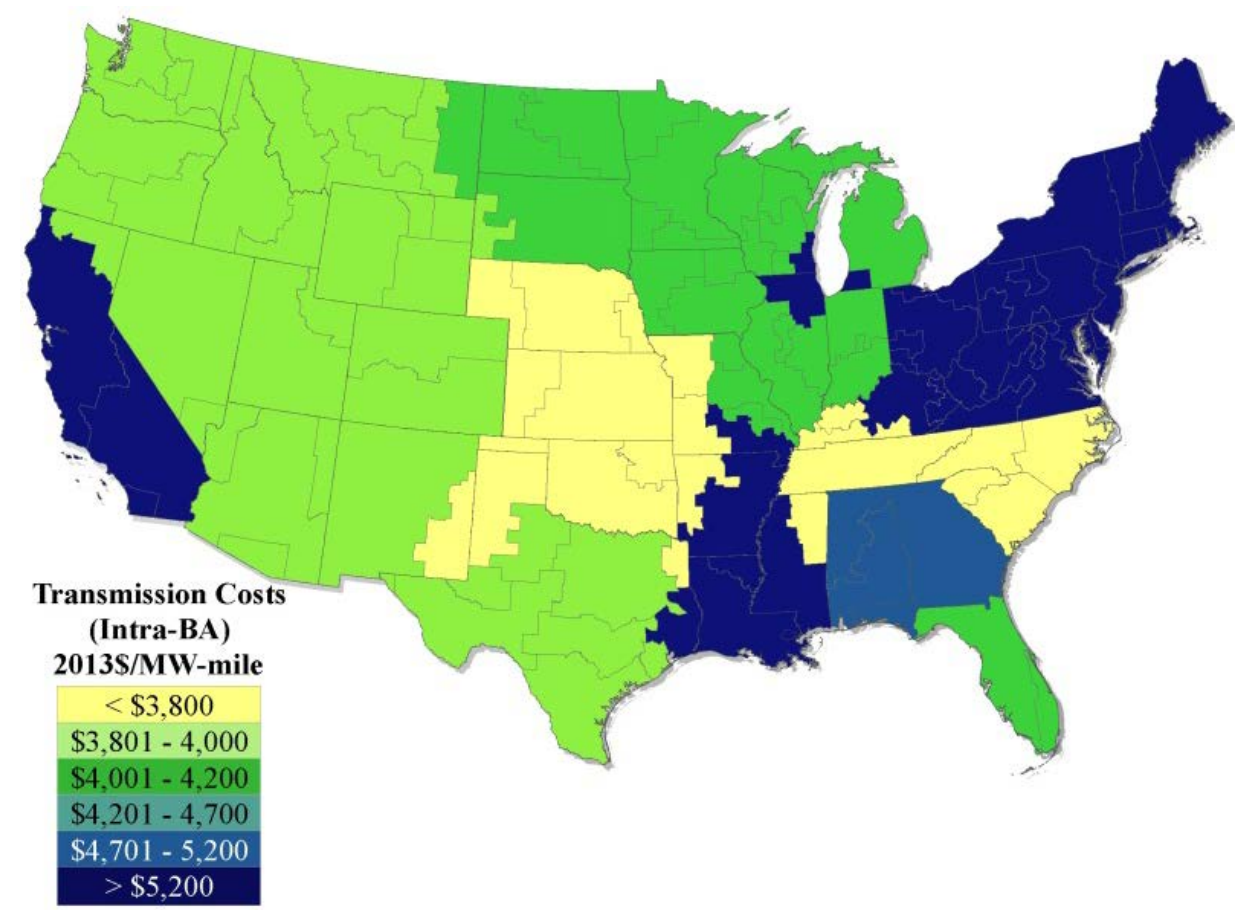

Figure 27. Map of spur-line transmission costs 


\subsection{Spur Lines}

In addition to long-distance inter-BA transmission, ReEDS also reflects the cost to interconnect new wind and solar capacity. These spur line and grid connection costs are derived from the analysis using reV, which is also used for the resource potential inputs for these technologies. Coupled with supply curves for the renewable resource itself, allow ReEDS to make internal decisions about tradeoffs between resource quality and interconnection cost.

The geospatial site-connection algorithm evaluates each potential link from a wind or solar resource site to an electricity infrastructure feature, and the model assigns to the link a cost of development. For the algorithm, wind resource assessed at 2-km resolution are downscaled to 90 $\mathrm{m}$ resolution for the purpose of identifying developable and non-developable locations based on numerous land cover, land use, and protected areas GIS data sets. The $90 \mathrm{~m}$ resolution pixels are then aggregated to a grid of roughly $5.7 \mathrm{~km}$ resolution to reduce the number of points to be used in additional analyses downstream. CSP sites are similarly grouped into $1.35 \mathrm{~km} \times 1.35 \mathrm{~km}$ cells, and PV sites are grouped into $3.15 \mathrm{~km} \mathrm{x} 3.15 \mathrm{~km}$ cells. Each resource site is characterized by a LCOE that includes the expected cost of interconnection.

The resource supply curves are the result of successively selecting the least-cost site-toinfrastructure link and allocating that site to the infrastructure component until the transmission lines are saturated. As the available capacity at transmission infrastructure features decreases, resource sites look farther afield for available linkages.

The resource supply curves are described in detail by Maclaurin et al. (2019), and Murphy et al. (2019).

\subsection{International Electricity Trade}

ReEDS is capable of endogenously representing Canada and Mexico (Section 11), but our default model configuration only covers the contiguous United States and represents electricity trade with Canada exogenously. In the default configuration, imports and exports are specified by Canadian province based on the National Energy Board's (NEB) Canadian Electricity Futures Reference Scenario (NEB 2018), with net exports across all regions shown in Figure 27 (values beyond NEB projections to 2040 are held constant at the 2040 value). Each province is required to send electricity to or receive electricity from any of the ReEDS BAs that have connecting transmission lines to that province, with the split among BAs approximated based on the transmission connecting the BAs to the provinces. Seasonal and time slice estimates for imports and exports are based on the historical monthly flows between the countries. ${ }^{38}$ Canadian imports are assumed to be from hydropower and are counted toward RPS requirements where allowed by state RPS regulations. Canadian imports also count toward reserve margin requirements.

\footnotetext{
${ }^{38}$ See https:/www.neb-one.gc.ca/nrg/sttstc/lctrct/stt/lctrctysmmr/lctrctysmmr-eng.html.
} 


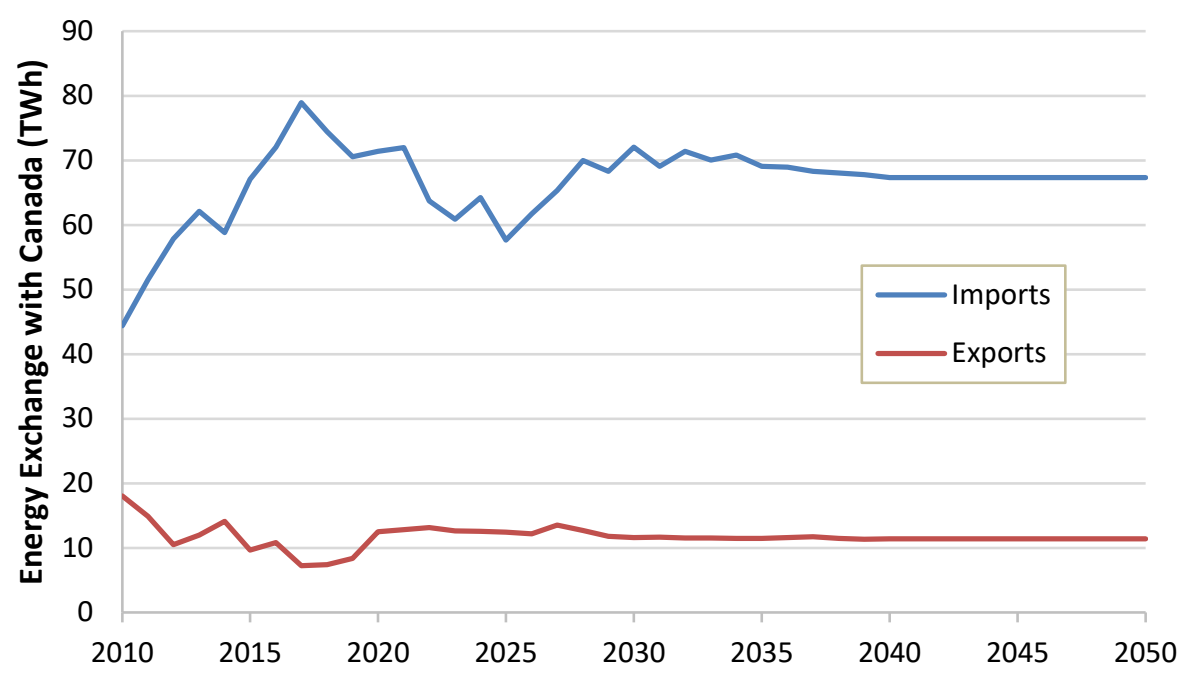

Figure 28. Imports from Canada to the United States and exports from the United States to Canada 


\section{Electricity System Operation and Reliability}

ReEDS finds the least-cost way of building and operating the electricity system while meeting certain requirements that are dominated by the need to meet electricity load while maintaining system adequacy and operational reliability.

\subsection{Electricity Load}

The primary constraint in ReEDS is to serve electricity load in each BA and time-slice. The enduse electricity load projection used in ReEDS is exogenously defined, ${ }^{39}$ based on scenarios from AEO2020 (EIA 2020). Hourly load profiles for 2012 are sourced directly from regional transmission organization (RTO) and independent system operator (ISO) websites for the applicable regions, with load data being requested at the most granular resolution available. For regions served by utilities, FERC Form 714 hourly load data are used. Hourly profiles for transmission zones are summarized and averaged to the 17 time-slice load profiles for the model BAs. These 2012 profiles are then scaled to ensure a match with the 2010 state-level annual retail energy load data from EIA's Electricity Data Browser (EIA 2015). Within a state in ReEDS, further adjustments to load profiles use county level load participation factors from Ventyx (2014). The regional growth factors for years after 2010 are calculated from the AEO scenario electricity consumption by census division. For each model year in ReEDS, the regional load profiles are scaled by regional growth factors, but the shape of the load profile is assumed to be constant throughout the study period. ${ }^{40}$ For capacity credit calculations, hourly load from the 2007-2013 weather years are used (see section 7.2).

The end-use load, described in the previous paragraph, is defined at the meter level. ReEDS includes inter-BA transmission system losses in the optimization but does not represent distribution losses, so the end-use load must be scaled up to busbar load to account for distribution losses. The 5\% distribution loss factor used for this conversion is estimated based on a combination of EIA and ReEDS numbers. ReEDS is required to generate sufficient power in each time-slice and BA (allowing for transmission of power but accounting for losses) to meet this busbar load. ${ }^{41}$

\subsubsection{Electrification}

Electrification of non-electric energy uses, creates significant regional and temporal shifts to the electric sector load representation. Detailed electrification load profiles were developed as part of the Electrification Futures Study (EFS) using EnergyPATHWAYS, which estimates hourly electric demand profiles, by state and subsector. (Sun et al. 2020) There are three levels of electrification load, Reference matches the ReEDS reference load using AEO 2018 disaggregated to the subsector level reaching $4790 \mathrm{TWh}$ of annual demand and $860 \mathrm{GW}$ peak demand. The Medium and High electrification cases layer on top of the Reference electrification

\footnotetext{
${ }^{39}$ An endogenous demand module is also available within ReEDS, though this module has not been used in any ReEDS analysis to date. More details on the module is available in the appendix under the section "Demand Module."

${ }^{40}$ Demand profiles and annual consumption can be altered with different plug-in hybrid electric vehicle and rooftop PV scenarios; however, absent these demand-side technologies, the profiles are assumed to be the same as those from 2010.

${ }^{41}$ Load balancing is implemented with equality constraints, so there is no physical representation of lost load and an associated cost.
} 
case the incremental growth from EnergyPATHWAYS. Medium electrification reaches 5800 TWh of annual demand and $1130 \mathrm{GW}$ of peak demand and High 6700 TWh of annual demand and $1320 \mathrm{GW}$ of peak demand. Hourly load representation with electrification scenarios uses a single 2012 weather year.

Electrification of natural gas consuming end uses impacts natural gas demand beyond the electric power sector. Alternate economy wide natural gas scenarios are available for use with electrification cases, which improve the representation of changing natural gas consumption outside of the electric sector.

\subsubsection{Demand Response}

Demand response is an available option in ReEDS based upon a representation developed as part of EFS. When active, however, demand response in ReEDS allows intraday shifting of electricity use during hours with high electricity prices or peak load. The flexible load profiles, considering power use subsectors, were generated using the EnergyPATHWAYS model. Flexibility cases are tied to the EFS electrification cases with three levels of demand response participation; 5\%-7\% (Current flexibility), 20\% (Base flexibility) 90\% (Enhanced flexibility). Using this capability, ReEDS can consider how flexible load is able to contribute towards resource adequacy and operating reserves. This capability has further impacts effecting investment and dispatch decisions.

\subsection{Resource Adequacy}

Resource adequacy is "the ability of supply- and demand-side resources to meet the aggregate electrical demand" (NERC 2016). Planning reserve requirements in ReEDS ensure adequate resource is available at all times, within an acceptable probability of failing to do so. In practice, this constraint is enforced by requiring the system to have sufficient firm capacity to meet the forecasted peak demand plus a reserve margin. This constraint is enforced for each season to accommodate the potential for peak net load to shift seasons as renewable penetration increases.

Each technology is assigned a capacity credit ${ }^{42}$ reflecting its expected availability when power is needed, typically during the highest-risk hours, which are ideally identified as the hours with highest loss of load probability (LOLP) ${ }^{43}$. For conventional non-variable generators in ReEDS, the $\mathrm{CC}$ is one.

\subsubsection{VRE Capacity Credit}

For VRE technologies (i.e., wind and solar), ReEDS estimates a seasonal capacity credit for each region/class combination via an hourly LDC approximation of expected load carrying capability $(\text { ELCC })^{44}$ performed between solve years. ${ }^{45}$ ELCC can be described as the amount of additional

\footnotetext{
${ }^{42}$ In ReEDS, capacity credit is defined as the fraction of nameplate capacity that contributes to the planning reserve requirement.

${ }^{43}$ LOLP is defined as the probability of a loss-of-load event in which the system load is greater than available generating capacity during a given period.

${ }^{44}$ ELCC is the contribution (units of MW that can then be reported as a fraction of the installed capacity to represent $\mathrm{CV}$ ) that an additional resource provides toward meeting the system's load while maintaining a fixed system-wide reliability level.

${ }^{45}$ When running intertemporally, these values are calculated after each intertemporal solve. The model solves, recomputes these values, then solves again, and continues until convergence is reached.
} 
load that can be accommodated by adding those generators while maintaining a constant reliability level. The "8760-based" methodology can capture the highest load and net load hours, which typically represent the highest risk hours, and can thereby support a reasonable representation of capacity credit. Details of this LDC approach, as well as a comparison against a former statistical method, can be found in Frew et al. (2017), though that approach has been expanded to consider 7 years of wind, solar, and load data (2007-2013) rather than just a single year.

The LDC approach for calculating capacity credit is based on explicit hourly $(8,760$ hours $\mathrm{x} 7$ years) tracking of time-synchronous load and VRE resources. The capacity method uses a capacity factor proxy that is applied to top 10 hours in load and net load-duration curves (LDCs and NLDCs) in each season to estimate ELCC by season. Figure 28 graphically represents the ReEDS capacity credit methodology. The LDC reflects the total load in a given modeling region, which is sorted from the hours of highest load to lowest load and is shown by the blue line. The NLDC represents the total load minus the time-synchronous contribution of VRE, where the resulting net load is then sorted from highest to lowest, as shown by the solid red line. ${ }^{46}$ The $\operatorname{NLDC}(\delta)$, which represents further addition of VRE resources, can be created by subtracting the time-synchronous generation of an incremental capacity addition from the NLDC, where the resulting time series is again sorted from highest to lowest; this is shown by the dashed red line.

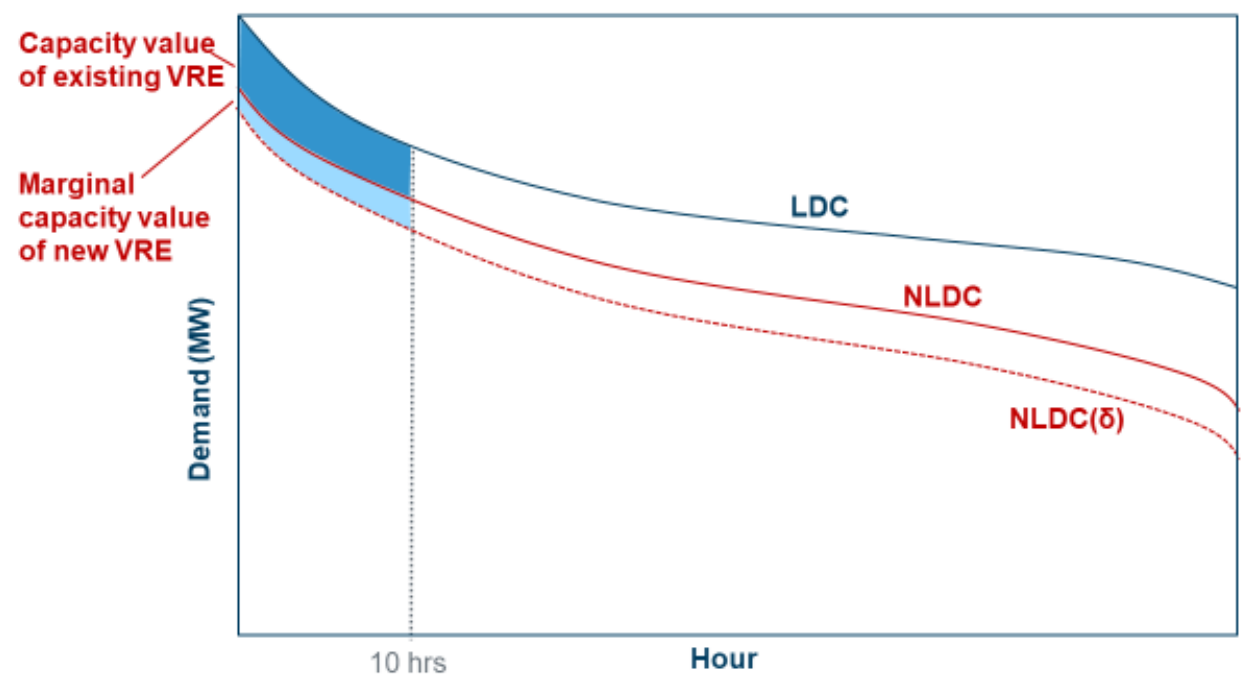

Figure 29. LDC-based approach to calculating CV

ReEDS calculates the ELCC as the difference in the areas between the LDC and NLDC during the top 10 hours of the duration curves in each season, as represented by the dark blue shaded area in Figure 28. These 10 hours are a proxy for the hours with the highest risk for loss of load (i.e., the LOLP). ${ }^{47}$ Similarly, the contribution of an additional unit of capacity to meeting peak load is the difference in the areas between the NLDC and the $\operatorname{NLDC}(\delta)$, as shown by the light blue shaded area in Figure 28. To ensure resource adequacy, ReEDS calculates capacity credit based on a 1,000-MW incremental capacity size of new solar and wind builds. These areas are

\footnotetext{
${ }^{46}$ Residual LDC, or RLDC, is an equivalent term to NLDC and is used in the literature.

${ }^{47}$ We currently use only a single year of wind, solar, and load data to calculate capacity. Expansion of this method to use multiple years of data would increase the robustness of this calculation, and it is currently under development.
} 
then divided by the corresponding installed capacity and number of top hours (10 hours per season in this case, although the number of hours can be adjusted by the user) to obtain a fractional seasonal-based capacity credit.

The resulting existing and marginal capacity credit ${ }^{48}$ values then feed into ReEDS to quantify each VRE resource's capacity contribution to the planning reserve requirement. Existing VRE capacity credit calculations are performed by region and technology. For all candidate VRE resources that might be built in the coming year, the marginal capacity credit is calculated by region, technology, and resource class. In all cases, the VRE profile is compared against the aggregated resource assessment region (RAR) load profile for determining the capacity credit (Figure 29). We use the RAR-level load profile to simplify the challenge of representing the ability of transmission to wheel VRE capacity from one BA to another. Essentially, we assume a copper plate within each RAR for the purpose of sharing VRE capacity. We use RAR regions rather than NERC regions for this assumption because transmission and trading tend to be more closely related to RAR regions than NERC regions.

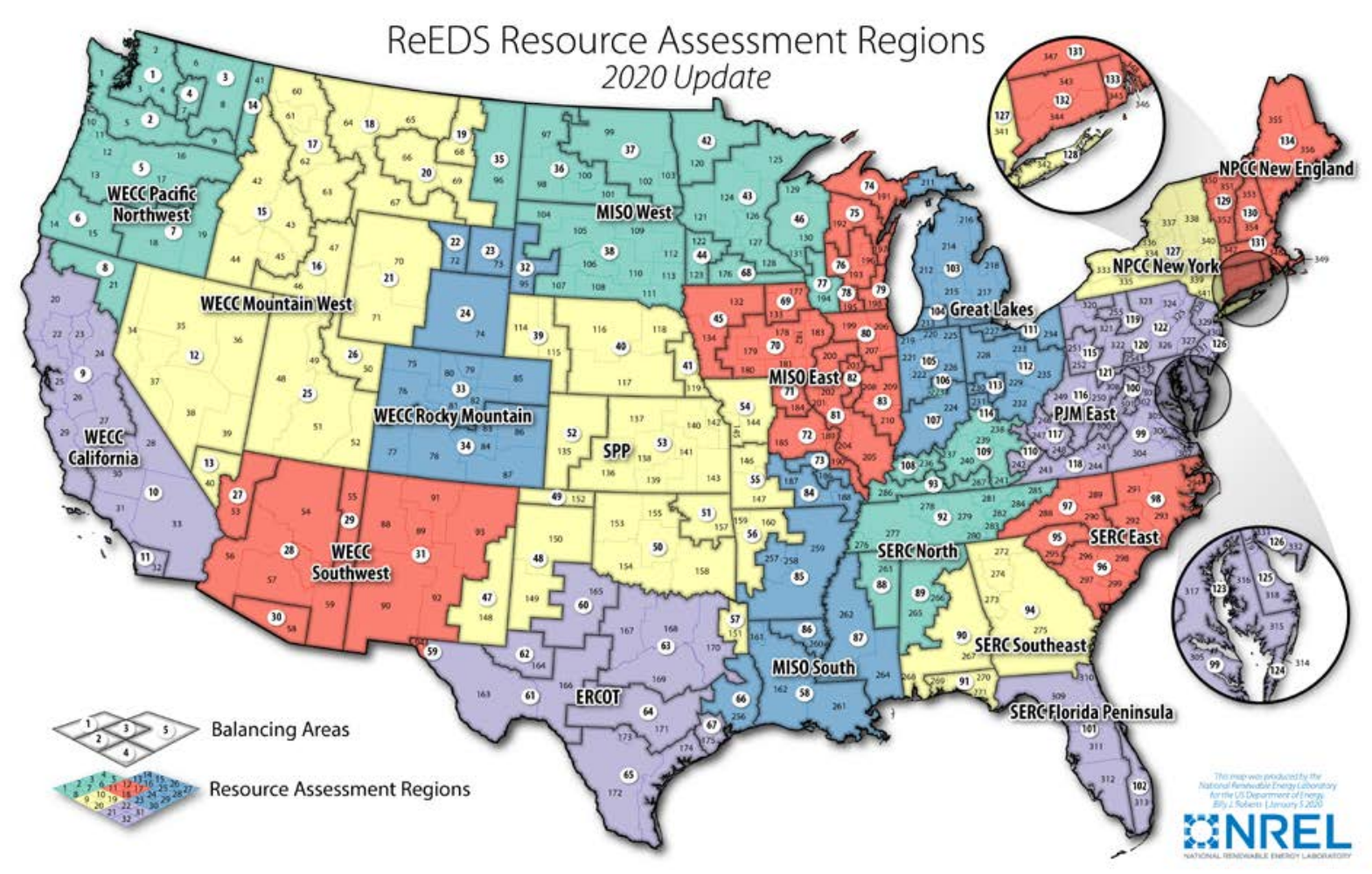

Figure 30. Map of ReEDS 134 BA regions and 18 resource assessment regions

\subsubsection{Storage Capacity Credit}

The storage capacity credit method in ReEDS characterizes the increase in storage duration that is needed to serve peak demand as a function of storage penetration. The potential of storage to serve peak demand is considered by performing several simulated dispatches against the load

\footnotetext{
${ }^{48}$ We refer to "existing" CV as the reliable capacity contribution from resources that have already been deployed in the model before the buildout of additional "marginal" resources.
} 
profiles within each of the resource assessment regions shown in Figure 29. Load profiles net of wind and PV generation are used to capture the effects of VRE resources on the overall net load profile shape in a region using the load, wind, and solar data from 2007-2013.

For each season and reliability assessment zone, a storage dispatch is simulated with peaking capacity prioritized over all other services (reflecting capacity market prioritization as discussed by Sioshansi, et al. (2014)).Transmission constraints are ignored within each reliability assessment zone for computational efficiency; this copper plate transmission assumption only applies to the capacity credit calculation - all transmission constraints are enforced in the actual planning reserve margin constraint and other system planning and operation modelling in ReEDS. Optimal coordination of dispatch among energy storage resources is also assumed. The transmission and coordination assumptions together allow for all storage within a reliability assessment zone to be represented as a single aggregate resource. The round-trip efficiency of this aggregated storage resource is assumed to be equal to the energy-capacity-weighted average round-trip efficiency of all installed storage capacity in that region.

All round-trip efficiency losses are included in storage charging. For example, a storage resource with a round-trip efficiency of $85 \%$ and a power capacity of $10,000 \mathrm{MW}$ can dispatch 10,000 MW to the grid for 1 hour using 10,000 MWh of energy capacity. However, when the same resource draws 10,000 MW from the grid for 1 hour, its state-of-charge increases by only $8,500 \mathrm{MWh}$.

Figure 30 illustrates the dispatch and calculation of the energy requirement for 5,000 MW of storage to receive full capacity credit in the NYISO region in 2020. First, the storage power capacity is subtracted from the peak load to set a net load maximum. Storage is required to discharge whenever the load profile exceeds this maximum, to ensure the peak net load (load minus storage in this example) is equal to the peak load minus the power capacity of the storage device. The storage is allowed to charge at all other times while ensuring the load maximum is not exceeded. 


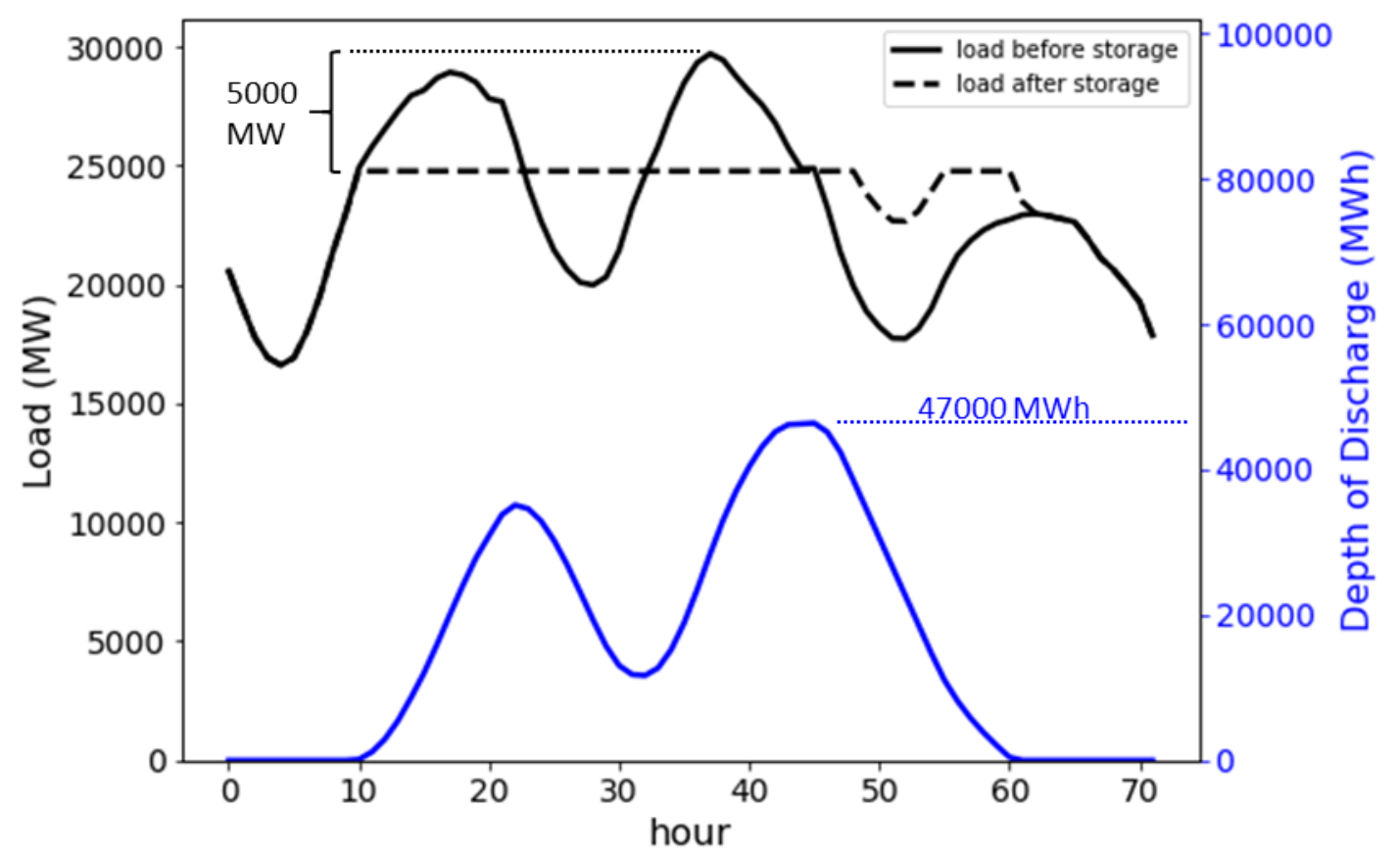

Figure 31: Model results for determining energy capacity requirements for storage in NYISO in 2020 for a 3-day example in August. 47,000 MWh is determined to be the necessary energy capacity for 5,000 MW of storage to receive full capacity credit. A depth of discharge of 0 indicates that the storage is full.

This dispatch is then used to calculate the energy requirement for storage to receive full capacity credit. At the beginning of the season, the state-of-charge of storage within the region is assumed to be full. The state-of-charge (or depth of discharge, as it is shown in Figure 304) is tracked over the course of the time-series with the maximum depth of discharge left unconstrained. This means the maximum depth of discharge value over the course of the season is equal to the amount of energy capacity that is needed for storage to receive full capacity credit. Dividing this energy by the power capacity used produces the minimum fleet-wide average duration (hours) for storage to receive full capacity credit. In the example in Figure 304, 5,000 MW of peak demand reduction from storage would require $47,000 \mathrm{MWh}$ of energy to receive full capacity credit, or a duration of 9.4 hours.

We repeat this process in each region for each season over a large range of storage power capacities (from $0 \%$ to $90 \%$ of peak demand in $100-\mathrm{MW}$ increments). The result of each dispatch is used to produce the "power-energy curve" in Figure 31, which allows us to calculate the marginal capacity credit for additional storage. The curve gives storage energy capacity that is required for full capacity credit as a function of storage penetration. ${ }^{49}$ At any point along the curve, the slope of the tangent to the curve represents the number of hours needed for marginal storage to receive full capacity credit. The incremental capacity credit of an additional unit of

\footnotetext{
${ }^{49}$ To account for forecasting errors and uncertainty in future loads, this curve is shifted by one hour of storage duration. Thus, 2-hour storage gets full capacity credit for meeting peaks that are 1 hour in duration, 4-hour storage gets full capacity credit for peaks that are 3 hours or shorter, etc.
} 
storage is equal to the duration of the additional unit installed divided by the duration requirement (slope) at the point on the curve corresponding to the installed storage penetration.

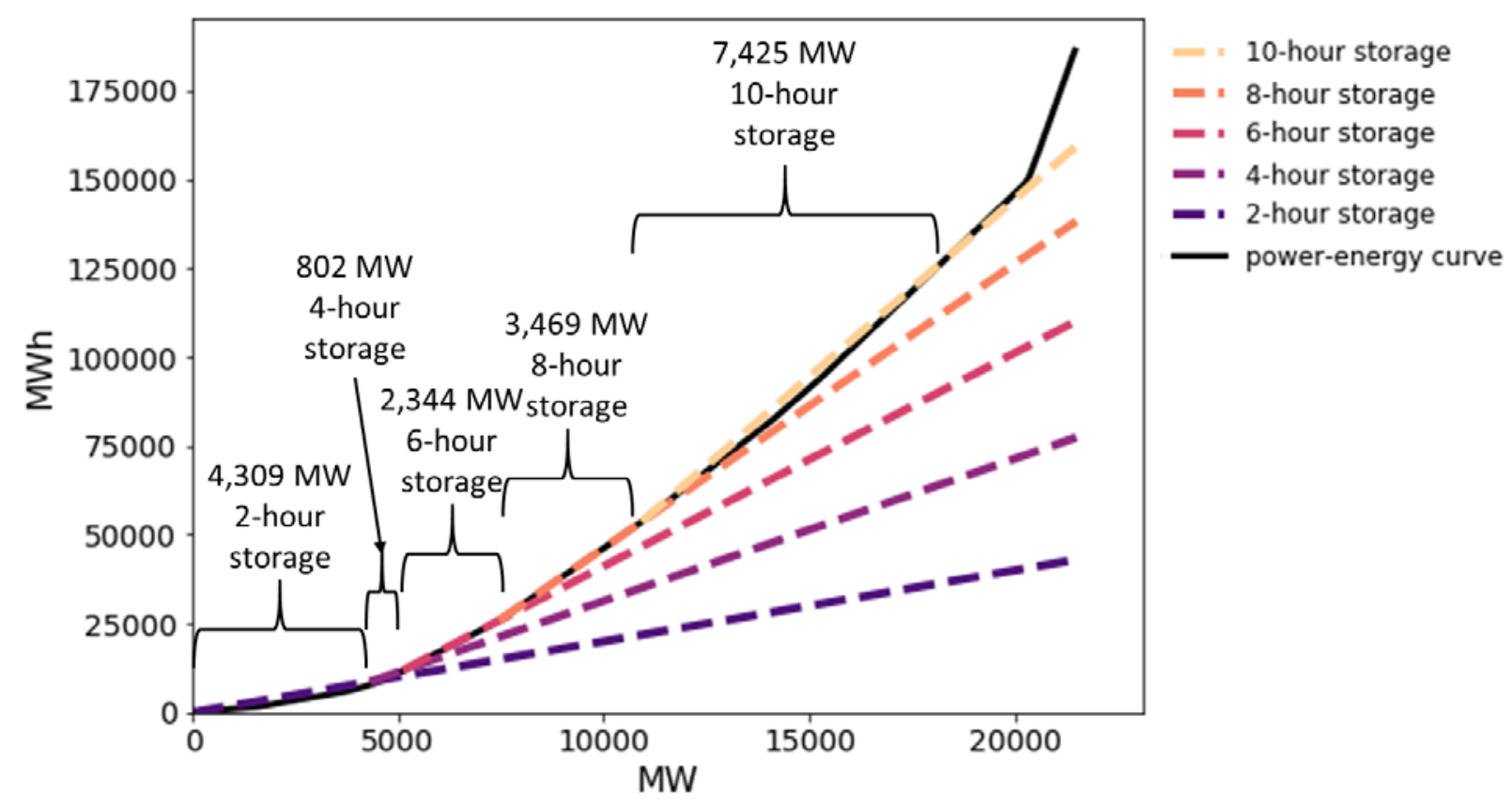

Figure 32: Determining storage peaking capacity potential in ReEDS. The slope of each dashed line is the power-to-energy ratio for the duration specified. Model results are for ERCOT in 2050. Note these capacities are cumulative, starting from the shortest duration and moving to the longest.

Figure 31 also illustrates how we create a more tractable solution by reducing the number of combinations considered. Storage in ReEDS is considered in several discrete durations, and these discrete durations are used to define the requirements needed to receive full capacity credit. Instead of a continuous function represented by the constantly varying slope of the power-energy curve, we create several discrete peak duration "bins" representing duration requirements. We start by plotting a line with constant slope equal to the shortest duration considered and find where it intersects with the power-energy curve. Then, starting from that point, we plot a line with the next shortest duration and find the point where it intersects with the power-energy curve, and so on, until we have obtained the cumulative limit for each discrete duration of storage to serve peak demand.

As an example, the first segment (having a slope of two) requires two hours to provide full capacity credit, even though it may be physically possible for some small amount of storage with a duration less than two hours to receive full capacity credit. In this example, at the point where 4,309 of 2-hour storage has been added, the lines intersect and the interpolation shifts to a slope of 4 hours, so a device with 4 hours is now required to achieve full capacity credit. The model is still allowed to build 2 hours storage, but it will only receive a 50\% (2/4) capacity credit, or the duration of the installed storage device divided by the discrete peak duration "bin". At each point, the marginal capacity credit is calculated by the physical capacity of the incremental unit, divided by the discrete duration requirement slope at any point along the curve. 
The limit for each duration to serve peak demand from Figure 32 is passed back to the ReEDS model, and the model optimizes the capacity credit of all storage (existing and new investments) together. One advantage of this is that it informs the model of when the capacity credit of storage should go up or down in response to changes in the net load profile shape. Another advantage is that total storage peaking capacity can be assessed in conjunction with other services storage can provide such as curtailment recovery, energy arbitrage, and operating reserves ${ }^{50}$, and a least-cost solution can be obtained overall.

Building on the results in the example above, Figure 326 shows the actual installed capacities in ERCOT from the low battery cost sensitivity scenario (discussed further in the results section). For each battery storage duration available to the model, installed battery capacity as well as the resource adequacy contribution determined by the model are shown. This resource adequacy contribution is the result of the model optimizing all grid services storage can provide, with capacity credit of all storage subject to the constraints of the peaking capacity limits from Figure 32.

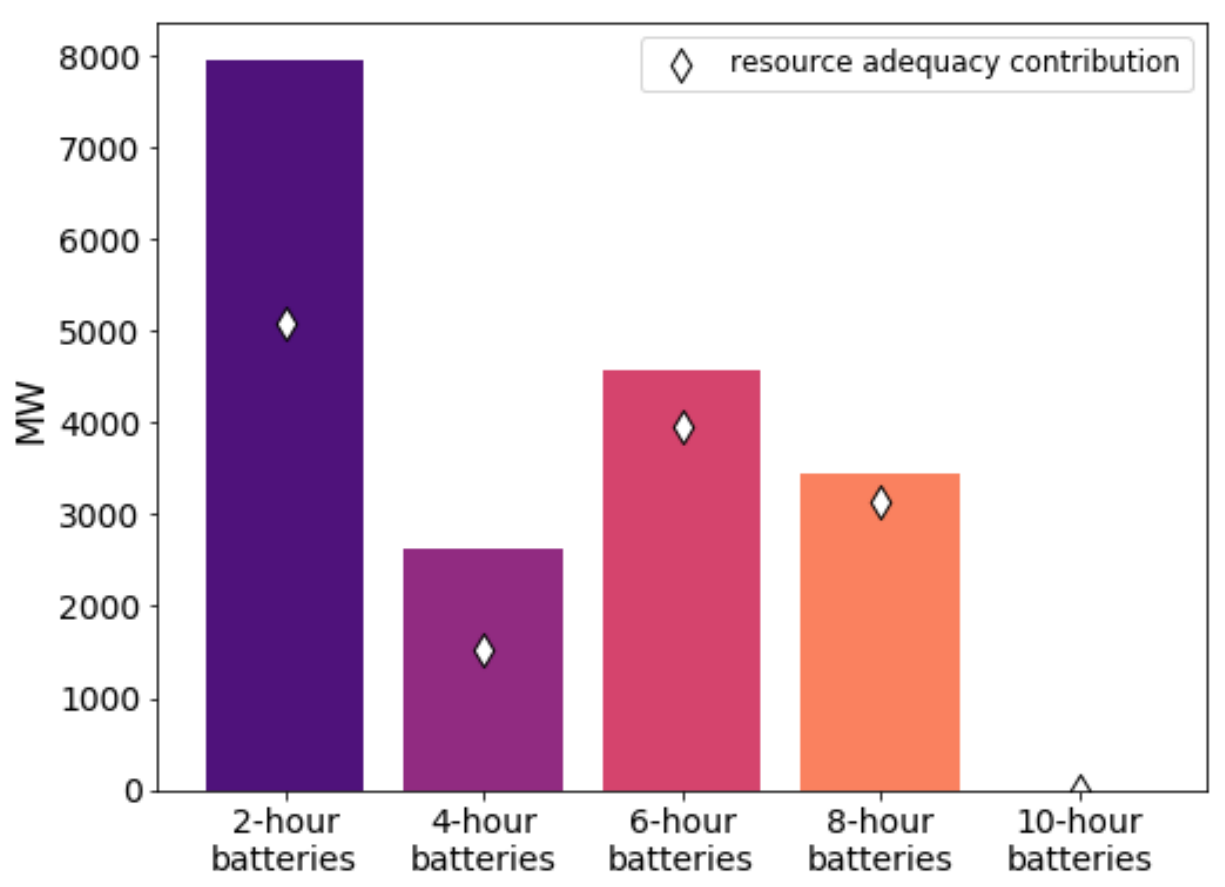

Figure 33: Installed battery capacity and resource adequacy contribution (capacity derated by capacity credit) in ReEDS. Model results for ERCOT in 2050.

This dynamic assessment of storage capacity credit enables the model to identify the limitations of energy storage to provide peaking capacity. It allows the model to identify the benefits, if they exist, of deploying short-duration resources at reduced capacity credit for energy arbitrage purposes or other grid services captured in the model. Alternatively, the model is also free to deploy longer-duration storage even when shorter durations would receive full capacity credit if

\footnotetext{
${ }^{50}$ It is worth noting that storage resources can provide resources to the electricity grid beyond peaking capacity and energy arbitrage. A capacity-expansion model like ReEDS has limited representation of these services, but to the extent that they are represented in the model these services are captured when assessing energy storage. See the ReEDS documentation (Cohen, et al., 2019) for more information on operating reserve representation in ReEDS.
} 
this leads to a least-cost solution for meeting all grid services. It also allows the model to respond to changes in net load shape from wind and PV deployment. The capacity credit of storage can change from one solve year to the next as a result of these net load profile shape changes.

Peaking capacity potential for longer durations of storage are also assessed within the model. The potential for 12- and 24-hour storage is included in the assessments described in Figure 31 and Figure 32. This is meant to accommodate the potential to derate the capacity credit of tenhour batteries and capture the capacity credit of pumped-hydro and compressed-air energy storage (which are assumed to have 12 hours of duration in ReEDS).

After this potential is determined, the actual storage capacity credit in ReEDS is determined within the optimization. The durations of storage devices that are installed by the model are evaluated based on the peaking capacity potential of storage (Figure 31). When determining the contribution of storage toward resource adequacy, two constraints were added to the model to make the capacity credit of storage dynamic and flexible to the many changes in the system that can affect storage capacity credit. The constraints for the formulation of storage capacity credit in ReEDS are as follows:

$$
\begin{gathered}
\sum_{p d} C_{p d, i d}=C_{i d} \\
\sum_{i d} C_{p d, i d} * c c_{p d, i d} \leq L_{p d}
\end{gathered}
$$

where $\mathrm{L}$ is the limit of peaking storage capacity (i.e. the megawatt values from Figure 5), $\mathrm{C}$ is the installed storage capacity, id is the duration of installed storage, pd is the duration of the peak demand contribution being considered, and cc is the capacity credit of an installed duration (id) of storage when applied to a specific peaking duration (pd). Storage capacity credit is equal to installed duration / peak duration, with a maximum of 1 . For each duration of installed storage id, its capacity can contribute to any duration of peak demand pd, but the total installed storage capacity $\mathrm{C}_{\mathrm{id}}$ must be equal to the sum of its contributions toward each duration of peak demand. And for each duration of peak demand pd, the total contribution of each installed duration id of storage capacity (adjusted for their capacity credit cc) cannot exceed the limit of peaking storage capacity L of that pd.

For example, consider a simple example where there is $100 \mathrm{MW}$ of peaking storage potential for each storage duration considered in ReEDS: two, four, six, eight, ten, 12, and 24 hours. In this example, $200 \mathrm{MW}$ of two-hour storage, $100 \mathrm{MW}$ of four-hour storage, and $50 \mathrm{MW}$ of six-hour storage are already installed. The model would optimize the capacity credit of storage by giving $100 \mathrm{MW}$ of two-hour storage full capacity credit for its two-hour contribution, the $100 \mathrm{MW}$ of four-hour storage full capacity credit for its four-hour contribution, and the $50 \mathrm{MW}$ of six-hour storage full capacity credit for its six-hour contribution (Figure 33). In this example, the peaking potential limit of two- and four-hour storage have been reached, so the remaining $100 \mathrm{MW}$ of two-hour storage would receive a capacity credit of $1 / 3$ and contribute $33.3 \mathrm{MW}$ for its six-hour peak demand contribution. The model could then build 16.7 MW of six-hour storage at full capacity credit, at which point the potential for six-hour storage to meet peak demand would be 
reached as well. The model would then be able to build two-, four-, or six-hour storage at a derated capacity credit with their contribution going toward the eight-hour peak demand "bin," or it could build 8-hour storage with full capacity credit.

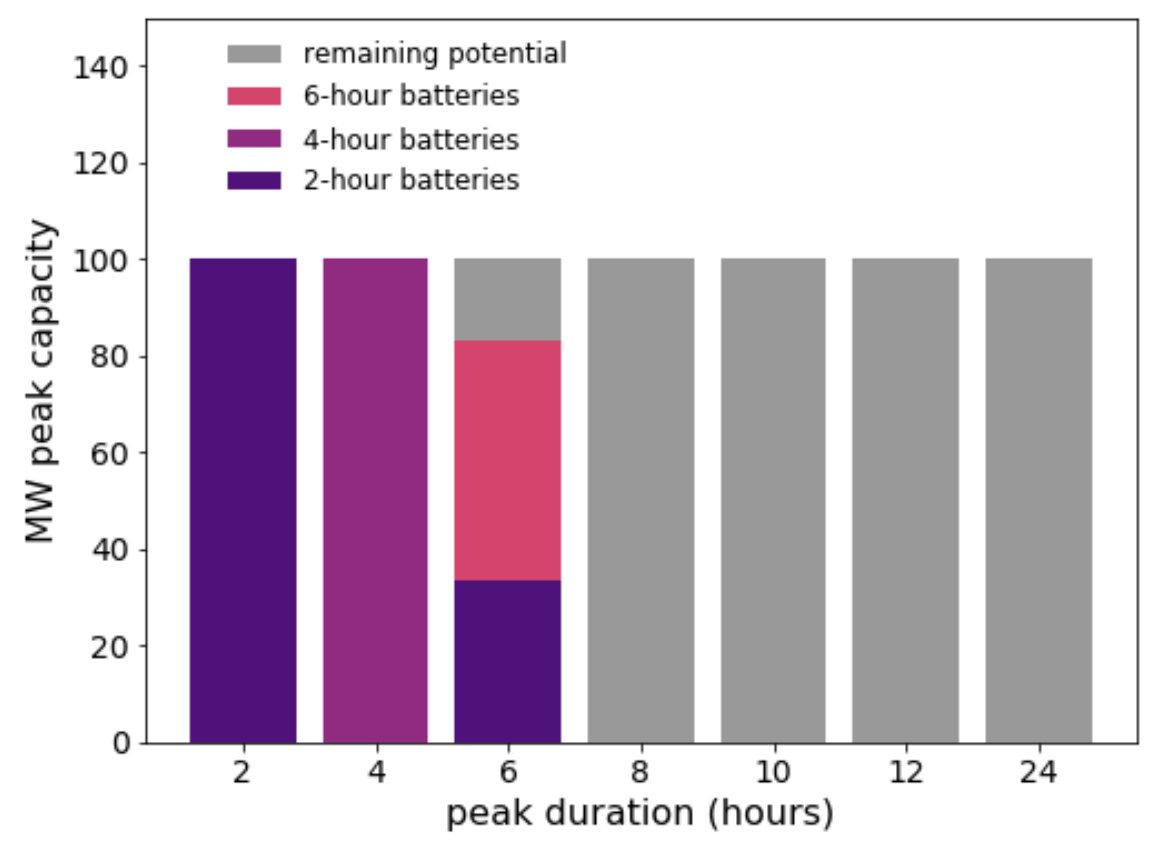

Figure 34. An example of storage capacity credit allocation in ReEDS. $200 \mathrm{MW}$ of 2-hour batteries exist but there is only $100 \mathrm{MW}$ of 2-hour peaking capacity potential. Since there is also $100 \mathrm{MW}$ of 4-hour batteries serving all $100 \mathrm{MW}$ of 4-hour peaking storage potential, the remaining $100 \mathrm{MW}$ of 2-hour storage provides $33.3 \mathrm{MW}$ towards the 6-hour peaking storage potential.

Now consider the same example but in addition to the two-, four-, and six-hour storage installed, there is also $300 \mathrm{MW}$ of pumped-hydro storage in this region (Figure 34). Pumped-hydro storage in ReEDS has a duration of 12 hours, but the potential for 12-hour storage to serve peak demand is only $100 \mathrm{MW}$. Rather than giving the remaining $200 \mathrm{MW}$ of pumped-hydro a capacity credit of $1 / 2$ for its contribution to the 24-hour peak demand period, it is optimal for the model to fill the 10- and 8-hour peak demand "bins" with the remaining pumped-hydro capacity at full capacity credit since there is no other storage allocated to those peak demand periods. Now, after the model builds 16.7 MW of six-hour storage at full capacity credit, the 8-, 10-, and 12-hour bins are already filled by pumped-hydro storage. So, if the model wants to build additional storage capacity, it will shuffle around the allocated storage capacity to the optimal "bins" as it fills the 24-hour bin. In this example, if any 8-hour storage is built it will be allocated to the 8-hour bin and some pumped-hydro capacity will be pushed out of that bin and re-allocated to the 24-hour bin at $1 / 2$ capacity credit ( 12 hours / 24 hours). So, even though the duration required for storage to receive full capacity credit at this point is 24 hours, 8 -hour storage would receive a marginal capacity credit of $1 / 2$ because there is an excess of 12 -hour storage already installed in the system. 


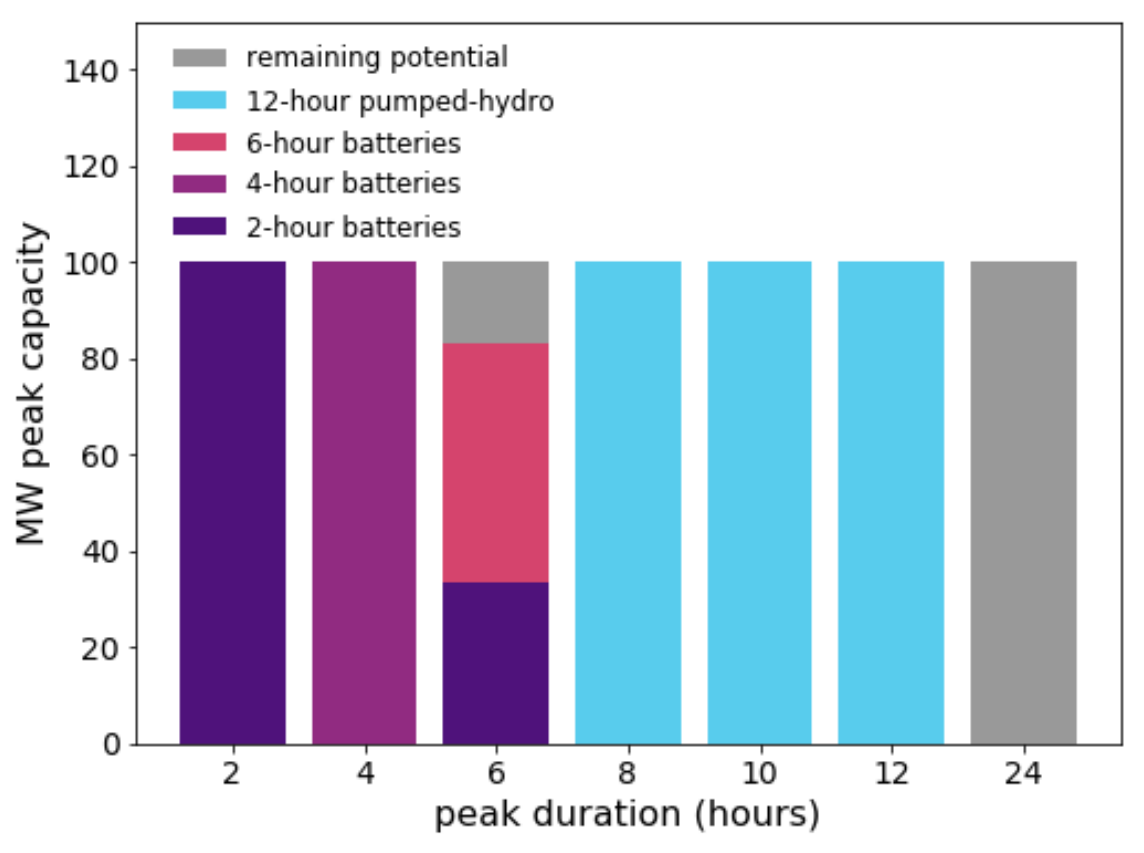

Figure 35. The same example from Figure 33 but this time with $300 \mathrm{MW}$ of 12-hour pumped hydro storage. Since there is only $100 \mathrm{MW}$ of 12 -hour peaking potential, remaining pumped-hydro capacity is allocated to serve shorter peak durations.

Storage capacity credit is sensitive to a variety of factors on the power system, so rather than ignoring the many factors that can influence storage capacity credit we simply pass the model information on what storage could do to serve peaking capacity based on load shape and storage duration and then allow the model to choose the least-cost option based on the suite of available resources and the entire set of storage revenue streams that are represented within the ReEDS model.

Denholm et al. (2019) and Frazier et al. (2020) demonstrated how the storage peaking potential of storage interacts with VRE penetration.

\subsubsection{Planning Reserve Margins}

The planning reserve margin fractions applied in ReEDS are based on reserve margin requirements for NERC reliability subregions (NERC 2010) (see Figure 35). Each ReEDS BA must meet the requirement, but regions can engage in bilateral contracts for firm capacity subject to transmission limits on AC or DC corridors. The planning reserve margin is enforced seasonally such that each BA much meet the reserve margin requirement in each of the four seasons. 


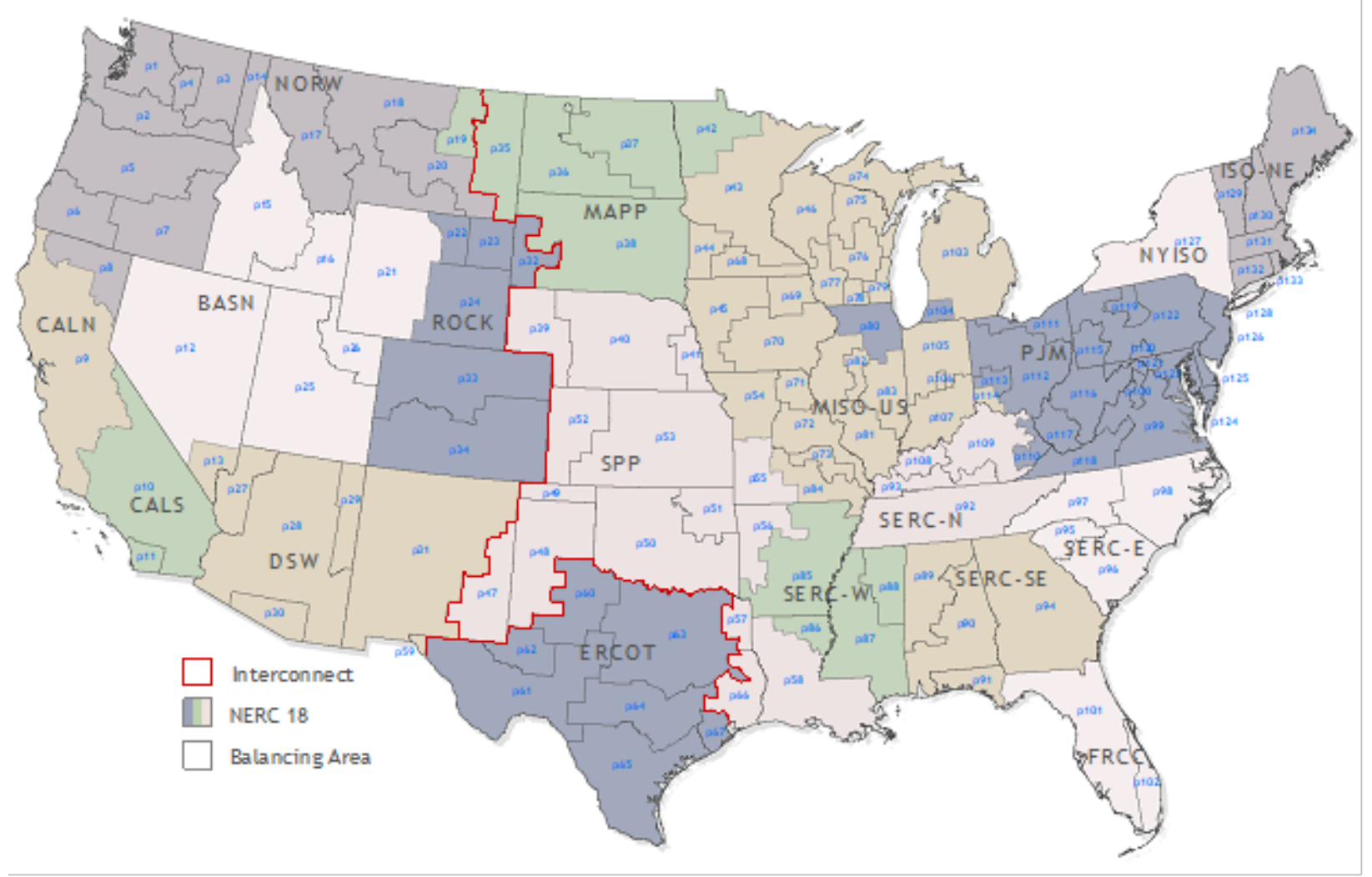

Figure 36. Map of ReEDS 134 BA regions and 18 NERC reliability subregions as applied to the ReEDS BA regions

The planning reserve margin is constant over time for all regions except ERCOT. Because ERCOT was below its NERC-recommended level in 2018-2020, the ERCOT reserve margin is set to the actual levels of $10.9 \%$ and $8.6 \%$ for 2018 and 2019 , respectively, and at the projected level of 10.6\% for 2020 (ERCOT 2019). The years from 2021 and onward are set at 13.75\%, and future planning reserve margin levels are anticipated to meet or exceed that target from 2021 and onward.

\subsection{Operational Reliability}

In addition to ensuring adequate capacity to satisfy long-term planning reserve requirements, ReEDS requires operational reliability - that is, the ability to continue operating the bulk-power system in the event of a sudden disturbance (NERC 2016). In practice, ancillary reserve requirements ensure there is sufficient flexibility from supply-side and demand-side technologies to rebalance fluctuations in generation and demand.

ReEDS represents three type of operating reserve products, including, spinning, regulation, and flexibility reserves (Cole, Eurek, et al. 2018). The requirement specified for each product in each time-slice is a function of load, wind generation, and photovoltaic capacity (during daytime 
hours). ${ }^{51}$ Technologies providing these reserve products must be able to ramp their output within a certain amount of time (Table 22).

Table 22. Summary of Operating Reserve Requirements

\begin{tabular}{|c|c|c|c|c|}
\hline $\begin{array}{l}\text { Reserve } \\
\text { Product }\end{array}$ & $\begin{array}{l}\text { Load Requirement } \\
(\% \text { of load) })^{a}\end{array}$ & $\begin{array}{l}\text { Wind Requirement } \\
\text { (\% of generation) })^{\mathbf{b}}\end{array}$ & $\begin{array}{l}\text { PV Requirement } \\
(\% \text { of capacity })^{b}\end{array}$ & $\begin{array}{l}\text { Time Requirement } \\
\text { to Ramp (minutes) }\end{array}$ \\
\hline Spinning & $3 \%$ & - & - & 10 \\
\hline Regulation & $1 \%$ & $0.5 \%^{c}$ & $0.3 \%^{c}$ & 5 \\
\hline Flexibility & - & $10 \%$ & $4 \%$ & 60 \\
\hline
\end{tabular}

a See Lew et al. (2013, Section 5.3.4).

${ }^{b}$ Reserve requirements for wind and PV are derived from the outcomes from Lew et al. (2013).

The flexibility requirement for wind is estimated as the ratio of the change in the reserve requirement to the change in wind generation from the Lew et al. High Wind scenario; the requirement was estimated similarly for PV using the Lew et al. High Solar scenario.

c The estimated regulation requirements $(0.5 \%$ wind generation and $0.3 \% \mathrm{PV}$ capacity) are based on incremental increases in regulation reserves across all scenarios in Lew et al. (2013).

All ancillary reserve requirements must be satisfied in each BA for each time-slice; however, reserve provision can be traded between BAs using AC transmission corridors. Trades are only allowed within an RTO and not across RTO boundaries. The amount of reserves that can be traded is limited by the amount of carrying capacity of an $\mathrm{AC}$ transmission corridor that is not already being used for trading energy.

The ability of technologies to contribute to reserves is limited by the ramping requirement for a given reserve product, the plant ramp rate, and online capacity (Table 23). Online capacity is approximated in ReEDS as the maximum generation from all time-slices within a modeled day. Reserves can be provided by generation and storage technologies that are turned on but not fully dispatched in a time-slice. In addition, demand-side interruptible load can also contribute to reserve requirements, if enabled in a scenario. Nuclear, PV, and wind are not allowed to contribute toward the supply of reserves.

The cost for providing regulation reserves is represented in ReEDS using data from (Hummon et al. 2013); see Table 24. Because ReEDS does not clearly distinguish between coal fuel types, $\$ 12.5 / \mathrm{MWh}$ is the assumed regulation cost for all coal technologies. The cost of providing regulation reserves from Gas-CT, geothermal, biopower, land-fill gas, and CAES is assumed to be the same as oil/gas steam.

\footnotetext{
${ }^{51}$ The PV reserve requirement is only valid during daytime hours when the PV systems are operating. In addition, the requirement is a function of capacity rather than generation because reserves are especially important around sunrise and sunset when PV generation is low.
} 
Table 23. Flexibility Parameters of the ReEDS Generation Technologies

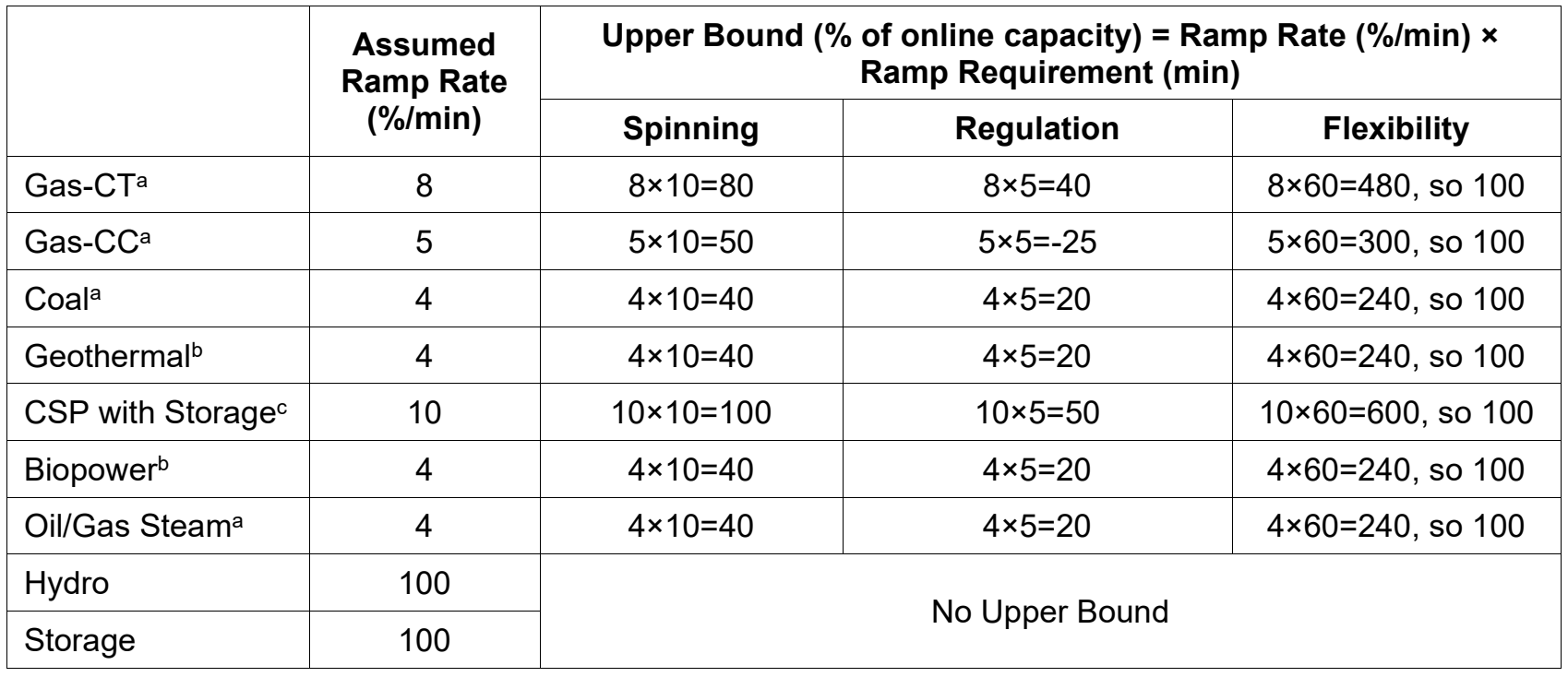

a See (Bloom et al. 2016b).

b Geothermal and biopower values are assumed to be the same as oil/gas steam units. In practice, geothermal plants typically do not ramp given their zero or near-zero variable costs, and therefore only provide energy and not operating reserves.

c. See (Jorgenson et al. 2013).

Table 24. Cost of Regulation Reserves

\begin{tabular}{|l|c|}
\hline Generator Type & $\begin{array}{l}\text { Cost of Regulation } \\
\text { Reserves (2013\$/MWh) }\end{array}$ \\
\hline Supercritical Coal & 15 \\
\hline Subcritical Coal & 10 \\
\hline Combined Cycle & 6 \\
\hline Gas/Oil Steam & 4 \\
\hline Hydro & 2 \\
\hline Pumped Storage Hydropower & 2 \\
\hline
\end{tabular}

\subsection{Curtailment}

Curtailment is a reduction in the output of a generator from what it could otherwise produce given available resources. Most renewable generators, being resource dependent and lacking fuel costs, are subject to curtailment that reduces plant revenue, in particular, when there is ample generating capacity committed, insufficient load to absorb it locally, and limited options to export surplus power via the transmission network. The economics of investment in renewable generators can be impacted by the amount of curtailment to which a plant will be subjected, so ReEDS estimates curtailment fractions for both existing renewable generators and candidate sites.

The Augur module is a new capability in ReEDS that is run in between ReEDS solve years. The module computes several nonlinear parameters that are then fed back into ReEDS as marginal 
linear values for the next solve year (see Figure 36). The primary purpose of Augur is to accurately compute these marginal values using chronological, hourly data of wind, PV and load. Augur computes the following parameters:

- Storage energy arbitrage revenue

- Amount of storage by duration that can receive full capacity credit (see Section 7.2.2)

- Firm capacity contribution of existing VRE generators (see Section 7.2.1)

- Marginal capacity credit of new wind and PV generators (see Section 7.2.1)

- Ability of storage to recover curtailed energy (differentiated by curtailment from existing generators versus from new generators)

- Curtailment from existing VRE generators

- Curtailment reduction potential of new transmission lines

These parameters require a finer time resolution than the ReEDS time-slices provide and are particularly important for accurately modeling storage and VRE deployment in capacity expansion. The ReEDS Augur module workflow is summarized in Figure 36.

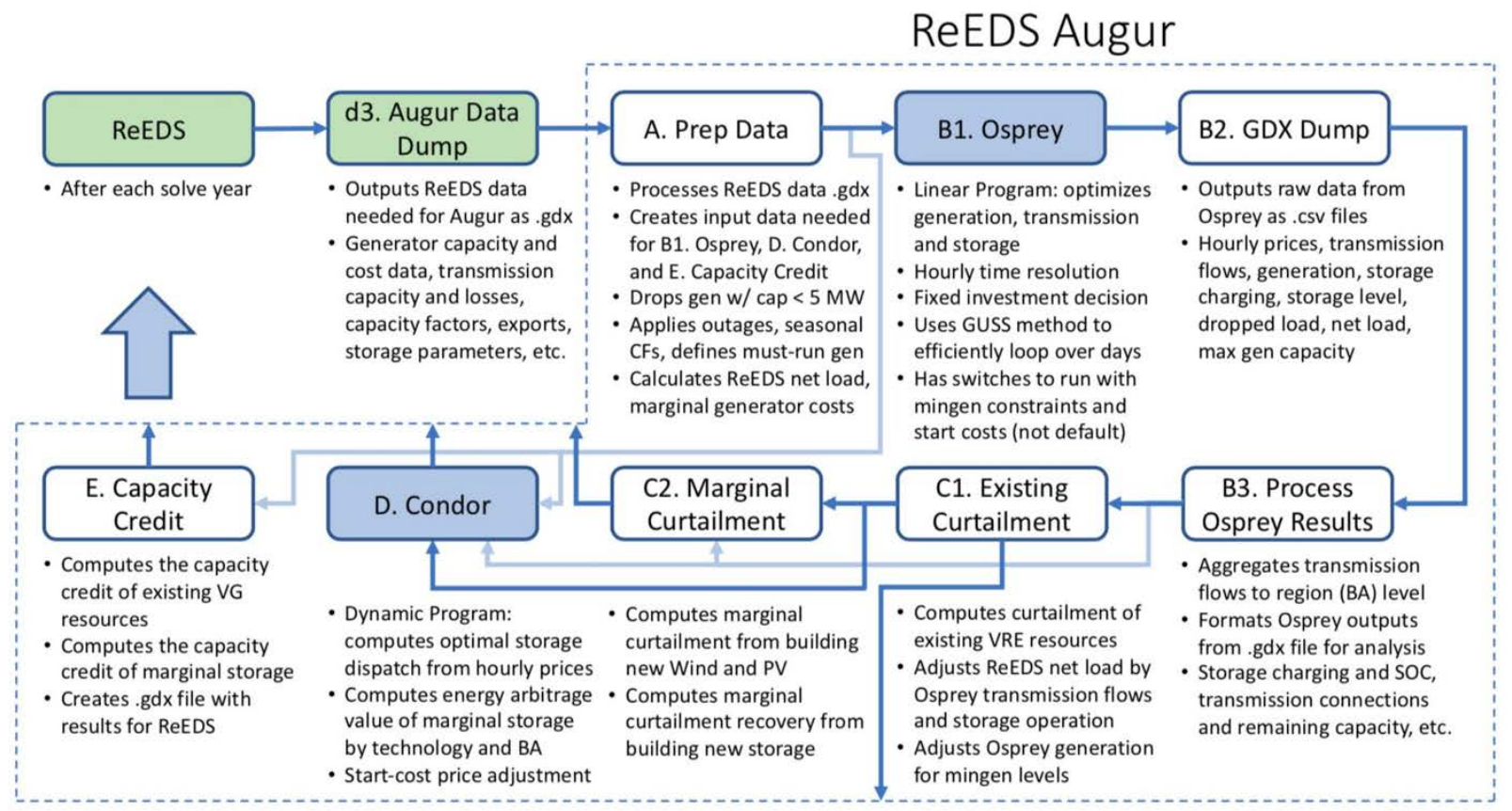

Figure 37: Summary workflow of the ReEDS Augur module. BA is balancing area, CF is capacity factor, GDX is GAMS (General Algebraic Modeling Language) Data eXchange, and SOC is state of charge. The names of the different elements of the flow chart correspond to the names of the scripts that are part of the ReEDS model.

A core piece of the ReEDS Augur module is a linear program we call Osprey that optimizes generation, transmission, and storage at the regional level across the entire United States at an hourly time resolution. This yields hourly prices by region which are then used in a dynamic program we call Condor to compute the energy arbitrage value of marginal storage. The storage deployment from Osprey is used to compute existing and marginal curtailment rates. The storage capacity credit contribution is computed from ReEDS results as previously described in (Frazier 
et al. 2020). The Augur results are aggregated to the time-slice level before being passed back to ReEDS, giving it the marginal values for the next solve year.

\subsubsection{ReEDS Output Processing}

After each ReEDS solve year, the relevant ReEDS outputs are prepared for Augur. In particular, the load growth for the following year is applied, and the generators scheduled for retirement in the next year are removed. Hourly net loads are computed for the entire year using resource profiles from the Renewable Energy Potential (reV) model (Maclaurin et al. 2019), and these are converted into EST so that energy trading among regions is not being distorted by differences in time zones. Generators with less than 5 MW of capacity are dropped and thus ignored in Augur. Generator operating costs are computed from ReEDS' fuel costs, heat rates, and variable operations and maintenance (VOM) costs. Exports to Canada are represented as additional load in regions where that occurs. These ReEDS outputs are then formatted and passed to Osprey.

\subsubsection{Osprey Linear Program}

Osprey is a linear program (LP) that optimizes generation, transmission flows, and storage operation across the 134 model regions at an hourly resolution. It does this quickly enough to run in between each ReEDS solve year without significant computational expense. This is accomplished because each day is solved independently, with storage generators being required to start and end at the same state of charge but being allowed to choose that state of charge. Furthermore, the following generator constraints are not enforced to reduce solve time: minimum generation levels, ramp rates, mean time between start-up and shut-down, start-up costs., and operating reserves. Despite these omissions, the transmission and generation behavior and the resulting hourly regional price profiles are sufficient to enable energy arbitrage values to be computed accurately (see Method Validation below). Additional adjustments to account for startup costs and minimum generation levels are applied downstream in other Augur components.

To get accurate generation behavior while ignoring start-up costs and minimum generation levels, certain generators are treated as must-run generators and are given seasonal capacity factors according to their seasonal outage rates. These include nuclear, geothermal, and non-dispatchable hydropower. To simplify the optimization problem, the contribution of these must-run generators is removed from the net load profile and the adjusted net load profile is used in Osprey. For dispatchable hydro, the seasonal hydro energy budget is used to create a minimum daily generation requirement. Canadian imports are treated in the same way as dispatchable hydro.

Transmission losses are modeled using the same loss values as ReEDS (1\% losses per 100 miles of transmission distance). Dropped load is allowed in order for the model to always be feasible. And in order to reduce degeneracy among transmission losses, storage losses, and VRE curtailment, we apply a small cost $(\$ 0.001 / \mathrm{MWh})$ to storage discharging and to transmission flows.

To solve the Osprey linear program efficiently, the GAMS Gather-Update-Solve-Scatter (GUSS) method is used to loop through the days while keeping the optimization program in memory. The parameters for each day are updated, including the adjusted net load profile, the maximum generation capacity available, and the daily required dispatchable hydro generation. As mentioned previously, the storage generation is constrained to start and end at the same level, effectively giving the optimization a circular boundary condition where it views future days as being identical 
to the current day. ${ }^{52}$ This method does not allow interday energy arbitrage and thus is currently unsuitable for long-duration storage.

\subsubsection{Osprey Results}

Osprey outputs include hourly prices, transmission flows, generation levels, storage charging, and storage levels, all by region and generator. The prices are taken as the marginal from the load balance constraint.

These results are processed for use in further analysis downstream. The transmission flows are aggregated to the region level, and the transmission-adjusted net load is computed by adjusting the regional net load for the regional transmission, with the must-run generators' contributions added back in.

The hourly prices that come out of Osprey are adjusted to account for generator start-up costs. For each hour, the number of transmission-connected regions ${ }^{53}$ are computed using the NetworkX Python package (Hagberg, Swart, and S Chult 2008). For each generator start, the start cost is applied by spreading it across the number of hours that the generator is on for a given day. Each generator's "bid price" is computed as its operating cost plus the amount needed to recover the start costs for that day. In each transmission-connected region and for each hour, the maximum generator bid price is computed, and the new price is the maximum of either the original Osprey price or the maximum generator bid price. Validation against PLEXOS production cost modeling results indicated that the start-costs are primarily responsible for the hourly price spikes, and removing start-costs from PLEXOS yielded price profiles that were very similar to those of Osprey. As the primary purpose of these prices is to compute the energy arbitrage value of storage using a price-taking dynamic program, spreading the start costs over the hours the generator was on compared to applying them all at once at the start will on average have a reasonably similar effect.

\subsubsection{Existing Curtailment}

With the generation profiles from Osprey, the curtailment from existing VRE resources can be computed. This method includes an adjustment for minimum generation levels that were ignored in the Osprey linear program. The curtailment of existing VRE resources is computed as follows:

- Generators that are on but below their minimum generation level are ramped up to that level.

\footnotetext{
52 This assumption was tested under a wide range of scenarios, including scenarios with up to $100 \%$ renewable energy, and it was never found to result in meaningful differences with other options that solved for 48 hours but only implemented the first 24 hours.

53 A transmission-connected region is a set of balancing areas that do not have transmission congestion between them. These transmission-connected regions are necessary for handling degeneracy in estimating curtailment. For example, if region A and B are connected with a $100 \mathrm{MW}$ transmission line, but using less than $100 \mathrm{MW}$ of that line, they would be a transmission-connected region. If region A is curtailing VRE, then that means region B does not have the capability to accept that energy, otherwise the transmission line would be used to move the curtailed power to region $B$. This also means that if new VRE is added in region B (which has no curtailment), the new VRE would have to be curtailed because region $\mathrm{B}$ already has the opportunity to import free power from region A. Transmission-connected regions can be different in each our because the transmission lines that are congested can change each hour.
} 
- Generators that are on but above their minimum generation level are ramped down to that level.

- The adjusted generation level is computed by summing the generation for each region.

- Storage generation is added to the transmission-adjusted regional net load.

- Curtailment is computed by subtracting the transmission-and-storage-adjusted net load from the adjusted generation levels for each region.

- The curtailment is required to be less than or equal to the VRE generation in that region.

In recognition that some aggregated ReEDS generators are much larger than actual generators, the minimum generation level is computed differently for generators above $500 \mathrm{MW}$ of capacity. For these large generators, the hourly minimum generation level is computed as a fraction of the generation. For all other generators, it is computed as a fraction of the generator capacity. For large generators in hours when the generation is below $500 \mathrm{MW}$, the minimum generation level is computed as a fraction of $500 \mathrm{MW}$ instead of the generation. Figure 37 summarizes this minimum generation level adjustment method. The minimum generation fractions used are shown in Table 25, and come from the Western Electricity Coordinating Council Transmission Expansion Planning Policy Committee Database (WECC 2015).

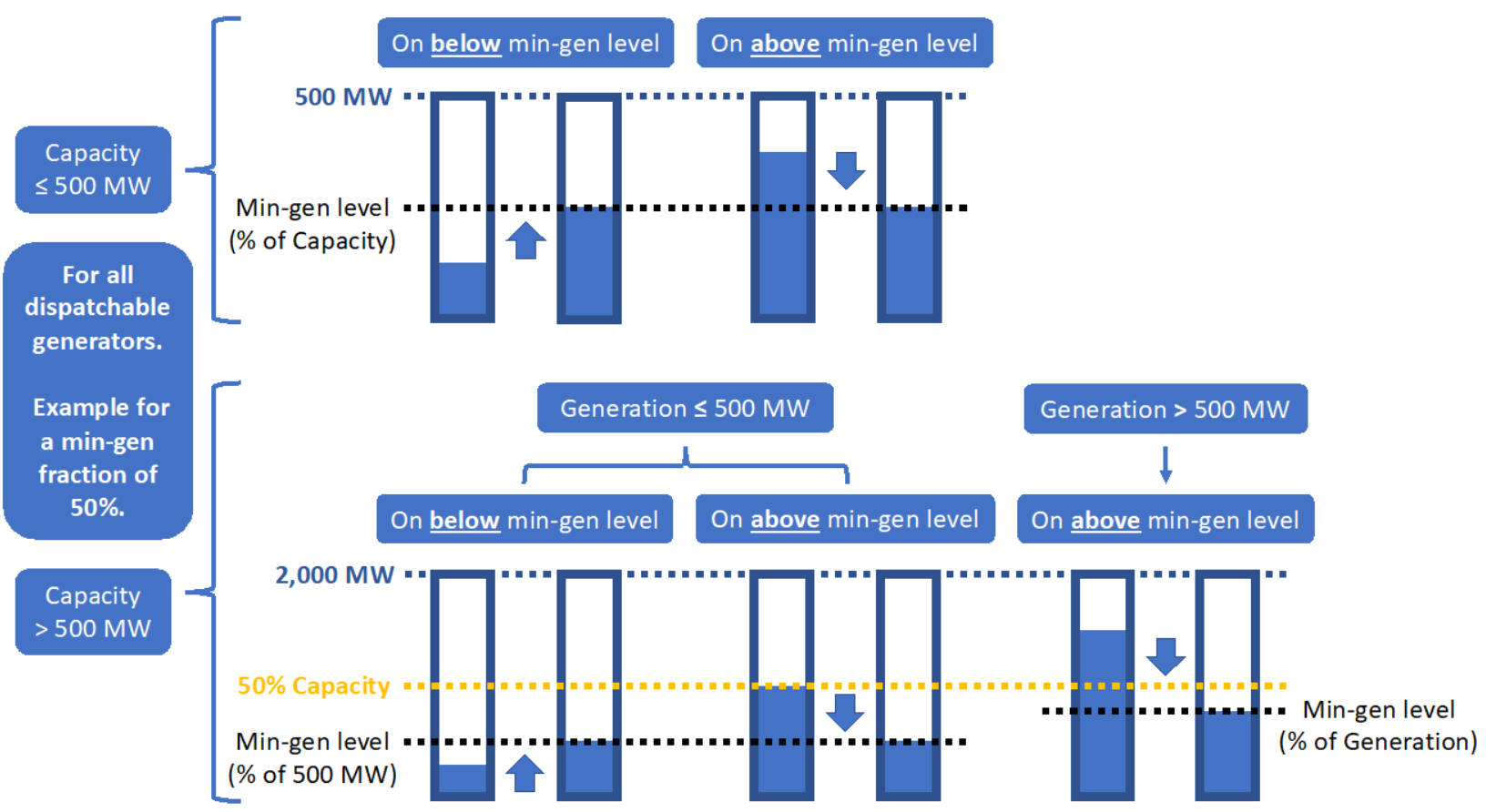

Figure 38: Summary of hourly minimum generation (min-gen) level adjustment used to compute existing curtailment. Example shown for a generator with a $50 \%$ min-gen fraction. 
Table 25: Generator Properties Used in Augur. Systems with carbon capture and sequestration (CCS) use the same values as the corresponding non-CCS systems.

\begin{tabular}{|l|r|r|}
$\begin{array}{l}\text { Technology } \\
\text { Type }\end{array}$ & $\begin{array}{l}\text { Start Cost } \\
\text { (\$/MW) }\end{array}$ & $\begin{array}{l}\text { Minimum } \\
\text { Generation Level } \\
\text { (fraction of capacity) }\end{array}$ \\
\hline Biopower & 5.3 & 0.3 \\
\hline Coal & 155.8 & 0.4 \\
\hline CSP & 0 & 0.2 \\
\hline Gas-CC & 83.7 & 0.55 \\
\hline Gas-CT & 33.9 & 0.45 \\
\hline Geothermal & 0 & 0.5 \\
\hline Landfill-gas & 5.3 & 0.3 \\
\hline Nuclear & 116.6 & 1 \\
\hline Oil/gas steam & 33.9 & 0.45 \\
\hline
\end{tabular}

\subsubsection{Marginal Curtailment}

Several different marginal curtailment parameters are computed from the Osprey results and the existing curtailment calculation. The regional net load adjusted for transmission and storage is further adjusted so that negative values represent hourly curtailment. The marginal PV and wind curtailment are computed by adding 1,000 MW of PV and wind capacity in each region and for each resource class. The marginal curtailment rate is computed as the fraction of this additional energy that cannot be used by the system, measured by subtracting the added generation from the adjusted net load profile and re-computing curtailment. These 1,000-MW marginal additions are done separately for each region and resource class.

The marginal storage curtailment recovery potential is computed using the same adjusted net load profiles from Osprey. One hundred megawatts of storage are added in each region to calculate the curtailment that can be reduced in that region via new storage. This is done separately for each storage duration. Cross terms are also calculated by adding both new storage and new wind or PV to each region to calculate the curtailment from new wind or PV that can be recovered by new storage.

Transmission is considered during these calculations by evaluating whether new wind or PV generation can be shared with other regions. For example, if a neighboring region has a net load of 1,000 MW in a given hour, and the transmission line to that region has 1,000 MW of unused capacity, up to $1,000 \mathrm{MW}$ of $\mathrm{PV}$ or wind generation can be shared with that region during that hour.

Marginal curtailment reduction rates are also computed for transmission by adding 1,000 MW of new transmission between regions and determining the curtailment impacts from that new transmission.

\subsubsection{Condor Dynamic Program}

The storage energy arbitrage value is computed by Condor, a price taker model that finds the optimal storage dispatch given hourly energy prices and an amount and a duration of storage. It 
works by discretizing the storage dispatch problem and dividing it into independent subproblems of identical form, solving them all exhaustively and recursively using backward induction and then constructing the optimal storage dispatch given a starting condition. It uses the regional prices from Osprey that have been adjusted for start costs and dispatches storage of each duration separately to find the maximum possible revenue. It runs at an hourly resolution for the entire year, making decisions in each hour that respect constraints on energy capacity and power. Since Condor uses perfect foresight, the storage capacity of each storage resource is reduced by one hour in order to make the values more realistic. This is consistent with estimates that forecast accuracy accounts for roughly $20 \%$ of the energy value of storage (Dunbar et al. 2014). In order to avoid doublecounting the energy arbitrage benefits of storage that was charged on otherwise curtailed energy and the curtailment recovery itself, the energy value of storage is reduced by the fraction of hours in each transmission-connected region that storage was charged when there was curtailment.

A central assumption of Condor is that prices are fixed. This assumption allows the decoupling of the balancing areas and storage devices when calculating arbitrage potential, because storage in one region is not allowed to influence prices for storage devices in other regions, and neither is storage within a region allowed to influence prices within that region. This price-taking approximation will become less accurate when storage deployment is very large in a given solve year. For large amounts of storage our approach will tend to over-estimate the energy arbitrage value, as it does not capture the smoothing effect of the storage deployment on prices. Capturing this more accurately would be computationally expensive. Future work is needed in this area to better understand the importance of this approximation.

Discretization is a requirement of dynamic programming, which suffers from the curse of dimensionality, and finer discretization increases the solve time exponentially. We performed tests on the results sensitivity to the discretization strategy and selected values accordingly. The storage energy levels are discretized in a manner that fixes the distance between each level, such that smaller duration storage has fewer discrete levels and larger duration storage has more. This causes the dynamic program to treat storage durations equally, instead of under-valuing longer duration storage relative to shorter duration storage (which would occur using a fixed number of discrete levels). In this work, the number of discrete energy levels for 2-hr duration storage is 15 , which means that 4-hr duration storage has 30, on up to 12-hr duration storage (PSH) which has 90.

Figure 38 shows a sample week-long dispatch from Condor for a 4-hr battery for a region in the winter. Storage arbitrages between periods of low price and high price with perfect foresight subject to charge and discharge constraints. The effect is a smoother net load profile. The total storage level is $600 \mathrm{MWh}$ due to the perfect foresight adjustment one-hour subtraction from the 4hr duration $200 \mathrm{MW}$ battery. The expenditure savings are computed as the cumulative difference between the cost to charge the battery and the revenue from discharging the battery at each hour. The storage efficiency penalty is applied to the storage charging, and the rate of charge doesn't quite reach $200 \mathrm{MW}$ because of this. 


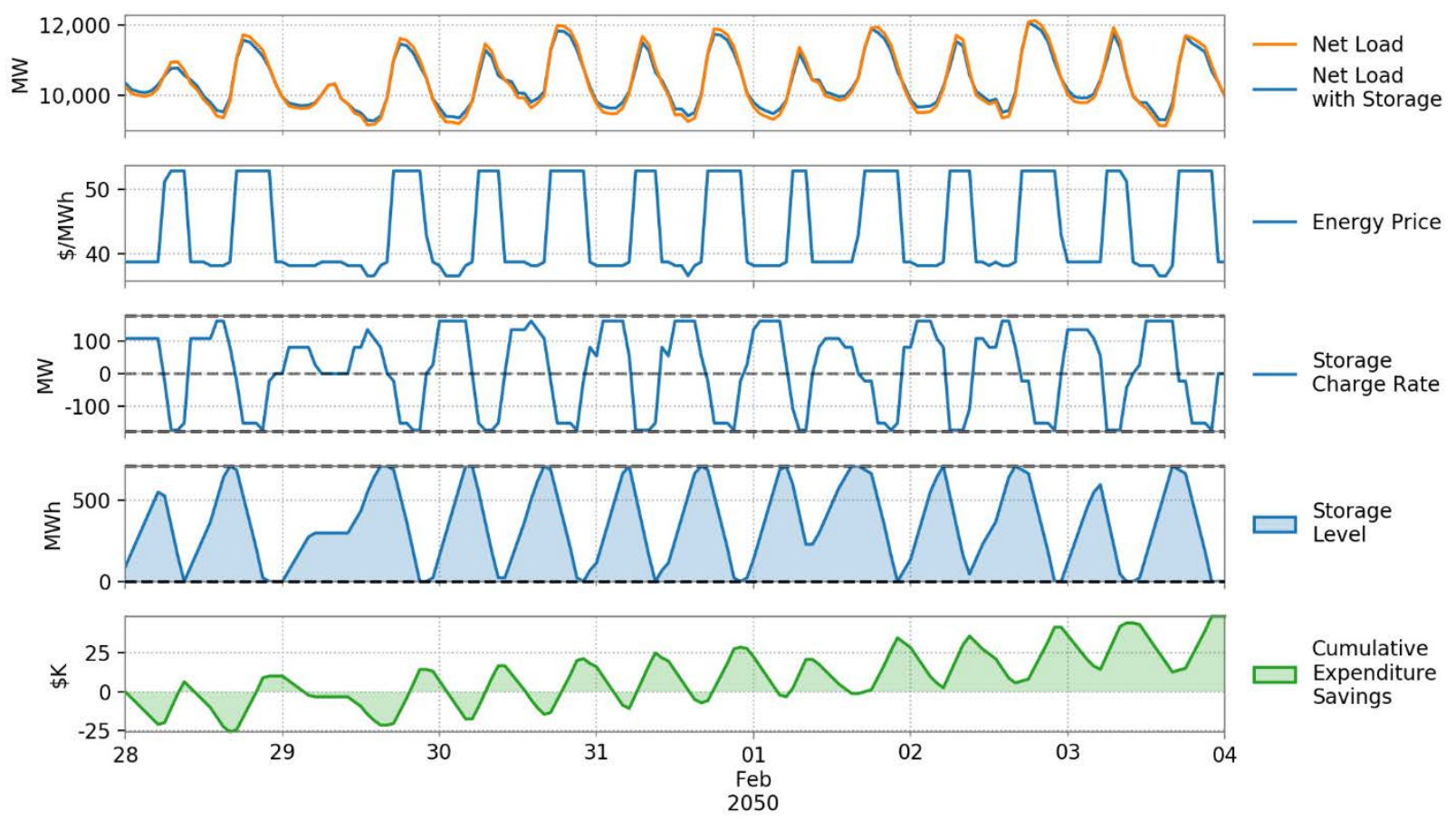

Figure 39: Condor dynamic program dispatch results for a 4-hr battery in a region during the winter.

To decrease solution time, Augur defaults to running Condor for 4-hour and 8-hour duration battery storage and then uses linear interpolation to compute the energy arbitrage revenue for the other storage durations for each region (with PSH modeled as 12-hour duration storage). This is done with the revenues normalized by duration, which makes the linear interpolation a fairly good approximation. The storage arbitrage revenue is exact for 4-hour and 8-hour duration storage, and in general slightly underestimates the value of 2-hr, 10-hr and 12-hr storage and overestimates the value of 6-hr storage. Using interpolation appreciably reduces the Condor solve time and is suitable for general ReEDS analysis. For storage-focused analysis, Condor can be run for each storage duration individually, which is the setting used for the results in this work. 


\section{Climate Impacts}

Previous versions of ReEDS, including the 2018 version (Cohen et al. 2019), included a representation of climate impacts. That representation was not included in the 2019 or 2020 versions of ReEDS, but it is anticipated to be reimplemented into the 2021 version of ReEDS. For more information on how the climate impacts worked, see Section 7 of the 2018 version documentation (Cohen et al. 2019). 


\section{Policy Descriptions}

Policies modeled in ReEDS include federal and state-level emission regulations, tax incentives, and portfolio standards. This section primarily focuses on existing policies, but Section 8.4 does discuss additional frameworks that exist in the model.

\subsection{Federal and State Emission Standards}

\subsubsection{Cross-State Air Pollution Rule}

ReEDS applies the Cross-State Air Pollution Rule (CSAPR) using caps on power plant emissions to the states in the eastern half of the United States over which the rules are imposed. From 2017 onward, CSAPR annual emission allowance budgets for $\mathrm{NO}_{\mathrm{x}}$ are applied at the state level using the Phase 2 caps (EPA 2016). The caps are applied only during the ozone season. ReEDS applies a seasonal estimate of these ozone season caps that adjusts for the overlap of ReEDS season definitions and ozone season definitions. States can trade allowance credits within the eligible trading groups, but must keep emissions below the required assurance levels.

Sulphur Dioxide $\left(\mathrm{SO}_{2}\right)$ emission limits are not represented in the model because the caps would not be binding in the model except in historical years.

\subsubsection{Mercury and Air Toxic Standards}

Because compliance with the Mercury and Air Toxic Standards (MATS) has already been largely achieved, we do not represent MATS in the ReEDS model.

\subsubsection{California Carbon Cap}

California's Global Warming Solution Act of 2016 (referred to as Assembly Bill 398 or AB 398) established a program to reduce economy-wide greenhouse gas emissions to 1990 levels by 2020. In 2016, legislation was passed that codified the 2030 greenhouse gas target to $40 \%$ below 1990 levels. In ReEDS, these state carbon caps are modeled as a cap on electricity-system $\mathrm{CO}_{2}$ emissions from generators either located in California or serving load in the state. Direct $\mathrm{CO}_{2}$ emissions from generators located in California count toward the cap. Imported electricity is assumed to have a emissions rate of 0.26 ton $\mathrm{CO}_{2} / \mathrm{MWh}$ (CARB 2019).

Because California's greenhouse gas reduction targets are legislated for all economic sectors while ReEDS only models the electricity sector, we rely on published economy-wide modeling results to estimate electric sector-specific caps that are used in ReEDS. In particular, we apply power sector caps based on the annual CA electric sector emissions (from in-state and imported electricity) from California Public Utilities Commission (CPUC 2018), which provides guidance for a 42 million $\mathrm{tCO}_{2}$ cap by 2030. We enforce that cap from 2030 to 2050. The pre-2030 cap ramps linearly from 60 million $\mathrm{tCO}_{2}$ in 2020 to the 42 million $\mathrm{tCO}_{2}$ in 2030. Note that we also model California's RPS policy.

\subsubsection{Regional Greenhouse Gas Initiative}

The Regional Greenhouse Gas Initiative (RGGI) cap-and-trade program limits the $\mathrm{CO}_{2}$ emissions for fossil fuel-fired power plants in eleven states: Connecticut, Delaware, Maine, Maryland, Massachusetts, New Hampshire, New Jersey, New York, Rhode Island, Vermont, and Virginia. 
We enforce allowance budgets from the updated model rule adopted in $2017 .{ }^{54}$ We ignore the provision for privately banked allowances and therefore use the unadjusted budgets: 165 million short tons in 2012 declining to 91 million by 2014, then declining $2.5 \%$ per year from 2015 to 2020. According to the 2017 Model Rule, the 2021 cap is set at 75 million short tons and decreases by 2.275 million tons per year until 2030. Beginning in 2020, we also enforce an additional budget of 18 million short tons for the addition of New Jersey to the set of states included in the RGGI ${ }^{55}$. The budget for New Jersey is set to decline by $30 \%$ through $2030^{56}$. Similarly, beginning in 2021, we apply an additional cap of 27.16 million short tons for the addition of Virginia as a RGGI state. This cap is set to decline at a rate of 0.84 short tons per year. ${ }^{57}$ We assume the budget remains constant beyond 2030 . We do not model banking of allowances, emissions offsets, or recycling of initiative allowance revenues.

\subsection{Federal and State Tax Incentives}

\subsubsection{Renewable Production and Investment Tax Credits}

Existing federal tax incentives for renewable energy are included in ReEDS. These include the PTC and the ITC - and the Modified Accelerated Cost Recovery System (MACRS) depreciation schedules. ${ }^{58}$ Current technology-specific depreciation schedules are modeled for all years, because we assume they are permanent parts of the tax code.

Model representations of the latest tax credit extensions are complicated by the "commencedconstruction" provision in these policies, the annual ramp-down in tax credit value, and the default two-year modeling intervals used in ReEDS. Because ReEDS accounts for when plants come online rather than when they begin construction, we represent the commenced-construction provision by assuming the tax credit received by facilities corresponds to the value of the tax credits at the time the plant would typically start construction. For wind and UPV, we assume a construction time of 4 years when the policy is in place, which declines to 3 years and 2 years, respectively after the tax credits phase down. Thus, a plant coming online in 2022 will receive the value of the tax credit from 2018 .

For utility solar, facilities must be placed in service before the end of 2023 to qualify for a tax credit greater than $10 \%$. When solving biennially, the effective value of the tax credit during each two-year model period is based on the average value of the tax credit available after accounting for these under construction periods. For example, an effective $28 \%$ ITC is modeled for utility-scale solar during the 2022 ReEDS model year (representing 2021-2022) based on the

\footnotetext{
54 “2017 Model Rule,” accessed April 26, 2018, https:/www.rggi.org/program-overview-and-design/programreview. For more information, see:

- "About the Regional Greenhouse Gas Initiative (RGGI)," fact sheet updated August 2016, https://www.rggi.org/docs/Documents/RGGI_Fact_Sheet.pdf

- “The RGGI CO 2 Cap,” https://www.rggi.org/design/overview/cap

- “Regional Greenhouse Gas Initiative,” December 2013, http://www.c2es.org/docUploads/rggi-brief-12-1813-updated.pdf.

${ }^{55}$ RGGI press release officially adding New Jersey to the set of RGGI states, https://www.rggi.org/sites/default/files/Uploads/Press-Releases/201906_17_NJ_Announcement_Release.pdf

${ }^{56}$ New Jersey State press release, specifying New Jersey's RGGI budget, https://nj.gov/governor/news/news/562019/approved/20190617a.shtml

${ }^{57}$ See https://www.deq.virginia.gov/Portals/0/DEQ/Air/Regulations/c140p7.pdf.

${ }^{58}$ Note that the eligible cost basis for MACRS is reduced by one-half the value of the tax credit.
} 
average of the $30 \%$ ITC available in 2019 and the $26 \%$ ITC available in $2020 .{ }^{59}$ Table 26 presents the effective wind PTC and solar ITC schedules modeled in ReEDS compared with the nominal schedule listed by the policy.

Though they are not shown in Table 26, we also include tax credits for other renewable energy technologies in the modeled scenarios. The model representation of the tax credit extensions includes effective PTCs for biopower, geothermal, and hydropower lasting through the 2020. A PTC value of $2.3 \phi / \mathrm{kWh}$ is applied to geothermal, and a PTC of $1.2 \phi / \mathrm{kWh}^{60}$ is applied to new hydropower during this period. No tax credits are assumed for hydropower or biopower after 2020. A geothermal ITC of $10 \%$ is modeled for all years after 2020. Another nuance not shown on Table 26 is that the ITC option may be taken in lieu of the PTC for certain qualifying facilities, including offshore wind. For offshore wind, we include a ITC ramp-down that follows the PTC schedule.

Due to these complexities and the required simplifications, we also limit near-term wind capacity deployment as discussed in Section 3.4.1.

Although nuclear technologies can qualify for a PTC, we do not model this PTC because no new construction is expected to occur because of the PTC (i.e., only already-under-construction plants are anticipated to be eligible for the PTC).

\footnotetext{
${ }^{59}$ This representation may underestimate the impact of the tax credit on near-term deployment, as more projects may be moved forward to gain the higher tax credit value in earlier years. However, we conducted test scenarios and found little impact in renewable energy capacity deployment results when shifting the effective tax credit schedule slightly to account for this behavior.

${ }^{60}$ These values in implemented in ReEDS in $2015 \$$.
} 
Table 26. Actual and Modeled Schedule of Wind and Solar Tax Credits

\begin{tabular}{|c|c|c|c|c|c|c|c|c|c|c|c|c|c|}
\hline & Actual Values & 2015 & 2016 & 2017 & 2018 & 2019 & 2020 & 2021 & 2022 & 2023 & 2024 & 2025 & Future \\
\hline \multicolumn{2}{|l|}{ Wind PTC } & Full & Full & $80 \%$ & $60 \%$ & $40 \%$ & $60 \%$ & $0 \%$ & $0 \%$ & $0 \%$ & $0 \%$ & $0 \%$ & $0 \%$ \\
\hline \multirow{3}{*}{ Solar ITC } & Utility & $30 \%$ & $30 \%$ & $30 \%$ & $30 \%$ & $30 \%$ & $26 \%$ & $22 \%$ & $10 \%$ & $10 \%$ & $10 \%$ & $10 \%$ & $10 \%$ \\
\hline & Commercial/Third-Party-Owned & $30 \%$ & $30 \%$ & $30 \%$ & $30 \%$ & $30 \%$ & $26 \%$ & $22 \%$ & $10 \%$ & $10 \%$ & $10 \%$ & $10 \%$ & $10 \%$ \\
\hline & Residential Host-Owned & $30 \%$ & $30 \%$ & $30 \%$ & $30 \%$ & $30 \%$ & $26 \%$ & $22 \%$ & $0 \%$ & $0 \%$ & $0 \%$ & $0 \%$ & $0 \%$ \\
\hline & Model Representation & \multicolumn{2}{|c|}{ 2015-16 } & \multicolumn{2}{|c|}{ 2017-18 } & \multicolumn{2}{|c|}{ 2019-20 } & \multicolumn{2}{|c|}{ 2021-22 } & \multicolumn{2}{|c|}{ 2023-24 } & \multicolumn{2}{|c|}{ Future } \\
\hline \multicolumn{2}{|l|}{ Wind PTC } & \multicolumn{2}{|c|}{ Full } & \multicolumn{2}{|c|}{ Full } & \multicolumn{2}{|c|}{$90 \%$} & \multicolumn{2}{|c|}{$70 \%$} & \multicolumn{2}{|c|}{$60 \%$} & \multicolumn{2}{|c|}{$0 \%$} \\
\hline \multirow{3}{*}{ Solar ITC } & Utility & $30 \%$ & & $30 \%$ & & $30 \%$ & & $28 \%$ & & $16 \%$ & & $10 \%$ & \\
\hline & Commercial/Third-Party-Owned & $30 \%$ & & $30 \%$ & & $30 \%$ & & $24 \%$ & & $10 \%$ & & $10 \%$ & \\
\hline & Residential Host-Owned & $30 \%$ & & $30 \%$ & & $28 \%$ & & $11 \%$ & & $0 \%$ & & $0 \%$ & \\
\hline
\end{tabular}

Table is adapted from Mai et al. (2016) but is updated to reflect the longer construction periods allowed for qualifying wind facilities and the extension of the wind PTC into 2020. Note that for model purposes the 40\% PTC in 2019 is treated as a $60 \%$ value to reflect the incentives to developers to commence construction in 2018 or 2020 but not 2019. 


\subsubsection{Section 45Q Tax Credit for CCS}

The Section 45Q tax credit for CCS technologies is represented as a PTC within the model, where the PTC value is calculated based on the assumed capture rate, carbon content, and efficiency, and capacity factor of the power plant, and assumes that PTC is provided for 12 years. Plants must commence construction by 2023 to be eligible for this tax credit.

\subsubsection{Penalty for Monetizing Tax Credit Incentives}

Many developers do not have the tax appetite to monetize the full value of non-refundable tax credit incentives (such as the ITC, PTC, and 45Q) as the credits accrue. They typically must be monetized either by applying the credits to the developer's tax burden in later years (which reduces the credit's effective value due to the time-value of money) or by finding equity partners with greater tax appetite (which reduces the credit's effective value, as the tax equity partners generally receive higher rates of return than a typical source of equity). ReEDS directly reduces the value of these tax credit incentives to reflect these monetization costs. The default penalty for all tax credit incentives is a one-third reduction in the value of the credit, although the penalty can vary by technology, year, and region. ${ }^{61}$ For a more thorough discussion of tax credit monetization, including a summary of studies that sought to estimate the costs of monetization, see Bolinger (2014).

\subsection{State Renewable Portfolio Standards}

ReEDS models state RPSs, including technology set-asides and renewable energy certificates (RECs) that can count toward RPS compliance. RPS rules are complex and can vary significantly between states. The RPS representation in ReEDS attempts to model the primary impacts of these RPS rules but includes many simplifying assumptions. In addition, in recent years there have been numerous changes to RPS legislation. We periodically update our representation to capture the recent changes to the legislation; however, the numerous and frequent changes to state laws create challenges to having a current representation of all RPS legislation.

Table 27 shows the respective RPS targets and technology set-asides for years 2020, 2025 and 2030 as a percentage of state electricity sales as modeled within ReEDS. These values - along with many other data that we use to represent nuanced RPS rules - are based on data compiled by Lawrence Berkeley National Laboratory, which takes into account the in-state REC multiplier incentives and load adjustments (e.g., sales-weighted RPS targets considering different loadserving entities subject to compliance, such as investor-owned utilities, municipal utilities, and cooperatives) ${ }^{62}$ Solar includes UPV and rooftop PV, wind includes both land-based and offshore technologies, and distributed generation (DG) includes rooftop PV and ground-mounted PV systems located within the distribution network. ${ }^{63}$ ReEDS also models alternative compliance

\footnotetext{
${ }^{61}$ When stating the value of tax credit incentives, note that we state the pre-penalty value. For example, we would say that the ITC value is $30 \%$, even if the monetization penalty would make it so that the incentive would ultimately only be worth $20 \%$ of the qualified capital costs.

${ }^{62}$ See Barbose (2017) and https://emp.lbl.gov/projects/renewables-portfolio. Spreadsheet accessed January, 2017.

${ }^{63}$ See Database of State Incentives for Renewables \& Efficiency (DSIRE) website at dsireusa.org . If data are unavailable, ReEDS forces RPS target to be met by using a default alternative compliance payment and solar alternative compliance payments of $\$ 200 / \mathrm{MWh}$ and $\$ 400 / \mathrm{MWh}$ respectively.
} 
payments for unmet RPS requirement for both main RPS targets and solar set-asides as is consistent with the available data. ${ }^{63}$

Technology eligibility for state RPS requirements is appropriately modeled for each state. ${ }^{63}$ For instance, California's RPS does not allow in-state rooftop solar technologies to contribute toward its RPS. ${ }^{64}$ Additionally, every state has specific rules regarding hydropower generation's eligibility toward contributing RECs, which are usually based on each unit's vintage and size (e.g., small hydro with specific capacity cut-offs are eligible in some states). ReEDS models these as allowable capacity fractions (estimated from ABB Velocity Suite database (ABB 2018)), which is imposed on each state's total hydropower generation thereby limiting the amount of hydropower RECs that each state could generate. Additionally, ReEDS also imposes an upper limit on the total hydropower RECs that a state can use toward its RPS based on historical data as compiled and estimated by Lawrence Berkeley National Laboratory.

Table 27 also lists the allowable states from which each state may import RECs; interstate REC transactions that are required to be bundled with energy are marked with an asterisk. Except for California, ReEDS enforces an upper limit on the total RECs (both bundled and unbundled) that can be imported for that state's RPS compliance. For California alone, due to its unique out-ofstate rules, ReEDS enforces two upper limits, one on the total unbundled REC imports and the other on the total bundled REC imports. There is a myriad of possibilities of interstate REC transactions, in terms of both which two states can transact and the quantity of those transactions. To constrain the solution space of ReEDS to credible values, the interstate REC trading modeling is based on historical observations (Holt 2016), as shown in the final two columns of Table 27. The out-of-state total REC import percentages for each state in are limited to those observed in 2012-2013 (Heeter 2015).

Several states have implemented policies directed at offshore wind. To represent these actions in ReEDS, we prescribe a floor to offshore wind capacity based on known projects and policy mandates. Specifically, we include offshore wind capacity that meets at least one of three criteria: (1) currently operating capacity; (2) projects in active solicitation processes; and (3) to meet statutory policy requirements. The projects are based on tracking conducted for the NREL Offshore Wind Technologies Market Report. The 2019 version of ReEDS relies on projects and policies as of July 2019 and includes estimated offshore wind capacity in six states (CT, MA, MD, NJ, NY, and RI) totaling 14,698 MW by the end of 2030 and 19,698 MW by the end of 2040 (see Table 28). The model allows for economic deployment of offshore wind capacity beyond these levels. All prescribed projects are assumed to be rebuilt once they are retired.

\footnotetext{
64 This version of ReEDS does not include CA Senate Bill 100 requiring $100 \%$ carbon-free electricity by 2045 , as this bill was passed too recently to be included in this model version. The CA Senate Bill 100 policy will be included in future ReEDS versions.
} 
Table 27. Effective State RPS Requirements in ReEDS

\begin{tabular}{|c|c|c|c|c|c|}
\hline \multirow[b]{2}{*}{ State } & \multicolumn{3}{|c|}{ RPS Target/Solar/Wind Set-Asides (\%) } & \multirow{2}{*}{$\begin{array}{l}\text { Allowable States for REC Import, includes } \\
\text { Canadian Provinces (*bundling requirement) }\end{array}$} & \multirow{2}{*}{$\begin{array}{l}\text { REC Import Limit } \\
\text { (\% of RPS target) }\end{array}$} \\
\hline & 2020 & 2030 & 2050 & & \\
\hline$A Z$ & $5.8 /-/-$ & $8.7 /-/-$ & $8.7 /-/-$ & $\mathrm{CA}^{*}, \mathrm{CO}^{*}, \mathrm{NM}^{*}$ & 100 \\
\hline CA & $30.4 /-/-$ & $55.4 /-/-$ & $55.4 /-/-$ & $A Z^{*}, I D, M T, N M, N V^{*}, O^{*}, U T^{*}, W A, W Y^{*}, M E X^{*}$ & $\begin{array}{l}25<2013 \\
15<2016 \\
10>2017 \\
\text { (only unbundled, } \\
100 \% \text { for bundled) }\end{array}$ \\
\hline $\mathrm{CO}^{\mathrm{a}}$ & $19.2 /-/-$ & 19.8/-/- & $20.1 /-/-$ & WY & 8 \\
\hline CT & $24.9 /-/-$ & $43.8 /-/-$ & $43.8 /-/-$ & $\begin{array}{l}\mathrm{MA}, \mathrm{ME}, \mathrm{NH}, \mathrm{NY}^{*}, \mathrm{RI}, \mathrm{VT}, \mathrm{NB}^{*}, \mathrm{NL}^{*}, \mathrm{NS}^{*}, \mathrm{QC}^{*} \text {, } \\
\mathrm{NFI}^{*}, \mathrm{PEI}^{*}\end{array}$ & 59 \\
\hline $\mathrm{DE}^{\mathrm{b}}$ & 13/1.7/- & $18.7 / 3 /-$ & $18.7 / 2.9 /-$ & $\mathrm{IL}^{*}, \mathrm{IN}^{*}, \mathrm{MD}, \mathrm{PA}^{*}, \mathrm{VA}^{*}, \mathrm{WV}^{*}$ & 94 \\
\hline$I^{\mathrm{b}, \mathrm{c}}$ & 14.4/1.4/1.4 & $24.4 / 2.9 / 2.9$ & 25.6/2.9/2.9 & $\begin{array}{l}\text { IA, IN, MD, MN, MO, ND, NY, OH, PA, SD, VA, WI, } \\
\text { WV }\end{array}$ & 60 \\
\hline$M A^{b}$ & $16.6 / 7.2 /-$ & $33 / 10 /-$ & $50.3 / 9.6 /-$ & $\begin{array}{l}\mathrm{CT}, \mathrm{ME}, \mathrm{NH}, \mathrm{NY}^{*}, \mathrm{RI}, \mathrm{VT}, \mathrm{NB}^{*}, \mathrm{NL}^{*}, \mathrm{NS}^{*}, \mathrm{QC}^{*} \text {, } \\
\mathrm{NFI}^{*}, \mathrm{PEI}^{*}\end{array}$ & 62 \\
\hline$M^{b, d}$ & $26.1 / 5.3 /-$ & $54.6 / 12.7 /-$ & $56.7 / 13.4 /-$ & $\begin{array}{l}\mathrm{DE}, \mathrm{IA}, \mathrm{IL}, \mathrm{IN}^{*}, \mathrm{NC}^{*}, \mathrm{NY}^{*}, \mathrm{OH}^{*}, \mathrm{PA}^{*}, \mathrm{TN}^{*}, \mathrm{VA}^{*}, \mathrm{WI}^{*} \text {, } \\
\mathrm{WV}^{*}\end{array}$ & 70 \\
\hline ME & $36 /-/-$ & 72.4/-/- & 72.4/-/- & $\begin{array}{l}\mathrm{CT}, \mathrm{MA}, \mathrm{NH}, \mathrm{RI}, \mathrm{VT}, \mathrm{NB}^{*}, \mathrm{NL}^{*}, \mathrm{NS}^{*}, \mathrm{QC}^{*}, \mathrm{NFI}^{*} \\
\mathrm{PEI}^{*}\end{array}$ & 18 \\
\hline Ml & 10.8/-/- & $12.5 /-/-$ & 11.9/-/- & IA, IN, MN, WI & 0 \\
\hline MN & 25.2/0.8/11.1 & 28/0.8/11.1 & 28/0.8/11.1 & IA, MI, ND, SD, WI, MB, ON, SK & 24 \\
\hline $\mathrm{MO}^{\mathrm{b}}$ & $6.7 / 0.1 /-$ & $10 / 0.2 /-$ & $10 / 0.2 /-$ & $\mathrm{IA}, \mathrm{KS}$ & 94 \\
\hline MT & 10.8/-/- & 10.8/-/- & 10.8/-/- & $\mathrm{ND}^{*}, \mathrm{OR}^{*}, \mathrm{WA}^{*}, \mathrm{BC}^{*}$ & 6 \\
\hline NC & $5 / 0.2 /-$ & $4.7 / 0.2 /-$ & $4.3 / 0.2 /-$ & $\begin{array}{l}\mathrm{AL}^{*}, \mathrm{FL}^{*}, \mathrm{GA}^{*}, \mathrm{LA}^{*}, \mathrm{MS}^{*}, \mathrm{OH}^{*}, \mathrm{PA}^{*}, \mathrm{SC}^{*}, \mathrm{TN}^{*}, \mathrm{VA}^{*}, \\
\mathrm{WV}^{*}\end{array}$ & 43 \\
\hline $\mathrm{NH}^{\mathrm{b}}$ & $17.4 / 0.7 /-$ & $20.6 / 0.7 /-$ & $20.6 / 0.7 /-$ & $\begin{array}{l}\mathrm{CT}, \mathrm{MA}, \mathrm{ME}, \mathrm{NY}^{*}, \mathrm{RI}, \mathrm{VT}, \mathrm{NB}^{*}, \mathrm{NL}^{*}, \mathrm{NS}^{*}, \mathrm{QC}^{*} \\
\mathrm{NFI}^{*}, \mathrm{PEI}^{*}\end{array}$ & 35 \\
\hline
\end{tabular}




\begin{tabular}{|c|c|c|c|c|c|}
\hline \multirow[b]{2}{*}{ State } & \multicolumn{3}{|c|}{ RPS Target/Solar/Wind Set-Asides (\%) } & \multirow{2}{*}{$\begin{array}{l}\text { Allowable States for REC Import, includes } \\
\text { Canadian Provinces (*bundling requirement) }\end{array}$} & \multirow{2}{*}{$\begin{array}{l}\text { REC Import Limit } \\
\text { (\% of RPS target) }\end{array}$} \\
\hline & 2020 & 2030 & 2050 & & \\
\hline$N J^{b}$ & $27.5 / 4.7 /-$ & $53.5 / 2.2 /-$ & $51.2 /-/-$ & $\mathrm{DE}, \mathrm{IL}^{*}, \mathrm{IN}^{*}, \mathrm{MD}, \mathrm{OH}^{*}, \mathrm{PA}^{*} \mathrm{VA}^{*}, \mathrm{WV}^{*}$ & 76 \\
\hline NM & $15.8 /-/-$ & $44.8 /-/-$ & 65.3/-/- & - & 0 \\
\hline NV & 16.6/-/- & $44.2 /-/-$ & 44.3/-/- & - & 100 \\
\hline NY & $32.4 /-/-$ & 74.5/-/- & $74.5 /-/-$ & $\mathrm{RI}^{*}, \mathrm{ON}^{*}, \mathrm{QC}^{*}$ & 4 \\
\hline $\mathrm{OH}^{\mathrm{b}}$ & $4.8 /-/-$ & $-/-/-$ & $-/-/-$ & $\mathrm{IN}^{*}, \mathrm{KY}^{*}, \mathrm{MI}^{*}, \mathrm{PA}^{*}, \mathrm{WV}^{*}$ & 57 \\
\hline $\mathrm{OR}^{\mathrm{b}}$ & 13.7/-/- & 25.1/-/- & $34.8 /-/-$ & $\mathrm{CA}^{*}, \mathrm{ID}^{*}, \mathrm{MT}^{*}, \mathrm{UT}^{*}, \mathrm{WA}^{*}, \mathrm{WY}^{*}, \mathrm{BC}^{*}$ & 42 \\
\hline$P A^{b}$ & $7.2 / 0.4 /-$ & $7.8 / 0.5 /-$ & $7.8 / 0.5 /-$ & $\mathrm{DE}, \mathrm{IL}, \mathrm{IN}, \mathrm{MD}, \mathrm{NC}, \mathrm{NJ}, \mathrm{OH}, \mathrm{VA}, \mathrm{WV}$ & 47 \\
\hline $\mathrm{RI}$ & 15.9/-/- & $30.8 /-/-$ & $38.2 /-/-$ & $\begin{array}{l}\mathrm{CT}, \mathrm{MA}, \mathrm{ME}, \mathrm{NH}, \mathrm{NY}^{*}, \mathrm{VT}, \mathrm{NB}^{*}, \mathrm{NL}^{*}, \mathrm{NS}^{*}, \mathrm{QC}^{*} \text {, } \\
\mathrm{NFI}^{*}, \mathrm{PEI}^{*}\end{array}$ & 77 \\
\hline $\mathrm{TX}$ & $4.2 /-/-$ & $3.8 /-/-$ & $3.5 /-/-$ & - & 0 \\
\hline VT & $59 /-/-$ & 71/-/- & 75/-/- & $\mathrm{CT}, \mathrm{MA}, \mathrm{ME}^{*}, \mathrm{NH}, \mathrm{RI}$ & 100 \\
\hline WA & $12.1 /-/-$ & $12.4 /-/-$ & $12.3 /-/-$ & ID, MT, OR, BC* & 43 \\
\hline WI & 9.9/-/- & 9.9/-/- & 9.9/-/- & $\mathrm{IA}^{*}, \mathrm{MI}^{*}, \mathrm{MN}^{*}, \mathrm{ND}^{*}, \mathrm{SD}^{*}, \mathrm{MB}^{*}, \mathrm{SK}^{*}$ & 41 \\
\hline
\end{tabular}

* Interstate REC transactions that are required to be bundled with energy are marked with an asterisk.

a Based on historical observation, only $50 \%$ of the actual DG carve out for Colorado is assumed to be met using distributed solar technologies (DUPV and distributed PV).

${ }^{\mathrm{b}}$ Based on historical observation, the solar carve out in these states are seen to be met primarily using distribution side solar technologies.

c Illinois allows for $50 \%$ of its RPS target to be met using alternative compliance payments, and hence ReEDS targets are adjusted to reflect this.

${ }^{d}$ Washington, D.C. RPS targets are rolled into Maryland (Washington D.C. load also rolled into Maryland). 
Table 28. Cumulative Offshore Wind Capacity (MW) Mandated in ReEDS

\begin{tabular}{|l|r|r|r|r|}
\hline State & $\mathbf{2 0 2 0}$ & $\mathbf{2 0 3 0}$ & $\mathbf{2 0 4 0}$ & $\mathbf{2 0 5 0}$ \\
\hline CT & - & 2,000 & 2,000 & 2,000 \\
\hline MA & - & 3,200 & 3,200 & 3,200 \\
\hline MD & - & 1,568 & 1,568 & 1,568 \\
\hline NJ & - & 3,500 & 3,500 & 3,500 \\
\hline NY & - & 4,000 & 9,000 & 2,530 \\
\hline RI & 30 & 430 & 430 & 430 \\
\hline
\end{tabular}

For example, there has been a total of 2,000 MW of offshore wind capacity mandated through 2050. This mandate represents a lower bound on offshore wind capacity.

\subsection{Clean Energy Standards}

As of July 2019, six states had clean energy standards (CESs) (see Table 29). These CESs are in effect generalized versions of RPSs; their model representations are very similar with technology eligibility being the only difference. For all but one of the CES policies (Massachusetts), we assume all zero-carbon-emitting sources (on a direct emissions basis) can contribute to the CES requirement. This includes all renewable energy technologies (including hydropower and distributed PV), nuclear power, and imports from Canada. ${ }^{65}$ The modeled CES policies set a floor on electricity generated from clean energy technologies but does not cap generation from nonclean sources. As a result, in the model representation, a state can continue to generate from existing fossil plants if the amount of clean energy generation exceeds the requirement (even if the requirement approaches $100 \%$ of sales). Most of the CES policies are assumed to start in 2030 and ramp to their final targets by 2040 or $2050 .{ }^{66}$ For other aspects of the CES model representation, we use the same assumptions as the corresponding state RPS. These include assumptions about credit trading and variations in load-serving entity requirements. In the case of Virginia, fossil plants are required to retire per the schedule indicated in the clean energy policy. ${ }^{67}$

\footnotetext{
${ }^{65}$ For Massachusetts, we assume CCS technologies are also eligible, but we disallow hydropower because of the post-2010 commercial operation date requirement in the state policy (DOER 2018).

${ }^{66}$ The modeled CES for $\mathrm{CO}_{2}$ is assumed to start in 2020 and includes the clean energy commitments from the largest electric utility in the state (Xcel Energy), which were codified into law in 2019. The modeled CES for Massachusetts begins at $16 \%$ in 2018 and increases to $80 \%$ by 2050 .

${ }^{67}$ To provide ReEDS with foresight to know that the phaseout is coming in Virginia, we implement an increasing capital cost financing multiplier to plants that are being phased out. This multiplier shortens the cost recovery period of the plant. For example, when evaluating whether to build a Gas-CC unit in 2040 ( 5 years before the scheduled phaseout), the financial multiplier for Gas-CC includes a 5-year cost recovery period.
} 
Table 29. Clean Energy Requirement as a Percentage of In-State Sales

\begin{tabular}{|l|r|r|r|r|r|r|r|}
\hline State & 2020 & 2025 & 2030 & 2035 & 2040 & 2045 & 2050 \\
\hline CA & $0 \%$ & $0 \%$ & $55 \%$ & $70 \%$ & $85 \%$ & $100 \%$ & $100 \%$ \\
\hline CO & $19 \%$ & $32 \%$ & $44 \%$ & $47 \%$ & $50 \%$ & $52 \%$ & $55 \%$ \\
\hline MA & $20 \%$ & $28 \%$ & $37 \%$ & $45 \%$ & $54 \%$ & $63 \%$ & $71 \%$ \\
\hline NM & $0 \%$ & $0 \%$ & $45 \%$ & $60 \%$ & $75 \%$ & $90 \%$ & $100 \%$ \\
\hline NY & $0 \%$ & $0 \%$ & $75 \%$ & $87 \%$ & $100 \%$ & $100 \%$ & $100 \%$ \\
\hline WA & $0 \%$ & $0 \%$ & $80 \%$ & $87 \%$ & $93 \%$ & $100 \%$ & $100 \%$ \\
\hline VA & $0 \%$ & $24 \%$ & $39 \%$ & $56 \%$ & $76 \%$ & $96 \%$ & $100 \%$ \\
\hline
\end{tabular}

\subsection{Storage Mandates}

Five state storage mandates are represented in ReEDS. ${ }^{68}$ These include a 1,503 MW storage requirement in California by 2024, a $50 \mathrm{MW}$ storage requirement in Massachusetts by 2020, a 2.5 MW storage requirement in Oregon by 2020, a 2,000 MW requirement in New Jersey by 2030, a 3,000 MW requirement in New York by 2030, and a 3,100 MW requirement in Virginia by 2035 . These are enforced through prescribed builds of four-hour battery storage in each of the states, and the mandates are required to be maintained throughout the model horizon (i.e., once a battery is retired it must be rebuilt if the retirement causes the capacity to fall below the mandate).

\subsection{Nuclear Power Plant Assistance Programs}

There are five states that have enacted that provide compensation or other assistance for in-state nuclear power plants: Connecticut, Illinois, New Jersey, New York, and Ohio. For these states, the nuclear power plants are not allowed to retire until after the policy expires, unless the power plant already has an announced retirement date. The policy end-dates are taken from EIA (2019b).

\subsection{Other Policy Capabilities}

In addition to the existing policies described above, ReEDS also includes several optional policy implementations that are useful for exploring alternative futures or the impact of existing policies. These additional policy frameworks include

- National Clean Energy Standard: This framework allows the user to specify which technologies count as "clean energy" and enforce a minimum limit for the penetration of these clean energy technologies.

- National Renewable Portfolio Standard: This standard enforces a national RPS, with the RPS trajectory defined by the user.

- Carbon Cap-and-Trade: This feature allows the user to specify national-or subnational carbon cap-and-trade policies, including options to represent trading limitations and banking and borrowing of allowances.

${ }^{68}$ Additional storage policies will be evaluated for inclusion in future model versions. 
- Carbon Tax: This feature implements a user-specified carbon tax on burner-tip emissions from the power sector.

- National Emissions Limit: This framework limits the total national emissions according to user-specified values. The limit is often referred to as a carbon cap or CO2 cap.

- Alternative ITC and PTC Schedules: In addition to the ITC and PTC schedules described in Section 8.2, the ITC and PTC can be modified to apply for any number of years and to any technology.

- Alternative Financing Measures: Policy-related financing impacts such as MACRS or the under-construction provisions for the ITC and PTC can be modified as specified by the user. 


\section{Capital Financing, System Costs, and Economic Metrics}

\subsection{Financing of Capital Stock}

The financing assumptions used in ReEDS are taken directly from the 2020 ATB spreadsheet (NREL 2020), using the "Market Factor Financials" and the 20-year capital recovery period options. The ATB has technology-specific and time-varying financing parameters, including interest rate, rate of return on equity, debt fraction, and tax rate. Other elements of the ATB included in ReEDS include construction schedules, MACRS depreciation schedules, and inflation rates. These values are further defined and explained in the ATB, with additional explanation of our financing implementation detailed in the Capital Cost Financial Multipliers appendix of this document.

In previous versions of ReEDS, technology-specific costs of capital were reflected through technology-specific discount rates. Due to the different model structure of the intertemporal mode, and the desire to keep the financial representations the same between modes, since the 2019 version the model has had only a single technology-agnostic discount rate. Instead of varying the discount rate, the impact of any difference between a technology's weighted average cost of capital (WACC) and the system average WACC is captured in a lump-sum adjustment that represents the present-value of the higher (or lower) return to capital. This representation implicitly assumes that differences in financing terms primarily come from diversifiable risk, as opposed to non-diversifiable risk.

\subsection{Electric Sector Costs}

Two system-wide cost metrics are calculated from each ReEDS run: a present value of direct electric sector system costs and electricity price. These cost calculations are not part of the ReEDS optimization process; they are calculated after the ReEDS optimizations have been conducted. The cost metrics provided directly from ReEDS do not include any environmental or health externalities (e.g., social cost of carbon emissions).

\subsubsection{Present Value of Direct Electric Sector Cost}

The present value system cost metric accounts for capital and operating expenditures incurred over the entire study horizon for all technology types considered, including generation, transmission, and storage. The cost in each future year is discounted by a user-defined discount rate, and by default it is set to $5 \%$. Not to be confused with the discount rate used in the optimization for investment decisions, the investment discount rate is selected to represent private-sector investment decisions for electric system infrastructure, and it approximates the expected market rate of return of investors. All costs incurred before the start of the specified economic horizon are assumed to be sunk and are therefore not included in the system cost metric. Details about how the system costs are calculated in ReEDS can be found in the Present Value of Direct Electric Sector Cost section of the appendix.

\subsubsection{Electricity Price}

ReEDS calculates "competitive" electricity prices at different regional aggregation levels (F. H. Murphy and Smeers 2005; Ventosa et al. 2005; EIA 2017b). This calculation takes advantage of 
the linear programming formulation of the model. Specifically, the marginal price on a model constraint represents how much the objective function would change given a change in the right side of the constraint. Each constraint can be viewed as a market with a marginal price and quantity. At optimality, the total revenue (i.e., the product of price and quantity) across all constraints equals the objective function value. The constraints within ReEDS are written such that the marginal values from the load constraints can be used as a proxy for the competitive electricity price. The load constraints are linked to the supply-demand balance constraints, capacity constraints, operating reserve constraints, and others through load variables. Taking the marginal value from the load balance constraint, we can find the marginal value of an additional unit of load (e.g., MWh) to the system, accounting for other requirements. Specifically, the reported competitive prices in ReEDS capture five categories of requirements, including energy, capacity, operating reserves, and state-level and national-level RPS requirements (see Table 30). The competitive prices can be reported at different regional aggregation level, scaled by requirement quantities. Details about how these prices are calculated in ReEDS can be found in the Marginal Electricity Prices section of the appendix.

Table 30. Relationships of Constraints to Grid Services Used to Calculate the Competitive Electricity Price

\begin{tabular}{|c|c|c|c|c|c|}
\hline \multirow[b]{2}{*}{$\begin{array}{l}\text { Constraint } \\
\text { Category }\end{array}$} & \multirow[b]{2}{*}{ Grid Service (s) } & \multirow[b]{2}{*}{ Region ( $r$ ) } & \multirow[b]{2}{*}{ Time (h) } & \multicolumn{2}{|l|}{ Units } \\
\hline & & & & Price $\left(p_{\text {srht }}\right)$ & Quantity $\left(q_{s r h t}\right)$ \\
\hline \multirow{4}{*}{ Operation } & Energy & BA & Time-slice & $\$ / M W h$ & MWh \\
\hline & $\begin{array}{l}\text { Flexibility } \\
\text { Reserve }\end{array}$ & BA & Time-slice & \$/MW-h & MW-h \\
\hline & $\begin{array}{l}\text { Regulation } \\
\text { Reserve }\end{array}$ & BA & Time-slice & \$/MW-h & MW-h \\
\hline & $\begin{array}{l}\text { Spinning } \\
\text { Reserve }\end{array}$ & BA & Time-slice & \$/MW-h & MW-h \\
\hline $\begin{array}{l}\text { Resource } \\
\text { Adequacy }\end{array}$ & Capacity & BA & Season & $\$ / k W-y r$ & kW \\
\hline \multirow{5}{*}{ Policy } & State RPS & State & Annual & $\$ / M W h$ & MWh \\
\hline & National RPS & National & Annual & $\$ / M W h$ & MWh \\
\hline & CO2 Cap & National & Annual & $\$ /$ metric ton & metric ton \\
\hline & RGGI CO2 Cap & Regional & Annual & $\$ /$ metric ton & metric ton \\
\hline & SB32 CO2 Cap & Regional & Annual & $\$ /$ metric ton & metric ton \\
\hline
\end{tabular}

Besides "competitive electricity prices", ReEDS also calculates unit cost of electricity at national or BA-level, reported as average electricity prices. These average prices are calculated as the annualized total costs of building and operating the system in a specific geographic area, divided by the electricity load in that area. Annualized costs for existing (i.e., pre-2010) power plants are also considered given plants' initial investment costs and the built year. BA-level average electricity prices also consider the impact of energy and capacity trading. These prices reflect the 
average costs to serve the load in certain areas. Detailed calculation equations can be found in the Average Electricity Prices section of the appendix.

\subsection{Modeled Economic Metrics}

ReEDS calculates multiple economic metrics for analyzing investment decisions in the model, including:

- Levelized cost of energy (LCOE)

- Technology value

- Net value of energy (NVOE)

- $\quad$ Net value of capacity (NVOC)

- System profitability

These metrics are described in detail below.

\subsubsection{Levelized Cost of Energy}

LCOE measures the unit cost of electricity of a specific technology, which is normally calculated as lifetime costs divided by energy production. Specifically, the LCOE is calculated as follows (NREL 2019):

$$
L C O E=\frac{F C R \times C A P E X+F O M}{C F \times 8,760}+V O M+F U E L
$$

where FCR is the fixed charge rate; CAPEX is the capital expenditures; FOM is the fixed operations and maintenance costs; $\mathrm{CF}$ is the capacity factor; 8,760 is the number of hours in a year; VOM is variable operations and maintenance costs; and FUEL is fuel costs (if applicable).

In each model year, ReEDS reports the LCOE for all technology options considering different variations in tax credit treatments and capacity factor assumptions. ReEDS also calculates the LCOE for technologies that are built in this model year using the generation from these technologies.

\subsubsection{Technology Value}

ReEDS reports the value that generators receive from providing grid services. Value is calculated as the product of service prices and service provision quantities. For example, the value of a generator that comes from providing energy service to meet planning reserve margin requirement is calculated as the price of capacity multiplied by the amount of firm capacity the generator can provide. The reported revenues capture energy, capacity, operating reserve, and state-level and national RPS requirements. Revenues can be normalized either by the amount of generation or by the amount of installed capacity.

Revenues are closely related to, but are different from the electricity price and service requirement quantity parameters. Revenues consider the provision of different services from a certain generator in a region, whereas service requirement quantities calculate the demand of different services in a region. The sum of revenues from all generating technologies in a specific 
region does not necessarily equal the sum of products of all service prices and corresponding service requirements.

\subsubsection{Net Value}

ReEDS reports different economic viability metrics that consider both costs and values of generating technologies to fully evaluate the economic competitiveness of a certain technology, and to provide intuitive explanations about investment decisions in the model. "Values" of a generator reflect the potential economic benefit from displacing or avoiding the cost of providing the services from other (marginal) assets, while "costs" aggregate all different sources of costs needed to build and operate a power plant to provide services. We define "net value" as the difference between values and costs. Net value is related to a concept in linear programming called "reduced cost." Mills and Wiser (2012) describe reduced cost in the context of electricity system modeling.

We report three types of such metrics to assess the economic viability of generators: net value of energy, net value of capacity, and system profitability metrics (Table 31). These metrics are reported both for new investments in certain model year and for existing generators that have been built.

Table 31. Summary of Net Value Metrics

\begin{tabular}{|l|l|}
\hline Metric & Conceptual Expression [Typical Units] \\
\hline Net value of energy (NVOE) & (Value - Cost)/Energy [\$/MWh] \\
\hline Net value of capacity (NVOC) & (Value - Cost)/Capacity [\$/kW-yr] \\
\hline System profitability & $\mathrm{f}($ Value/Cost) [unitless] \\
\hline
\end{tabular}

Net value of energy (NVOE) measures the unit profit of a specific technology, calculated as the difference between generator revenue and costs, then normalized by the energy production. The typical unit is dollars per megawatt-hour (\$/MWh). Similarly, net value of capacity (NVOC) measures the unit profit of a specific technology, calculated as the difference between generator revenue and costs, then normalized by the installed capacity. The typical unit is dollars per megawatt $(\$ / \mathrm{MW})$.

Both of these two metrics are normalized metrics; because the denominators vary broadly for different generator types, they may not reflect the competitiveness of technologies consistently. Therefore, we report a third type of economic viability metric, namely system profitability metrics, which are essentially unitless functions of the ratio between values and costs. Examples include profitability index (value/cost) and return on investment (value/cost minus one). We report both metrics in ReEDS, acknowledging that there are other formats of system profitability metrics.

These economic viability metrics help explain investment decisions in the model. Specifically, for all types of new investment in a certain model year, the model considers all the costs to build and operate a certain technology as costs, and the contribution of the technology to all binding constraints as values (i.e., service provision). Typical value sources are discussed above in Section 10.3.2. In calculations of economic viability metrics, however, other types of "values" 
are included to fully reflect model decisions. For example, an increase of ancillary service requirements that are due to higher wind penetration is counted as a negative value stream for wind, and it is included in the metrics calculation here. Therefore, these metrics fully reflect all the model constraints related to the investment decision. 


\section{ReEDS North American Expansion}

As discussed in Section 6.4, ReEDS includes an exogenous representation of Canada. However, the ReEDS model also includes the capability to model both Canada and Mexico endogenously. This continental version of the ReEDS model, which is referred to as ReEDS-North America, is described here. Country specific models can be run separate from the continental model as ReEDS-Canada and ReEDS-Mexico. The ReEDS-Canada model includes 20 additional BAs, regions as shown in Figure 39, and 47 new wind/CSP resource. The Canadian BAs only cover areas where the grid is directly connected to the U.S. system and therefore do not include the Yukon, Northwest Territories, and Nunavut. The ReEDS-Mexico model includes 49 additional BAs, which are also used for defining wind/CSP resource regions. This representation directly aligns with the transmission regions used by Secretaría de Energía for Mexico (SENER) in their annual report Programa de Desarrollo del Sistema Eléctrico Nacional (PRODESEN). The Mexican BAs cover all regions in Mexico but do not include exporting generators on the Mexico-California border, which are modeled endogenously when modeling the United States. 


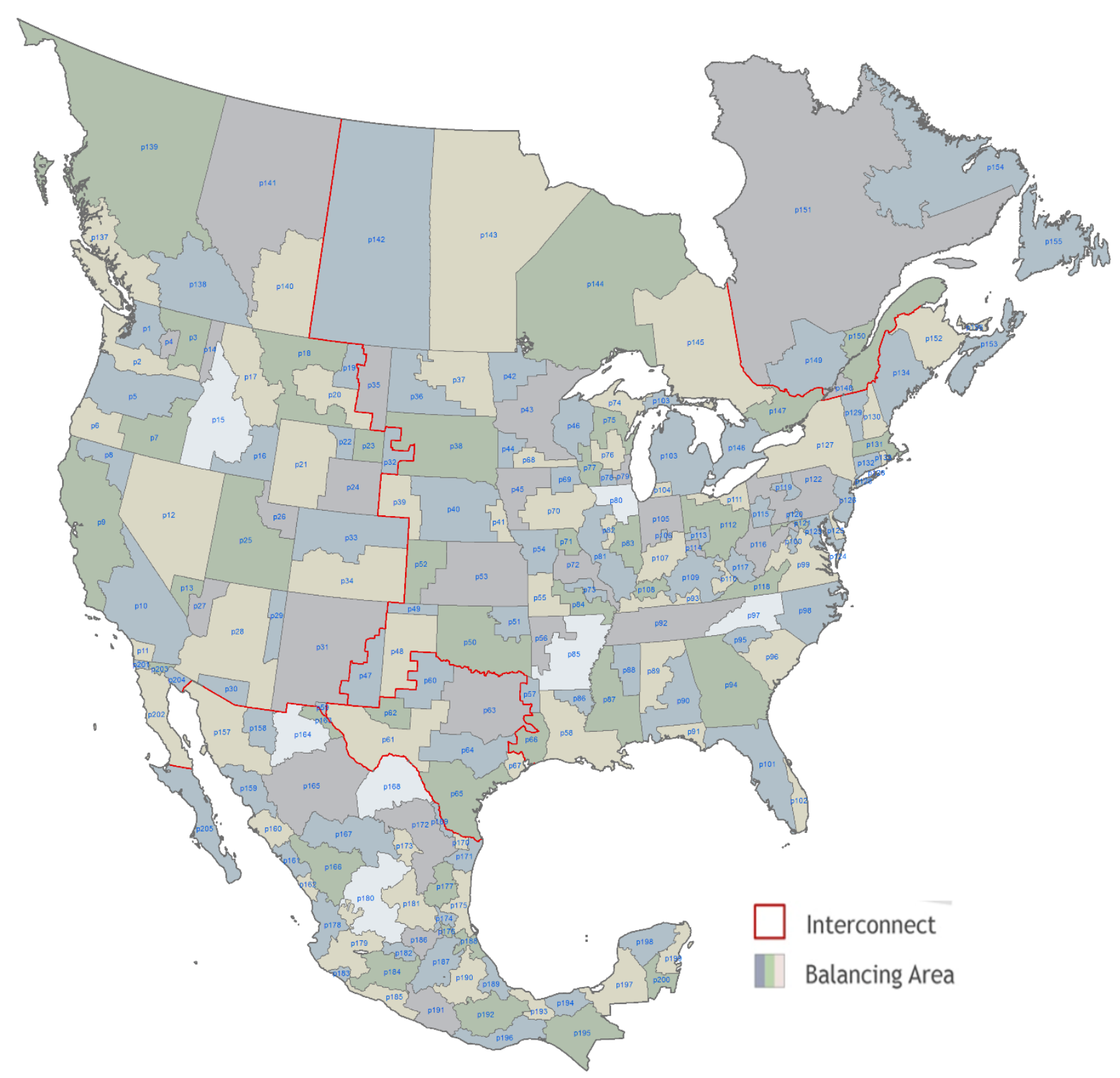

Figure 40. Regions defined in the North America version of the ReEDS model

\subsection{Fuel Price and Availability}

Natural gas supply and demand dynamics are represented in ReEDS through regional supply curves along EIA Census Division boundaries (see the Natural Gas Supply Curves section of the appendix). For Canadian provinces, the U.S.-only regional supply curves are modified based on consumption projections from the National Energy Board's Canada's Energy Future 2016 (NEB 2016). Natural gas supply curves are modified to capture the additional supply and demand for natural gas in Canadian regions; adjacent Canadian provinces are assigned to EIA census divisions. A map of this allocation is shown in Figure 40. 


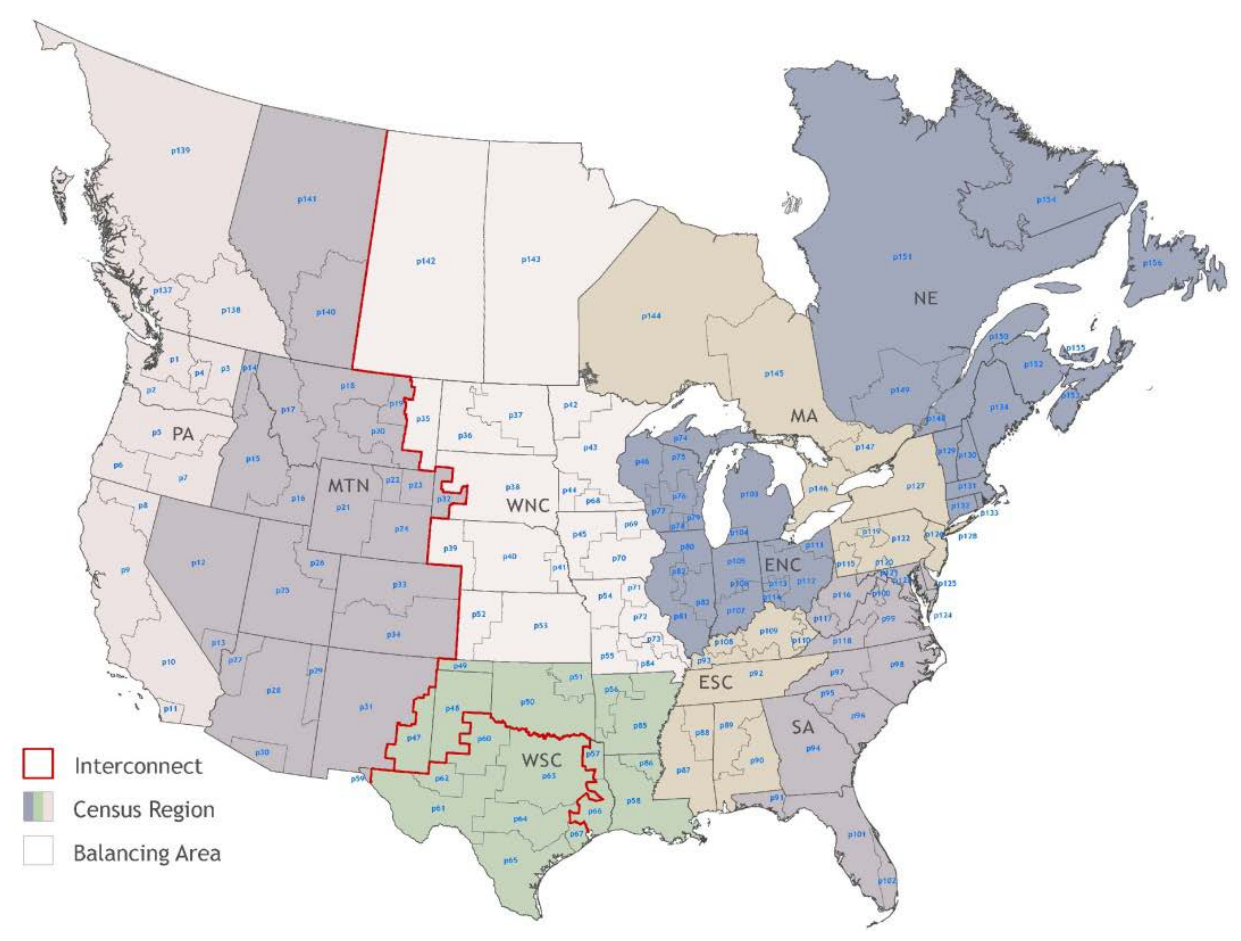

Figure 41. Map of EIA Census Division boundaries extended to Canadian provinces

A single Mexican natural gas curve is adapted from the WSC census division in the AEO. Mexico-specific natural gas consumption is taken from PRODESEN 2018 and incorporated in the new gas curve. Prices were inflated by $9 \%$ for Mexico relative to WSC to reflect the higher price of natural gas in Mexico, based on Henry Hub prices from 2010 to 2015.

Canadian coal prices are provincial and represented as inelastic to changes in consumption; they are consistent with Canadian provincial coal price projections from NEB (2016). The price of nuclear fuel for Canadian units is assumed to be same as those for nuclear units in the United States.

Mexican coal and uranium prices are matched with the WSC census division in the AEO and are inelastic.

\subsection{Electricity Demand}

Canadian annual electricity demand projections are based on the NEB (2016) reference scenario, and they reflect annual provincial load reduced by customer-sited electricity cogeneration. Provincial and zonal load shapes are described in Martinez et al. (2013). For provinces composed of multiple ReEDS BAs (Alberta, British Columbia, Ontario, and Quebec), the spatial distribution of annual provincial electricity demand among BAs is also described in Martinez et al. (2013).

Mexican load shapes and annual demand projections are based on 2016 PRODESEN. The PRODESEN load projection extends through 2030. For projections beyond 2030 load growth is projected based on the average load growth for the years 2020-2030. Load shape data in 
PRODESEN are available for nine regions that were mapped to the ReEDS BA representation through provided load participation factors.

\subsection{Generation Fleet Representation}

Consistent with the ReEDS representation of the generation fleet in the contiguous United States, the ABB Velocity Suite is used as a basis for Canadian and Mexican generation units (ABB 2018). This data set is then cross-referenced with NEB (2016) for Canada, PRODESEN for Mexico, and any Canadian provincial energy plans to represent the Canadian fleet. The existing fleet, prescribed new builds, and prescribed retirements are based on the ABB Velocity Suite database. Additionally, any new hydropower or geothermal capacity projected in NEB (2016) and PRODESEN is also included in ReEDS (ReEDS does not include hydropower or geothermal resource supply curves for Canada or Mexico, and thus cannot represent new builds of those technologies endogenously).

There are currently 18,215 MW of existing transmission capacity between the United States and Canada from a combination of AC and DC lines dispersed across the border. Potential new transmission lines between the United States and Canada are derived from a list of pending applications as of January 2016 (DOE 2016a). Lines that are not yet under construction can be built in the ReEDS-Canada model, but they are not prescribed.

There are currently 2,238 MW of existing transmission capacity between the United States and Mexico, which include DC lines connecting Texas and Mexico and the AC lines connecting southern California to Mexico. Potential new transmission lines between the United States and Mexico are limited to reinforcements of existing cross-border connections. New connections specified in PRODESEN, including the DC interconnection between the main Mexican system asynchronous Baja California system and the Baja California Sur system, are allowed but not forced to be built in the ReEDS-Mexico model.

Transmission lines in Canada and Mexico are assumed to have the same cost as their neighboring regions in the United States. Table 32 summarizes pending cross-border transmission lines as of January 2016. 
Table 32. Pending Cross-Border Transmission Lines as of January 2016 (DOE 2016a)

\begin{tabular}{|c|c|c|c|c|c|c|c|}
\hline Name & Sponsor & State-Province & $\begin{array}{l}\text { Length } \\
\text { (miles) }\end{array}$ & $\begin{array}{l}\text { Voltage and } \\
\text { Capacity }\end{array}$ & Purpose & $\begin{array}{l}\text { In-service } \\
\text { Date }\end{array}$ & Permit Status \\
\hline $\begin{array}{l}\text { Champlain } \\
\text { Hudson Power } \\
\text { Express }\end{array}$ & $\begin{array}{l}\text { Transmission } \\
\text { Developers Inc. }\end{array}$ & $\begin{array}{l}\text { New York- } \\
\text { Québec }\end{array}$ & 333 & $\begin{array}{l}1,000 \mathrm{MW}, \\
\mathrm{HVDC}^{\mathrm{a}} \\
\text { (underwater, } \\
\text { underground, } \\
\text { merchant) }\end{array}$ & $\begin{array}{l}\text { Deliver hydro and } \\
\text { wind energy from } \\
\text { QC to New York } \\
\text { City area }\end{array}$ & $\begin{array}{l}\text { Fall } 2017 \\
\text { (expected) }\end{array}$ & $\begin{array}{l}\text { Permit issued } \\
\text { October } 2014\end{array}$ \\
\hline $\begin{array}{l}\text { Great Northern } \\
\text { Transmission } \\
\text { Line }\end{array}$ & $\begin{array}{l}\text { Minnesota } \\
\text { Power (MP) }\end{array}$ & $\begin{array}{l}\text { Minnesota- } \\
\text { Manitoba }\end{array}$ & 220 & $\begin{array}{l}500 \mathrm{kV} \\
750 \mathrm{MW}, \mathrm{AC}\end{array}$ & $\begin{array}{l}\text { Part of MP-MB } \\
\text { Hydro PPA; } \\
\text { supports building } \\
\text { wind in North } \\
\text { Dakota }\end{array}$ & $\begin{array}{l}\text { June } 2020 \\
\text { (expected) }\end{array}$ & $\begin{array}{l}\text { Application filed } \\
\text { April } 2014\end{array}$ \\
\hline $\begin{array}{l}\text { Lake Erie } \\
\text { Connector }\end{array}$ & ITC & $\begin{array}{l}\text { Pennsylvania- } \\
\text { Ontario }\end{array}$ & 72.4 & $\begin{array}{l}\text { 1,000 MW, } \\
\text { HVDC } \\
\text { (underwater, } \\
\text { merchant) }\end{array}$ & $\begin{array}{l}\text { Deliver surplus ON } \\
\text { renewable energy, } \\
\text { enhance service } \\
\text { reliability }\end{array}$ & Q4 2019 & $\begin{array}{l}\text { Application filed } \\
\text { May } 2015\end{array}$ \\
\hline $\begin{array}{l}\text { New England } \\
\text { Clean Power } \\
\text { Link }\end{array}$ & $\begin{array}{l}\text { TDI-New } \\
\text { England }\end{array}$ & $\begin{array}{l}\text { Vermont- } \\
\text { Québec }\end{array}$ & 154 & $\begin{array}{l}\text { 1,000 MW, } \\
\text { HVDC } \\
\text { (underwater, } \\
\text { underground, } \\
\text { merchant) }\end{array}$ & $\begin{array}{l}\text { Deliver renewable } \\
\text { energy from QC into } \\
\text { VT and New } \\
\text { England }\end{array}$ & $\begin{array}{l}2019 \\
\text { (expected) }\end{array}$ & $\begin{array}{l}\text { Application filed } \\
\text { May } 2014\end{array}$ \\
\hline Northern Pass & $\begin{array}{l}\text { Northern Pass } \\
\text { Transmission } \\
\text { LLC }\end{array}$ & $\begin{array}{l}\text { New Hampshire- } \\
\text { Québec }\end{array}$ & 187 & $\begin{array}{l}\text { 1,200 MW, } \\
\text { HVDC line with } \\
345 \mathrm{kV} \mathrm{AC} \mathrm{spur}\end{array}$ & $\begin{array}{l}\text { Deliver QC hydro } \\
\text { into } \mathrm{NH} \text { and New } \\
\text { England }\end{array}$ & $\begin{array}{l}2017 \\
\text { (expected) }\end{array}$ & $\begin{array}{l}\text { Application filed } \\
\text { October 2010; } \\
\text { re-filed with new } \\
\text { route July } 2013\end{array}$ \\
\hline $\begin{array}{l}\text { Soule River } \\
\text { Hydroelectric } \\
\text { Project }\end{array}$ & $\begin{array}{l}\text { Soule Hydro, } \\
\text { LLC }\end{array}$ & $\begin{array}{l}\text { Alaska-British } \\
\text { Columbia }\end{array}$ & 10 & $\begin{array}{l}138 \mathrm{kV}, \mathrm{HVAC} \\
\text { (submarine) }\end{array}$ & $\begin{array}{l}\text { Support } 77 \mathrm{MW} \\
\text { hydro project in } \mathrm{AK} \\
\text { (sales to BC or } \\
\text { Pacific NW) }\end{array}$ & $\begin{array}{l}\text { To be } \\
\text { determined }\end{array}$ & $\begin{array}{l}\text { Application filed } \\
\text { March } 2013\end{array}$ \\
\hline
\end{tabular}

a high-voltage, direct current 


\subsection{Renewable Energy Representation}

\subsubsection{Hydropower Generation Capacity}

ReEDS is not allowed to endogenously build new hydropower capacity in Canada or Mexico due to a lack of available hydropower supply curves that are compatible with those developed for the United States. Instead, we rely on a schedule of expected builds from NEB (2016) for new Canadian hydropower units. Though annual hydropower output can fluctuate significantly from year to year based on precipitation and other weather patterns, we assume there is no inter-annual variation in available hydropower generation in ReEDS; rather, average capacity factors are assumed that reflect long-run historical averages. Seasonal hydropower capacity factors are specified for each Canadian province and are derived from NEB (2013).

In Mexico, existing hydropower capacity is represented, but no new prescribed capacity is added to the system. Operating characteristics are determined from the historical fleetwide capacity factor from PRODESEN.

\subsubsection{Wind Resource}

For Canada and Mexico, the onshore-wind resource is represented using the same methodology described in Section 2.1.1. Using reV, the quality, capacity, and spur line costs are calculated and represented within the model at the wind resource region level. Wind turbine performance is modeled using results from the WIND Toolkit. Toolkit data include complete coverage of Mexico and Southern Canada. Meteorological data for northern Canada are supplemented using NASA's MEERA-2 data set. Resource calculations are preformed using 2012 data; however, the methodology flexibly supports alternate weather years.

Offshore-wind technology is not represented as an available resource for Canada or Mexico because a comprehensive resource assessment has not been completed.

\subsubsection{Solar Resource}

UPV and DUPV resources are calculated for Canada and Mexico using the same approach described in Section 2.1.3. The quality, capacity, and spur line costs are calculated using reV and represented within the model for $\mathrm{BA}$ regions. The performance of $\mathrm{PV}$ panels is based on insolation data from the NSRDB 2.0 using a 2012 metrological year.

The deployment of residential and commercial rooftop PV systems is exogenously defined in for the United States using output from NREL's dGen model (see Section 3.1.3). Rooftop PV projections for Canada and Mexico are available but currently unpublished. Direct normal irradiance throughout Canada is below the threshold necessary to produce economic CSP generation, and thus is not represented in Canada. Though the direct normal irradiance is high in Mexico, comprehensive resource data for CSP in Mexico have not been developed due to its expected competitive disadvantage relative to PV. Thus, CSP is not represented as an available resource in Mexico. 


\subsubsection{Geothermal Resource}

Geothermal technologies are not available for development outside the United States due to a lack of sufficient information on the location and potential of geothermal resources. Mexico does currently produce electricity from geothermal technology, and any existing capacity is included in ReEDS-Mexico.

\subsubsection{Biomass Resource}

The biomass feedstock supply curve for each Canadian BA is assumed to be the same as that of the contiguous BAs in the United States (scaling to account for differences in area). Biomass is not available as a resource or generation technology in Mexico because resource data are unavailable. Future resource assessments for biomass feedstocks are needed to improve these representations.

\subsection{Policy and Regulation}

ReEDS represents existing RPS requirements for:

- New Brunswick: $40 \%$ by $2020^{69}$

- Nova Scotia: $5 \%$ by $2011,10 \%$ by $2013,25 \%$ by 2015 , and $40 \%$ by 2020 (Nova Scotia Department of Energy 2010)

- Prince Edward Island: 15\% by 2010 (Department of Environment, Energy and Forestry, n.d.).

Canadian contributions to U.S. state RPS (and vice versa) are permitted in alignment with existing laws, regulations, and practices as of October 2014. We list the rules for U.S.-Canada REC trading in Table 33, focusing on U.S. states that are physically or electrically adjacent to a Canadian province, or where international REC trading activity has been observed in practice.

Table 33. International REC Trading Rules Implemented in ReEDS

\begin{tabular}{|l|l|l|}
\hline State/Province & $\begin{array}{l}\text { Canadian RECs } \\
\text { Accepted? }\end{array}$ & Notes \\
\hline California & Yes & Power must be delivered to state \\
\hline Colorado & No & - \\
\hline Massachusetts & Yes & Power must be delivered to ISO-New Englanda \\
\hline Maine & No & - \\
\hline Michigan & No & - \\
\hline Minnesota & Yes & Power must be delivered to state from Manitoba \\
\hline Montana & No & - \\
\hline Nevada & No & - \\
\hline New Hampshire & No & - \\
\hline New York & No & - \\
\hline
\end{tabular}

69 "Provincial Government Strengthens its Commitment to Renewable Energy," news release dated August 7, 2014 http://www2.gnb.ca/content/gnb/en/news/news_release.2014.08.1007.html. 


\begin{tabular}{|l|l|l|}
\hline State/Province & $\begin{array}{l}\text { Canadian RECs } \\
\text { Accepted? }\end{array}$ & Notes \\
\hline Nova Scotia & Yes & RECs accepted from New England Power Pool \\
\hline Ohio & No & - \\
\hline Oregon & Yes & Subject to same bundling rules as U.S. states \\
\hline Pennsylvania & No & - \\
\hline Rhode Island & Yes & Power must be delivered to ISO-New England \\
\hline Washington & Yes & Power must be delivered to state \\
\hline Wisconsin & Yes & Power must be delivered to state \\
\hline
\end{tabular}

a ISO = independent system operator

British Columbia has a carbon tax that is applied to in-province electricity generation (British Columbia Ministry of Finance 2015). This tax is also applied to imported electricity; in this case, the average carbon intensity of delivered electricity is endogenously calculated from the imported generation mix in the previous solve year ${ }^{70}$ and taxed appropriately. We also implement the British Columbia 2016 requirement for electricity self-sufficiency ${ }^{71}$ (Clean Energy Act of 2010 2010).

New Canadian coal units that do not have carbon capture and storage are not in allowed in the model beginning in the 2016 solve year. Any early retirements of existing coal units are reflected in the exogenous retirements of Canadian coal units. ${ }^{72}$

The Mexico clean energy standard of 35\% of load by 2024 is also modeled. (Presidencia de la República 2016) Renewable energy and nuclear power are allowed to contribute to this policy, while CCS is excluded.

\footnotetext{
${ }^{70}$ This calculation uses a proportional sharing construct adapted from Bialek (1996).

${ }^{71}$ The requirement is structured such that plants within British Columbia must generate as much energy as is required to serve load within the province.

${ }^{72}$ For details about the electricity regulations for coal units in Canada, see "Coal-Fired Electricity Generation Regulations: Overview," Government of Canada, modified December 16, 2013, https://ec.gc.ca/cc/default.asp?lang=En\&n=C94FABDA-1.
} 


\section{Model Linkages}

\subsection{ReEDS-dGen}

All ReEDS scenarios utilize dGen to project rooftop PV deployment, but the two models are also capable of operating in a more tightly coupled manner with two-way feedback in each solve year. Under this arrangement, ReEDS provides dGen with estimated curtailment of rooftop PV resources, which dGen uses to update its projected rooftop PV deployment for the following solve year. This coupled configuration improves rooftop PV projections by disincentivizing new capacity that would achieve low utilization within the interconnected bulk system modeled in ReEDS. Additional details on this linkage and its influence on results can be found in (W. Cole et al. 2016; Gagnon et al. 2017).

\subsection{ReEDS-PLEXOS}

The ReEDS reduced-form dispatch and variable renewable parameterization aims to represent enough operational detail for realistic capacity expansion decisions, but the model cannot explicitly represent detailed power system operations. To verify the feasibility of ReEDS solutions and better inform its representation of system operation, NREL has developed utilities to implement a ReEDS capacity expansion solution for any solve year in the PLEXOS production-cost model (PCM).

PLEXOS is a commercial PCM tool capable of representing individual generating units and transmission nodes for least-cost dispatch optimization at hourly or subhourly time resolution. It can incorporate unit-commitment decisions and detailed operating constraints (e.g., ramp rates, minimum runtime) to simulate realistic power system operations. NREL has previously used PLEXOS in several analyses such as the Western Wind and Solar Renewable Integration Study and the Eastern Renewable Grid Integration Study (Lew et al. 2013; Bloom et al. 2016a).

The ReEDS-PLEXOS linkage involves disaggregating the ReEDS solution and adding necessary parameters for to the resolution necessary for PLEXOS. To facilitate the translation, the existing linkage maintains the spatial resolution of ReEDS and operates PLEXOS as a zonal model matching ReEDS BAs to PLEXOS transmission zones. PLEXOS uses the ReEDS transmission line capacity, and reactance and resistance are calculated from ReEDS transmission properties to represent the aggregated transmission system. Generating capacity within each zone is, however, converted from aggregate ReEDS capacity to individual units in PLEXOS using a characteristic unit size for each technology. For consistency, ReEDS cost and performance parameters are used when possible and reasonable, but values are taken from the average across WECC data when parameters are not available from ReEDS or are available but used inconsistently in ReEDS due to structural differences between the models. ${ }^{73}$

Once the ReEDS solution is converted to a PLEXOS database, one can simulate hourly dispatch over a full year and compare results with ReEDS outcomes. A consistent solution builds confidence in the effectiveness of ReEDS capacity expansion decisions, while inconsistencies

\footnotetext{
${ }^{73}$ Minimum load is an example of one such parameter. The aggregate representation of minimum load in ReEDS at the technology-BA level does not effectively reflect unit-level operating constraints used in PLEXOS, so PLEXOS uses native assumptions for minimum load.
} 
and reliability concerns such as load shedding indicate the need for improving capacity expansion model structures. Additional details are available in Frew et al. (2019).

\subsection{ReEDS-Cambium}

Leveraging the capabilities of the ReEDS-PLEXOS linkage, a third model — Cambium — has been developed. Cambium draws from ReEDS and PLEXOS model solutions to assemble a structured database of hourly cost and operational data for modeled futures of the U.S. electric sector. In addition to directly reporting some metrics from both ReEDS and PLEXOS (e.g., capacity buildouts from ReEDS and generation by technology from PLEXOS), Cambium postprocesses the outputs from both models to develop new metrics that are designed to be useful for long-term decision-making, such as a long-run marginal emission rate. ${ }^{74}$

Data sets derived through Cambium can be viewed and downloaded at https://cambium.nrel.gov/. The documentation for Cambium contains descriptions of the metrics reported in the databases and the methods for calculating those metrics (cite https://www.nrel.gov/docs/fy21osti/78239.pdf).

\subsection{ReEDS-JEDI}

A linkage between ReEDS outputs and the Jobs and Economic Development Impact Models (JEDI) allows the analysis of technology-specific economic results (jobs, earnings, value added, total output) to ReEDS scenarios. Currently, linkages have been built for the JEDI land-based wind, photovoltaics, natural gas, and coal models, so economic results are limited to these technologies alone. ReEDS outputs of capacity, generation, fuel use, capital cost, O\&M cost, and fuel cost by BA are processed through the JEDI models to produce state-level economic results.

\subsection{ReEDS-reV}

The ReEDS supply curve for renewable technologies, including onshore wind, CSP, and utility scale PV are produced by reV. The ReEDS-reV linkage allows for regional ReEDS investment decisions to be mapped backed to individual reV supply curve sites. Site-specific supply curve data from reV is binned for the ReEDS supply curve into five spur line cost bins, from which investment decisions are made. By tracking the timing and investment decisions within each of these bins, the ReEDS-rev linkage maps regional capacity back to the individual sites from which the bins were derived.

The resulting siting data is used to further the understanding of the ReEDS capacity expansion decisions and identify areas for improvement for resource siting in reV. The ReEDS-reV linkage is a key component in the translation of ReEDS capacity expansion results to a nodal production cost modeling databases.

\footnotetext{
74 The long-run marginal emission rate is a metric designed to help estimate the emissions induced (or avoided) by a persistent change in electricity consumption. Unlike the short-run marginal emission rate, the long-run marginal emission rate reflects the structural changes to the grid that can be induced by a persistent change in electricity consumption.
} 


\section{References}

40 CFR Parts 122 and 125. 2014. Vol. 79. https://www.gpo.gov/fdsys/pkg/FR-2014-0815/pdf/2014-12164.pdf.

ABB. 2013. “ABB Velocity Suite.” 2013. https://new.abb.com/enterprise-software/energyportfolio-management/market-intelligence-services/velocity-suite.

—. 2018. “ABB Velocity Suite.” 2018. http://new.abb.com/enterprise-software/energyportfolio-management/market-intelligence-services/velocity-suite.

Arora, Vipin. 2014. "Estimates of the Price Elasticities of Natural Gas Supply and Demand in the United States.” MPRA Paper No. 54232. U.S. Energy Information Administration. http://mpra.ub.uni-muenchen.de/54232/.

Augustine, Chad R., Jonathan L. Ho, and Nathan J. Blair. 2019. "GeoVision Analysis Supporting Task Force Report: Electric Sector Potential to Penetration.” NREL/TP-6A20-71833. Golden, CO: National Renewable Energy Laboratory. https://doi.org/10.2172/1524768.

Beiter, Philipp, Walter Musial, Levi Kilcher, Michael Maness, and Aaron Smith. 2017. “An Assessment of the Economic Potential of Offshore Wind in the United States from 2015 to 2030.” NREL/TP-6A20-67675. National Renewable Energy Lab. (NREL), Golden, CO (United States). https://doi.org/10.2172/1349721.

Beiter, Philipp, and Tyler Stehly. 2016. "A Spatial-Economic Cost-Reduction Pathway Analysis for U.S. Offshore Wind Energy Development from 2015-2030.” NREL/PR-6A20-67204. National Renewable Energy Lab. (NREL), Golden, CO (United States). https://www.osti.gov/biblio/1330939-spatial-economic-cost-reduction-pathway-analysisoffshore-wind-energy-development-from.

Bernstein, Mark A., and James M. Griffin. 2006. "Regional Differences in the Price-Elasticity of Demand for Energy." NREL/SR-620-39512. Golden, CO: National Renewable Energy Laboratory. http://www.nrel.gov/docs/fy06osti/39512.pdf.

Bialek, Janusz. 1996. "Tracing the Flow of Electricity." IEE Proceedings-Generation, Transmission and Distribution 143 (4): 313-20.

Black \& Veatch. 2012. "Cost and Performance Data for Power Generation Technologies." Overland Park, KS: Black \& Veatch Corporation.

Bloom, Aaron, Aaron Townsend, David Palchak, Joshua Novacheck, Jack King, Clayton Barrows, Eduardo Ibanez, et al. 2016a. "Eastern Renewable Generation Integration Study.” NREL/TP-6A20-64472. Golden, CO: National Renewable Energy Laboratory, RePPAE LLC, GE. http://www.nrel.gov/docs/fy16osti/64472.pdf. . 2016b. "Eastern Renewable Generation Integration Study." NREL/TP-6A20-64472. National Renewable Energy Lab. (NREL), Golden, CO (United States). https://doi.org/10.2172/1318192.

Bolinger, Mark. 2014. "An Analysis of the Costs, Benefits, and Implications of Different Approaches to Capturing the Value of Renewable Energy Tax Incentives." LBNL-6610E. Berkeley, CA: Lawrence Berkeley National Laboratory. https://emp.lbl.gov/publications/analysis-costs-benefits-and.

British Columbia Ministry of Finance. 2015. "Carbon Tax: Overview of the Revenue-Neutral Carbon Tax." 2015. http://www.fin.gov.bc.ca/tbs/tp/climate/carbon_tax.htm.

Brown, Maxwell, Wesley Cole, Kelly Eurek, Jon Becker, Dave Bielen, Ilya Chernyakhovskiy, Stuart Cohen, et al. 2020. "Regional Energy Deployment System (ReEDS) Model Documentation: Version 2019." NREL/TP-6A20-74111. Golden, CO: National Renewable Energy Laboratory. https://doi.org/10.2172/1505935. 
Bureau of Reclamation. 2011. "Hydropower Resource Assessment at Existing Reclamation Facilities." Denver, CO: U.S. Department of the Interior, Bureau of Reclamation, Power Resources Office.

http://www.usbr.gov/power/AssessmentReport/USBRHydroAssessmentFinalReportMarc h2011.pdf.

CARB. 2019. "California Greenhouse Gas Emissions for 2000 to 2017.” California Air

Resources Board.

https://ww3.arb.ca.gov/cc/inventory/pubs/reports/2000_2016/ghg_inventory_trends_0016.pdf.

Clean Energy Act of 2010. 2010. https://www.leg.bc.ca/pages/bclasslegacy.aspx\#/content/legacy/web/39th2nd/1st_read/gov17-1.htm.

Clemmer, Steve, John Rogers, Sandra Sattler, Jordan Macknick, and Trieu Mai. 2013.

"Modeling Low-Carbon US Electricity Futures to Explore Impacts on National and Regional Water Use." Environmental Research Letters 8 (1): 015004. https://doi.org/10.1088/1748-9326/8/1/015004.

Cohen, Stuart, Jonathon Becker, David A. Bielen, Maxwell Brown, Wesley J. Cole, Kelly P. Eurek, Allister Frazier, et al. 2019. "Regional Energy Deployment System (ReEDS) Model Documentation: Version 2018.” NREL/TP-6A20-72023. Golden, CO: National Renewable Energy Laboratory. https://doi.org/10.2172/1505935.

Cole, Wesley, Sean Corcoran, Nathaniel Gates, Daniel Mai, Trieu, and Paritosh Das. 2020. "2020 Standard Scenarios Report: A U.S. Electricity Sector Outlook." NREL/TP-6A2077442. Golden, CO: National Renewable Energy Laboratory. https://www.nrel.gov/docs/fy21osti/77442.pdf.

Cole, Wesley, Kelly P. Eurek, Nina M. Vincent, Trieu T. Mai, Gregory L. Brinkman, and Matthew Mowers. 2018. "Operating Reserves in Long-Term Planning Models." NREL/PR-6A20-71148. Golden, CO: National Renewable Energy Laboratory. https://doi.org/10.2172/1455165.

Cole, Wesley, and Will A. Frazier. 2020. “Cost Projections for Utility-Scale Battery Storage: 2020 Update.” Technical Report NREL/TP-6A20-75385. Golden, CO: National Renewable Energy Laboratory. https://www.nrel.gov/docs/fy20osti/75385.pdf.

Cole, Wesley, Bethany Frew, Pieter Gagnon, Andrew Reimers, Jarett Zuboy, and Robert Margolis. 2018. "Envisioning a Low-Cost Solar Future: Exploring the Potential Impact of Achieving the SunShot 2030 Targets for Photovoltaics." Energy 155 (July): 690-704. https://doi.org/10.1016/j.energy.2018.04.166.

Cole, Wesley, Nathaniel Gates, Trieu Mai, Daniel Greer, and Paritosh Das. 2019. "2019 Standard Scenarios Report: A U.S. Electricity Sector Outlook.” NREL/TP-6A20-74110. Golden, CO: National Renewable Energy Laboratory. https://doi.org/10.2172/1481848.

Cole, Wesley, Daniel Greer, Jonathan Ho, and Robert Margolis. 2020. "Considerations for Maintaining Resource Adequacy of Electricity Systems with High Penetrations of PV and Storage." Applied Energy 279 (December): 115795. https://doi.org/10.1016/j.apenergy.2020.115795.

Cole, Wesley J., and Nina M. Vincent. 2019. "Historical Comparison of Capacity Build Decisions from the Regional Energy Deployment System (ReEDS) Model.” NREL/TP6A20-71916. Golden, CO: National Energy Technology Laboratory. https://doi.org/10.2172/1505552. 
Cole, Wesley, Haley Lewis, Ben Sigrin, and Robert Margolis. 2016. "Interactions of Rooftop PV Deployment with the Capacity Expansion of the Bulk Power System." Applied Energy 168 (April): 473-81. https://doi.org/10.1016/j.apenergy.2016.02.004.

Cole, Wesley, Trieu Mai, Kelly Eurek, Daniel C. Steinberg, and Robert Margolis. 2015. "Considering the Role of Solar Generation under Rate-Based Targets in the EPA's Proposed Clean Power Plan." The Electricity Journal 28 (8): 20-28. https://doi.org/10.1016/j.tej.2015.09.002.

Cole, Wesley, Kenneth B. Medlock III, and Aditya Jani. 2016. "A View to the Future of Natural Gas and Electricity: An Integrated Modeling Approach.” Energy Economics 60 (November): 486-96. https://doi.org/10.1016/j.eneco.2016.03.005.

CPUC. 2018. Decision Setting Requirements for Load Serving Entities Filing Integrated Resource Plans. Vol. 16-02-007. http://docs.cpuc.ca.gov/PublishedDocs/Published/G000/M209/K771/209771632.PDF.

Davis, Lucas W. 2008. "Durable Goods and Residential Demand for Energy and Water: Evidence from a Field Trial.” The RAND Journal of Economics 39 (2): 530-46. https://doi.org/10.1111/j.0741-6261.2008.00026.x.

Denholm, Paul, Jacob Nunemaker, Pieter Gagnon, and Wesley Cole. 2019. "The Potential for Battery Energy Storage to Provide Peaking Capacity in the United States." NREL/TP6A20-74184. Golden, CO: National Renewable Energy Laboratory. https://www.nrel.gov/docs/fy19osti/74184.pdf.

Department of Environment, Energy and Forestry. n.d. "Energy Strategy Securing Our Future: Energy Efficiency and Conservation." Charlottetown, Prince Edward Island, Canada: Department of Environment, Energy and Forestry. http://www.gov.pe.ca/photos/original/env_snergystr.pdf.

Dieter, Cheryl A., and Kristin S. Linsey. 2017. "Estimated Use of Water in the United States County-Level Data for 2015.” U.S. Geological Survey. https://doi.org/10.5066/F7TB15V5.

DOE. 2008. "20\% Wind Energy by 2030: Increasing Wind Energy's Contribution to U.S. Electricity Supply.” Technical Report DOE/GO-102008-2567. Washington, D.C.: U. S. Department of Energy. http://www.nrel.gov/docs/fy08osti/41869.pdf. . 2011. "US Billion-Ton Update: Biomass Supply for a Bioenergy and Bioproducts Industry." ORNL/TM-2011/224. Agricultural and Biosystems Engineering Technical Reports and White Papers. Oak Ridge, TN: Oak Ridge National Laboratory. https://www1.eere.energy.gov/bioenergy/pdfs/billion_ton_update.pdf. . 2012. "SunShot Vision Study." DOE/GO-102012-3037. Washington, D.C.: U.S. Department of Energy. http://www.nrel.gov/docs/fy12osti/47927.pdfDOE/GO-1020123037.

. 2015. "Wind Vision: A New Era for Wind Power in the United States." DOE/GO102015-4557. Washington, D.C.: U.S. Department of Energy. http://www.energy.gov/sites/prod/files/WindVision_Report_final.pdf. . 2016a. "Pending Applications | Department of Energy." 2016. http://energy.gov/oe/services/electricity-policy-coordination-andimplementation/international-electricity-regulation/pending-applications. . 2016b. "Hydropower Vision: A New Chapter for America's 1st Renewable Electricity Source." Technical Report DOE/GO-102016-4869. Washington, D.C.: U. S. Department 
of Energy. http://energy.gov/eere/water/articles/hydropower-vision-new-chapter-americas-1st-renewable-electricity-source.

. 2019. "GeoVision: Harnessing the Heat Beneath Our Feet." Washington, D.C.: U.S.

Department of Energy. https://www.energy.gov/sites/prod/files/2019/06/f63/GeoVisionfull-report-opt.pdf.

- 2020. "Alternative Fuel Price Report." Washington, D.C.: U. S. Department of Energy. https://afdc.energy.gov/files/u/publication/alternative_fuel_price_report_july_2020.pdf.

DOER. 2018. "Electricity Sector Regulations: Fact Sheet." Boston, MA: Massachusetts

Department of Environmental Protection.

https://www.mass.gov/files/documents/2018/09/26/3dfs-electricity.pdf.

Dubin, Jeffrey A., and Daniel L. McFadden. 1984. "An Econometric Analysis of Residential Electric Appliance Holdings and Consumption.” Econometrica 52 (2): 345-62. https://doi.org/10.2307/1911493.

Dunbar, A., F. Tagliaferri, I. M. Viola, and G. P. Harrison. 2014. "The Impact of Electricity Price Forecast Accuracy on the Optimality of Storage Revenue." In 3rd Renewable Power Generation Conference (RPG 2014), 1-6. https://doi.org/10.1049/cp.2014.0902.

EIA. 2013. "Updated Capital Cost Estimates for Utility Scale Electricity Generating Plants." Washington, D.C.: U.S. DOE Energy Information Administration. http:/www.eia.gov/forecasts/capitalcost/pdf/updated_capcost.pdf.

—. 2014. “Annual Energy Outlook 2014.” DOE/EIA-0383(2014). Washington, D.C.: U.S. DOE Energy Information Administration.

—. 2015. "Electric Power Detailed State Data." 2015. http://www.eia.gov/electricity/data/state/. . 2016a. "Electric Sales, Revenue, and Average Price.” Washington, D.C.: U.S. Energy Information Administration. https://www.eia.gov/electricity/sales_revenue_price/. . 2016b. "Capital Cost Estimates for Utility Scale Electricity Generating Plants." Washington, D.C.: U.S. DOE Energy Information Administration. http://www.eia.gov/analysis/studies/powerplants/capitalcost/pdf/capcost_assumption.pdf. . 2017a. "Annual Energy Outlook 2017 with Projections to 2050.” AEO2017. Annual Energy Outlook. Washington, D.C.: U.S. Energy Information Administration. https://www.eia.gov/outlooks/archive/aeo17/. . 2017b. "The Electricity Market Module of the National Energy Modeling System: Model Documentation 2016.” Washington, D.C.: U.S. Energy Information Administration. https://www.eia.gov/outlooks/aeo/nems/documentation/electricity/pdf/m068(2016).pdf. . 2019a. "Annual Energy Outlook 2019." Washington, D.C.: U.S. Energy Information Administration. https://www.eia.gov/outlooks/aeo/pdf/aeo2019.pdf. . 2019b. "Five States Have Implemented Programs to Assist Nuclear Power Plants." October 7, 2019. https://www.eia.gov/todayinenergy/detail.php?id=41534.

—. 2020. "Annual Energy Outlook 2020 with Projections to 2050." Annual Energy Outlook. Washington, D.C.: U.S. Energy Information Administration. https://www.eia.gov/outlooks/aeo/pdf/AEO2020.pdf.

EIPC. 2012. "Phase 2 Report: DOE Draft - Parts 2-7 Interregional Transmission Development and Analysis for Three Stakeholder Selected Scenarios." Eastern Interconnect Planning Collaborative. 
http://nebula.wsimg.com/2964d965b867c8786028b950057c7e52?AccessKeyId=E28DF

A42F06A3AC21303\&disposition=0\&alloworigin $=1$.

EPA. 2008. "EGRID2007 Version1.1 Year 2005 Summary Tables.” Washington, D.C.: U.S.

Environmental Protection Agency. https://www.epa.gov/energy/egrid2007-version11year-2005-summary-tables.

—. 2016. "Resources for Implementation | Air Transport | US EPA." 2016.

https://www3.epa.gov/crossstaterule/stateinfo.html\#states.

ERCOT. 2019. "News Release: ERCOT's Reserve Margin Climbs 2\% for Summer 2020."

December 5, 2019. http://www.ercot.com/news/releases/show/195806.

"Form EIA-860 Detailed Data with Previous Form Data (EIA-860A/860B)." 2018. 2018. https://www.eia.gov/electricity/data/eia860/.

Frazier, A. Will, Wesley Cole, Paul Denholm, Daniel Greer, and Pieter Gagnon. 2020.

"Assessing the Potential of Battery Storage as a Peaking Capacity Resource in the United States." Applied Energy 275 (October): 115385. https://doi.org/10.1016/j.apenergy.2020.115385.

Frew, Bethany, Wesley Cole, Paul Denholm, A. Will Frazier, Nina Vincent, and Robert

Margolis. 2019. "Sunny with a Chance of Curtailment: Operating the US Grid with Very High Levels of Solar Photovoltaics." IScience 21 (November): 436-47. https://doi.org/10.1016/j.isci.2019.10.017.

Frew, Bethany, Wesley Cole, Yinong Sun, James Richards, and Trieu Mai. 2017. "8760-Based Method for Representing Variable Generation Capacity Value in Capacity Expansion Models.” NREL/CP-6A20-68869. Golden, CO: National Renewable Energy Laboratory. https://www.nrel.gov/docs/fy17osti/68869.pdf.

Fry, Joyce, George Xian, Suming Jin, Jon Dewitz, Collin Homer, Limin Yang, Christopher Barnes, Nathaniel Herold, and James Wickham. 2011. "Completion of the 2006 National Land Cover Database for the Conterminous United States." Photogrammetric Engineering \& Remote Sensing 77 (9): 858-64.

Fu, Ran, David Feldman, and Robert Margolis. 2018. "U.S. Solar Photovoltaic System Cost Benchmark: Q1 2018.” Technical Report NREL/TP-6A20-72399. Golden, CO: National Renewable Energy Laboratory. https://doi.org/10.2172/1484344.

Gagnon, Pieter, Wesley J. Cole, Bethany Frew, and Robert Margolis. 2017. "The Impact of Retail Electricity Tariff Evolution on Solar Photovoltaic Deployment." The Electricity Journal, Energy Policy Institute's Seventh Annual Energy Policy Research Conference, 30 (9): 22-28. https://doi.org/10.1016/j.tej.2017.10.003.

Guertin, Chantal, Subal C. Kumbhakar, and Anantha Kumar Duraiappah. 2003. "Determining Demand for Energy Services: Investigating Income-Driven Behaviours." International Institute for Sustainable Development. https://www.iisd.org/pdf/2003/energy_determing_demand.pdf.

Hadjerioua, B., S.-C. Kao, R.A. McManamay, M.F.K. Pasha, D. Yeasmin, A.A. Oubeidillah, N.M. Samu, et al. 2013. "An Assessment of Energy Potential from New Stream-Reach Development in the United States: Initial Report on Methodology." Oak Ridge, TN: Oak Ridge National Laboratory.

Hadjerioua, B., Yaxing Wei, and Shih-Chieh Kao. 2012. "An Assessment of Energy Potential at Non-Powered Dams in the United States." GPO DOE/EE-0711. Oak Ridge, TN: Oak Ridge National Laboratory. 
Hagberg, Aric, Pieter Swart, and Daniel S Chult. 2008. "Exploring Network Structure, Dynamics, and Function Using Networkx.” LA-UR-08-05495; LA-UR-08-5495. Los Alamos National Lab. (LANL), Los Alamos, NM (United States). https://www.osti.gov/biblio/960616.

Hamilton, Sofia D., Dev Millstein, Mark Bolinger, Ryan Wiser, and Seongeun Jeong. 2020. "How Does Wind Project Performance Change with Age in the United States?" Joule 4 (5): 1004-20. https://doi.org/10.1016/j.joule.2020.04.005.

Haratyk, Geoffrey. 2017. "Early Nuclear Retirements in Deregulated US Markets: Causes, Implications and Policy Options." https://assets.documentcloud.org/documents/3723775/MIT-Early-Nuclear-Retirement-32017.pdf.

Hargreaves, Jeremy J., and Ryan A. Jones. 2020. "Long Term Energy Storage in Highly Renewable Systems." Frontiers in Energy Research 8. https://doi.org/10.3389/fenrg.2020.00219.

Heeter, Jenny. 2015. "Cross-State RPS Visualization.” 2015. http://www.nrel.gov/analysis/docs/index.html.

Holt, Ed. 2016. "Potential RPS Markets for Renewable Energy Generators.” Ed Holt \& Associates, Inc. http://www.cesa.org/assets/2016-Files/Potential-RPS-Markets-ReportHolt.pdf.

Hostick, Donna, David B. Belzer, Stanton W. Hadley, Tony Markel, Chris Marnay, and Michael Kintner-Meyer. 2012. "Renewable Electricity Futures Study. Volume 3. End-Use Electricity Demand.” NREL/TP-6A20-52409-3. Golden, CO: National Renewable Energy Laboratory. https://doi.org/10.2172/1219713.

HSIP. 2012. "Homeland Security Infrastructure Project."

Hummon, Marissa, Paul Denholm, Jennie Jorgenson, David Palchak, Brendan Kirby, and Ookie Ma. 2013. "Fundamental Drivers of the Cost and Price of Operating Reserves." NREL/TP-6A20-58491.

Huntington, Hillard. 2013. "EMF 26: Changing the Game? Emissions and Market Implications of New Natural Gas Supplies." Stanford, CA: Energy Modeling Forum, Stanford University. https://web.stanford.edu/group/emf-research/docs/emf26/Summary26.pdf.

Jorgenson, Jennie, Paul Denholm, Mark Mehos, and Craig Turchi. 2013. "Estimating the Performance and Economic Value of Multiple Concentrating Solar Power Technologies in a Production Cost Model." NREL/TP-6A20-58645. National Renewable Energy Lab. (NREL), Golden, CO (United States). https://doi.org/10.2172/1260920.

Kao, Shih Chieh, Ryan A. McManamay, Kevin M. Stewart, Nicole M. Samu, Boualem Hadjerioua, Scott T. DeNeale, Dilruba Yeasmin, et al. 2014. "New Stream-Reach Development : A Comprehensive Assessment of Hydropower Energy Potential in the United States." GPO DOE/EE-1063. U.S. Department of Energy Wind \& Water Power Technologies Office, prepared by Oak Ridge National Laboratory. http://nhaap.ornl.gov/sites/default/files/ORNL_NSD_FY14_Final_Report.pdf.

Lantz, Eric, Daniel Steinberg, Michael Mendelsohn, Owen Zinaman, Ted James, Gian Porro, Maureen Hand, et al. 2014. "Implications of a PTC Extension on U.S. Wind Deployment." Technical Report NREL/TP-6A20-61663. Golden, CO: National Renewable Energy Laboratory. http://www.nrel.gov/docs/fy14osti/61663.pdf.

Lazard. 2016. "Lazard's Levelized Cost of Storage - Version 2.0." https://www.lazard.com/media/438042/lazard-levelized-cost-of-storage-v20.pdf. 
Lew, D., G. Brinkman, E. Ibanez, A. Florita, M. Heaney, B.-M. Hodge, M. Hummon, G. Stark, J. King, and S. A. Lefton. 2013. "The Western Wind and Solar Integration Study Phase 2.” NREL/TP-5500-55588. Golden, CO: National Renewable Energy Laboratory. http://www.osti.gov/scitech/servlets/purl/1095399.

Logan, Jeffrey, Anthony Lopez, Trieu Mai, Carolyn Davidson, Morgan Bazilian, and Douglas Arent. 2013. "Natural Gas Scenarios in the US Power Sector." Energy Economics 40: 183-95.

Lopez, Anthony, Trieu Mai, Eric Lantz, Dylan Harrison-Atlas, Travis Williams, and Galen Maclaurin. 2021. "Land Use and Turbine Technology Influences on Wind Potential in the United States.” Energy 223. https://doi.org/10.1016/j.energy.2021.120044.

Lopez, Anthony, Billy Roberts, Donna Heimiller, Nate Blair, and Gian Porro. 2012. "US Renewable Energy Technical Potentials: A GIS-Based Analysis.” NREL/TP-6A2051946. Golden, CO: National Renewable Energy Laboratory. http://cdn.decarboni.se/sites/default/files/publications/138258/US-renewable-energytechnical-potentials-GIS-based-analysis.pdf.

Macknick, J., R. Newmark, G. Heath, and K. C. Hallett. 2012. "Operational Water Consumption and Withdrawal Factors for Electricity Generating Technologies: A Review of Existing Literature." Environmental Research Letters 7 (4): 045802. https://doi.org/10.1088/17489326/7/4/045802.

Macknick, Jordan, Stuart Cohen, Robin Newmark, Andrew Martinez, Patrick Sullivan, and Vince Tidwell. 2015. "Water Constraints in an Electric Sector Capacity Expansion Model.” NREL/TP-6A20-64270. Golden, CO: National Renewable Energy Laboratory. http://www.nrel.gov/docs/fy15osti/64270.pdf.

Maclaurin, Galen, Nick Grue, Anthony Lopez, and Dona Heimiller. 2019. "The Renewable Energy Potential (ReV) Model: A Geospatial Platform for Technical Potential and Supply Curve Modeling.” NREL/TP-6A20-73067. Golden, CO: National Renewable Energy Laboratory. https://www.nrel.gov/docs/fy19osti/73067.pdf.

Mahone, Amber, Liz Mettetal, John Stevens, Sharad Bharadwaj, Anthony Fratto, Manohar Mogadali, Vignesh Venugopal, Mengyao Yuan, and Arne Olson. 2020. "Hydrogen Opportunities in a Low-Carbon Future." San Francisco, CA: Energy and Environmental Economics, Inc. https://www.ethree.com/wpcontent/uploads/2020/07/E3_MHPS_Hydrogen-in-the-West-Report_Final_June2020.pdf.

Mai, Trieu, Wesley Cole, Venkat Krishnana, and Mark Bolinger. 2015. "Impact of Federal Tax Policy on Utility-Scale Solar Deployment Given Financing Interactions." NREL/PR6A20-65014. Golden, CO: National Renewable Energy Laboratory.

Mai, Trieu, Anthony Lopez, Matthew Mowers, and Eric Lantz. 2021. "Interactions of Wind Energy Project Siting, Wind Resource Potential, and the Evolution of the U.S. Power System.” Energy 223. https://doi.org/10.1016/j.energy.2021.119998.

Mai, Trieu, David Mulcahy, M. Maureen Hand, and Samuel F. Baldwin. 2014. "Envisioning a Renewable Electricity Future for the United States.” Energy 65 (February): 374-86. https://doi.org/10.1016/j.energy.2013.11.029.

Mai, Trieu, R. Wiser, D. Sandor, G. Brinkman, G. Heath, P. Denholm, D. J. Hostick, N. Darghouth, A. Schlosser, and K. Strzepek. 2012. "Exploration of High-Penetration Renewable Electricity Futures. Vol. 1 of Renewable Electricity Futures Study." NREL/TP-6A20-52409-1. Golden, CO: National Renewable Energy Laboratory. 
Martinez, Andrew, Kelly Eurek, Trieu Mai, and Andrew Perry. 2013. "Integrated Canada-US Power Sector Modeling with the Regional Energy Deployment System (ReEDS)." NREL/TP-6A20-56724. Golden, CO: National Renewable Energy Laboratory.

Mignone, Bryan K., Thomas Alfstad, Aaron Bergman, Kenneth Dubin, Richard Duke, Paul Friley, Andrew Martinez, et al. 2012. "Cost-Effectiveness and Economic Incidence of a Clean Energy Standard.” Economics of Energy \& Environmental Policy 1 (3). https://doi.org/10.5547/2160-5890.1.3.5.

Mills, Andrew, and Ryan Wiser. 2012. "An Evaluation of Solar Valuation Methods Used in Utility Planning and Procurement Processes.” Berkeley, CA: Lawrence Berkeley National Laboratory. https:/emp.lbl.gov/sites/all/files/lbnl-5933e.pdf.

Mitsubishi. 2020. "Intermountain Power Agency Orders MHPS JAC Gas Turbine Technology for Renewable-Hydrogen Energy Hub.” Mitsubishi Power Americas, Inc. 2020. https://power.mhi.com/regions/amer/news/200310.html.

Montgomery, Watson, and Harza. 2009. "Hydropower Modernization Initiative, Phase I, Needs and Opportunities Evaluation and Ranking. Report Prepared for the U.S. Army Corps of Engineers Northwest Division Hydroelectric Design Center." Contract No. W9127N-08D-0003, Task Order 0013.

Murphy, Caitlin, Yinong Sun, Wesley Cole, Galen Maclaurin, Craig Turchi, and Mark Mehos. 2019. "The Potential Role of Concentrating Solar Power within the Context of DOE's 2030 Solar Cost Targets.” NREL/TP-6A20-71912. Golden, CO: National Renewable Energy Laboratory.

Murphy, Frederic H., and Yves Smeers. 2005. "Generation Capacity Expansion in Imperfectly Competitive Restructured Electricity Markets.” Operations Research 53 (4): 646-661.

Musial, Walter, Philipp Beiter, Paul Spitsen, Jacob Nunemaker, and Vahan Gevorgian. 2019. “2018 Offshore Wind Technologies Market Report.” 2019. Washington, D.C.: U. S. Department of Energy. https://doi.org/10.2172/1375395.

NEB. 2013. "Canada's Energy Futures 2013: Energy Supply and Demand Projections through 2035.” NE2-12/2013E-PDF. National Energy Board. http://www.nebone.gc.ca/nrg/ntgrtd/ftr/2016/2016nrgftr-eng.pdf. . 2016. "Canada's Energy Futures 2016: Energy Supply and Demand Projections through 2040.” NE2-12/2015E-PDF. National Energy Board. http://www.nebone.gc.ca/nrg/ntgrtd/ftr/2016/2016nrgftr-eng.pdf. . 2018. "Canada's Energy Futures 2018: Energy Supply and Demand Projections through 2040.” NE2-12/2015E-PDF. National Energy Board. https://www.nebone.gc.ca/nrg/ntgrtd/ftr/2018/index-eng.html.

NERC. 2010. “2010 Long-Term Reliability Assessment.” North American Electric Reliability Corporation (NERC). http://www.nerc.com/files/2010\%20LTRA.pdf. . 2016. "Glossary of Terms Used in NERC Reliability Standards." North American Electric Reliability Corporation. http://www.nerc.com/files/glossary_of_terms.pdf.

—. 2018. "2018 Long-Term Reliability Assessment." North American Electric Reliability Corporation. https://www.nerc.com/pa/RAPA/ra/Reliability\%20Assessments\%20DL/NERC_LTRA_2 018_12202018.pdf.

Newell, Richard G., and Juha Siikamäki. 2015. "Individual Time Preferences and Energy Efficiency." American Economic Review 105 (5): 196-200. https://doi.org/10.1257/aer.p20151010. 
Nova Scotia Department of Energy. 2010. "Renewable Electricity Plan: A Path to Good Jobs, Stable Prices, and a Cleaner Environment." Halifax, Nova Scotia, Canada: Province of Nova Scotia. http://energy.novascotia.ca/sites/default/files/renewable-electricity-plan.pdf.

NREL. 2012. "Renewable Electricity Futures Study." NREL/TP-6A20-52409. Golden, CO: National Renewable Energy Laboratory.

—. 2019. "2019 Annual Technology Baseline.” Golden, CO: National Renewable Energy Laboratory. https://atb.nrel.gov/.

—. 2020. "2020 Annual Technology Baseline.” Golden, CO: National Renewable Energy Laboratory. https://atb.nrel.gov/.

O’Connor, Patrick, Qin Fen Zhang, Scott T. Deneale, Dol Raj Chalise, and Emma Centurion. 2015. "Hydropower Baseline Cost Modeling." ORNL/TM-2015/14. Oak Ridge, TN: Oak Ridge National Laboratory. http://hydropower.ornl.gov/docs/pubs/Hydropower_Baseline_Cost_Modeling.pdf.

Parker, Robert Nash, and Rudy Fenwick. 1983. "The Pareto Curve and Its Utility for OpenEnded Income Distributions in Survey Research." Social Forces 61 (3): 872-85. https://doi.org/10.2307/2578140.

Paul, Anthony C., Erica C. Myers, and Karen L. Palmer. 2009. "A Partial Adjustment Model of US Electricity Demand by Region, Season, and Sector.” RFF DP 08-50. Resources for the Future. https://media.rff.org/archive/files/sharepoint/WorkImages/Download/RFFDP-08-50.pdf.

Ponce, Micaela, and Anne Neumann. 2014. "Elasticities of Supply for the US Natural Gas Market." https://www.diw.de/documents/publikationen/73/diw_01.c.441773.de/dp1372.pdf.

Previsic, Mirko, Jeff Epler, Maureen Hand, Donna Heimiller, Walter Short, and Kelly Eurek. 2012. "The Future Potential of Wave Power in the United States." RE Vision Consulting. http://www.revision.net/documents/The\%20Future \%20of\%20Wave\%20Power\%20MP\%209-20$12 \% 20 \mathrm{~V} 2 . p d f$.

Rapson, David. 2014. "Durable Goods and Long-Run Electricity Demand: Evidence from Air Conditioner Purchase Behavior." Journal of Environmental Economics and Management 68 (1): 141-60. https://doi.org/10.1016/j.jeem.2014.04.003.

Reiss, Peter C., and Matthew W. White. 2005. "Household Electricity Demand, Revisited." The Review of Economic Studies 72 (3): 853-83. https://doi.org/10.1111/0034-6527.00354.

Richards, James, and Wesley J. Cole. 2017. "Assessing the Impact of Nuclear Retirements on the U.S. Power Sector.” The Electricity Journal, Energy Policy Institute's Seventh Annual Energy Policy Research Conference, 30 (9): 14-21. https://doi.org/10.1016/j.tej.2017.10.007.

Ruth, Mark F., Paige Jadun, Nicholas Gilroy, Elizabeth Connelly, Richard Boardman, A. J. Simon, Amgad Elgowainy, and Jarett Zuboy. 2020. "The Technical and Economic Potential of the H2@Scale Hydrogen Concept within the United States." NREL/TP6A20-77610. Golden, CO: National Renewable Energy Laboratory. https://doi.org/10.2172/1677471.

Sengupta, Manajit, Yu Xie, Anthony Lopez, Aron Habte, Galen Maclaurin, and James Shelby. 2018. "The National Solar Radiation Data Base (NSRDB)." Renewable and Sustainable Energy Reviews 89 (June): 51-60. https://doi.org/10.1016/j.rser.2018.03.003. 
Short, W., D. J. Packey, and T. Holt. 1995. "A Manual for the Economic Evaluation of Energy Efficiency and Renewable Energy Technologies." NREL/TP-462-5173. National Renewable Energy Lab., Golden, CO (United States). https://doi.org/10.2172/35391.

Short, Walter, Nate Blair, Donna Heimiller, and Vikram Singh. 2003. "Modeling the Long-Term Market Penetration of Wind in the United States." NREL/CP-620-34469. Golden, CO: National Renewable Energy Laboratory. http://www.nrel.gov/docs/fy03osti/34469.pdf.

Short, Walter, Nate Blair, Patrick Sullivan, and Trieu Mai. 2009. "ReEDS Model Documentation: Base Case Data and Model Description." Golden, CO: National Renewable Energy Laboratory.

Sigrin, Benjamin, Michael Gleason, Robert Preus, Ian Baring-Gould, and Robert Margolis. 2016. "The Distributed Generation Market Demand Model (DGen): Documentation." NREL/TP-6A20-65231. Golden, CO: National Renewable Energy Laboratory. http://www.nrel.gov/docs/fy16osti/65231.pdf.

Sioshansi, Ramteen. 2014. "A Dynamic Programming Approach to Estimate the Capacity Value of Energy Storage.” IEEE TRANSACTIONS ON POWER SYSTEMS 29 (1): 9.

Smith, S. 2014. "EPA: Clean Power Plan Could Increase Power Sector Gas Use by $1.2 \mathrm{Tcf}$ in 2020." SNL Financial, June 2, 2014.

Steckler, Nicholas. 2017. "Half of U.S. Nuclear Power Plants Are Underwater." Bloomberg New Energy Finance.

Steinberg, Daniel, Dave Bielen, Josh Eichman, Kelly Eurek, Jeff Logan, Trieu Mai, Colin McMillan, Andrew Parker, Laura Vimmerstedt, and Eric Wilson. 2017. "Electrification and Decarbonization: Exploring U.S. Energy Use and Greenhouse Gas Emissions in Scenarios with Widespread Electrification and Power Sector Decarbonization." NREL/TP--6A20-68214. Golden, CO: National Renewable Energy Laboratory. https://doi.org/10.2172/1372620.

Stoll, Brady, Juan Andrade, Stuart Cohen, Greg Brinkman, and Carlo Brancucci MartinezAnido. 2017. "Hydropower Modeling Challenges." NREL/TP-5D00-68231. Golden, CO: National Renewable Energy Laboratory. https://doi.org/10.2172/1353003.

Sullivan, Patrick, Wesley Cole, Nate Blair, Eric Lantz, Venkat Krishnan, Trieu Mai, David Mulcahy, and Gian Porro. 2015. "2015 Standard Scenarios Annual Report: U.S. Electric Sector Scenario Exploration.” NREL/TP-6A20-64072. Golden, CO: National Renewable Energy Laboratory.

Sun, Yinong, Jadun Paige, Nelson Brent, Muratori Matteo, Murphy Caitlin, Jeffrey Logan, and Trieu Mai. 2020. "Electrification Futures Study: Methodological Approaches for Assessing Long-Term Power System Impacts of End-Use Electrification.” Technical Report NREL/TP-6A20-73336.

Tester, Jefferson W., Brian J. Anderson, Anthony S. Batchelor, David D. Blackwell, Ronald DiPippo, Elisabeth M. Drake, John Garnish, et al. 2006. "The Future of Geothermal Energy.” INL/EXT-06-11746. Idaho Falls, ID: Idaho National Laboratory. https://energy.mit.edu/wp-content/uploads/2006/11/MITEI-The-Future-of-GeothermalEnergy.pdf.

Tidball, Rick, Joel Bluestein, Nick Rodriguez, and Stu Knoke. 2010. "Cost and Performance Assumptions for Modeling Electricity Generation Technologies." NREL/SR-6A2048595. Golden, CO: National Renewable Energy Laboratory. http://www.nrel.gov/docs/fy11osti/48595.pdf. 
Tidwell, Vincent C., Barbie D. Moreland, Calvin R. Shaneyfelt, and Peter Kobos. 2018. "Mapping Water Availability, Cost and Projected Consumptive Use in the Eastern United States with Comparisons to the West." Environmental Research Letters 13 (1): 014023. https://doi.org/10.1088/1748-9326/aa9907.

Train, Kenneth. 1985. "Discount Rates in Consumers' Energy-Related Decisions: A Review of the Literature." Energy 10 (12): 1243-53. https://doi.org/10.1016/0360-5442(85)90135-5.

Union of Concerned Scientists. 2012. "UCS EW3 Energy-Water Database V.1.3.” 2012. www.ucsusa.org/ew3database.

Uria-Martinez, Rocio, Patrick W. O’Connor, and Megan M. Johnson. 2015. “2014 Hydropower Market Report.” DOE/EE-1195. Washington, D.C.: U.S. Department of Energy Wind \& Water Power Technologies Office, prepared by Oak Ridge National Laboratory. http://www.energy.gov/sites/prod/files/2015/04/f22/2014\%20Hydropower\%20Market\%2 0Report_20150424.pdf.

USEIA. 2018. "Thermoelectric Cooling Water Data." 2018. https://www.eia.gov/electricity/data/water/.

Ventosa, Mariano, Álvaro Baíllo, Andrés Ramos, and Michel Rivier. 2005. "Electricity Market Modeling Trends.” Energy Policy 33 (7): 897-913. https://doi.org/10.1016/j.enpol.2003.10.013.

WECC. 2013. "2013 Interconnection-Wide Plan Tools and Models.” Western Electricity Coordinating Council. https://www.wecc.biz/Reliability/2013Plan_ToolsandModels.docx. . 2015. “TEPPC Study Report - 2024 PC1 Common Case.” Western Electricity Coordinating Council. https://www.wecc.biz/Administrative/150805_2024\%20CCV1.5_StudyReport_draft.pdf.

Williams, Colin F., Marshall J. Reed, and Robert H. Mariner. 2008. "A Review of Methods Applied by the US Geological Survey in the Assessment of Identified Geothermal Resources." 1296.

Wiser, Ryan, and Mark Bolinger. 2019. "Benchmarking Anticipated Wind Project Lifetimes: Results from a Survey of U.S. Wind Industry Professionals.” Berkeley, CA: Lawrence Berkeley National Laboratory. https://escholarship.org/content/qt7gj3x2dj/qt7gj3x2dj.pdf.

Zhang, Jun. 2016. "Carbon Tax Incidence and Household Energy Demand in the U.S." In . Boston, MA: Agricultural and Applied Economics Association. https://ideas.repec.org/p/ags/aaea16/235569.html. 


\section{Appendix}

\section{Natural Gas Supply Curves}

The ReEDS model does not explicitly model the U.S. natural gas (NG) system, which involves multiple sectors of the economy and includes complex infrastructure and markets. Rather, a regional supply curve representation is a used to approximate the NG system as it interacts with the electric sector. For more information on the impact of natural gas representation in ReEDS, see Cole et al. (2016).

The premise of using regional supply curves is that the price in each region will be a function of both the regional and national NG demand. The supply curves are parameterized from AEO scenarios for each of the nine EIA census divisions (see Figure 41). Two methods exist to parameterize the natural gas supply curves and both are discussed here. The first method which involves estimating a linear regression of prices on regional and national quantities has been used in previous version in ReEDS and is discussed first. The second method is relatively new to ReEDS and involves parameterizing a constant elasticity of supply curve and is discussed second. Through multiple tests, we have found minimal differences in results between the two versions ( $1 \%$ or less of a change in national generation by technology).

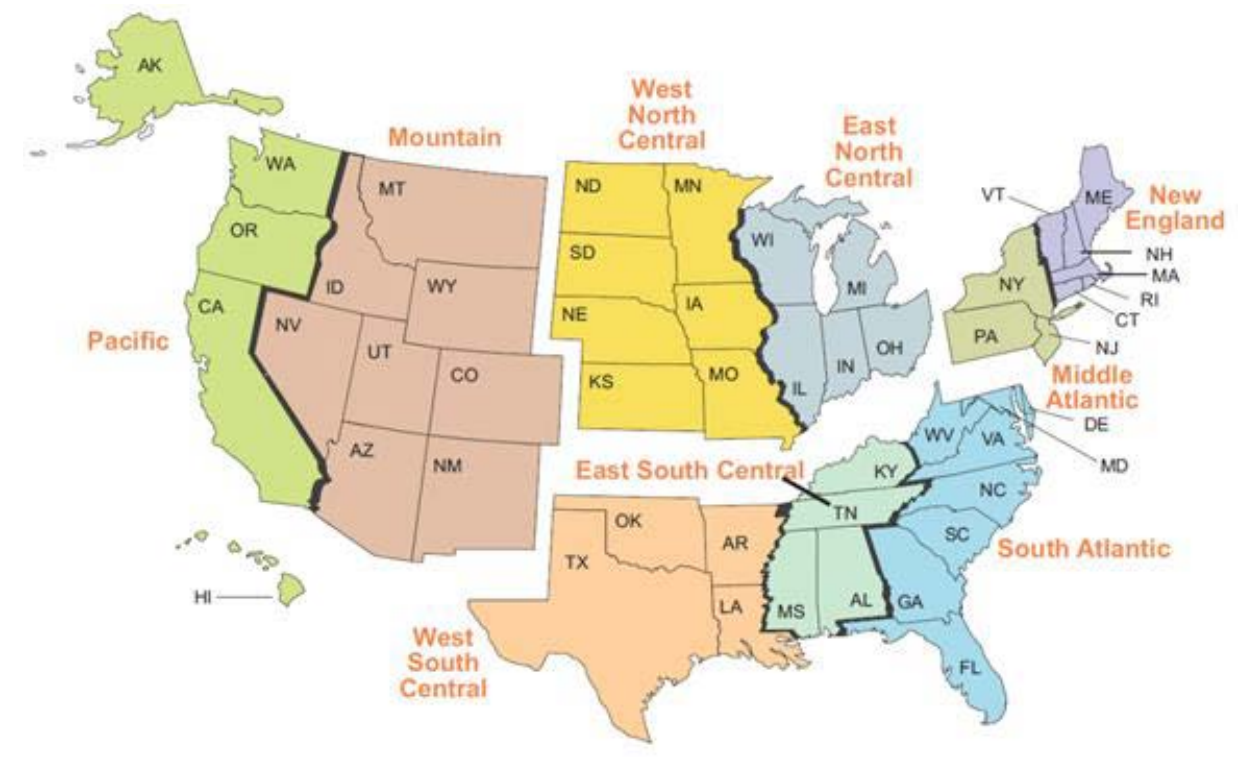

Figure 42. The nine census divisions defined by EIA (EIA 2014)

A regional supply curve was created in ReEDS for each of these census divisions.

\section{Linear Regression Approach}

The AEO scenarios were used to estimate parameters for the following NG price-consumption model:

$$
P_{i, j}=\alpha+\alpha_{i}+\alpha_{j}+\alpha_{i, j}+\beta_{n a t} Q_{n a t_{j}}+\beta_{i} Q_{i, j}
$$

where $P_{i, j}$ is the price of natural gas (in $\$ / \mathrm{MMBtu}$ ) in region $i$ and year $j$, the $\alpha$ parameters are the intercept terms of the supply curves with adjustments made based on region $\left(\alpha_{i}\right)$, year $\left(\alpha_{j}\right)$, and 
the region-year interaction $\left(\alpha_{i, j}\right), \beta_{\text {nat }}$ is the coefficient for the national NG demand $\left(Q_{n a t}\right.$, in quads), $\beta_{i}$ is the coefficient for the regional NG demand $\left(Q_{i, j}\right)$ in region $i$. Note that the four $\alpha$ parameters in [1] can in practice be represented using only $\alpha_{i, j}$.

The $\beta$ terms are regressed from AEO2014 scenarios, with nine of the 31 AEO2014 scenarios removed as outliers (EIA 2014). These outlier scenarios typically include cases of very low or very high natural gas resource availability, which are useful for estimating NG price as a function of supply but not for estimating NG price as a function of demand-for given supply scenarios. The national and regional $\beta$ terms are reported in Figure 42 . We made a specific posthoc adjustment to the regression model's outputs for one region; the $\beta$ i term for the West North Central division was originally an order of magnitude higher than the other $\beta i$ values because the West North Central usage in the electricity sector is so low $\left(0.05\right.$ quad $^{75}$ in 2013 , compared to $\sim 0.5$ quad or more in most regions). The overall natural gas usage (i.e., not just electricity sector usage) in West North Central is similar to the usage in East North Central, so intuitively it makes sense to have a $\beta$ i for West North Central relatively close to that of East North Central. We therefore manually adjusted the West North Central $\beta$ i term to be 0.6 (in 2004\$/MMBtu/quad) and recalculated the alpha terms with the new beta to achieve the AEO2014 target prices. The situation in West North Central whereby such a small fraction of NG demand goes to electricity is unique; we do not believe that the other regions warrant similar treatment.

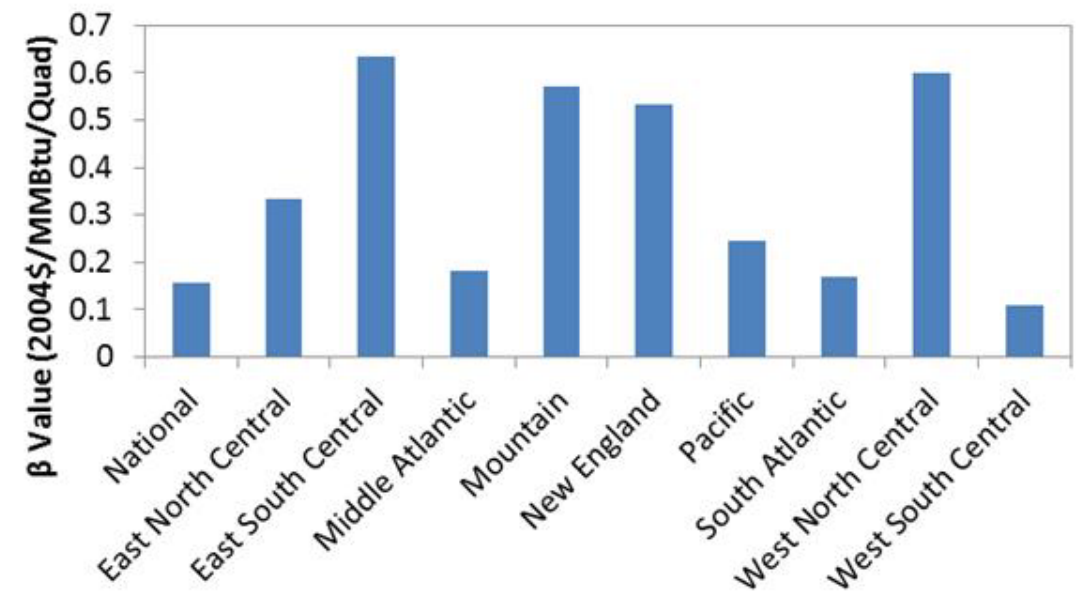

Figure 43. $\beta$ values for the nine census divisions

The "National" value at the far left is $\beta_{\text {nat. }} A \beta$ of 0.2 means that if demand increases by one quad, the price will increase by $\$ 0.20 / \mathrm{MMBtu}$ (see Equation [1]).

The $\alpha$ terms are then regressed for each individual scenario assuming the same $\beta$ values for all scenarios. Although the $\beta$ terms are derived from AEO2014 data, $\alpha$ terms are regressed using AEO2018 data for the scenario they are intended to represent (EIA 2019a). Thus, we assume natural gas price elasticity has remained constant while price projections shift over time as represented by the $\alpha$ values.

\footnotetext{
${ }^{75}$ A quad is a quadrillion Btu, or $10^{15}$ Btu.
} 


\section{Comparison of Elasticities from Regression Approach to Literature Values}

Technical literature tends to report the price elasticity of supply and the price elasticity of demand, which are estimates of the supply and demand, respectively, of a good given a change in price. In the formulation given by Equation [1], we attempt to estimate a value that is similar to the price elasticity of demand - we estimate a change in price given a change in demand. Therefore, we present here a comparison against the price elasticity of demand as the closest available proxy, noting however that it is not necessarily identical to estimates of $\beta$. Price elasticity of demand is typically negative but is reported here as a positive number for convenience.

External sources are varied and often vague in their estimates of price sensitivity of natural gas. Using the reported domestic NG market demand given for 2012 in AEO2014, the $\beta$ values reported here yield an overall NG sector elasticity value of $0.36-0.92$ (higher values of $\beta$ correspond to lower elasticity values). Arora (2014) estimated the price elasticity of demand for NG to be $0.11-0.70$, depending on the granularity and time horizon of the NG price data considered. Bernstein and Griffin (2006) examined the price elasticity of demand for residential NG usage, and they estimated the long-run elasticity to be $0.12-0.63$ depending on the region. The Energy Modeling Forum at Stanford University reports NG price elasticity of demand for 13 different energy models (Huntington 2013). The reported elasticity ranges from 0 to 2.20 depending on the year, model, and scenario considered. For the NEMS model, which is used for the AEO, the elasticity ranges from 0.22 to 0.81 depending on the year and scenario (Huntington 2013).

The EPA's proposed Clean Power Plan included a projection that natural gas usage will increase by 1.2 quads in 2020 , resulting in an $8 \%-12 \%$ increase in NG prices for the electric sector (Smith 2014). This corresponds to a $\beta_{\text {nat }}$ of $0.38-0.51$ in $2004 \$ / M M B t u / q u a d$.

\section{Constant Elasticity of Supply}

The second method for representing gas price adjustments leverages a constant elasticity of supply curve for census division prices as a function of the quantities consumed. The general form of the equation relies on a reference price $(\bar{p})$, a reference quantity $(\bar{q})$, and a price elasticity of supply $(\epsilon)^{76}$ to determine the endogenous price $(p)$ based on an endogenous quantity $(q)$ such that:

$$
p=\bar{p}\left(\frac{q}{\bar{q}}\right)^{\epsilon}
$$

When parameterizing for the census division representations, the supply curve should reflect the change in price given a change in the census division's quantity consumed in the electricity sector. To the best of our knowledge, no published studies estimate the elasticity of supply for natural gas specific to each sector and region. Therefore, the calibrated curve needs to consider the change in the census division's price given a change in the consumption of natural gas in the region's electricity sector with respect to other regions and sectors. To do this, the reference price, numerator, and denominator in the previous equation are adjusted to reflect the

76 The default value of $\epsilon$ is assumed to be 0.76 from values estimated by Ponce and Neuman (2014) 
consumption change only in the electricity sector. Explicitly, the constant elasticity of supply parameters are now indexed by census division $(r)$ and sector $s \in\{$ electricity, industrial, residential, commercial, vehicles\}). The equation used to populate the supply curve in the model becomes:

$$
p_{e l e, r}=\bar{p}_{e l e, r}\left(\frac{\sum_{s^{\prime} \notin e l e, r^{\prime} \notin r} \bar{q}_{s^{\prime}, r^{\prime}}+q_{e l e, r}}{\sum_{s, r} \bar{q}_{s, r}}\right)^{\epsilon}
$$

A potential addition to this representation, included as a switch in the model, also includes national price adjustments as deviations from the reference point. By denoting the national price as $p_{\text {ele,nat }}$, the deviation from the benchmark price based on national quantities consumed in the electricity sector can be computed as:

$$
\Delta p_{\text {ele,nat }}=\bar{p}_{\text {ele,nat }}\left(1-\frac{\sum_{s^{\prime} \notin e l e, r} \bar{q}_{s^{\prime}, r}+\sum_{r} q_{\text {ele }, r}}{\sum_{s, r} \bar{q}_{s, r}}\right)^{\epsilon}
$$

\section{Seasonal Natural Gas Price Adjustments}

We use natural gas futures prices to estimate the ratio of winter to non-winter natural gas prices to implement seasonal gas price differences in ReEDS. We chose futures prices for two reasons: (1) ReEDS represents a system with no unforeseen disturbances, which is similar to futures prices and (2) historical natural gas prices have fluctuated greatly since the deregulation of natural gas prices.

Figure 43 shows the cyclical nature of the natural gas futures prices. Figure 44 breaks the same prices out into seasons, showing that the non-winter seasons have nearly the same price while wintertime prices are consistently higher. Wintertime prices are on average 1.054 times higher than non-winter prices. The standard deviation of this price ratio is 0.004 , indicating that the ratio shows very little year-to-year variation.

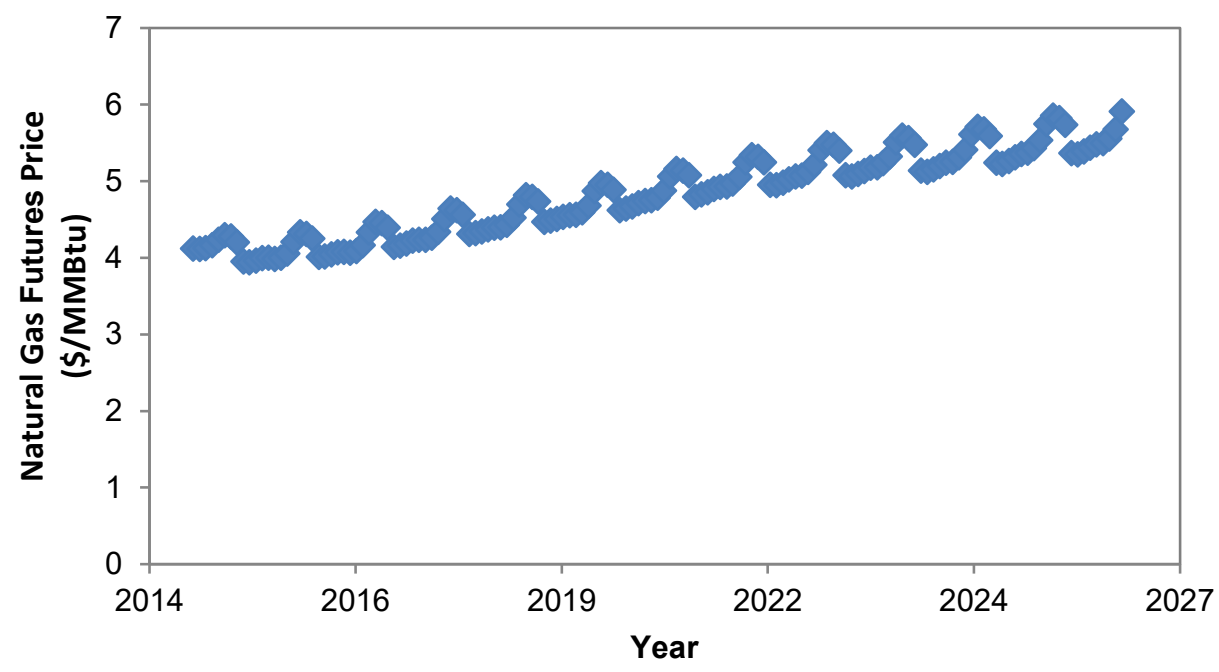

Figure 44. Natural gas futures prices from the New York Mercantile Exchange for July 10, 2014 
The prices show the higher wintertime prices and the cyclical nature of the prices.

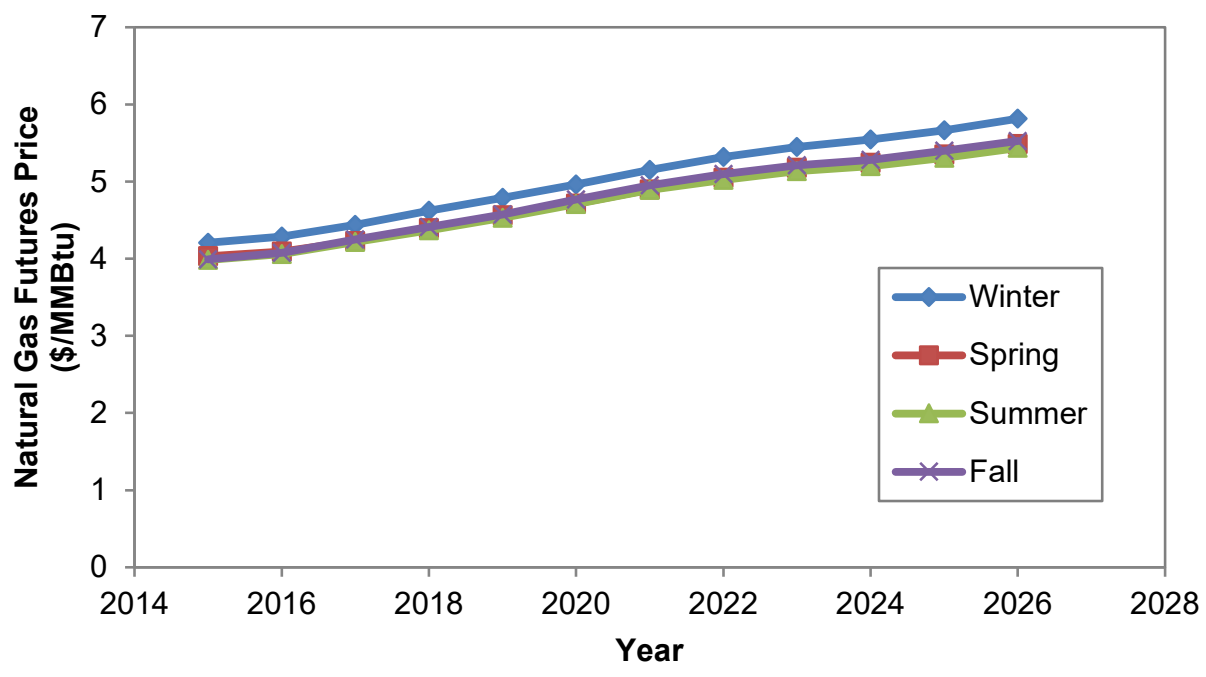

Figure 45. Natural gas futures prices from Figure 43 separated by season

Non-winter prices are nearly the same while wintertime prices are consistently higher.

A seasonal natural gas price multiplier is calculated in ReEDS based on the natural gas price ratio such that wintertime prices are 1.054 times higher than non-winter prices without changing the year-round average price. Mathematically, this can be expressed as

$$
\begin{gathered}
P_{\text {year-round }}=W_{\text {winter }} P_{\text {winter }}+\left(1-W_{\text {winter }}\right) P_{\text {non-winter }} \\
P_{\text {winter }}=1.054 P_{\text {non-winter }} \\
P_{\text {winter }}=\rho P_{\text {year-round }} \\
P_{\text {non-winter }}=\sigma P_{\text {year-round }}
\end{gathered}
$$

where $\mathrm{P}$ is the natural gas price for the period indicated by the subscript, $\mathrm{W}_{\text {winter }}$ is the fraction of natural gas consumption that occurs in the winter months, and $\rho$ and $\sigma$ are the seasonal multipliers for winter and non-winter, respectively. The multipliers $\rho$ and $\sigma$ are determined by solving Equations [2] through [5].

\section{Capital Cost Financial Multipliers}

The financial multiplier represents the present value of revenue requirements necessary to finance a new investment, including construction financing, return to equity holders, interest on debt, taxes, and depreciation. The formula is based on (W. Short, Packey, and Holt 1995). 


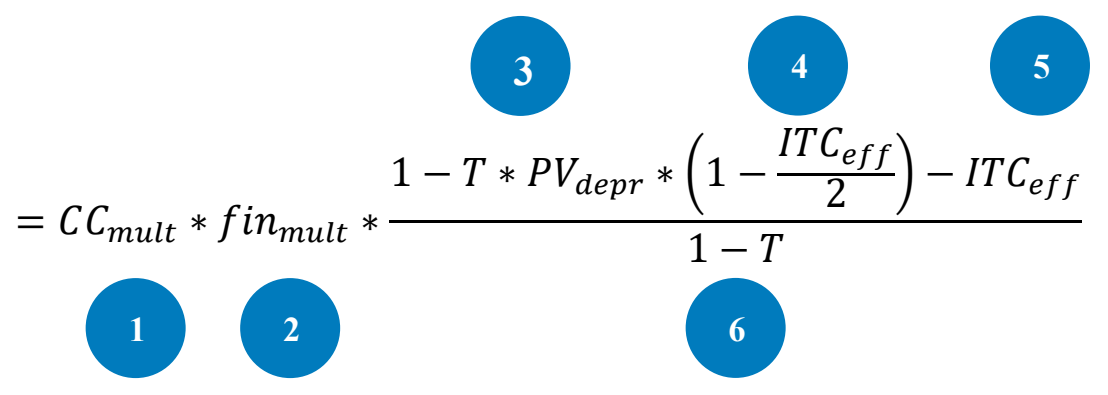

1. Construction cost multiplier: additional cost for finance construction

2. Financing multiplier: adjust required returns for diversifiable risk

3. Depreciation Expense: reduce the taxable income by the depreciation expense

4. Depreciable Basis: reduce the depreciable basis due to the investment tax credit

5. Investment tax credit: reduce the tax liability by the ITC

6. Taxes: additional revenues are required to pay taxes

Construction Cost Multiplier: The construction cost multiplier $\left(\mathrm{CC}_{\text {mult }}\right)$ captures the cost to finance the construction of the plant at construction interest rate $i$. We use a mid-year discounting and account for the deduction of interest payments for taxes.

$$
C C_{\text {mult }}=1+\sum_{t} x_{t} \cdot\left\{(1+i)^{t}-1\right\} \cdot(1-T)
$$

The derivation of the construction cost multiplier is given below.

The total payment $(T P)$ required to finance $x$ percent of construction investment (Inv) at interest rate $i$ in construction year $t$---where $t$ is defined relative to the in-service date $(\mathrm{t}=0$ is the final year of construction; $t=1$ is penultimate year of construction; etc.)---is the following:

$$
T P_{t}=x_{t} \cdot \operatorname{Inv} \cdot(1+i)^{t}
$$

Define the interest payment $(I)$ in year $t$ as a function of the total payment $(T P)$ and the principal payment $(P)$ :

$$
\begin{aligned}
I_{t} & =T P_{t}-P_{t} \\
& =x_{t} \cdot \operatorname{Inv} \cdot(1+i)^{t}-x_{t} * \operatorname{Inv} \\
& =x_{t} \cdot \operatorname{Inv} \cdot\left\{(1+i)^{t}-1\right\}
\end{aligned}
$$

The tax savings $(S)$ from interest deductions in year $t$ at tax rate $T$ is equal to: 


$$
S_{t}=I_{t} \cdot T
$$

Therefore, the absolute net change in the investment cost due to construction financing is the interest payments less the tax savings:

$$
\begin{aligned}
\Delta \operatorname{cost} & (\text { absolute })=\sum_{t} I_{t}-S_{t} \\
& =\sum_{t} I_{t}-I_{t} \cdot T \\
& =\sum_{t} I_{t} \cdot(1-T) \\
& =\sum_{t} x_{t} \cdot \operatorname{Inv} \cdot\left\{(1+i)^{t}-1\right\} \cdot(1-T)
\end{aligned}
$$

Finally, the total relative change in the investment cost due to construction financing is:

$\Delta \operatorname{cost}($ relative $)=$

$$
\begin{aligned}
& =\left(\operatorname{Inv}+\sum_{t} I_{t}-S_{t}\right) / \operatorname{Inv} \\
& =1+\frac{1}{\operatorname{Inv}} \cdot \sum_{t} x_{t} \cdot \operatorname{Inv} \cdot\left\{(1+i)^{t}-1\right\} \cdot(1-T) \\
& =1+\sum_{t} x_{t} \cdot\left\{(1+i)^{t}-1\right\} \cdot(1-T)
\end{aligned}
$$

Financing Multiplier: The financing multiplier (not to be confused with the financial multiplier) is an adjustment to reflect either higher or lower returns to capital, relative to the system-wide average return to capital. Conceptually, it is a multiplier that reflects the total present-value of a stream of higher (or lower) payments to capital, relative to what the payments would be at the system's average cost of capital. For example, if a technology's WACC $\left(W A C C_{t e c h}\right)$ is $7 \%$ and the system-wide WACC is $5 \%\left(W A C C_{s y s}\right)$, and the technology is being evaluated for a 20 -year horizon (1) at a real discount rate of $5 \%\left(d_{r}\right)$, the financing multiplier $\left(\right.$ fin $\left._{\text {mult }}\right)$ would be 1.25 , per the equation below. This multiplier represents that the total present-value of the returns to capital for this technology must be higher (by an amount equal to $25 \%$ of the initial investment), relative to a technology with average financing terms. The difference is the technology WACC and system WACC represents the difference is returns to capital due to diversifiable risk.

$$
f \operatorname{fin}_{\text {mult }}=1+\left(\text { WACC }_{\text {tech }}-W A C C_{\text {sys }}\right) \cdot \frac{1-\frac{1}{\left(1+d_{r}\right)^{l}}}{d_{r}}
$$


To derive the above equation, begin with the definition of the capital recovery factor $(C R F)$ for real discount rate $\left(d_{r}\right)$ and economic horizon $(l)$ :

$$
\begin{gathered}
C R F=\frac{\text { Annuity }}{\text { Present Value of Annunity }}=\frac{1-\frac{1}{\left(1+d_{r}\right)^{l}}}{d_{r}} \\
\text { Present Value of Annuity }=\frac{1}{C R F} \cdot \text { Annuity }
\end{gathered}
$$

Therefore, for every dollar invested in a technology, the absolute difference in required return is:

$$
\Delta \text { returns }(\text { absolute })=\$ 1 \cdot W A C C_{t e c h} \cdot \frac{1}{C R F}-\$ 1 \cdot W A C C_{\text {sys }} * \frac{1}{C R F}
$$

Finally, the relative difference in required return per dollar invested is:

$$
\Delta \text { returns }(\text { relative })=\frac{\$ 1+\Delta}{\$ 1}=1+\Delta
$$

Depreciation Expense: The present value of depreciation (PVdepr) expense is computed based on the fraction of the plant value that is depreciable in each year. All investments use a MACRS depreciation schedule with $f_{t}^{d e p r}$ representing deprecation fraction in year $\mathrm{t}$. This depreciation is sheltered from taxes, which is reflected by the term $1-T * P V_{\text {depr }}$ in the financial multiplier equation above.

$$
P V_{\text {depr }}=\sum_{t} \frac{1}{\left(1+d_{n}\right)^{t}} \cdot f_{t}^{d e p r}
$$

Depreciable Basis: The eligible cost basis for MACRS depreciation expense is reduced by onehalf the effective value of the tax credit:

$$
P V_{d e p r} *\left(1-\frac{I T C_{e f f}}{2}\right)
$$

Investment Tax Credit: The value of the ITC is reduced, to reflect the costs of monetizing it $\left(m_{I T C}\right)$. The effective investment tax credit value $\left(I T C_{e f f}\right)$ reduces the tax burden of the investments.

$$
I T C_{e f f}=I T C \cdot m_{I T C}
$$

Taxes: The denominator term of the financial multiplier equation, "1-T", reflects the additional revenues necessary to pay taxes. The tax burden is adjusted for depreciation expenses as well as the effective investment tax credit. 
Weighted Average Cost of Capital: The technology-agnostic, nominal discount rate is represented as the average WACC. Where, $\mathrm{d}_{\mathrm{f}}$ is the debt fraction, rore $_{n}$ is the nominal rate of return on equity, $T$ is the effective tax rate, and $I_{n}$ is the nominal interest rate on debt.

$$
d_{n}=(1-d f) * \operatorname{rore}_{n}+(1-T) * d f * I_{n}
$$

\section{Present Value of Direct Electric Sector Cost}

The equations in this section are used to calculate the present value cost of building and operating the system for some defined economic analysis period. To calculate the present value of total system cost, the cost in each future year $t$ is discounted to the initial year of the economic analysis period, $t_{0}$, by a social discount rate, $d_{\text {social }}$. The real social discount rate used here for present value calculation is different from the investment discount rate assumptions, or cost of capital (WACC) assumptions.

The present value, or $P V$ in the equation, consists of two cost components: 1) the present value of all operational costs in the model for the analysis period, $P V_{\text {operational }}$, including fixed and variable operating and maintenance costs for all sectors, as well as fuel costs and 2) the present value of all new capital investments, $P V_{\text {capital }}$. The present value of energy system costs is then calculated as:

$$
P V=P V_{\text {operational }}+P V_{\text {capital }}
$$

Operational costs, $P V_{\text {operational }}$, and capital costs category, $P V_{\text {capital }}$, are discounted from year $t$ by $\frac{1}{\left(1+d_{\text {social }}\right)^{t-t_{0}}}$ for each year in the analysis period:

$$
\begin{gathered}
P V_{\text {operational }}=\sum_{t=t_{0}}^{t_{f}} C_{o p, t} \times \frac{1}{\left(1+d_{\text {social }}\right)^{t-t_{0}}} \\
P V_{\text {capital }}=\sum_{t=t_{0}}^{t_{f}} C_{\text {cap }, t} \times \frac{1}{\left(1+d_{\text {social }}\right)^{t-t_{0}}}
\end{gathered}
$$

where $C_{o p, t}$ is the operational costs in year $\mathrm{t}$, and $C_{c a p, t}$ is the capital costs in year $t$. For all ReEDS system cost results, we assume the operational costs for the non-modeled year are the same as the closest model year.

In this present value calculation, the economic analysis period is 2018-2050. The social discount rate used for present value calculations, $d_{\text {social }}$, is assumed to be $7 \%$ (real). This is different from the WACC assumption for investment decisions.

\section{Marginal Electricity Prices}

ReEDS marginal "competitive" electricity prices are derived from the linear programming formulation.

In standard form, the primal formulation of a linear program is:

$$
\begin{aligned}
& \text { (P) } \quad \min c^{T} x \\
& \text { s.t. } \quad A x \geq b
\end{aligned}
$$




$$
x \geq 0
$$

The associated dual formulation of the primal is:

$$
\begin{array}{cc}
\text { (D) } & \max y^{T} b \\
\text { s.t. } & y^{T} A \leq c^{T} \\
& y \geq 0
\end{array}
$$

Consider a simplified formulation of the ReEDS model with a subset of constraints: (1) resource limits, (2) capacity limits, (3) supply/demand balance, (4) planning reserve margin requirement, (5) operating reserve requirement, and (6) national and/or state-level RPS requirements. The primal formulation is:

\section{Parameters}

capcost $_{i}$ : capital cost of model plant i $(\$ / \mathrm{MW})$

vomcost $t_{i}$ : variable O\&M cost of model plant i $(\$ / \mathrm{MWh})$

$s_{i}$ : available supply of model plant i (MW)

load: electric load (MW)

$c v_{i}$ : capacity value of model plant i (MW)

$f^{\text {prm }}$ : planning reserve margin (unitless)

$f^{o r}$ : operating reserve requirement (unitless)

$f^{R P S}$ : national and/or state-level RPS requirement (unitless)

\section{Variables}

$C_{i}$ : capacity of model plant i (MW)

$G_{i}$ : generation of model plant i (MWh)

$O R_{i}$ : operating reserve allocation of plant $i(\mathrm{MWh})$

$$
\text { minimize } \sum_{i} \operatorname{capcost}_{i} \cdot C_{i}+\text { vomcost }_{i} \cdot G_{i}
$$

Subject to:

$$
\begin{array}{r}
G_{i} \leq s_{i} \quad \forall i \\
8,760+\frac{O R_{i}}{8,760}-C_{i} \leq 0 \quad \forall i \\
\sum_{i} G_{i}=\text { load } \\
\sum_{i} c v_{i} \cdot C_{i} \geq \frac{\left(1+f^{p r m}\right)}{8760} \cdot \text { load } \\
\sum_{i} O R_{i} \geq f^{o r} \cdot \text { load } \\
\sum_{i \in R E} G_{i} \geq f^{R P S} \cdot \text { load } \\
C_{i}, G_{i}, O R_{i} \geq 0 \quad \forall i
\end{array}
$$


Constraints [1] define the resource limits for each model plant. Constraints [2] limit how capacity is allocated for each model plant (i.e., for energy or reserves). Constraint [3] requires the total generation supplied to equal the load. Constraint [4] ensures the total firm capacity meets the planning reserve margin requirement. Constraint [5] ensures the total operating reserves meet the operating reserve requirement. Constraint [6] requires that total generation from renewable technologies meets the state-level and national RPS requirements.

From the dual formulation of the primal, the objective function is:

$$
y^{T} b=y_{1} \cdot s+y_{2} \cdot 0+y_{3} \cdot \text { load }+y_{4} \cdot \frac{(1+\text { prm })}{8760} \cdot \text { load }+y_{5} \cdot f^{\text {or }} \cdot \text { load }+y_{6} \cdot f^{R P S} \cdot \text { load }
$$

Reformulating the primal with Constraints [3], [4], [5], and [6] "linked" with a "load" variable, $L$, an alternative, but equivalent, primal formulation is the following:

Subject to:

$$
\text { minimize } \sum_{i} \text { capcost }_{i} \cdot C_{i}+\text { vomcost }_{i} \cdot G_{i}
$$

$$
\begin{array}{rr}
C_{i} \leq s_{i} \quad \forall i \quad[1] \\
\frac{G_{i}}{8760}+\frac{O R_{i}}{8760}-C_{i} \leq 0 \quad \forall i \quad[2] \\
\sum_{i} G_{i}-L \geq 0 \quad\left[3^{\prime}\right] \\
\sum_{i} O v_{i} \cdot C_{i}-\frac{\left(1+f^{\text {prm }}\right)}{8760} \cdot L \geq 0 \quad\left[4^{\prime}\right] \\
\sum_{i \in R E} G_{i}-f^{R P S} \cdot L \geq 0 \\
C_{i}, G_{i}, O R_{i} \geq 0 \\
L=\text { load } \quad\left[6^{\prime}\right]
\end{array}
$$

From the dual formulation of the alternative primal, the objective function is:

$$
y^{T} b=y_{1} \cdot s+y_{2} \cdot 0+y_{3^{\prime}} \cdot 0+y_{4^{\prime}} \cdot 0+y_{5^{\prime}} \cdot 0+y_{6^{\prime}} \cdot 0+y_{8^{\prime}} \cdot \text { load }
$$

Equating the dual objective functions from the two equivalent primal formulations, we find that the marginal off the linking constraint [8'] is a blending of all constraints containing the "load" variable, including, constraints [3], [4], [5], and [6]:

$$
\begin{gathered}
y_{8^{\prime}} \cdot \text { load }=y_{3} \cdot \text { load }+y_{4} \cdot \frac{\left(1+f^{\text {prm }}\right)}{8760} \cdot \text { load }+y_{5} \cdot f^{\text {or }} \cdot \text { load }+y_{6} \cdot f^{R P S} \cdot \text { load } \\
y_{8^{\prime}}=y_{3}+y_{4} \cdot \frac{\left(1+f^{\text {prm }}\right)}{8760}+y_{5} \cdot f^{\text {or }}+y_{6} \cdot f^{R P S}
\end{gathered}
$$


Therefore, we define the marginal off the linking constraint $\left[\mathrm{y}_{8^{\prime}}\right]$ as the "all-in" marginal price of electricity (i.e., change in total cost [objective function] given a small change in load). This marginal electricity price includes the energy price, capacity price, operating reserve prices, and potential RPS prices. Marginal electricity prices are reported at BA level with different requirement categories. These prices can be aggregated at different regional level, weighted by corresponding requirement quantities for certain category.

\section{Average Electricity Prices}

Average electricity prices are calculated as the annualized total costs of building and operating the system in certain geographic area, divided by the electricity load in that area. At national level, the prices are calculated as:

$$
p(\text { costtype }, \text { year })=\frac{\text { systemcost } t_{\text {costtype }, y e a r}}{\text { load }_{\text {year }}}
$$

where system costs include both annualized capital and operational costs. Annualized costs for existing (i.e. pre-2010) power plants are also considered given plants' initial investment costs and the built year.

At BA-level, average electricity prices also consider the impact of energy and capacity trading:

$$
\begin{aligned}
p\left(\text { costtype }, B^{B}\right. & , \text { year }) \\
= & \text { capital }_{\text {costtype }, B A, y e a r}+\text { opeartional }_{\text {costtype }, B A, y e a r} \\
& +\left[\sum_{n} \text { import }_{n, p, h, \text { year }} \times \text { price }_{n, h, y e a r}\right. \\
& \left.-\sum_{n} \text { export }_{p, n, h, y e a r} \times \text { price }_{p, h, y e a r}\right]_{\text {energy }} \\
& +\left[\sum_{n} \text { import }_{n, p, \text { szn,year }} \times \text { price }_{n, \text { szn,year }}\right. \\
& \left.-\sum_{n} \text { export }_{p, n, h, y e a r} \times \text { price }_{p, s z n, y e a r}\right]_{\text {capacity }}
\end{aligned}
$$

Where $\mathrm{n}, \mathrm{p}$ and BA all indicate balancing areas, $\operatorname{import}_{n, p, h, t}$ indicates energy or capacity transfer from $\mathrm{n}$ top; export $_{p, n, h, t}$ indicates energy or capacity transfer from $\mathrm{p}$ to $\mathrm{n}$. Capital costs also include annualized costs for pre-2010 power plants.

Specifically, the energy import/export is calculated as:

$$
\begin{aligned}
& \sum_{n} \text { import }_{n, p, h, t} \times \text { price }_{n, h, t} \\
&= \sum_{n} \text { powerfracupstream }_{n, p, h, t} \times \text { gen }_{p, h, t} \times \text { price }_{n, h, t} \times \operatorname{hours}_{h} \times\left(1+\operatorname{loss}_{n, p, h, t}\right) \\
& \sum_{n} \text { export }_{p, n, h, t} \times \text { price }_{p, h, t}=\sum_{n} \text { powerfracdownstream }_{p, n, h, t} \times \text { gen }_{p, h, t} \times \text { price }_{p, h, t} \times \text { hours }_{h}
\end{aligned}
$$


where $\mathrm{t}$ is year, $\mathrm{p}$ and $\mathrm{n}$ are both balancing areas, $\mathrm{h}$ indicates time slices.

\section{Demand Module}

In this section, we discuss the underlying data and structure of the demand model. The main exogenous inputs include reference levels of energy service demand, existing device stock and new stock totals, and characteristics of new devices. Much of our data comes from EIA's National Energy Deployment System (NEMS), and its Annual Energy Outlook (EIA 2017a). Table A-1, which is referred to throughout the rest of this section, summarizes the end uses and device types modeled in ReEDS.

Table A-1. End Uses and Devices Modeled in ReEDS

\begin{tabular}{|c|c|c|c|}
\hline End-use & $\begin{array}{l}\text { Service } \\
\text { units }\end{array}$ & Device types & Device options \\
\hline \multirow{3}{*}{ Space heating } & \multirow{3}{*}{ BTU } & Electric radiator & 1 efficiency level \\
\hline & & Air-source heat pump & 3 efficiency levels \\
\hline & & Ground-source heat pump & 2 efficiency levels \\
\hline \multirow{4}{*}{ Space cooling } & \multirow{4}{*}{ BTU } & Central air conditioning & 3 efficiency levels \\
\hline & & Room air conditioning & 3 efficiency levels \\
\hline & & Air-source heat pump & 3 efficiency levels \\
\hline & & Ground-source heat pump & 2 efficiency levels \\
\hline Clothes washing & Cycles & Clothes washer & 2 efficiency levels \\
\hline Dishwashing & BTU & Dishwasher & 2 efficiency levels \\
\hline \multirow{2}{*}{ Water heating } & \multirow{2}{*}{ BTU } & Electric water heater & 5 efficiency levels \\
\hline & & Solar water heater & 1 efficiency level \\
\hline Cooking & Unitless & Cookstove & 1 efficiency level \\
\hline Clothes drying & BTU & Clothes dryer & 2 efficiency levels \\
\hline \multirow{3}{*}{ Refrigeration } & \multirow{3}{*}{ Unitless } & Refrigerator - top freezer & 3 efficiency levels \\
\hline & & Refrigerator - bottom freezer & 2 efficiency levels \\
\hline & & Refrigerator - side-by-side & 2 efficiency levels \\
\hline \multirow{2}{*}{ Freezing } & \multirow{2}{*}{ Unitless } & Chest freezer & 2 efficiency levels \\
\hline & & Upright freezer & 2 efficiency levels \\
\hline \multirow{4}{*}{ Lighting } & \multirow{4}{*}{ Lumens } & General service light bulb & Incandescent, CFL, LED \\
\hline & & Reflector light bulb & Halogen, CFL, LED \\
\hline & & Exterior light bulb & $\begin{array}{l}\text { Incandescent, halogen, LED, high- } \\
\text { pressure sodium }\end{array}$ \\
\hline & & Linear fluorescent light bulb & T12, T8, LED \\
\hline Miscellaneous & Unitless & Generic & 1 efficiency level \\
\hline Furnace fans & Unitless & Generic & 1 efficiency level \\
\hline Secondary heat & Unitless & Generic & 1 efficiency level \\
\hline
\end{tabular}

CFL: compact fluorescent lamp; LED: light-emitting diode 


\section{Energy Service Demand}

For the residential buildings sector, electricity demand in ReEDS is derived from energy service demand and the composition of devices used to meet that demand, while it is directly specified for the commercial buildings and industrial sectors. In this section, we discuss how we calculate reference levels of demand, including how we identify the hours that contribute to the summer peak time-slice (H17, Table 1, page 14). We also discuss our sources for demand elasticities. Currently, ReEDS only includes a detailed representation of energy service demand for the residential buildings sector. We model 13 end uses in the residential sector, which are listed in Table A-1 alongside the units we use for service demand. End-use categories that do not have explicit service units are denoted in the table as "unitless". For these categories, service demands are treated as relative quantities but do not have any physical interpretation.

\section{Reference Levels}

Reference demand levels are needed to parameterize demand curves. This requires several sources of data, including electricity consumption values (obtained from the AEO), capital stock characteristics for residential buildings (also from the AEO), and hourly load shapes (obtained from Steinberg et al. (2017) for residential and commercial buildings and from Hostick et al. (2012) for industrial facilities). Preparing the data requires the steps described below. Because of lack of data, we must make several simplifying assumptions, such as that each BA within a state observing the same load shape and load shapes remains constant for all years.

\section{Residential}

Our calculation of reference service demand levels for residential buildings requires two primary inputs: electricity consumption and average efficiency levels. Here, we discuss the details of this calculation and the key assumptions that we make. Fundamentally, the calculation is of the form:

$$
\text { Service consumption }=\text { Electricity consumption } \cdot \text { Average efficiency }
$$

where average efficiency is denoted in terms of number of service units (e.g., lumens) per unit of electricity (e.g., watt-hours), though several steps are needed to prepare the raw data first.

Service consumption in ReEDS is defined by end use, device type, BA, income class, time-slice, and year. The raw energy consumption data from AEO is disaggregated by end use, device type, building type, census division, and year. ${ }^{77}$ The average efficiency data are indexed over the same elements, with additional base year data for 2009. Preparing the data requires the following steps:

\section{Add consumption from distributed generation (DG) to the energy consumption} levels. Because of the way NEMS results are reported, the reported energy consumption levels omit consumption of DG. Therefore, we have to add these values to the raw totals. Following NEMS convention, 65\% of solar PV DG is applied to central air-conditioning in single-family housing, while the remainder is applied to miscellaneous end uses in

\footnotetext{
77 The end uses and device types correspond to those listed in Table. Building types include single-family housing, multi-family housing, and manufactured housing. The AEO data covers all years from 2010 to 2050.
} 
single-family housing. All other DG is credited to miscellaneous end uses in singlefamily housing.

2. Calculate lighting efficiencies. In contrast to other end uses, NEMS does not report a true efficiency metric for lighting. Instead, average lighting efficiency levels over time are reported in watts. To convert these values to lumens per watt, we divide the total lumen level of a baseline device by the average wattage for each category. For general service, reflector, and exterior lighting, the baseline device is an incandescent bulb. For linear fluorescent lighting, the baseline device is a T12 bulb. ${ }^{78}$

3. Calculate relative efficiencies for certain end uses. For electric stoves, refrigerators, freezers, and clothes washers, efficiencies are converted to a relative scale by dividing the average efficiency value by the corresponding base year efficiency value. This means the efficiency value in the base year will be equal to one, and average efficiency values in subsequent years will be less than one, provided average device efficiency improves over time.

4. Multiply energy consumption by average efficiency and aggregate service consumption over building types. To obtain service levels for each end use, device type, building type, census division, and year, we multiply energy consumption by average efficiency. Because ReEDS does not separately model different building types, service consumption is aggregated over the NEMS building types.

5. Disaggregate service consumption by BA and income class. The last step in preparing reference service consumption levels is to disaggregate along temporal, spatial, and income dimensions. The spatial and income disaggregation is informed using population data obtained from SNL Financial in 2017. Using county-level counts of households in each income class, we first calculate the number of households per income class in each BA. We then divide this value by the total number of households in each census division (because service consumption has been calculated at the census division level) to obtain the proportion of households belonging to each BA-income class combination in each census division. This proportion is multiplied by the service consumption values obtained from the previous step to generate service consumption by end use, device type, income class, BA, and year.

6. Disaggregate service consumption by time slice. The final step is to disaggregate service consumption into time-slices by multiplying service consumption by a load-shape factor for each time-slice. The profiles provide end-use load-shape proportions for each hour by state, which are translated to the time-slice level and applied to the appropriate BAs and end uses in the service consumption data. This process requires us to identify the hours that contribute to the peak time-slice (H17, Table 1, page 14), which is described in the Peak Electricity Demand section below.

\section{Commercial and Industrial}

Currently, electricity consumption for the commercial and industrial sectors are modeled at an aggregate level, without specifying end-use service consumption and devices. To calculate

\footnotetext{
${ }^{78}$ Our use of base year general service incandescent bulbs assumes energy use of 60 watts with an efficiency of 14 lumens per watt, for a total of 840 lumens per bulb. And our use of baseline bulbs for reflector, linear fluorescent, and exterior lighting assume $650(65 \times 10), 2,880(40 \times 72)$, and 1,136 $(71 \times 16)$ lumens per bulb respectively.
} 
reference levels of electricity consumption for these sectors, we combine historical and projected electricity demand estimates with demographic data from SNL Financial. The data preparation steps are as follows:

1. Add consumption from DG to the energy consumption levels. For commercial buildings, the first step is to subtract the quantity of DG sales to the grid from total DG. Then, following NEMS convention, $12 \%$ of DG is applied to cooling, $13 \%$ to ventilation, $16 \%$ to lighting, and the rest (59\%) to "miscellaneous." 79 The accounting for industrial facilities does not require DG to be added back in.

2. Disaggregate electricity consumption to the BA level. Commercial and industrial electricity consumption is disaggregated spatially in two steps. To disaggregate from the census division to the state level, we calculate historical state proportions of census division consumption using EIA data (EIA 2017a). For model years before 2016, we use year-specific proportions, while for model years in 2016 and beyond, we fix the proportions at the 2016 values. To disaggregate consumption from the state to the BA, we use population proportions for commercial buildings and the fraction of state land that each BA contains for industrial facilities.

3. Disaggregate electricity consumption to the time slice level. For commercial buildings, hourly load shapes are applied for BAs and end uses, while industrial load shapes are not specified by end use. The profiles provide end-use load-shape proportions for each hour by state, which are aggregated up to the time-slice level and applied to the appropriate BAs and, for commercial buildings, end uses in the electricity consumption data. Finally, commercial building consumption is aggregated across end uses to generate reference demand. As was the case for residential buildings, this step requires us identify the hours that contribute to the peak time-slice (H17, Table 1, page 14), which is discussed next.

\section{Peak Electricity Demand}

We calculate peak electricity demand by combining electricity consumption and load shapes for each sector. The data preparation steps, which are listed below, mirror the steps used to construct reference demand levels.

1. Add consumption from DG to the energy consumption levels and aggregate to the appropriate level. Adding DG follows the same procedure as described in the first step in the Residential and Commercial and Industrial sections above. Once DG totals are applied, energy consumption for residential and commercial buildings are aggregated by census division, end use, and year. There is no end-use index for industrial facilities.

2. Disaggregate electricity consumption to the BA level. For residential buildings, this step is the same as Step 5 from the Residential section, except there is no disaggregation along the income dimension. For the commercial and industrial sectors, this step is the same as Step 2 from the Energy Service Demand: Commercial and Industrial section above.

\footnotetext{
${ }^{79}$ Although ReEDS does not currently model commercial demand at the end-use level, the end uses used to create load shapes include heating, cooling, water heating, ventilation, cooking, lighting, refrigeration, office equipment (computers and non-computers), and miscellaneous.
} 
3. Disaggregate electricity consumption to the hourly level. For commercial and residential buildings, hourly load shapes are applied for BAs and end uses, while industrial load shapes are not specified by end use.

4. Aggregate electricity demand across sectors, compute peak load, and identify H17 hours. The final step begins by aggregating sectoral consumption levels to obtain total consumption by BA, hour, and year. The top 40 hours within the $\mathrm{H} 3$ time-slice are then assigned to H17 (Table 1, page 14), with the top hour representing peak demand.

Currently, the calculation of peak demand and identification of the peak time-slice is not performed dynamically within a ReEDS solve, primarily because of their data-intensive natures. Future work will focus on updating these elements dynamically in response to changing demand conditions.

\section{Elasticities}

Though the economics literature is replete with estimates of the price elasticity of electricity demand, few studies have attempted to estimate the price elasticity of service demand for specific end uses. This is perhaps due to the substantial data requirements needed to perform such an analysis, specifically household-level information on appliances, electricity consumption for specific end uses, and utility rate schedules ${ }^{80}$ Therefore, we take a conservative approach to parameterizing our energy service demand curves, tending toward lower elasticity values, with the expectation that future work will lend better insight into appropriate elasticity values. Our default elasticity assumptions are presented in Table A-2Table. For the industrial and commercial sectors, we use the short-run electricity demand elasticities estimated by Paul, Myers, and Palmer (2009). Because we do not currently model service demand for the industrial and commercial sectors, the elasticities are consistent with our modeling approach. For the residential sector, we use the corresponding short-run elasticity value from the same study for end uses for which we do not have service elasticity estimates. For the remaining end uses, we use estimates from a variety of studies. Though the empirical techniques differ, all are designed to estimate service elasticity for a particular end use. We also assume the elasticities for furnace fans and secondary heating are the same as those estimated for primary space heating.

\footnotetext{
${ }^{80}$ Several studies, including Reiss and White (2005) and Zhang (2016), estimate end-use electricity demand elasticities using total household electricity consumption via conditional demand analysis. Though these studies do not account for device efficiency, preliminary work at NREL using similar techniques that attempts to account for device efficiency suggests that doing so does not change the results significantly.
} 
Table A-2. Default Electricity and Energy Service Demand Elasticity Values

\begin{tabular}{llll}
\hline \multirow{2}{*}{ Sector } & End Use & $\begin{array}{l}\text { Elasticity } \\
\text { value }\end{array}$ & Source \\
\hline & Space heating & -0.26 & Dubin and McFadden (1984) \\
\cline { 2 - 4 } Space cooling & $-0.20 \dagger$ & Rapson (2014) \\
\cline { 2 - 4 } Clothes washing & -0.06 & Davis (2008) \\
\cline { 2 - 4 } Dishwashing & -0.13 & Paul, Myers, and Palmer (2009) \\
\cline { 2 - 4 } Residential & Water heating & -0.26 & Dubin and McFadden (1984) \\
\cline { 2 - 4 } & Cooking & -0.13 & Paul, Myers, and Palmer (2009) \\
\cline { 2 - 4 } & Clothes drying & -0.13 & Paul, Myers and Palmer (2009) \\
\cline { 2 - 4 } & Refrigeration & -0.13 & Paul, Myers and Palmer (2009) \\
\cline { 2 - 4 } & Freezing & -0.13 & Paul, Myers and Palmer (2009) \\
\cline { 2 - 4 } & Lighting & -0.40 & Guertin, Kumbhakar, and Duraiappah (2003) \\
\cline { 2 - 4 } & Miscellaneous & -0.13 & Paul, Myers, and Palmer (2009) \\
\cline { 2 - 4 } & Furnace fans & -0.26 & Dubin and McFadden (1984) \\
\cline { 2 - 4 } & Secondary heat & -0.26 & Dubin and McFadden (1984) \\
\hline Commercial & All & -0.11 & Paul, Myers, and Palmer (2009) \\
\hline Industrial & All & -0.16 & Paul, Myers, and Palmer (2009) \\
\hline
\end{tabular}

$\dagger$ This value represents the midpoint between room and central air conditioning elasticities for the non-California U.S. sample

\section{Capital Stock}

ReEDS explicitly models the evolution of the capital stock of energy service devices for 10 end uses in the residential buildings sector. In this section, we describe how the initial, preexisting stock of devices is determined, how the capital stock evolves over time, and the technology options available to consumers. We also discuss our assumed distribution of discount rates by income class. Table A-1 lists the modeled device types associated with each service demand category and the options for each device type. For some end uses, the capital stock is not explicitly tracked (denoted in the table as having a "Generic" device type). For these end uses, users still have the option to model efficiency improvements, though this is not the default. Currently, our default technology options correspond to the options represented in the NEMS data files. A key assumption we make for modeling the residential capital stock is that devices are retired, or scrapped, according to exogenous survival rates. The lifetime (in years) of each device is assumed to follow a Weibull distribution, with scale parameter $\alpha$ and shape parameter $\beta$; examples of survival functions are illustrated in Figure $45 .{ }^{81}$ An alternative approach, which could be pursued in future iterations of the model, would be to make the scrappage rate responsive to device prices.

\footnotetext{
${ }^{81}$ The survival function is defined as $\mathrm{S}(\mathrm{x})=1-\mathrm{F}(\mathrm{x})$, where $\mathrm{F}(\cdot)$ is the cumulative distribution function of device lifetime.
} 


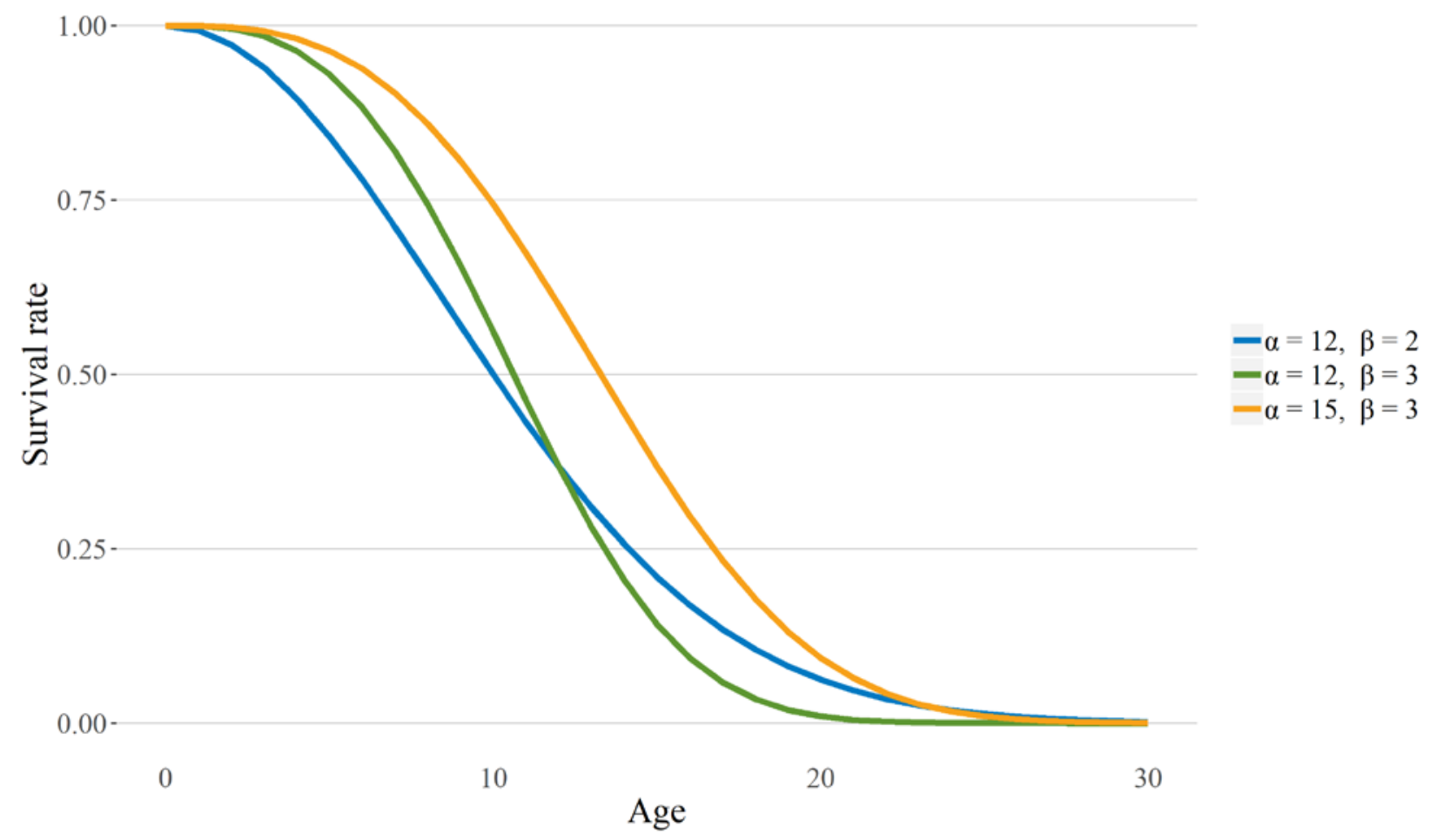

Figure 46. Examples of survival rates for different scale and shape parameterizations

\section{Initial Stock}

To model the evolution of the stock of end-use devices, we need to characterize the initial stock in the model. We project the phaseout of these devices using exogenous cumulative retirement fractions. The primary source of these data is the AEO, which we supplement with demographic data from SNL Financial from 2017. The data processing steps are as follows:

1. Calculate retirement fractions for lighting. Though we have AEO data on cumulative retirement fractions for the initial stock for most device types, light bulbs are an exception. To address this, we calculate Weibull distribution parameters for light bulb lifetimes (in years) using light bulb lifetimes (in hours) from NEMS for all the bulb type categories identified in the third column of Table A-1Table. ${ }^{82}$ Imposing the assumption that all bulbs in the initial stock are purchased in $2009,{ }^{83}$ we use the survival functions to calculate cumulative retirement fractions for each year from 2010 to 2050.

\footnotetext{
${ }^{82}$ Calculating these parameters requires several steps. First, from NEMS data files, we obtain shares of general service lighting assumed to be used $0.5,1.5,2.5,4.5,8.0$, and 10.0 hours a day (i.e., lighting is separated into six bins, each with an assumed daily use level). These shares are used to calculate empirical annual survival rates assuming a one-hour lifetime. For example, if $65 \%$ of bulbs are assumed to be used 0.5 hours per day and $16 \%$ of bulbs are assumed to be used at least 1.5 hours per day, $65 \%$ of bulbs remain after $1 / 1.5 \div 365=0.002$ years and $0 \%$ remain after $1 / 0.5 \div 365=0.005$ years. Fitting a Weibull survival function to the empirical survival rates yields a scale parameter of 0.00277384 and a shape parameter of 1.74169 . To construct a survival function for a light bulb with a lifetime of $x$ hours, the scale parameter is equal to $0.00277384 \mathrm{x}$ and the shape parameter remains the same. Because we do not have binned data on other lighting categories, we use the same scale and shape parameters. ${ }^{83}$ This assumption means our model will tend to understate the pace at which the initial stock of bulbs is replaced, depending on the accuracy of our survival functions.
} 
2. Calculate remaining stock of devices in each year. To calculate the remaining devices from the initial stock in each year, we multiply the initial stock counts by the cumulative retirement fractions for each device. Before this calculation can be done, we must first disaggregate the base stock of light bulbs into type categories (e.g., incandescent and LED.) based on shares from NEMS data files.

3. Disaggregate initial stock by BA and income class. The final step in preparing the initial stock data is to disaggregate the devices spatially and by income class. The process for this step is identical to the disaggregation of reference service demand described in Step 5 from the residential Energy Service Demand section above.

\section{New Device Purchases}

In ReEDS, new device purchases are made to replace scrapped devices and to meet new demands reflecting dynamics such as population growth. Consumers can choose from among device technology options that differ according to their capital costs, efficiency levels, and, in the case of light bulbs, lifetimes. ${ }^{84}$ AEO is the data source for total device counts from 2010 to 2050. The process for determining the number of new device purchases is as follows:

1. Disaggregate total device counts by BA and income class. The first step in determining the number of new device purchases is to disaggregate the total device counts spatially and by income class. The process for this step is identical to the disaggregation of the initial stock described in Step 3 from the Capital Stock: Initial Stock section above.

2. Calculate the exogenous device requirement for each year.

We define the exogenous device requirement as the difference between the total device counts and the number of devices remaining from the initial stock. Because both those quantities are exogenous to the model, we can calculate this quantity outside of the optimization.

3. Calculate the number of new device purchases in each year. The number of new device purchases in a given year is equal to the exogenous device requirement for that year minus any devices remaining from purchases in prior years, not including the initial stock. Because the number of devices remaining from prior-year purchases depends on which devices were purchased, this step occurs within the optimization of the model.

\section{Discount Rates}

The key differentiating factor in the decision-making of consumers of different income classes is the assumed discount rate used in assessing present and future costs of purchasing and operating devices. Train (1985) provides reviews that estimate discount rates for energy durables, including several that estimate negative relationships between income and discount rates. More recently, Newell and Siikamäki (2015) estimate a relationship between income and discount rate for energy efficiency decisions using survey responses. We parameterize our model using their regression results - from Model 1 in their Table A6-which estimate a constant of 0.334 and a coefficient on the log of income of -0.035 . Table illustrates our default income class and discount rate assumptions. For the first 11 income classes, we assume income levels equal to the midpoint of the range (with zero representing the lower bound on income) to calculate the discount rates

\footnotetext{
${ }^{84}$ Future model developments could incorporate other factors affecting consumer device choices, such as the color rendering index of light bulbs or the orientation of refrigerators and freezers.
} 
for each class. For the top, open-ended income class, we follow a procedure from Parker and Fenwick (1983) to calculate an income level based on a distributional assumption. Denoting the lower bound of income class bin $i$ by $x_{i}$ and the number of individuals in bin $i$ by $n_{i}$, the income value for the top bin is estimated by:

$$
\begin{gathered}
x_{12}=\frac{v}{v-1} \\
v=\frac{\log \left(n_{11}+n_{12}\right)-\log \left(n_{12}\right)}{\log \left(x_{12}\right)-\log \left(x_{11}\right)}
\end{gathered}
$$

We use the national, rather than county, values for $n_{i}$ to calculate $v$.

Table A-3. Default Assumptions for Discount Rates by Income Class

\begin{tabular}{lll}
\hline Income range from SNL & Income for model & Discount rate \\
\hline$<15,000$ & 7,500 & $26.3 \%$ \\
$15,000-24,999$ & 20,000 & $22.9 \%$ \\
$25,000-34,999$ & 30,000 & $21.5 \%$ \\
$35,000-49,999$ & 42,500 & $20.2 \%$ \\
$50,000-74,999$ & 62,500 & $18.9 \%$ \\
$75,000-99,999$ & 87,500 & $17.7 \%$ \\
$100,000-124,999$ & 112,500 & $16.9 \%$ \\
$125,000-149,999$ & 137,500 & $16.2 \%$ \\
$150,000-199,999$ & 175,000 & $15.3 \%$ \\
$200,000-249,999$ & 225,000 & $14.4 \%$ \\
$250,000-499,999$ & 375,000 & $12.7 \%$ \\
$\geq 500,000$ & $1,119,391$ & $8.6 \%$ \\
\hline
\end{tabular}

\section{Differences from the 2019 Model Version}

Table A-4 summarizes the key differences from the 2019 model version. Table A-5 summarizes the key differences in the dGen model, which is used to provide the rooftop PV input projections for ReEDS.

Table A-4. Key Differences in Model Inputs and Treatments for ReEDS Model Versions

\begin{tabular}{|l|l|l|}
\hline $\begin{array}{l}\text { Inputs and } \\
\text { Treatments }\end{array}$ & 2019 Version (July 2019) & 2020 Version (July 2020) \\
\hline Fuel prices & AEO2019 & AEO2020 \\
\hline Demand growth & AEO2019 & AEO2020 \\
\hline $\begin{array}{l}\text { Generator } \\
\text { technology cost, } \\
\text { performance, and } \\
\text { financing }\end{array}$ & ATB 2019a & ATB 2020a \\
\hline $\begin{array}{l}\text { Regional } \\
\text { Greenhouse Gas } \\
\text { Initiative (RGGI) }\end{array}$ & Virginia not included in RGGI & Virginia included in RGGI \\
\hline $\begin{array}{l}\text { Endogenous } \\
\text { retirements }\end{array}$ & $\begin{array}{l}\text { Off by default; when turned on, plants } \\
\text { retire when they cannot recover their } \\
\text { fixed O\&M }\end{array}$ & $\begin{array}{l}\text { On by default; when turned on, plants } \\
\text { retire when they cannot recover at } \\
\text { least half of their fixed O\&M }\end{array}$ \\
\hline
\end{tabular}




\begin{tabular}{|c|c|c|}
\hline $\begin{array}{l}\text { Inputs and } \\
\text { Treatments }\end{array}$ & 2019 Version (July 2019) & 2020 Version (July 2020) \\
\hline Coal fixed O\&M & Escalate from online year & $\begin{array}{l}\text { Escalates from } 2019 \text { using } \\
\text { assumptions from AEO2019 }\end{array}$ \\
\hline Nuclear fixed O\&M & Escalate from 2010 & $\begin{array}{l}\text { Escalates from } 2019 \text { using } \\
\text { assumptions from AEO2019 }\end{array}$ \\
\hline $\begin{array}{l}\text { Wind, solar, and } \\
\text { load data }\end{array}$ & Includes 2012 data only & $\begin{array}{l}\text { Includes data for } 2007-2013 \text {; dispatch } \\
\text { is done using } 2012 \text { data and capacity } \\
\text { credit calculations are done using } \\
2007-2013 \text { data (W. Cole, Greer, et } \\
\text { al. 2020) }\end{array}$ \\
\hline Electrification & Not included & Includes three levels of electrification \\
\hline $\begin{array}{l}\text { Demand-side } \\
\text { flexibility }\end{array}$ & Not included & Includes three levels of flexibility \\
\hline $\begin{array}{l}\text { Renewable fuel } \\
\text { combustion turbine }\end{array}$ & Not included & $\begin{array}{l}\text { Includes combustion turbine that runs } \\
\text { on a generic renewable fuel with a } \\
\text { minimum } 6 \% \text { capacity factor }\end{array}$ \\
\hline Upgrades & Not included & $\begin{array}{l}\text { Thermal technologies can be } \\
\text { upgraded (e.g., by adding CCS). }\end{array}$ \\
\hline $\begin{array}{l}\text { Storage curtailment } \\
\text { recovery }\end{array}$ & $\begin{array}{l}\text { Assume that every } 1 \mathrm{MWh} \text { of storage } \\
\text { charging reduces curtailment in that } \\
\text { region by } 0.5 \mathrm{MWh}\end{array}$ & $\begin{array}{l}\text { Uses hourly net load profiles and a } \\
\text { dispatch algorithm to determine the } \\
\text { amount of curtailment that can be } \\
\text { recovered by storage }\end{array}$ \\
\hline $\begin{array}{l}\text { Battery storage } \\
\text { durations }\end{array}$ & 4-hour batteries only & $\begin{array}{l}\text { Includes 2-, 4-, 6-, 8-, and 10-hour } \\
\text { battery storage }\end{array}$ \\
\hline $\begin{array}{l}\text { Storage capacity } \\
\text { credit }\end{array}$ & $\begin{array}{l}\text { Calculated using one year of hourly } \\
\text { data, applies a linear approximation in } \\
\text { the optimization model }\end{array}$ & $\begin{array}{l}\text { Calculated using seven years of } \\
\text { hourly data; capacity credit bins by } \\
\text { duration allow for nonlinear changes in } \\
\text { the optimization model; one-hour } \\
\text { buffer accounts for uncertainty in } \\
\text { forecasts and ability to dispatch }\end{array}$ \\
\hline $\begin{array}{l}\text { Wind and solar } \\
\text { capacity credit }\end{array}$ & $\begin{array}{l}\text { Calculated using one year of hourly } \\
\text { resource and load data }\end{array}$ & $\begin{array}{l}\text { Calculated using seven years of } \\
\text { hourly resource and load data }\end{array}$ \\
\hline Wind supply curve & $\begin{array}{l}\text { Exclusions based on land-use land- } \\
\text { cover categories as specified in Lopez } \\
\text { et al. (2012) }\end{array}$ & $\begin{array}{l}\text { Spatially-explicit modeling of multiple } \\
\text { exclusions and setbacks from } \\
\text { buildings, roads, transmission rights- } \\
\text { of-way, and radar along with other } \\
\text { exclusion layers }\end{array}$ \\
\hline Wind degradation & Not included & $\begin{array}{l}\text { Annual degradation of } 0.27 \% \text { per year } \\
\text { represented based on empirical data } \\
\text { (Hamilton et al. 2020) }\end{array}$ \\
\hline PV degradation & $0.5 \% / y r$ & $0.7 \% / y r$ per the ATB 2020 \\
\hline $\begin{array}{l}\text { Wind and solar } \\
\text { curtailment }\end{array}$ & $\begin{array}{l}\text { Modeled using convolutions of } \\
\text { resource and load data at a time-slice } \\
\text { resolution }\end{array}$ & $\begin{array}{l}\text { Modeled using a simplified hourly } \\
\text { dispatch model }\end{array}$ \\
\hline
\end{tabular}




\begin{tabular}{|c|c|c|}
\hline $\begin{array}{l}\text { Inputs and } \\
\text { Treatments }\end{array}$ & 2019 Version (July 2019) & 2020 Version (July 2020) \\
\hline $\begin{array}{l}\text { Pumped-hydro } \\
\text { capital cost }\end{array}$ & Static over time & $\begin{array}{l}\text { Declines over time per Hydropower } \\
\text { Vision (DOE 2016b) }\end{array}$ \\
\hline $\begin{array}{l}\text { Storage energy } \\
\text { arbitrage value }\end{array}$ & $\begin{array}{l}\text { Calculated at the ReEDS } 17 \text {-time-slice } \\
\text { resolution }\end{array}$ & Calculated using hourly prices \\
\hline $\begin{array}{l}\text { Minimum capacity } \\
\text { factor for NGCT }\end{array}$ & None & $\begin{array}{l}\text { 1\% per PLEXOS runs of the } 2019 \\
\text { Standard Scenarios }\end{array}$ \\
\hline Tax credits & $\begin{array}{l}\text { Use a three-year safe harbor } \\
\text { construction period; tax credits for } \\
\text { CCS not represented }\end{array}$ & $\begin{array}{l}\text { Use a four-year safe harbor } \\
\text { construction period; December } 2019 \\
\text { production tax credit update } \\
\text { represented; tax credits for CCS } \\
\text { represented (use of captured carbon } \\
\text { is not considered) }\end{array}$ \\
\hline State policies & Policies as of July 2019 & Policies as of June 2020 \\
\hline $\begin{array}{l}\text { Nuclear power } \\
\text { plant assistance }\end{array}$ & $\begin{array}{l}\text { Assistance for Illinois and New York } \\
\text { represented }\end{array}$ & $\begin{array}{l}\text { Assistance for Connecticut, Illinois, } \\
\text { New Jersey, New York, and Ohio } \\
\text { represented }\end{array}$ \\
\hline Outage rates & $\begin{array}{l}\text { Outage rates based on 2003-2007 } \\
\text { Generating Availability Data System } \\
\text { data }\end{array}$ & $\begin{array}{l}\text { Outage rates based on } 2014-2018 \\
\text { Generating Availability Data System } \\
\text { data }\end{array}$ \\
\hline
\end{tabular}

a The default cost recovery period is 20 years in ReEDS and 30 years in the ATB.

Table A-5. Key Differences in dGen Model Versions

\begin{tabular}{|l|l|l|}
\hline Inputs and Treatments & 2019 Version & 2020 Version \\
\hline Demand growth & AEO2019 & AEO2020 \\
\hline Technology cost & ATB 2019 & ATB 2020 \\
\hline Tariff set & Curated in January 2019 & Curated in June 2020 \\
\hline $\begin{array}{l}\text { Wholesale electricity } \\
\text { prices }\end{array}$ & ReEDS 2019 & ReEDS 2020 \\
\hline $\begin{array}{l}\text { State and utility net } \\
\text { energy metering policies }\end{array}$ & Updated in March 2019 & Updated in June 2020a \\
\hline
\end{tabular}

a If states have no mandated NEM expiry dates, a distributed solar penetration threshold was implemented, which was determined from values of peer states. 


\section{ReEDS Model Contributors}

All NREL contributors to the ReEDS model are listed below.

Jon Becker

Ross Beppler

David Bielen

Nate Blair

Max Brown

Patrick Brown

Wesley Cole

Sean Corcoran

Paul Denholm

Victor Diakov

Kelly Eurek

Will Frazier

Bethany Frew

Nathaniel Gates

Danny Greer

Sameera Gudladona

Maureen Hand

Donna Heimiller

Jonathan Ho
Eduardo Ibanez

Paige Jadun

Charles Kang

Saroj Khanal

Venkat Krishnan

Katie Lamb

Anthony Lopez

Scott Machen

Madeline Macmillan

Trieu Mai

Andrew Martinez

Dana Max

Maureen McDaniel

Matthew Mowers

David Mulcahy

Caitlin Murphy

John Nangle

Scott Nicolson

Hyungseon $\mathrm{Oh}$
Andrew Reimers

James Richards

Anna Schleifer

Brian Sergi

Walter Short

Ben Sigrin

Travis Simpkins

Ramteen Sioshansi

Elina Spyrou

Dan Steinberg

Patrick Sullivan

Aaron Townsend

Caroline Uriarte

Nina Vincent

Tibebe Woldeyesus

Ella Zhou

Owen Zinaman

Matt Zwerling 